UNIVERSIDADE DE SÃO PAULO

ESCOLA DE ENGENHARIA DE SÃO CARLOS

DEPARTAMENTO DE HIDRÁULICA E SANEAMENTO

CARLOS DANILLO CAVALCANTE SAMPAIO

\title{
INVESTIGAÇÃO DAS INFLUÊNCIAS DAS CONDIÇÕES CONFINANTES DO ESCOAMENTO NO CÁLCULO DOS PARÂMETROS GEOMÉTRICOS DE RESSALTOS HIDRÁULICOS E DA DISSIPAÇÃO DE ENERGIA
}

Orientador: Prof. Dr. Harry Edmar Schulz

VERSÃO CORRIGIDA

São Carlos - SP

2020 

UNIVERSIDADE DE SÃO PAULO

ESCOLA DE ENGENHARIA DE SÃO CARLOS

DEPARTAMENTO DE HIDRÁULICA E SANEAMENTO

\title{
INVESTIGAÇÃO DAS INFLUÊNCIAS DAS CONDIÇÕES CONFINANTES DO ESCOAMENTO NO CÁLCULO DOS PARÂMETROS GEOMÉTRICOS DE RESSALTOS HIDRÁULICOS E DA DISSIPAÇÃO DE ENERGIA
}

Tese de doutorado apresentada à Escola de Engenharia de São Carlos da Universidade de São Paulo, como parte dos requisitos para obtenção do título de Doutor em Ciências: Engenharia Hidráulica e Saneamento.

Orientador: Prof. Dr. Harry Edmar Schulz

\author{
VERSÃO CORRIGIDA \\ São Carlos - SP \\ 2020
}



AUTORIZO A REPRODUÇÃO TOTAL OU PARCIAL DESTE TRABALHO, POR QUALQUER MEIO CONVENCIONAL OU ELETRONICO, PARA FINS DE ESTUDO E PESQUISA, DESDE QUE CITADA A FONTE.

Ficha catalográfica elaborada pela Biblioteca Prof. Dr. Sérgio Rodrigues Fontes da EESC/USP com os dados inseridos pelo(a) autor(a).

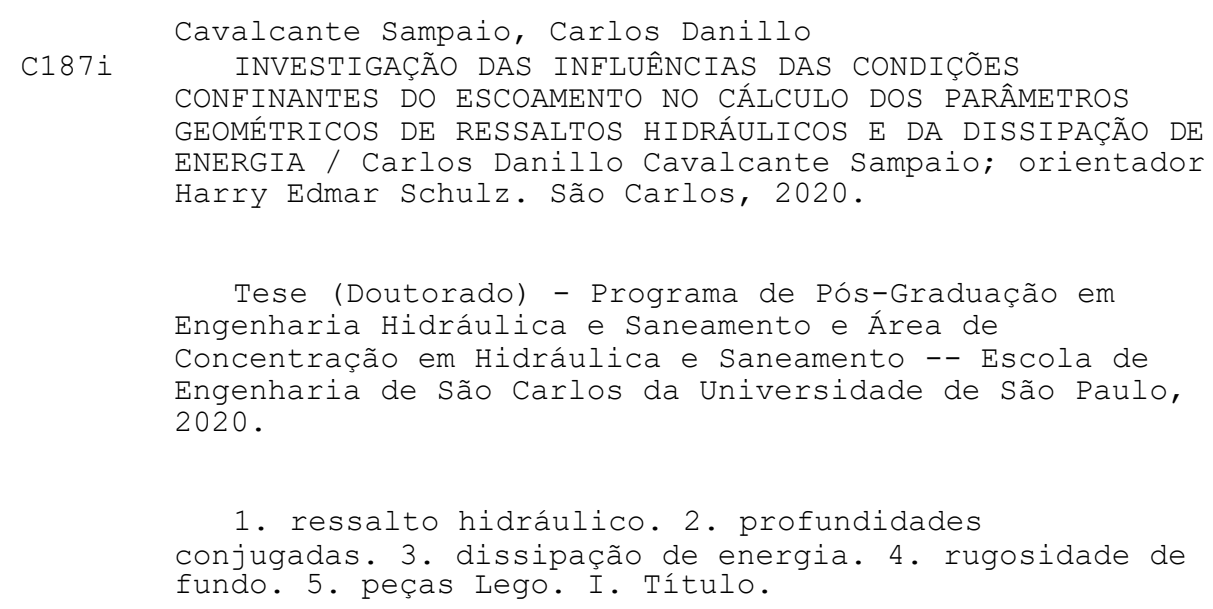

Eduardo Graziosi Silva - CRB - 8/8907 



\section{FOLHA DE JULGAMENTO}

\section{Candidato: CARLOS DANILLO CAVALCANTE SAMPAIO}

Título da tese: "Investigação das influências das condições confinantes do escoamento no caículo dos parâmetros geométricos de ressaltos hidráulicos e da dissipação de energia"

Data da defesa: $20 / 03 / 2020$

\section{Comissão Julgadora}

Prof. Dr. Nivaldo Aparecido Correa (orientador)

(Escola de Engenharia de São Carlos- EESC/USP)

Prof. Associado Rodrigo de Melo Porto

(Escola de Engenharia de São Carlos- EESC/USP)

Prof. Dr. Carlos Eugenio Pereira

(Universidade Federal de Uberlândia- UFU)

Prof. Dr. Daniel Jadyr Leite Costa

(Universidade Federal de São Carlos- UFSCar)

Prof. Dr. Marllus Gustavo Ferreira Passos das Neves

(Universidade Federal de Alagoas)

\section{$\underline{\text { Resultado }}$}

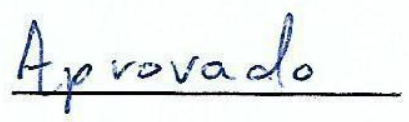

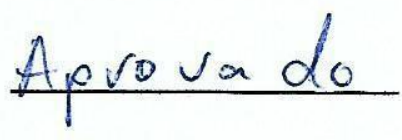
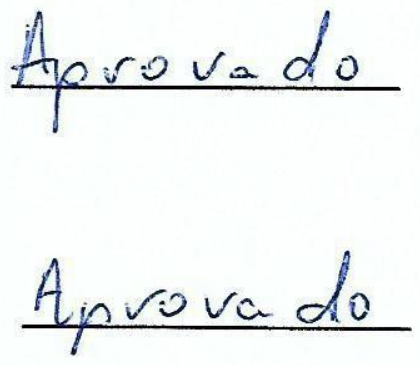

Coordenador do Programa de Pós-Graduação em Engenharia Hidráulica e Saneamento:

Prof. Dr. Eduardo Mario Mendiondo

Presidente da Comissão de Pós-Graduação:

Prof. Titular Murilo Araujo Romero 



\section{AGRADECIMENTOS}

Agradeço, primeiramente, à Deus, por me guiar, dar sabedoria e colocar pessoas maravilhosas em minha jornada.

Aos meus pais, Genisval e Josineide, por todo apoio, conselhos, orações e amor incondicional em todos os momentos.

Aos meus irmãos, Diego, Daniel e Bia, pelos momentos de conversa, o companheirismo e ajuda na edição do texto.

À minha noiva, Ingryde, pela grande paciência, amor e carinho durante o andamento do doutorado, pois sei que não foi fácil devido a distância.

A todos os demais familiares que, de alguma forma, deram apoio para a conclusão de mais uma etapa.

Aos amigos Inaê, Rhasta, Pata, Juliana, Hernani, Alex, Isa, Raul, Chris, Hélio, Lívia, e tantos outros, novos ou de longa data, que tornaram a rotina em laboratório e o dia-a-dia em São Carlos bem mais agradável e alegre.

Em especial, gostaria de agradecer imensamente ao meu orientador, Prof. Harry, pelo incessante incentivo à pesquisa, recomendações de leitura, dicas e correções precisas, simplicidade e atenção em meus momentos de frustração e crise, que serviram de motivação indispensável durante o andamento de nosso trabalho.

A Selva, pelos conselhos e pela ajuda na aquisição dos materiais para pesquisa.

Ao Prof. Edson, pelo empréstimo de equipamentos durante a fase de testes.

Ao Prof. Mario, pelas conversas, enorme compreensão e oportunidade de engajamento em seu grupo de discussão.

A Prof. Maria, pelo auxilia na calibração do medidor de vazão.

Ao Prof. Nivaldo e ao Prof. Rodrigo pelas dicas na montagem dos experimentos e esclarecimento de conceitos. 
Ao amigo e técnico Luis, pela convivência e conversas diárias, por toda a ajuda e criatividade na solução dos inúmeros ajustes necessários para os experimentos, assim como as diversas manutenções nas bombas, pelo auxílio na escolha das peças e materiais, e também pelos momentos de descontração nas apresentações do grupo de samba aos finais de semana.

Aos funcionários Sá, Rose, Luciane, Priscila, André, Bergamo pela prontidão em ajudar e pelo carinho.

Ao Laboratório de Hidráulica, onde o estudo foi desenvolvido.

Ao Departamento de Hidráulica e Saneamento da EESC/USP, pela oportunidade de realizar essa pesquisa, e a todos os professores, pelo ensinamento.

À Coordenação de Aperfeiçoamento de Pessoal de Nível Superior (CAPES), pela bolsa concedida durante o doutorado.

A todos que, de alguma maneira, contribuíram para a conclusão desse trabalho. 


\section{RESUMO}

SAMPAIO, C. D C. Investigação das influências das condições confinantes do escoamento no cálculo dos parâmetros geométricos de ressaltos hidráulicos e da dissipação de energia. 2020. 143 p. Tese (Doutorado) - Escola de Engenharia de São Carlos, Universidade de São Paulo, São Paulo, 2020.

Dois canais de escoamento retangulares foram usados para geração de ressalto hidráulico com duas condições de controle a jusante, comporta plana e vertedor de soleira espessa. Um dos canais possui paredes de concreto e largura de $41 \mathrm{~cm}$, podendo comportar vazões de até 40 L/s. O Outro canal tem $3 \mathrm{~m}$ de extensão e $10 \mathrm{~cm}$ de largura, com paredes de vidro, e permite ajustar vazões até a faixa de 7,5 L/s. A obtenção dos dados de profundidade foi realizada por meio de processamento de imagens e sensor ultrassônico. Cinquenta condições experimentais distintas foram obtidas, na faixa de número de Froude supercrítico de 1,29 a 3,94, com variação dos parâmetros de vazão, declividade e rugosidade de fundo. Os elementos de rugosidade consistiram em combinações de peças Lego e placas base para as mesmas, assim como material emborrachado antiderrapante. Os dados resultantes obtidos compreenderam profundidades conjugadas, comprimentos do rolo, perfil de superfície livre, intensidade de rugosidade e energia relativa dissipada. Dados experimentais de profundidades conjugadas e comprimento do rolo foram usados para aprimorar modelos teóricos existentes, para fornecer uma ferramenta de previsão mais completa na determinação das profundidades conjugadas e comprimentos do ressalto e do rolo para canais retangulares, considerando o efeito da rugosidade de fundo e declividade. Os coeficientes ajustados do modelo teórico utilizado apontaram, no canal com paredes de vidro, uma adequação para segregação dos dados por declividade e por geometria do tipo de estrutura, com concavidades da curva semelhantes para estruturas também semelhantes. Para o canal com paredes de concreto, os coeficientes ajustados mostraram um comportamento de concavidade para baixo da curva, para fundo liso e uma das configurações com peças Lego. Verificou-se uma dissipação de energia de até 40 $\%$, considerando as seções de início e fim do ressalto. O estudo se mostra importante, pois há certa divergência entre os autores sobre a determinação de medidas de comprimento do ressalto, como por exemplo, a seção final do rolo.

Palavras-chaves: ressalto hidráulico, profundidades conjugadas, dissipação de energia, rugosidade de fundo. 



\begin{abstract}
SAMPAIO, C. D C. Investigation of the influences of the confining conditions of the flow in the calculation of the geometric parameters of hydraulic jumps and energy dissipation. 2020. 139 p. Tese (Doutorado) - Escola de Engenharia de São Carlos, Universidade de São Paulo, São Paulo, 2020.

Two rectangular channels were used to generate hydraulic jumps with two control conditions downstream, a sluice gate and a thick sill spillway. One of the channels has concrete walls and a width of $41 \mathrm{~cm}$, with a flow rate of up to $40 \mathrm{~L} / \mathrm{s}$. The Other channel is $3 \mathrm{~m}$ long and 10 $\mathrm{cm}$ wide, with glass walls, and allows to adjust flow rates up to the range of $7.5 \mathrm{~L} / \mathrm{s}$. The depth data was obtained by means of image processing and an ultrasonic sensor. Fifty different experimental conditions were obtained, in the range of supercritical Froude range of 1.29 to 3.94 , with variation of flow parameters, slope and bottom roughness. The roughness elements consisted of combinations of Lego pieces and base plates for them, as well as nonslip rubberized material. The resulting data obtained comprised sequent depths, roller lengths, free surface profile, roughness intensity and dissipated relative energy loss. Experimental data of sequent depths and roller lengths were used to improve existing theoretical models, to provide a more complete forecasting tool in determining the sequent depths and hydraulic jump and roller lengths for rectangular channels, considering the effect of bottom roughness and slope. The adjusted coefficients of the theoretical model used indicated, in the channel with glass walls, an adequacy for data segregation by slope and by geometry of the type of structure, with similar curve concavities for similar structures. For the channel with concrete walls, the adjusted coefficients showed a curve with concavity facing down, for a smooth bottom and one of the configurations with Lego pieces. It was observed a relative energy loss of up to $40 \%$, considering the start and end sections of the hydraulic jump. The study proves to be important, as there is some divergence among the authors regarding the determination of jump length measurements, such as the final section of the roller.
\end{abstract}

Keywords: hydraulic jump, sequent depths, energy dissipation, bottom roughness. 



\section{LISTA DE FIGURAS}

Figura 1. Ressalto hidráulico em bacia horizontal (Adaptado de NÓBREGA, 2014).

Figura 2. Classificação do ressalto hidráulico conforme número de Froude $\left(\operatorname{Fr}_{1}\right)$ na seção de entrada (Adaptado de BUREAU OF RECLAMATION, 1987).

Figura 3. Estrutura do ressalto hidráulico (Adaptado de ALVES, 2008). 30

Figura 4. Tipos de ressalto em canais com declividade (Adaptado de KINDSVATER, 1944).

Figura 5. Energia específica em função da profundidade do escoamento (Adaptado de SOUSA, 2011)

Figura 6. Relação entre a eficiência de dissipação de energia no ressalto hidráulico e o número de Froude (PETERKA, 1984).

Figura 7. Abordagem do ressalto hidráulico segundo os volumes de controle 1 e 2 . $\mathrm{L}_{\mathrm{r}}$ é o comprimento do rolo, $\mathrm{y}_{1}$ e $\mathrm{y}_{2}$ são as profundidades conjugadas e H é a diferença entre elas. .41 Figura 8. Forças atuantes no $\mathrm{VCl}$ e regiões $\mathrm{A}, \mathrm{B}$ e $\mathrm{C}$ com velocidades $\mathrm{V}_{\text {down }}, \mathrm{V}_{1}$ e $\mathrm{V}_{\text {up }}$, respectivamente.

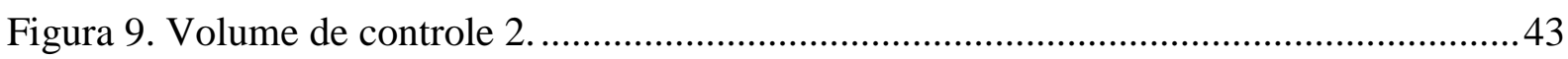

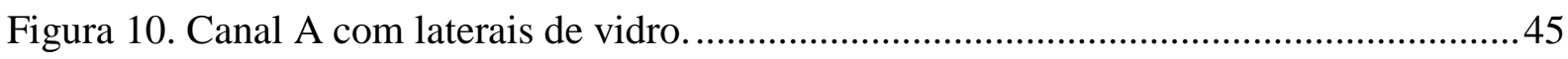

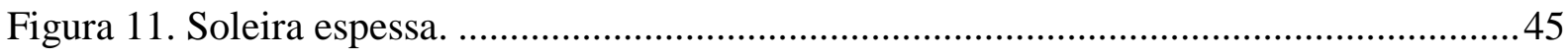

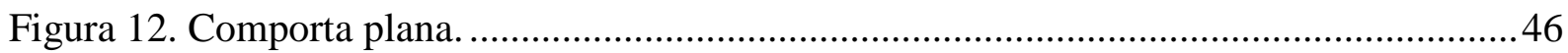

Figura 13. Desenho esquemático do aparato experimental do canal A, com uso de vertedor e comporta para formação do ressalto hidráulico. Adaptado de Simões, Schulz e Porto (2012).

Figura 14. Canal B, soleira espessa e comporta ao final do canal..........................................47

Figura 15. Sensor ultrassônico utilizado para medição das profundidades. ............................48

Figura 16. Desenho esquemático do aparato experimental do canal B. Fonte: Simões, Schulz e

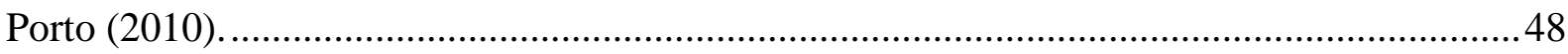

Figura 17. Curva de calibração para o medidor eletrônico de vazão. ......................................49

Figura 18. Vertedor triangular de parede delgada para aferição da vazão no canal B. ............50

Figura 19. Piezômetro usado para medição da carga no vertedor triangular. ...........................50

Figura 20. Regulador para controle manual da inclinação no canal......................................51

Figura 21. Esquema para ilustrar a medição da declividade. ................................................52

Figura 22. Esquema para a posição de início do ressalto nos canais estudados.......................53

Figura 23. Esquema da visão frontal e lateral para uma placa base. .....................................54 
Figura 24. Esquema da disposição das peças Lego ao longo de uma placa base. 54

Figura 25. Dimensões dos bricks $2 \times 4$ utilizados

Figura 26. Arranjo com placas base e peças Lego em experimentos com vertedor, no canal A.

Figura 27. Visão frontal e lateral de cada placa de material emborrachado.

Figura 28. Placas de material emborrachado acopladas ao fundo do canal B. 57

Figura 29. Configuração LEGO1 para o canal B. 58

Figura 30. Configuração LEGO2 para o canal B. 59

Figura 31. Configuração LEGO3 para o canal B. 59

Figura 32. Configuração LEGO4 para o canal B. 60

Figura 33. Imagens das 4 configurações elaboradas com peças Lego e placas base no canal B.

Figura 34. Resumo do procedimento para obtenção das medidas no canal A.

Figura 35. Interface do software Tracker, usado para a medição das profundidades conjugadas. 64

Figura 36. Interface do software Logger Lite $®$.

Figura 37. Barbante e anel de plástico usados para determinar a zona de estagnação da superfície livre. 66

Figura 38. Razão entre alturas conjugadas observadas x Bélanger obtidas no canal A........... 70 Figura 39. Dados $\mathrm{y}_{2} / \mathrm{y}_{1}$ de Nóbrega (2014) e deste estudo x Bélanger para o canal A............ 71 Figura 40. Dados $\mathrm{y}_{2} / \mathrm{y}_{1}$ de Nóbrega (2014) e deste estudo para o Canal A na condição "liso e sem declividade" em comparação com a equação de Bélanger. ............................................... 72 Figura 41. Dados para canal liso e rugoso, vertedor e comporta, horizontal......................... 75 Figura 42. Dados para canal liso e rugoso, vertedor e comporta, inclinado. .......................... 75 Figura 43. Medições e previsão utilizando a Eq. (24) $\operatorname{com} \alpha=-0,2489$ e $\beta=3,526 . r^{2}=0,991$ na regressão multilinear.

Figura 44. Medições e previsão utilizando a Eq. (24) $\operatorname{com} \alpha=0,1262$ e $\beta=1,353 . r^{2}=0,995$ na regressão multilinear 79

Figura 45. Os diferentes comportamentos que a formulação em teste permite cobrir. 80 Figura 46. Medições e previsão utilizando a equação (24) com $\alpha=-0,4319$ e $\beta=7,181$. $r^{2}=0,981$ na regressão multilinear, para experimentos no canal inclinado. 81

Figura 47. Medições e previsão utilizando a equação (24) $\operatorname{com} \alpha=0,1908$ e $\beta=1,907 . r^{2}=0,994$ na regressão multilinear, para experimentos no canal inclinado. 
Figura 48. Tendências dos coeficientes $\alpha$ e $\beta$ nas condições experimentais do canal A.

Figura 49. $y_{2} / y_{1}$ medidos e calculados considerando os coeficientes $\alpha$ e $\beta$..........

Figura 50. Conjunto completo de $L_{r} / y_{1}$ medido e calculado utilizando $\gamma=4,137$ e $\delta=-0,6050$.

Figura 51. $L_{r} / y_{1}$ medido e calculado para estrutura hidráulica do vertedor, liso, rugoso, inclinado e horizontal, utilizando $\gamma=3,570$ e $\delta=-0,3700$. NVH=Nóbrega, Vertedor, Horizontal; PVHILR=Presente, Vertedor, Horizontal, Inclinado, Liso, Rugoso.

Figura 52. $L_{r} / y_{1}$ medido e calculado para estrutura hidráulica de comporta, liso, rugoso, inclinado e horizontal, utilizando $\gamma=4,903$ e $\delta=-0,9401$.

Figura 53. Ajuste para os dados de $L_{r} / y_{1}$ medido e calculado, utilizando os dados da Tab. 18.

Figura 54. Energia relativa por $F_{1}$ para vertedor horizontal (liso e rugoso), vertedor inclinado (liso e rugoso), comporta horizontal (liso e rugoso) e comporta inclinada (liso e rugoso), utilizando os dados da Tab. 19. .91

Figura 55. Energia relativa por $F_{1}$ para liso e rugoso, utilizando os dados da Tab. 19...........91

Figura 56. Malhas das diferentes configurações de fundo rugoso para o canal B. .................95

Figura 57. Diferentes evoluções da superfície da água para o canal liso. ...............................96

Figura 58. Diferentes evoluções da superfície da água para com material emborrachado. .....96

Figura 59. Razões $\mathrm{y}_{2} / \mathrm{y}_{1}$ medidas e calculadas, sem distinção de experimentos. .97

Figura 60. Razões $\mathrm{y}_{2} / \mathrm{y}_{1}$ medidas e calculadas sem distinção de experimentos e equação de

Bélanger em relação a $F_{1}$ .97

Figura 61. Razões $\mathrm{y}_{2} / \mathrm{y}_{1}$ medidas e calculadas fazendo a distinção de experimentos. 98

Figura 61. Razões $\mathrm{y}_{2} / \mathrm{y}_{1}$ medidas e calculadas com distinção de experimentos e equação de Bélanger em relação da $\mathrm{F}_{1}$....

Figura 63. Dados experimentais e curvas teóricas obtidas com os valores de $\alpha$ e $\beta$ ajustados para a equação (24). 100

Figura 64. Razões $\mathrm{y}_{2} / \mathrm{y}_{1}$ medidas, separados nas intensidades de rugosidade $(I)$ e equação de Bélanger em relação a $F_{1}$ 102

Figura 65. Dados experimentais e curvas teóricas obtidas com os valores de $\alpha$ e $\beta$ ajustados para a equação (24). 103

Figura 66. $\mathrm{L}_{\mathrm{r}} / \mathrm{y}_{1}$ medidos e calculados, sem distinção de experimentos 105

Figura 67. $\mathrm{L}_{\mathrm{r}} / \mathrm{y}_{1}$ medidos e calculados em relação ao número de Froude $\mathrm{F}_{1}$, sem distinção de experimentos 
Figura 68. $\mathrm{L}_{\mathrm{r}} / \mathrm{y}_{1}$ medidos e calculados com distinção de experimentos 106 Figura 69. Dados experimentais e curvas teóricas obtidas com os valores de $\gamma$ e $\delta$ ajustados para a Eq. (27). 107

Figura 70. Comparação da energia relativa determinada por dados experimentais e através dos dados de $\mathrm{y}_{2} / \mathrm{y}_{1}$ ajustados pela Eq. (24). 109 Figura 71. Energia relativa $\Delta \mathrm{E} / \mathrm{E}_{1} \times \mathrm{F}_{1}$ para as diferentes rugosidades de fundo no canal B. 110 Figura 72. Energia relativa $\Delta \mathrm{E} / \mathrm{E}_{1} \times \mathrm{F}_{1}$ para as os grupos de intensidade fornecidos na Tab. 23 . 


\section{LISTA DE TABELAS}

Tabela 1. Equações para o comprimento do ressalto hidráulico. $\mathrm{L}_{\mathrm{j}}=$ comprimento do ressalto; $\mathrm{v}_{\mathrm{c}}, \mathrm{v}_{1}, \mathrm{v}_{2}=$ velocidade crítica, velocidade supercrítica e velocidade subcrítica, respectivamente; $g$ = aceleração da gravidade; $\mathrm{y}_{1}, \mathrm{y}_{2}=$ altura supercrítica e altura subcrítica, respectivamente; $F_{1}=$ número de Froude. Fonte: Elevatorski (1959) apud Simões (2008), Hager et al. (1990), Peterka (1984), Teixeira (2003) e Schulz et al. (2015a)..........................32 Tabela 2. Equações empíricas para comprimento do rolo. $\mathrm{L}_{\mathrm{r}}=$ comprimento do rolo; $\mathrm{v}_{1}=$ velocidade supercrítica; $\mathrm{y}_{1}, \mathrm{y}_{2}=$ altura supercrítica e altura subcrítica, respectivamente; $\operatorname{Fr}_{1}=$ número de Froude Fonte: Elavatorski (1957) apud Simões (2008), Hager et al. (1990) e

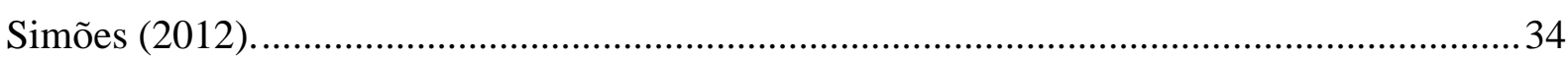

Tabela 3. Características das diferentes configurações de fundo para o canal A. ....................55

Tabela 4. Características das diferentes configurações de fundo para o canal B. ...................61

Tabela 5. Dados dos experimentos para a soleira espessa no canal A. .................................67

Tabela 6. Dados dos experimentos para a comporta vertical no canal A................................68

Tabela 7. Razão entre alturas conjugadas observadas x Bélanger obtidas no canal A............69

Tabela 8. Dados para a soleira espessa no canal A obtidos por Nóbrega (2014)....................71

Tabela 9. Dados para a comporta vertical no canal A obtidos por Nóbrega (2014). ...............71

Tabela 10. Dados do Canal A para condição horizontal, liso e rugoso...................................73

Tabela 11. Dados do Canal A para condição inclinado, liso e rugoso. ...................................74

Tabela 12. Dados do Canal A para vertedor, horizontal, liso e rugoso. ...............................78

Tabela 13. Dados do Canal A para comporta, horizontal, liso e rugoso................................ 78

Tabela 14. Dados do Canal A para vertedor, inclinado, liso e rugoso. .................................81

Tabela 15. Dados do Canal A para comporta, inclinado, liso e rugoso. ................................ 81

Tabela 16. Valores de $\alpha$ e $\beta$ para as diferentes condições experimentais no canal A.............83

Tabela 17. Dados de Nóbrega (2014) para comprimento do rolo no canal A.........................85

Tabela 18. Valores de $\gamma$ e $\delta$ para as diferentes condições experimentais no canal A...............88

Tabela 19. Dados de $\Delta \mathrm{E} / \mathrm{E}_{1}$ calculados para o canal A, por meio da $\mathrm{Eq}(28)$.........................90

Tabela 20. Variáveis relevantes medidas e $\mathrm{y}_{2} / \mathrm{y}_{1}$ e $\mathrm{L}_{\mathrm{r}} / \mathrm{y}_{1}$ medidos e calculados. ......................92

Tabela 21. $\alpha$ e $\beta$ obtidos e variação experimental do número de Froude................................99

Tabela 22. Características geométricas dos diferentes fundos rugosos para o canal B.......... 101

Tabela 23. $\alpha$ e $\beta$ obtidos e variação experimental do número de Froude para os grupos de intensidade. 
Tabela 24. $\gamma$ e $\delta$ obtidos e variação experimental do número de Froude 106

Tabela 25. Dados relevantes medidos e valores de $\Delta \mathrm{E} / \mathrm{E}_{1}$ experimentais e calculados para $\mathrm{o}$ canal B, com base na Eq (24). 108 


\section{SÚMARIO}

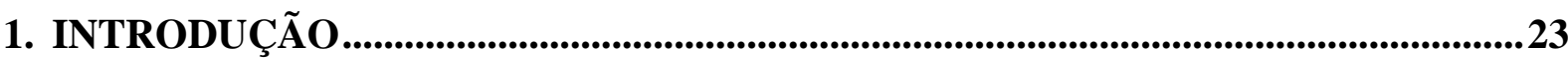

2. OBJETIVO

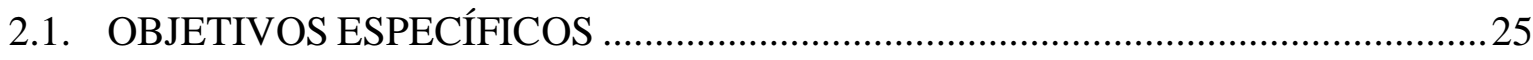

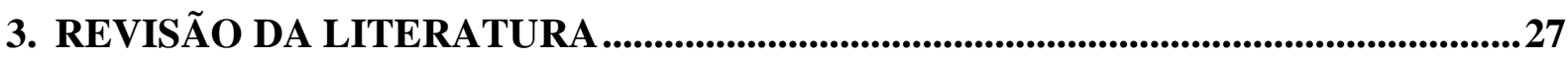

3.1. ASPECTOS GERAIS DO RESSALTO HIDRÁULICO .........................................2

3.2. RESSALTO HIDRÁULICO CLÁSSICO E FORÇADO ..........................................29

3.3. COMPOSIÇÃO E GEOMETRIA DO RESSALTO HIDRÁULICO ..........................30

3.3.1. Alturas ou profundidades conjugadas.................................................................... 30

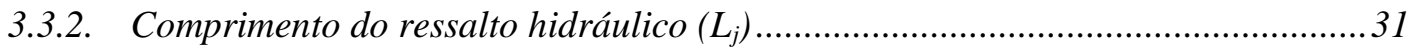

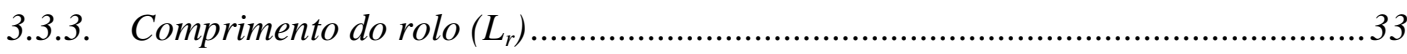

3.4. RESSALTO HIDRÁULICO EM CANAIS COM DECLIVIDADE ............................35

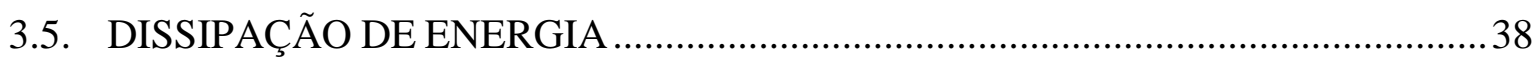

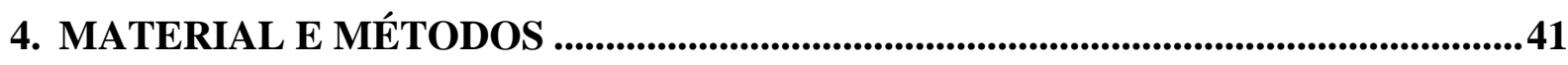

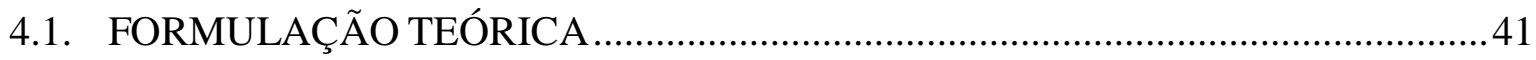

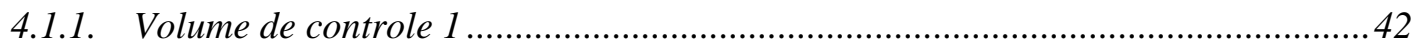

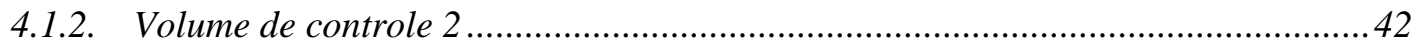

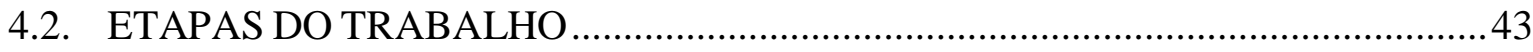

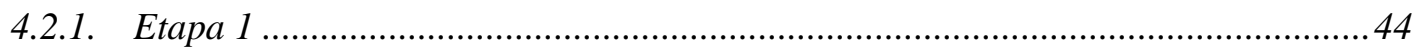

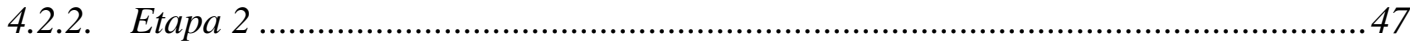

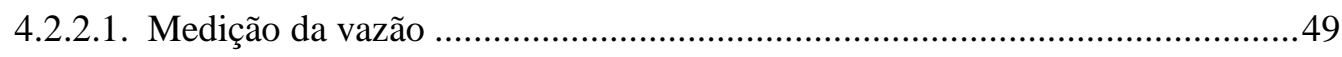

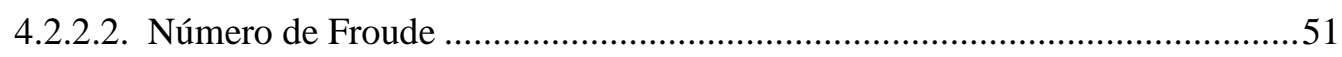

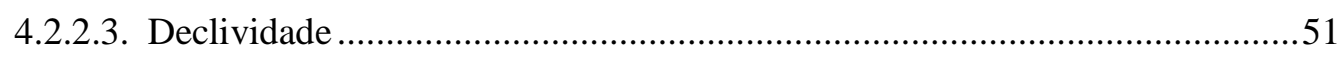

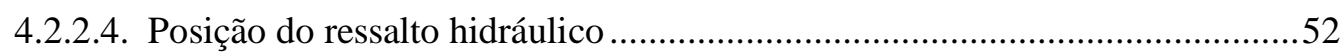

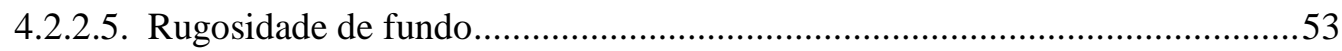

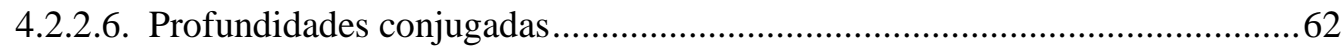

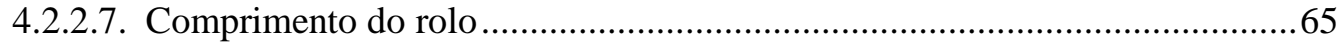

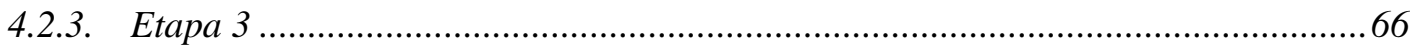

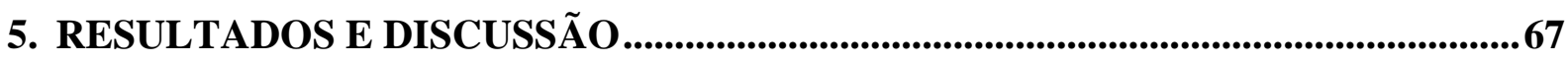

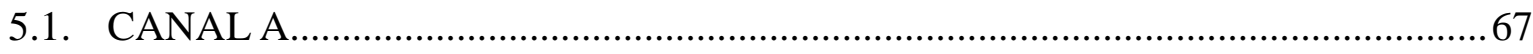

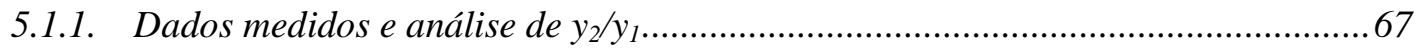


5.1.2. Análise comparativa de $y_{2} / y_{1}$ com dados de estudos anteriores ..............................70

5.1.3. Comparações de $y_{2} / y_{1}$ com propostas conceituais mais abrangentes......................76

5.1.4. Análises dos comprimentos do rolo no canal A .....................................................84

5.1.5. Análise da dissipação de energia ............................................................................8

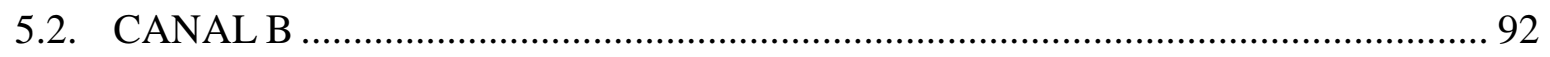

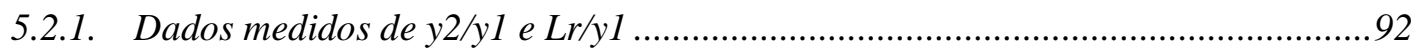

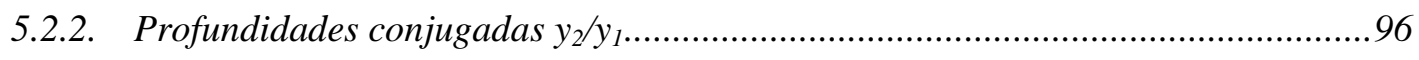

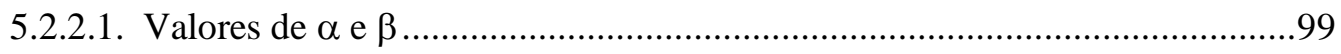

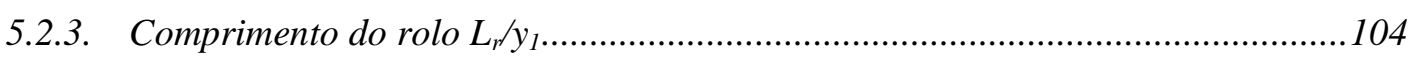

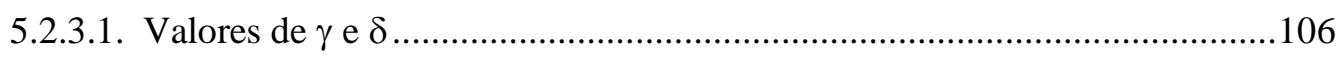

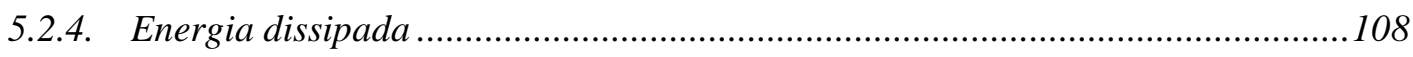

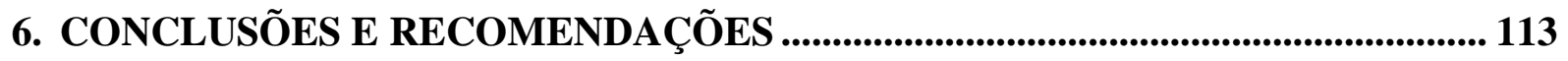

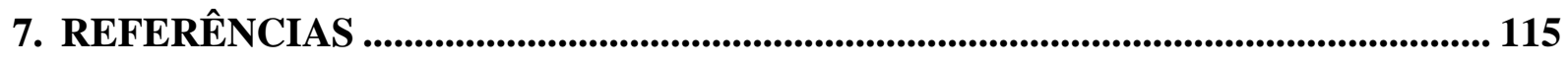

8. APENDICES .................................................................................................................................. 119

8.1. APÊNDICE A - FOTOS DOS EXPERIMENTOS ................................................ 119

8.2. APÊNDICE B - SOBREPOSIÇÃO DOS QUADROS DA FILMAGEM PAR O

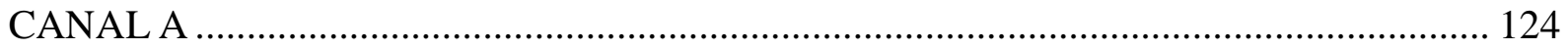

8.3. APÊNDICE C - PERFIL DE SUPERFÍCIE LIVRE PARA EXPERIMENTOS DO

CANAL B 


\section{INTRODUÇÃO}

O ressalto hidráulico é um fenômeno bastante estudado, dada sua importância em estruturas utilizadas para medição de vazão, mistura de substâncias, transporte de sedimentos ou dissipação de energia (PORTO, 2006). No que tange a Engenharia Hidráulica, o ressalto é comumente utilizado em bacias de dissipação a jusante de vertedouros de barragens. As bacias de dissipação são estruturas que tem a finalidade de confinar o ressalto e evitar que a energia cinética do escoamento proporcione danos às margens do rio ou ao leito.

Para aplicações referentes à dissipação de energia, é importante destacar o desenvolvimento de turbulência de grande escala devido a grandes variações de velocidade e pressão ao fundo de escoamentos, incorporação de ar e desordenada oscilação dos níveis d'água (PRÁ et al., 2016).

O ressalto ocorre através da passagem de um escoamento supercrítico para um escoamento subcrítico em um canal. Caso necessário, o ressalto também pode ser obtido através da introdução de acessórios ou obstáculos na bacia de dissipação (NÓBREGA, 2014).

As características do ressalto dependerão essencialmente da forma do escoamento a montante (CHOW, 1957), podendo variar conforme o valor do número de Froude $\left(\mathrm{Fr}_{1}\right)$. A partir do $\mathrm{Fr}_{1}$ e da determinação das características geométricas do ressalto é possível prever a eficiência na dissipação de energia (PETERKA, 1984). Essas informações são fundamentais para o pré-projeto de bacias de dissipação, influenciando não apenas nas dimensões da bacia, como também na necessidade ou não de proteção de fundo.

O uso de equações de previsão para as dimensões do ressalto auxiliam no dimensionamento das bacias, contudo diferenças entre dados experimentais e teóricos podem contribuir em erros no projeto da estrutura hidráulica. Formulações clássicas para a determinação das características geométricas do ressalto, muitas vezes não consideram a influência de forças cisalhantes ou declives. Esses fatores funcionam como singularidades que oferecem dissipação adicional de energia e geram uma perda de carga maior no escoamento (SCHULZ et al., 2015a).

Dessa forma, o presente trabalho se propõe a investigar as características geométricas do ressalto e da linha de energia do escoamento, comparando resultados obtidos durante o projeto com dados disponíveis em literatura. Para tanto, o modelo teórico de previsão dessas características proposto por Schulz et al. (2015a) foi aprofundado em termos da dissipação 
global de energia, contribuindo para o desenvolvimento de uma equação mais completa e aplicável a diferentes condições experimentais. 


\section{OBJETIVO GERAL}

Investigar experimentalmente a geometria e aspectos quantitativos do ressalto hidráulico. Como também, estudar a influência dos parâmetros confinantes declividade do canal e rugosidade de fundo, para o ressalto hidráulico e a dissipação de energia.

\subsection{OBJETIVOS ESPECÍFICOS}

- Aplicação das conclusões do uso dos princípios físicos de conservação de massa, quantidade de movimento e energia a dois volumes de controle fixos, na extensão para a avaliação da dissipação de energia;

- Avaliar o modelo proposto por Schulz et al (2015a,b) para obtenção de equações de previsão sobre as caraterísticas do ressalto em canal retangular;

- Acoplamento das conclusões experimentais com as equações teóricas já existentes e a obter, para o cálculo da dissipação de energia, fornecendo uma ferramenta de previsão mais completa na determinação das profundidades conjugadas e dos comprimentos do ressalto e do rolo em canais retangulares, considerando-se o efeito da rugosidade de fundo e a declividade do canal. 


\section{REVISÃO DA LITERATURA}

\subsection{ASPECTOS GERAIS DO RESSALTO HIDRÁULICO}

Em um escoamento em conduto livre, o ressalto hidráulico ocorre a partir da transição de um regime supercrítico para um regime subcrítico. Esse fenômeno se caracteriza pela elevação do nível d'água, instabilidade da superfície e formação de ondas, adesão de ar no escoamento, turbulência e dissipação de energia. Uma das principais funções do ressalto para a engenharia hidráulica é evitar a erosão do leito após o vertedor, pois serve como dissipador de energia cinética da corrente d'água. Outros usos do ressalto compreendem a boa mistura de substâncias químicas para efeito de tratamento de água, medição de vazão na Calha Parshall e transporte de sedimentos para jusante (PORTO, 2006).

A Fig. 1 ilustra um ressalto hidráulico em uma bacia de dissipação horizontal. As seções A e B delimitam o ressalto, $\mathrm{y}_{\mathrm{A}}$ е $\mathrm{y}_{\mathrm{B}}$ são alturas ou profundidades conjugadas, L é o comprimento da região de dissipação de energia. Os efeitos do ressalto não mais são percebidos a partir da seção B em diante, no sentido do escoamento.

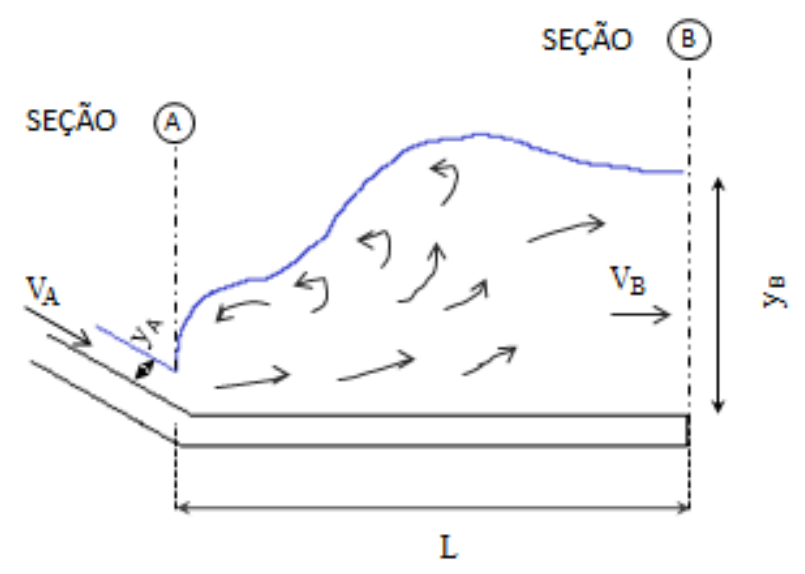

Figura 1. Ressalto hidráulico em bacia horizontal (Adaptado de NÓBREGA, 2014).

O ressalto hidráulico pode ser entendido como uma onda estacionária, confinado entre duas seções: a montante com escoamento torrencial e a jusante com escoamento fluvial. A intensidade da velocidade a montante determina a forma que o ressalto e o rolo d'água apresentam, isto é, o ressalto pode ser classificado de acordo com o número de Froude (CHOW, 1959).

Peterka (1984) propôs uma classificação dos ressaltos tomando o valor do número de Froude supercrítico como indicativo. Algumas características de cada tipo de ressalto são apresentados (ORTIZ, 1981): 
- Ressalto ondular, $1,0<\mathrm{Fr}_{1}<1,7$ : profundidade supercrítica está um pouco abaixo da profundidade crítica, aspecto do escoamento se assemelha mais a uma onda estacionária do que um ressalto propriamente dito, dissipação de energia é muito baixa.

- Ressalto fraco ou pre-ressalto, 1,7 $<\mathrm{Fr}_{1}<2$,5: para $\mathrm{Fr}_{1}$ próximos de 1,7 há o aparecimento de pequenos rolos sobre a superfície, tornando-se mais intensos quando $\mathrm{Fr}_{1}$ se aproxima de 2,5, a superfície livre se apresenta relativamente suave, dissipação de energia inferior a $20 \%$.

- Ressalto oscilante, $2,5<\mathrm{Fr}_{1}<4,5$ : jato de entrada que oscila entre a superfície e o fundo sem um período regular, presença de ondas que se propagam por longas distâncias a jusante (podendo causar danos em alguns canais ou leitos).

- Ressalto estável: 4,5 $<\mathrm{Fr}_{1}<$ 9,0: ressalto apresenta menor sensibilidade aos níveis a montante, dissipação de energia na faixa de 45 a $70 \%$.

- Ressalto forte: $\mathrm{Fr}_{1}>$ 9,0: elevada e intensa turbulência, formação de fortes ondas a jusante do ressalto, grande diferença entre as profundidades conjugadas, dissipação de energia pode chegar a $85 \%$.

A Fig. 2 apresenta uma ilustração dos ressaltos fraco, oscilante, estável e forte, de acordo com a classificação feita por Peterka (1984). 


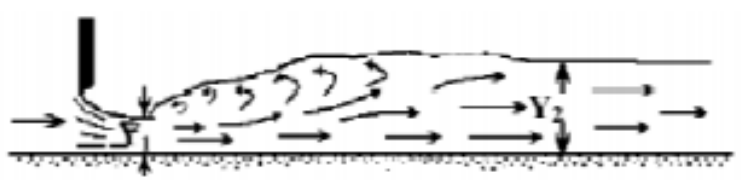

Pré-ressalto: $1,7<\mathrm{Fr}_{1}<2,5$

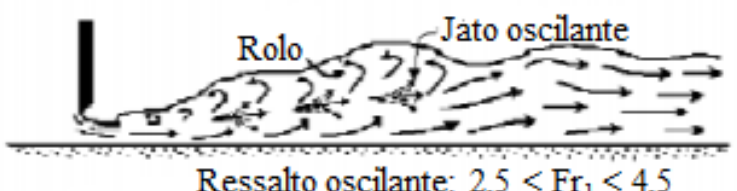

Ressalto oscilante: $2,5<\mathrm{Fr}_{1}<4,5$
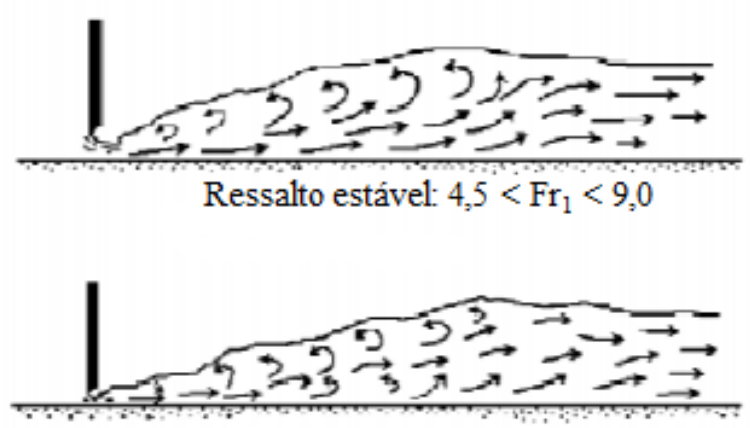

Ressalto forte: $\mathrm{Fr}_{1}>9,0$

Figura 2. Classificação do ressalto hidráulico conforme número de Froude ( $\left.\mathrm{Fr}_{1}\right)$ na seção de entrada (Adaptado de BUREAU OF RECLAMATION, 1987).

A condição de ressalto estável ou estacionário é a mais utilizada em obras hidráulicas, devido à posição relativamente fixa e dissipação média da energia fornecida a montante na faixa de $60 \%$. A enorme turbulência gerada em situações com número de Froude $>9,0$ aumenta o risco de cavitação pela maior presença de bolhas de ar.

\subsection{RESSALTO HIDRÁULICO CLÁSSICO E FORÇADO}

O ressalto formado em canal relativamente liso, plano e com seção constante, retangular, é conhecido como ressalto hidráulico clássico. Há diversos estudos na literatura sobre esse tipo de ressalto e é um tema bem discutido, sobretudo no que diz respeito a bacias de dissipação. Caso a altura do final do ressalto não seja suficiente para gerar um ressalto hidráulico clássico, este pode ser produzido pela inclusão de acessórios na bacia dissipação, sendo então conhecido por ressalto hidráulico forçado. Na prática, bacias de dissipação com ressalto clássico são raros, devido a grande variação dos níveis a jusante. Então, o que ocorre na maioria dos casos é o uso de equações simplificadas para situações de ressalto clássico, quando na realidade existe a presença de elementos que forçam a formação do ressalto. 


\subsection{COMPOSIÇÃO E GEOMETRIA DO RESSALTO HIDRÁULICO}

Nesta seção são apresentadas as características geométricas do ressalto hidráulico e suas previsões de acordo com os modelos matemáticos mais conhecidos. A Fig. 3 ilustra os componentes do ressalto abordadas a seguir.

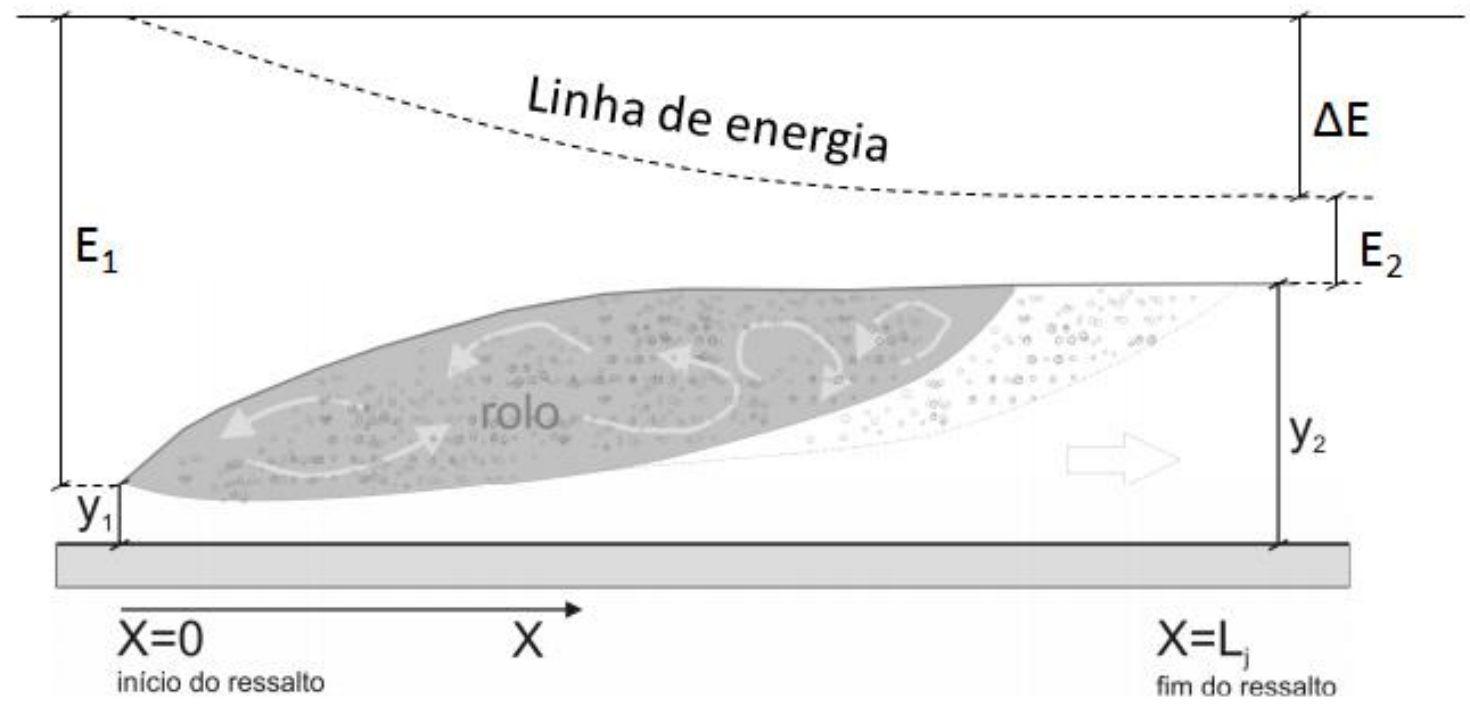

Figura 3. Estrutura do ressalto hidráulico (Adaptado de ALVES, 2008).

\subsubsection{Alturas ou profundidades conjugadas}

As profundidades conjugadas são parâmetros importantes para o dimensionamento de bacias de dissipação de energia. Elas representam as alturas da lâmina d'água a jusante e a montante, que delimitam o ressalto hidráulico. A equação de Bélanger (Eq. (1)) fornece a razão entre as profunidades conjugadas, baseando-se nos princípios de conservação de quantidade de movimento a um canal, como o da Fig. 1, e desprezando a ação de tensões de cisalhamento.

$$
\frac{y_{2}}{y_{1}}=\frac{1}{2}\left(-1+\sqrt{1+8 F r_{1}^{2}}\right) \quad \text { Eq. } 1
$$

Apesar de mostrar uma boa correlação com os dados experimentais, a equação de Bélanger apresenta limitações por não considerar as forças de cisalhamento. A ausência dessas forças não leva em conta as perdas de cargas relacionadas, na linha de energia ao longo do ressalto. Rajaratnam $(1965,1967)$ constatou esse fato e relatou que um ressalto muito próximo à comporta pode resultar em uma diminuição da altura subcrítica do escoamento. Beirami e Chamani (2006) concluíram que uma pequena diferença entre os dados 
experimentais e a equação de Bélanger se devia a ação das forças de cisalhamento, acentuando-se a diferença à medida que o número de Froude na seção de entrada aumentava.

Rajaratnam (1968) propôs o acréscimo de um coeficiente $\alpha$ no termo do número de Froude, com a finalidade de incorporar o efeito da rugosidade de fundo no ressalto hidráulico, resultando na Eq. (2).

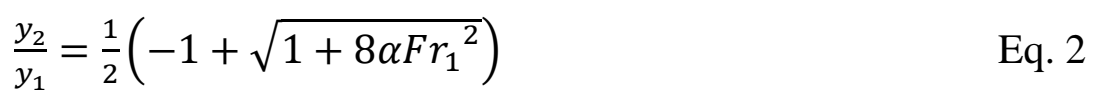

Estudos de Hughes e Flack (1984) demonstraram que a variação da rugosidade de fundo em canal horizontal influencia na relação $\mathrm{y}_{2} / \mathrm{y}_{1}$. Em seus experimentos, o aumento da rugosidade e do número de Froude provocava uma diminuição no comprimento do ressalto e na razão entre as profundidas conjugadas. Carollo, Ferro e Pampalone (2007) igualmente perceberam essa discrepância na razão entre as profundidades.

Carollo e Ferro (2004) realizaram análises de ressaltos hidráulicos em canal de fundo rugoso, para aprimorar a Eq. (2), resultando num valor para o coeficiente $\alpha=7,42$. Posteriormente os autores incorporaram um termo $\beta$ para levar em conta o tamanho dos elementos de rugosidade, chegando a Eq. (3):

$$
\begin{aligned}
& \frac{y_{2}}{y_{1}}=\frac{1}{2}\left(-1+\sqrt{1+8(1-\beta) F r_{1}^{2}}\right) \quad \text { Eq. } 3 \\
& \beta=0,42 \times\left(t / y_{1}\right) \\
& \text { em que, } \mathrm{t}=\text { "altura de rugosidade" }
\end{aligned}
$$

Neluwala et al. (2013) obteve uma melhor relação entre as características do ressalto hidráulico e propriedades da rugosidade no canal, ao considerar uma nova variável na Eq. (3), chamada de "densidade de rugosidade", que definiu como a razão entre a largura do elemento de rugosidade pelo espaçamento entre cada elemento.

\subsubsection{Comprimento do ressalto hidráulico $\left(L_{j}\right)$}

O comprimento do ressalto é a distância horizontal entre as profundidades $\mathrm{y}_{1}$ e $\mathrm{y}_{2}$. Essa medida é fundamental para o dimensionamento de estruturas de dissipação de energia, como as bacias de dissipação. A eficiência da estrutura está intimamente relacionada com o conhecimento da extensão dos efeitos do ressalto hidráulico (WIEST, 2008). 
Para calcular o comprimento do ressalto, é necessário, antes de tudo, definir seu início e fim. A definição do final do ressalto é uma tarefa difícil devido à presença de turbulência residual e ondas na superfície livre, havendo divergências sobre metodologias de identificação na literatura, embora a maioria delas considere a estabilidade da altura a jusante do ressalto como parâmetro de controle comum. (CAROLLO; FERRO; PAMPALONE, 2012).

Segundo Hager (1992), na seção do final do ressalto há horizontalidade na superfície livre, ocorre diminuição notável da turbulência na superfície, não há presença de bolhas de ar no escoamento e o regime de escoamento gradualmente variado ressurge. Já Ortiz (1981) usou um parâmetro chamado de intensidade turbulenta relativa, $\mathrm{k}_{\mathrm{v}}$, para determinar o final do ressalto. A seção do escoamento em que $\mathrm{k}_{\mathrm{v}}$ se aproximava de 0,1 era considerada o final da zona de transição, ou seja, o escoamento retornava ao cenário característico de escoamento turbulento em canais.

Assim como Ortiz, os pesquisadores Simões et al. (2012) usaram um coeficiente para a determinação da seção de término do ressalto hidráulico. Os efeitos turbulentos do ressalto sob a superfície livre a jusante eram considerados finalizados quando o parâmetro adimensional $\mathrm{L}_{\mathrm{j}} /\left(\mathrm{y}_{2}-\mathrm{y}_{1}\right)$ fosse independente da posição ao longo do canal. Em ensaios com $\mathrm{F}_{1}=3$, foi encontrado um comprimento adimensional 9,52.

A Tab. 1 mostra fórmulas empíricas de diversos autores para o cálculo do ressalto hidráulico. Como pode ser observado, há um grande esforço por parte dos pesquisadores, em desenvolver equações de estimativa para a determinação do comprimento do ressalto hidráulico.

Tabela 1. Equações para o comprimento do ressalto hidráulico. $\mathrm{L}_{\mathrm{j}}=$ comprimento do ressalto; $\mathrm{v}_{\mathrm{c}}, \mathrm{v}_{1}, \mathrm{v}_{2}=$ velocidade crítica, velocidade supercrítica e velocidade subcrítica, respectivamente; $g$ = aceleração da gravidade; $\mathrm{y}_{1}, \mathrm{y}_{2}=$ altura supercrítica e altura subcrítica, respectivamente; $\mathrm{F}_{1}=$ número de Froude. Fonte: Elevatorski (1959) apud Simões (2008), Hager et al. (1990), Peterka (1984), Teixeira (2003) e Schulz et al. (2015a).

\begin{tabular}{c|c|c}
\hline Autor & Data & Equação \\
\hline Riegel, Beebe & 1917 & $\mathrm{~L}_{\mathrm{j}}=5 \cdot\left(\mathrm{y}_{2}-\mathrm{y}_{1}\right)$ \\
\hline Knapp & 1932 & $\mathrm{~L}_{\mathrm{j}}=\left[\left(\frac{62,5 \cdot \mathrm{y}_{1}}{\mathrm{H}_{2}}\right)+1,13\right] \cdot\left[\frac{\left(\mathrm{v}_{2}-\mathrm{v}_{1}\right)^{2}}{2 \mathrm{~g}}-\frac{\mathrm{H}_{\mathrm{r}}}{\mathrm{H}_{\mathrm{j}}}\right]$ \\
& & $\mathrm{H}=\mathrm{y}+\frac{\mathrm{v}^{2}}{2 \mathrm{~g}}$ \\
\hline
\end{tabular}




\begin{tabular}{|c|c|c|}
\hline Woycicki & 1934 & $\mathrm{~L}_{\mathrm{j}}=\left(y_{2}-y_{1}\right)\left(8-\frac{0,05 \cdot y_{2}}{y_{1}}\right)$ \\
\hline Smatana & 1934 & $\mathrm{~L}_{\mathrm{j}} \approx 6 .\left(y_{2}-y_{1}\right)$ \\
\hline Chrtoussov & 1935 & $\mathrm{~L}_{\mathrm{j}}=10,3 \cdot \mathrm{y}_{2} \cdot\left(\mathrm{Fr}_{1}-1\right)^{0,81}$ \\
\hline Aravin & 1935 & $\mathrm{~L}_{\mathrm{j}}=5,4 \cdot\left(\mathrm{y}_{2}-\mathrm{y}_{1}\right)$ \\
\hline Bakhmeteff-Matzke & 1936 & $\mathrm{~L}_{\mathrm{j}}=5 .\left(\mathrm{y}_{2}-\mathrm{y}_{1}\right)$ \\
\hline Ludin & 1936 & $\mathrm{~L}_{\mathrm{j}}=\frac{\mathrm{y}_{1}}{0,22-0,17 \cdot \frac{\mathrm{v}_{\mathrm{c}}}{\mathrm{v}_{1}}}$ \\
\hline Kimey & 1941 & $\mathrm{~L}_{\mathrm{j}}=6,02 \cdot\left(y_{2}-y_{1}\right)$ \\
\hline Posey & 1941 & $\mathrm{~L}_{\mathrm{j}}=4,5-7 \cdot\left(y_{2}-y_{1}\right)$ \\
\hline $\mathrm{Wu}$ & 1949 & $\mathrm{~L}_{\mathrm{j}}=10 \cdot\left(y_{2}-y_{1}\right) \cdot \mathrm{Fr}_{1}{ }^{-0,16}$ \\
\hline Peterka & 1958 & $\begin{array}{c}\mathrm{L}_{\mathrm{j}}=6,1 \cdot \mathrm{y}_{2} \\
4,5 \leq \mathrm{Fr}_{1} \leq 9,0\end{array}$ \\
\hline Elevatorski & 1959 & $\mathrm{~L}_{\mathrm{j}}=6,9 \cdot\left(y_{2}-y_{1}\right)$ \\
\hline Silverster & 1964 & $\mathrm{~L}_{\mathrm{j}}=9,75 \cdot y_{1} \cdot\left(F r_{-} 1-1\right)^{1,01}$ \\
\hline Marques et al. & 1997 & $\mathrm{~L}_{\mathrm{j}}=8,5 \cdot\left(y_{2}-y_{1}\right)$ \\
\hline Teixeira & 2003 & $\mathrm{~L}_{\mathrm{j}}=8,0 \cdot\left(y_{2}-y_{1}\right)$ \\
\hline Simões & 2008 & $\begin{array}{r}\mathrm{L}_{\mathrm{j}} / \mathrm{h}_{2}=\left(\mathrm{Fr}_{1}^{2}-81,85 \mathrm{Fr}_{1}+61,13\right) \\
/\left(-0,62-10,71 \mathrm{Fr}_{1}\right)\end{array}$ \\
\hline Simões et al. & 2012 & $\mathrm{~L}_{\mathrm{j}}=9,52 \cdot\left(\mathrm{y}_{2}-\mathrm{y}_{1}\right)$ \\
\hline
\end{tabular}

\subsubsection{Comprimento do rolo $\left(L_{r}\right)$}

O rolo é a região do ressalto destacada na Fig. 3 e se caracteriza por apresentar turbulência de maior intensidade. O início do rolo corresponde à seção de início do ressalto, e em seu final se nota a presença de um ponto de estagnação e a passagem para uma zona de 
transição (NÓBREGA, 2014). O comprimento do rolo $\left(\mathrm{L}_{\mathrm{r}}\right)$ é, portanto, a distância entre a seção de início do ressalto e esse ponto.

De acordo com Rajaratnam (1967), o final do rolo corresponde ao ponto de altura $\mathrm{y}_{\mathrm{t}}$ igual a $95 \%$ da profundidade conjugada $\mathrm{y}_{2}$. Essa proximidade entre as duas profundidade aumenta a medida que $F_{1}$ também aumenta. $O$ autor fornece uma equação empírica para a determinação da altura $y_{t}$ :

$$
\frac{\mathrm{y}_{1}}{\mathrm{y}_{2}}=0,834+0,012 . \mathrm{Fr}_{1} \quad \text { Eq. } 4
$$

Beirami e Chamani (2010) analisaram o efeito da declividade no comprimento do ressalto. Segundo seus estudos, para canais inclinados o comprimento do ressalto muda em comparação com canais horizontais, sugerindo-se que o comprimento $\mathrm{L}_{\mathrm{j}}$ fosse adotado como sendo o comprimento do rolo.

Simões et al. (2012) adotaram como final do rolo a seção em que a profundidade passa a ser constante, por meio de análise do perfil médio da superfície livre. A equação resultante foi a seguinte:

$$
\frac{\mathrm{L}_{\mathrm{r}}}{\mathrm{y}_{2}-\mathrm{y}_{1}}=6 \quad \text { Eq. } 5
$$

Sendo o rolo uma região responsável pela maior parte da dissipação de energia no ressalto, diversos autores elaboraram metodologias para o desenvolvimento de equações empíricas relacionando o comprimento do rolo e as profundidades conjugadas, como mostra a Tab. 2.

Tabela 2. Equações empíricas para comprimento do rolo. $\mathrm{L}_{\mathrm{r}}=$ comprimento do rolo; $\mathrm{v}_{1}=$ velocidade supercrítica; $\mathrm{y}_{1}, \mathrm{y}_{2}=$ altura supercrítica e altura subcrítica, respectivamente; $\mathrm{Fr}_{1}=$ número de Froude Fonte:

Elavatorski (1957) apud Simões (2008), Hager et al. (1990) e Simões (2012).

\begin{tabular}{c|c|c}
\hline Autor & Data & Equação \\
\hline Safranez & 1929 & $\frac{\mathrm{L}_{\mathrm{r}}}{\mathrm{y}_{1}}=6 . \mathrm{Fr}_{1}$ \\
\hline Pietrkowski & 1932 & $\frac{\mathrm{L}_{\mathrm{r}}}{\mathrm{y}_{1}}=5,9 . \mathrm{Fr}_{1}$ \\
\hline Einwachter & 1933 & $\mathrm{~L}_{\mathrm{r}}=\left(15,2-\frac{0,24 \cdot y_{2}}{y_{1}}\right)\left[\frac{\mathrm{y}_{2}}{y_{1}}-1-v_{1} \cdot\left(\frac{\mathrm{y}_{2}}{y_{1}}\right)-1\right]$ \\
\hline
\end{tabular}




\begin{tabular}{c|c|c}
\hline Douma & 1942 & $\mathrm{~L}_{\mathrm{r}}=3 \cdot \mathrm{y}_{2}$ \\
\hline Peterka & 1957 & $\mathrm{~L}_{\mathrm{r}}=4,5 \cdot \mathrm{y}_{2}$ \\
& & $4,5 \leq \mathrm{Fr}_{1} \leq 9,0$ \\
\hline Newnham & 1973 & $\mathrm{~L}_{\mathrm{r}}=6,73 .\left(\mathrm{Fr}_{1}-1\right)$ \\
\hline Sarma e Newnham & 1973 & $\frac{\mathrm{L}_{\mathrm{j}}}{\mathrm{L}_{\mathrm{r}}}=1,3$ \\
\hline Busch & 1981 & $\mathrm{~L}_{\mathrm{r}}=\alpha \cdot R^{* \beta} \cdot F r_{1}^{\gamma} \cdot \omega^{\delta} . \ln \left(y^{*}\right)$ \\
& & $\alpha=1,285 ; \beta=0,0683 ; \gamma=1,1017$ \\
& & $\delta=0,1605 ; \mathrm{y}^{*}=\mathrm{y}_{2} / \mathrm{y}_{1}($ Bélanger $)$ \\
\hline Marques et al. & 1997 & $\omega=\mathrm{y}_{1} / \mathrm{b} ; \mathrm{b}=1$ largura do canal \\
\hline Simões et al. & 2012 & $\mathrm{~L}_{\mathrm{r}}=6,0 .\left(y_{2}-y_{1}\right)$ \\
\hline
\end{tabular}

Como pôde ser observada, a análise do ressalto hidráulico e do rolo está intimamente relacionada com as profundidades conjugadas. E, embora haja um vasto estudo na tentativa de maior correlação entre as equações empíricas e dados experimentais, ainda se faz necessário uma maior investigação dos princípios físicos de conservação de massa, quantidade de movimento e energia, a fim de fornecer uma formulação mais abrangente que contemple diferentes condições experimentais.

A rugosidade de fundo e a declividade do canal também são fatores importantes que afetam a dissipação de energia, mas por vezes não são contabilizados nas equações. Neste sentido, o estudo aprofundado da dissipação de energia e a influência da declividade para o ressalto, mostram-se como temas interessantes de pesquisa para um maior entendimento dos ressaltos hidráulicos e auxílio em pré-projetos de bacias de dissipação de energia.

\subsection{RESSALTO HIDRÁULICO EM CANAIS COM DECLIVIDADE}

O projeto de canais com declividade, em comparação com canais horizontais, pode ser vantajoso em termos de dissipação de energia. Embora a solução para o problema do ressalto hidráulico clássico esteja bem discutida na literatura, o mesmo não ocorre para o ressalto em canais com declividade. Os principais problemas que dificultam a solução deste último 
envolvem o cálculo do peso do ressalto e termos de pressão na equação de conservação da quantidade de movimento, que não são bem definidos. Por esse motivo, parte da solução de problemas sobre a formação do ressalto em canais com declividade é encontrada empiricamente (SULTANA, 2011).

O ressalto hidráulico em canais com declividade é dividido em seis tipos, de acordo com a classificação feita por Kindsvater (1994) e Rajaratnam (1966). O ressalto A é formado inteiramente em plano horizontal. Para o ressalto B, o "pé" do ressalto se forma em uma declividade positiva e o final está num plano horizontal. $\mathrm{O}$ ressalto $\mathrm{C}$ se inicia na declividade positiva e termina na transição entre essa declividade e o plano horizontal. O ressalto D se localiza inteiramente no plano inclinado. No ressalto $\mathrm{E}$, a superfície da água é paralela ao fundo do canal, mesmo após o ressalto, não havendo descontinuidade da declividade no canal. $\mathrm{O}$ ressalto tipo $\mathrm{F}$ é um caso raro em que o ressalto se apresenta em declividade negativa. A Fig. 4 ilustra os seis tipos de ressalto mencionados. Neste estudo será analisado um canal com ressalto tipo E.

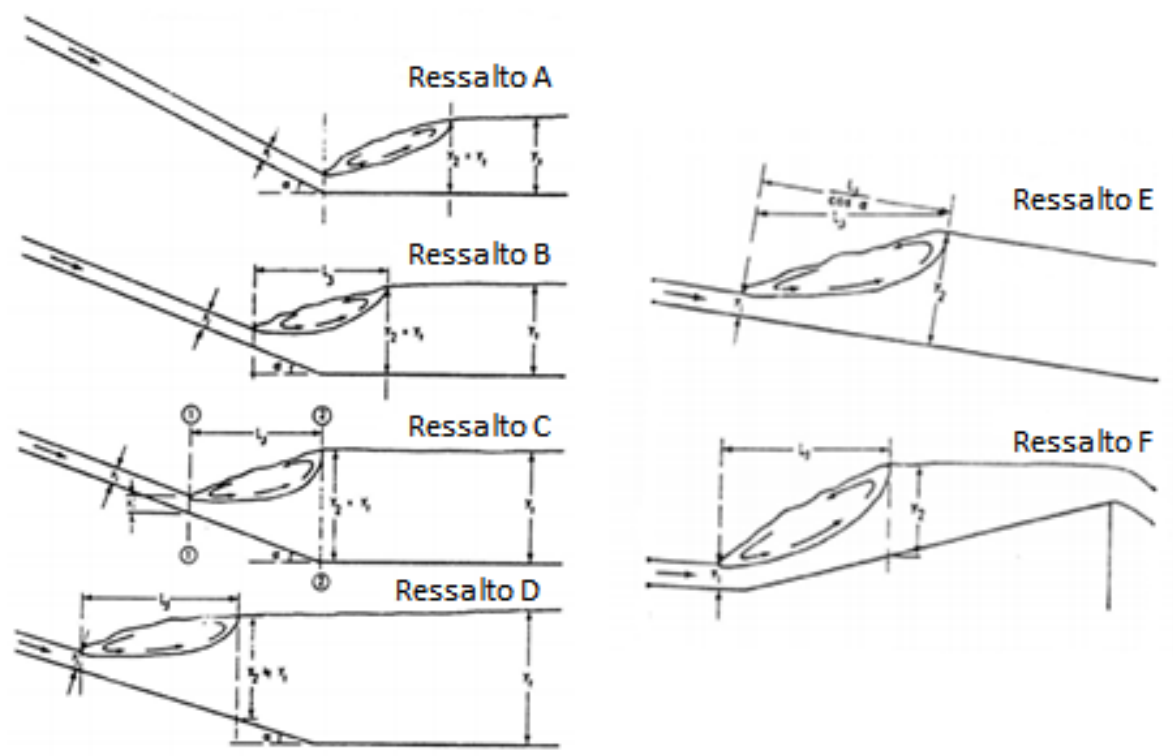

Figura 4. Tipos de ressalto em canais com declividade (Adaptado de KINDSVATER, 1944).

Em canais não horizontais, o nível da água mesmo a jusante do ressalto pode variar, devido a declividade, sobretudo em canais em que o final do ressalto ainda estiver numa seção com declividade. Devido a essa dificuldade, Kindsvater (1944) sugeriu que o final do rolo poderia ser tomado como o final do ressalto.

O estudo convencional do ressalto hidráulico, em canais com declividade, para determinar a relação entre as profundidades conjugadas, envolve o uso de um número de 
Froude moficado. A Eq. 6 apresenta a razão para as profundidades conjugadas, encontrada por Kindsvater (1944) para um ressalto C.

$$
\frac{y_{2}}{y^{\prime}{ }_{1}}=\frac{1}{2 \cos \theta}\left[\sqrt{1+8 F r_{1}^{2}\left(\frac{\cos ^{3} \theta}{1-2 N_{F} \tan \theta}\right)}-1\right] \quad \text { Eq. } 6
$$

Onde $\theta$ é o ângulo de inclinação e $\mathrm{N}_{\mathrm{F}}$ é um fator empírico relacionado com o comprimento do ressalto.

Kindsvater (1944) reescreveu a Eq. (6) de forma semelhante a equação de Bélanger, como mostra a Eq. (7), Eq. (8), Eq. (9) e Eq. (10).

$$
\frac{y_{2}}{y_{1}}=\frac{1}{2}\left(-1+\sqrt{1+8 G_{1}^{2}}\right) \quad \text { Eq. } 7
$$

Em que:

$$
\begin{array}{ll}
G_{1}^{2}=K_{1}^{2} F r_{1}^{2} & \text { Eq. } 8 \\
K_{1}^{2}=\frac{\cos ^{3} \theta}{1-2 N_{F} \tan \theta} & \text { Eq. } 9 \\
y^{\prime}{ }_{1}=\frac{y_{1}}{\cos \theta} & \text { Eq. } 10
\end{array}
$$

Outros autores, como Rajaratnam (1967) e Peterka (1963), também escreveram o número de Froude modificado como uma função de $\mathrm{F}_{1}$ e $\theta$, de forma semelhante à Eq. (8) e Eq. (9).

Alhamid e Negm (1996) avaliaram a influência da declividade e rugosidade de fundo em um canal retangular, na razão entre as profundidades conjugadas. O modelo de previsão obtido pode ser visto na Eq. (11).

$$
\frac{y_{2}}{y^{\prime} \prime_{1}}=\frac{1}{2}\left(-1+\sqrt{1+\frac{8}{\left(1-C_{s}\right) \cos \theta}\left(1-\frac{C_{r}}{2}\right) F r_{1}^{2}}\right) \quad \text { Eq. } 11
$$

Os efeitos da declividade e elementos de rugosidade foram incluídos por meio dos adimensionais $\mathrm{C}_{\mathrm{s}}$ e $\mathrm{C}_{\mathrm{r}}$, respectivamente, e calibrados experimentalmente, de modo a obter as relações da Eq. (12) e Eq. (13).

$$
\begin{array}{ll}
C_{S}=1,8524 S_{o}^{0,595} & \text { Eq. } 12
\end{array}
$$

Onde $\mathrm{S}_{\mathrm{o}}$ é declividade no canal. 


$$
\frac{C_{r}}{I}=0,0007\left[\frac{1}{\frac{F r_{1} L_{R}}{I} y_{b}}\right]^{-0,8963}
$$

Em que: I é a densidade de rugosidade; $\mathrm{y}_{\mathrm{b}}$ é a altura do elemento de rugosidade; $\mathrm{L}_{\mathrm{R}}$ é o comprimento da extensão da rugosidade alocada no fundo.

\subsection{DISSIPAÇÃO DE ENERGIA}

Uma das principais funções do ressalto hidráulico é proporcionar a dissipação da energia do escoamento, através da passagem de um escoamento rápido para um escoamento lento. Para uma dada vazão, a mudança de profundidade $y_{1}$ para $\mathrm{y}_{2}$ causa uma mudança de energia $E_{1}$ para $E_{2}$.

A Fig. 5 mostra a forma da curva de energia x profundidade do escoamento. $O$ ponto de mínima energia representa a profundidade crítica.

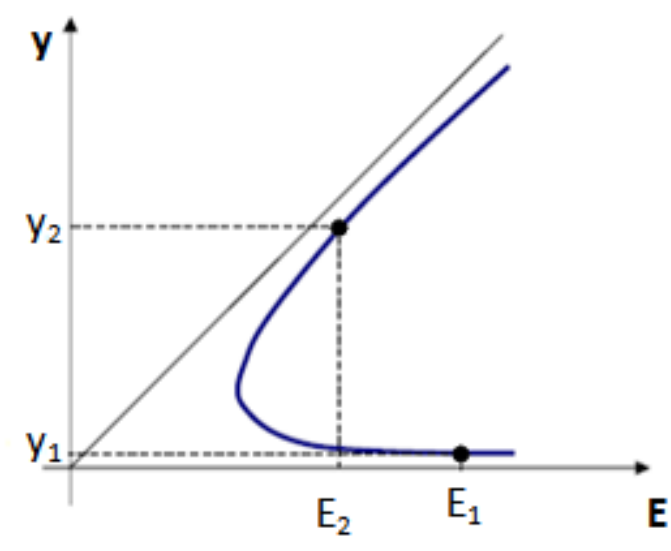

Figura 5. Energia específica em função da profundidade do escoamento (Adaptado de SOUSA, 2011).

Uma forma comum de determinar a perda de energia provocada pelo ressalto é calcular a energia específica nas seções de início e fim do ressalto. Utilizando a equação de conservação de quantidade de movimento para encontrar a perda de energia no ressalto, chega-se na Eq. (14). Combinando a Eq. (14) com a equação de Bélanger, pode-se calcular a perda de energia no ressalto a partir das profundidades conjugadas, Eq. (15). Vale ressaltar que a equação de Bélanger apresenta uma relação para canal horizontal, e também não considera o efeito das tensões de cisalhamento.

$$
\begin{array}{ll}
\Delta \mathrm{E}=E_{1}-E_{2}=\left(y_{1}+\frac{V_{1}}{2 g}\right)-\left(y_{2}+\frac{V_{2}}{2 g}\right) & \text { Eq. } 14 \\
\Delta E=\frac{\left(y_{2}-y_{1}\right)^{3}}{4 y_{1} y_{2}} & \text { Eq. } 15
\end{array}
$$


A "perda" de energia no ressalto também pode ser avaliada em termos de eficiência. O adimensional $\eta$ é geralmente usado para mostrar a razão entre a "perda" de energia e a energia específica na seção supercrítica.

$$
\eta=\frac{\Delta E}{E_{1}}
$$

Em seu estudo, Peterka (1984) afirmou que a eficiência da dissipação de energia no ressalto é diretamente proporcional ao número de Froude (Fig. 6), mas não de forma linear, de modo que a medida que o número de Froude aumenta, o ganho na eficiência aumenta.

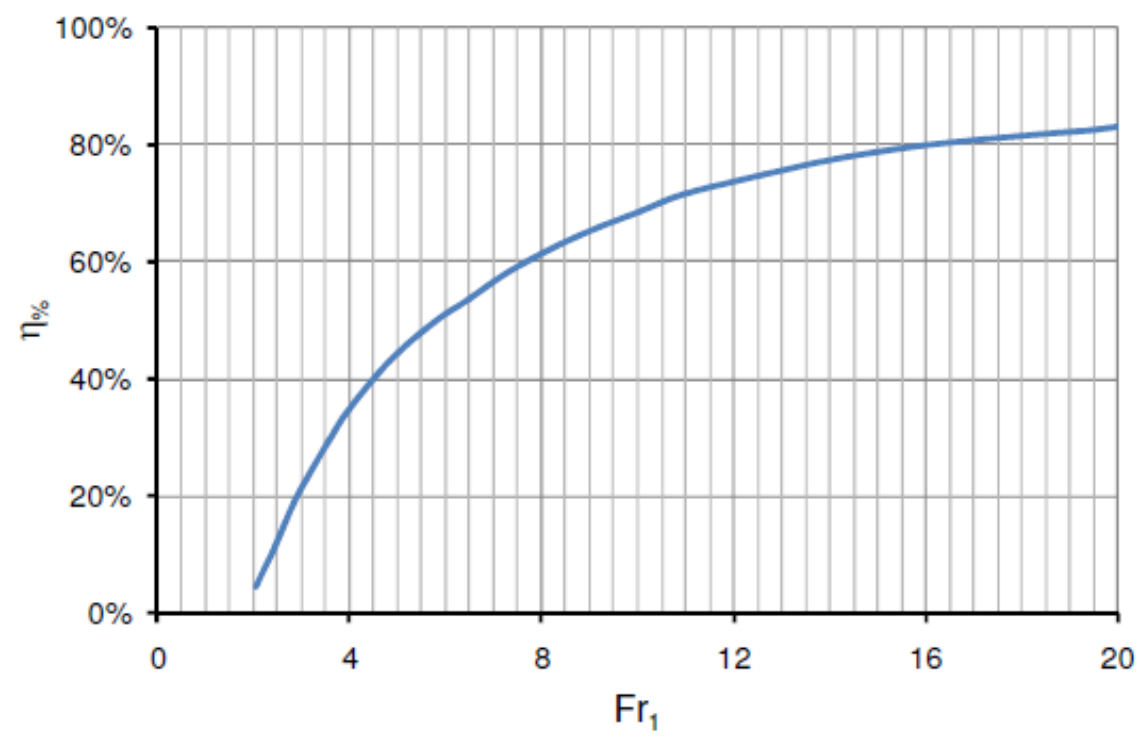

Figura 6. Relação entre a eficiência de dissipação de energia no ressalto hidráulico e o número de Froude (PETERKA, 1984).

No estudo da dissipação de energia do ressalto em canais com fundo rugoso, é importante uma análise preliminar da influência dos elementos de rugosidade presentes no fundo do canal, nas características do ressalto. Sendo interessante a consideração das dimensões e distribuição dos elementos de rugosidade no canal, como feito nos estudos de Alhamid e Negm (1996), e Neluwala et al. (2013).

Para a avaliação do efeito da declividade na dissipação de energia, faz-se necessário definir as condições de contorno para a obtenção da equação de quantidade de movimento no ressalto, a fim de definir as variáveis que interferem na razão entre as profundidades conjugadas, comparando dados experimentais com as equações de previsão propostas.

O desenvolvimento de equações referentes aos princípios de conservação de massa, quantidade de movimento e energia, aplicados ao escoamento, exigem a resolução de equações diferenciais, que em sua maioria, apresentam soluções não explícitas. Neste sentido, 
métodos numéricos e simulações podem ser utilizados como ferramentas para simplificação e análise dessas equações (CHUNG, 2002).

Segundo Schulz et al (20015a), o uso de métodos numéricos aplicados ao estudo do escoamento são bem-vindos, de modo que simulações adequadas ajudam a dar uma primeira visão das características do ressalto hidráulico, sem que haja necessidade de construir modelos físicos para o teste de cada situação.

Apesar da facilidade proposta, tentativas de simulação envolvendo superfície livre para caracterização de escoamento apresentam certo nível de dificuldade, pois a localização da superfície é um fator a ser determinado. É necessário um grau de refinamento elevado na malha e um grande número de iterações para se obter resultados satisfatórios (LOBOSCO \& SCHULZ, 2010; CHANSON, 2011; SIMÕES, 2012). 


\section{MATERIAL E MÉTODOS}

Para obtenção de equações de previsão sobre as características do ressalto em canal retangular com rugosidade de fundo e/ou declividade, este estudo foi baseado na proposta teórica discutida por Schulz et al (2015a,b) para análise do escoamento, considerando dois volumes de controle fixos. A seção 4.1 reproduz os principais pontos da proposição teórica proposta pelo autor.

\subsection{FORMULAÇÃO TEÓRICA}

O ressalto hidráulico foi estudado sob a óptica de dois volumes de controle fixos. O volume de controle 1 ( VC1) corresponde a região do rolo do ressalto e o volume de controle 2 (VC2) se refere à região de escoamento com predominância longitudinal. A Fig. 7 apresenta um esquema dos dois volumes de controle.

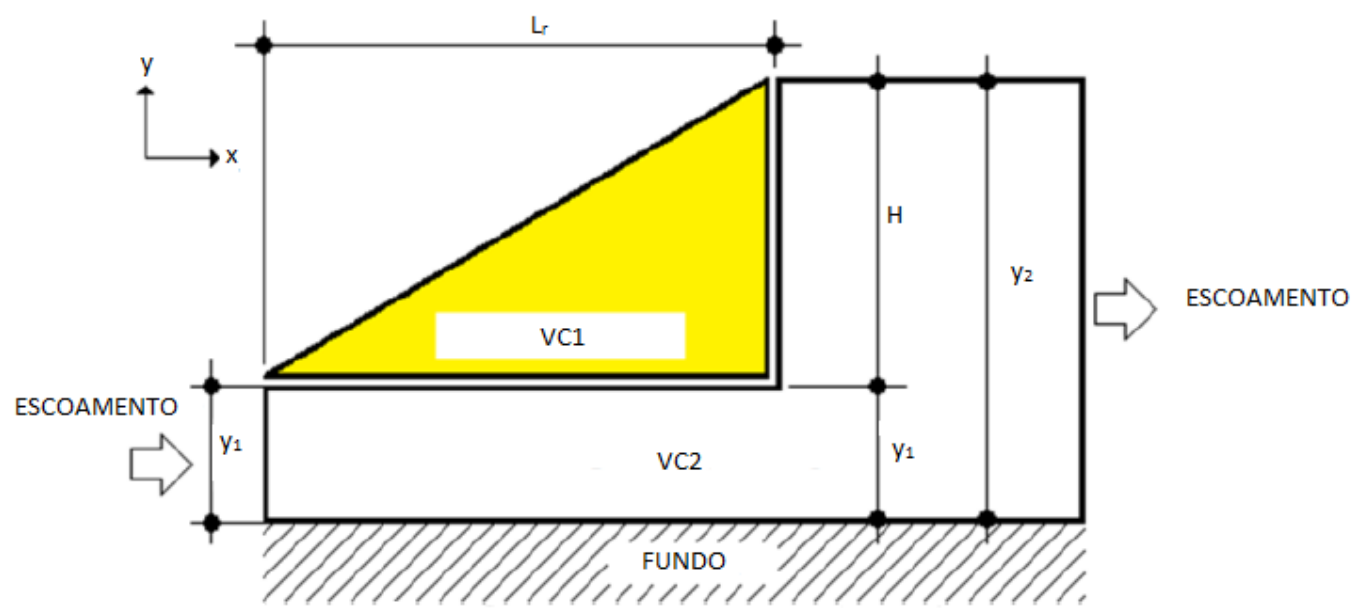

Figura 7. Abordagem do ressalto hidráulico segundo os volumes de controle 1 e 2 . $\mathrm{L}_{\mathrm{r}}$ é o comprimento do rolo, $\mathrm{y}_{1}$ e $\mathrm{y}_{2}$ são as profundidades conjugadas e $\mathrm{H}$ é a diferença entre elas.

O desenvolvimento das equações referentes aos princípios de conservação de massa, quantidade de movimento e energia seguiu as hipóteses simplificadoras descritas nas seguintes considerações:

- Escoamento médio permanente, que não se deforma e nem se descola com o tempo;

- VC1 não troca massa com o VC2;

- Há troca de quantidade de movimento e energia entre VC1 e VC2, como resultado das forças entre as interfaces;

- Distribuição de pressão hidrostática no início e final do ressalto; 
- Energia que entra em VC1 é totalmente convertida em energia térmica (equação de energia pode ser igualada a zero);

- O escoamento no VC2 é unidimensional ao longo das fronteiras.

A análise do escoamento nos volumes de controle é feita separadamente.

\subsubsection{Volume de controle 1}

Tendo-se o VC1 isolado e em equilíbrio, as forças atuantes são: $\mathrm{F}_{\mathrm{xt}}$ e $\mathrm{F}_{\mathrm{yt}}$ (forças de cisalhamento que o VC2 ocasiona no $\mathrm{VC} 1$, devido ao escoamento nas direções $\mathrm{x}$ e $\mathrm{y}$, respectivamente), força de pressão (força exercida pelo fluido fora do VC1 na superfície vertical devido à pressão).

Há inserção de energia no VC1 devido as forças de cisalhamento, responsáveis pela movimentação do fluido. Essa energia é convertida em energia térmica pela ausência de transferência de massa através da superfície de controle. Eventualmente, a energia térmica é perdida para o ambiente, gerando uma nova situação permanente.

A quantificação da energia dissipada foi realizada levando-se em conta a existência de três regiões de velocidades características no VC1 (Fig. 8), sendo cada região associada a uma perda de energia. A perda de energia total do escoamento no VC1 é a soma das perdas em cada região.

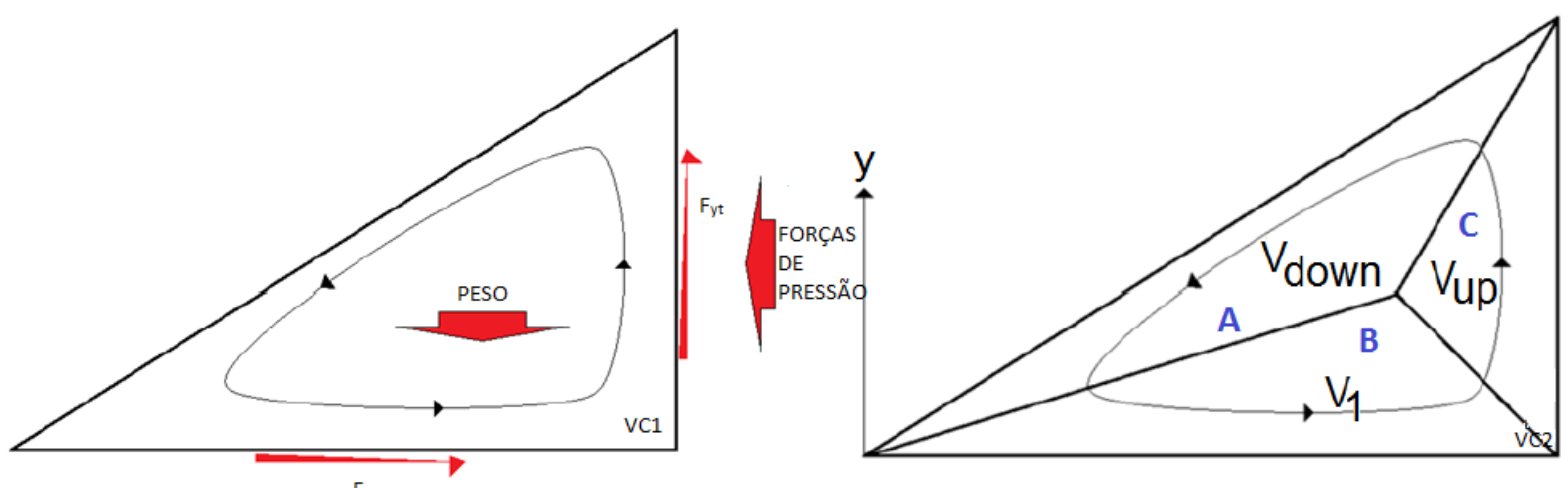

Figura 8. Forças atuantes no $\mathrm{VC} 1$ e regiões $A, B$ e $C$ com velocidades $V_{\text {down }}, V_{1}$ e $V_{\text {up }}$, respectivamente.

\subsubsection{Volume de controle 2}

Considerando um escoamento estacionário, o VC2 é apresentado na Figura 9. 


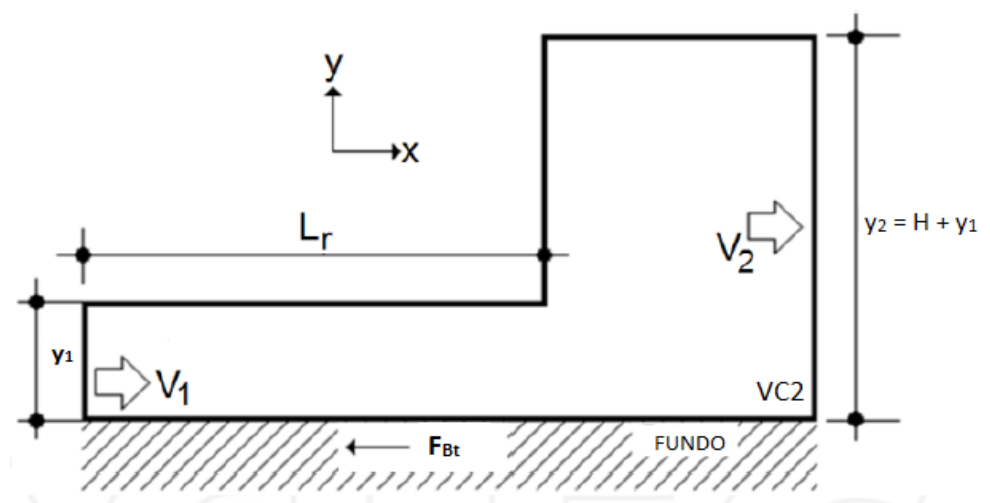

Figura 9. Volume de controle 2.

A partir dessas definições iniciais, do desenvolvimento e resolução das equações de conservação de massa, quantidade de movimento e energia aplicadas aos dois volumes de controle, Schulz et al. (2015a) definem as seguintes equações principais para as características geométricas do ressalto hidráulico (para mais detalhes consultar bibliografia original):

$$
\begin{array}{ll}
\frac{\mathrm{L}}{\mathrm{y}_{1}}=\eta \frac{\mathrm{Fr}_{1}}{\sqrt{\mathrm{y}^{*}}}+\sigma \mathrm{Fr}_{1}^{3} \sqrt{\mathrm{y} *} & \text { Eq. } 17 \\
\frac{\mathrm{L}}{\mathrm{y}_{2}}=\eta \frac{\mathrm{Fr}_{1}}{\mathrm{y}^{\#} \sqrt{\mathrm{y}^{*}}}+\sigma \frac{\mathrm{Fr}_{1}^{3} \sqrt{\mathrm{y}^{*}}}{\mathrm{y}^{\#}} & \text { Eq. } 18 \\
\mathrm{y}^{\#}=\eta^{\prime \mathrm{Fr}_{1}^{2}}+\sqrt{\left(\eta^{\prime} \mathrm{Fr}_{1}^{2}\right)^{2}+\sigma^{\prime} \mathrm{Fr}_{1}^{2}} & \text { Eq. } 19
\end{array}
$$

Em que: $\mathrm{y}^{*}=\mathrm{y}_{1} /\left(\mathrm{y}_{2}-\mathrm{y}_{1}\right), \mathrm{y}^{\#}=\mathrm{y}_{2} / \mathrm{y}_{1}, \mathrm{e} \sigma, \sigma^{\prime}, \eta$, $\eta^{\prime}$ são coeficientes a serem ajustados. Essas equações mostraram uma ótima correlação com os dados de Peterka (1984), e também com os dados de Hughes e Flack (1984), para diferentes rugosidades. As relações adimensionais propostas foram confrontadas com os dados experimentais obtidos neste estudo, no capítulo 5, contemplando-se experimentos com declives e diferentes rugosidades no fundo, para análise da dissipação de energia na formulação teórica e no ajuste dos coeficientes.

\subsection{ETAPAS DO TRABALHO}

O presente projeto foi conduzido conforme três etapas principais:

Etapa 1 - obtenção de ressalto hidráulico em dois canais de escoamento, inserção de peças Lego e material emborrachado no fundo para diferente rugosidade. 
Etapa 2 - estudo das características geométricas do ressalto hidráulico e análise da dissipação de energia ao longo do escoamento, variando-se parâmetros operacionais (rugosidade de fundo, declividade do canal, etc.).

Etapa 3 - comparação dos dados experimentais e avaliação da adequação de equações teóricas para a previsão dos dados.

\subsubsection{Etapa 1}

Os dois canais retangulares usados para a realização dos experimentos estão localizados no Laboratório de Hidráulica, pertencente ao Departamento de Engenharia Hidráulica e Saneamento da Escola de Engenharia de São Carlos da Universidade de São Paulo - EESC / USP.

Um dos canais possui laterais de vidro, sendo designado neste estudo por canal A, com comprimento útil de 3,0 m e largura de $0,10 \mathrm{~m}$. O canal escoa água por meio de um circuito fechado, sendo a água bombeada para o canal por meio de uma bomba, e em seguida retornando para o mesmo. Ao final do canal há uma comporta plana utilizada para controlar a profundidade do escoamento. Os ressaltos hidráulicos foram obtidos através da aceleração do escoamento no vertedor, com uma soleira espessa de dimensões de 0,09 $\mathrm{m}$ de altura e $0,38 \mathrm{~m}$ de comprimento; e jatos de fundo utilizando uma comporta plana. A Fig. 10, Fig. 11 e Fig. 12 mostram o canal, a soleira espessa e a comporta plana, respectivamente. 


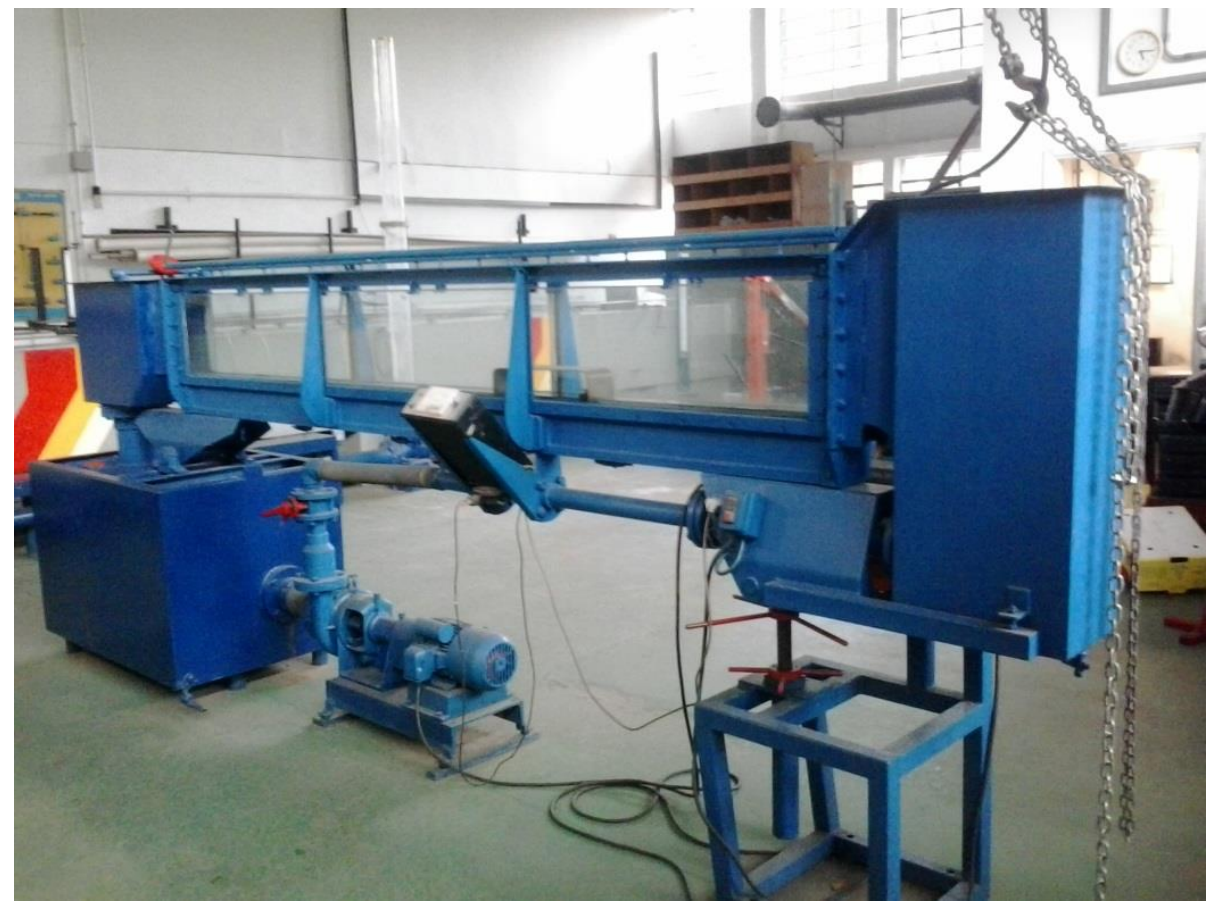

Figura 10. Canal A com laterais de vidro.

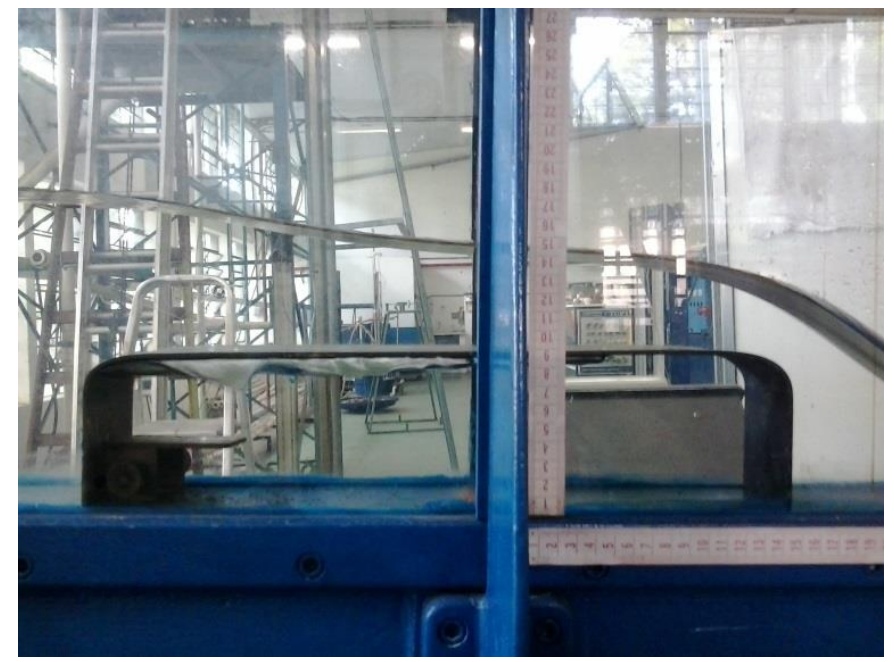

Figura 11. Soleira espessa. 


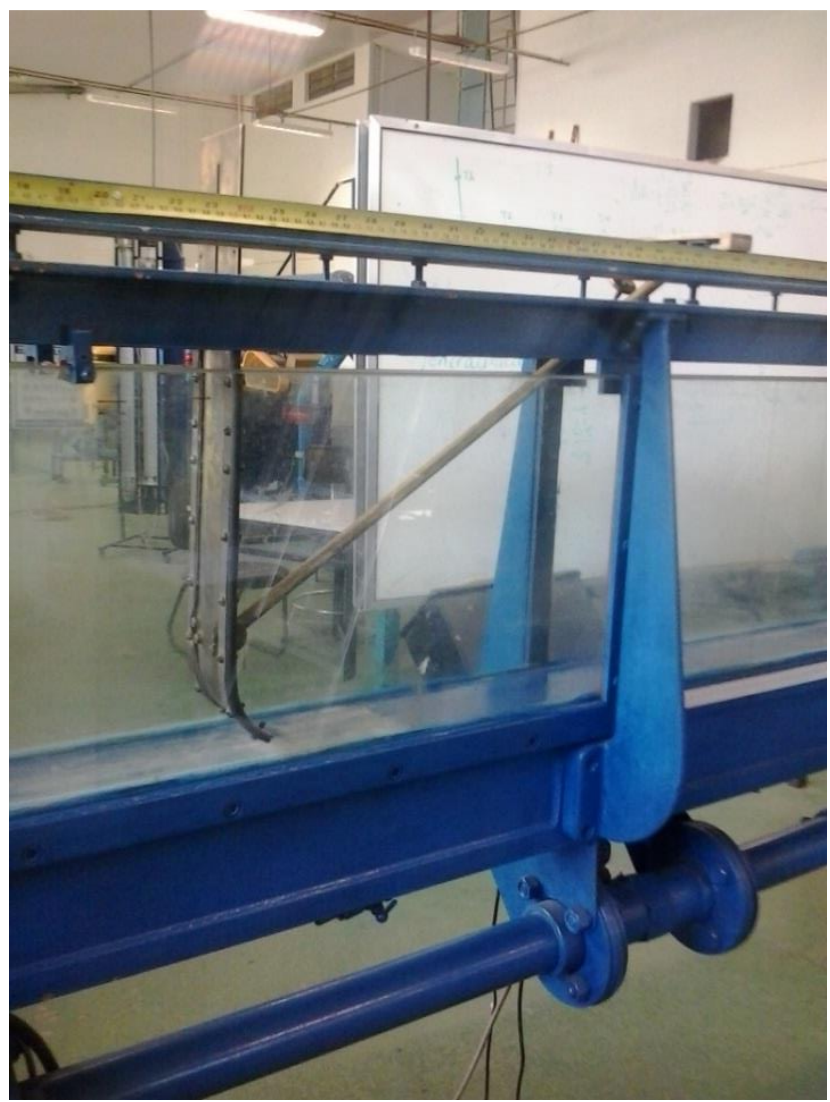

Figura 12. Comporta plana.

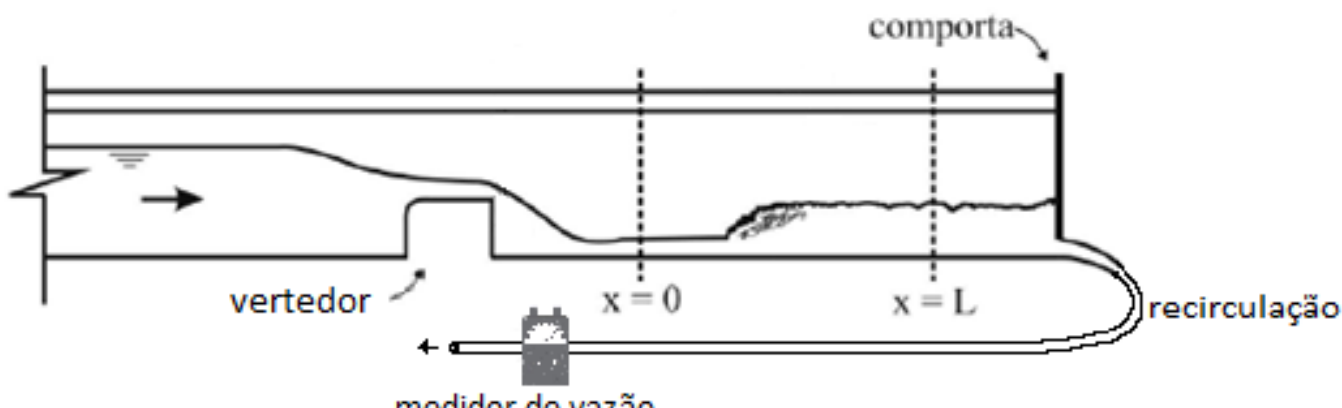

medidor de vazão

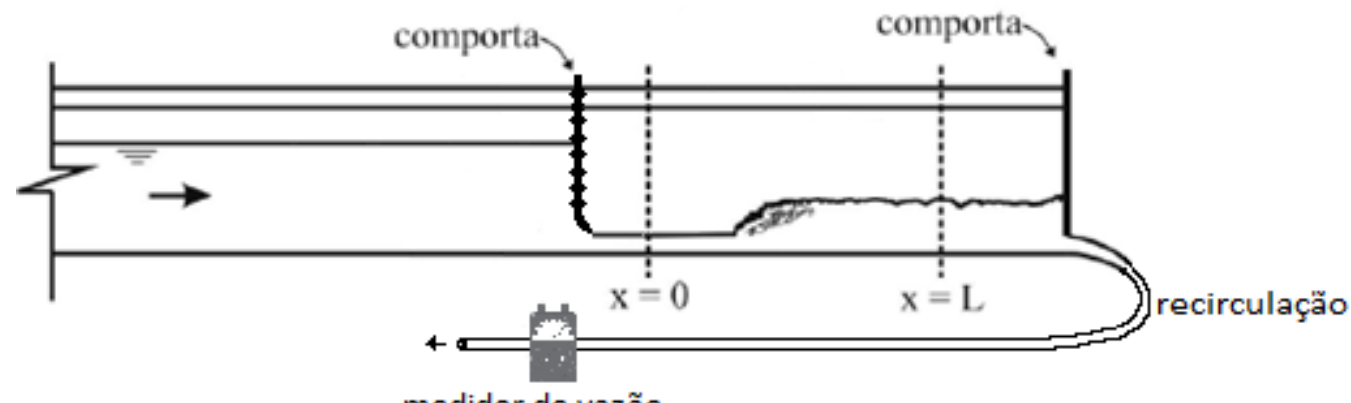

medidor de vazão

Figura 13. Desenho esquemático do aparato experimental do canal A, com uso de vertedor e comporta para formação do ressalto hidráulico. Adaptado de Simões, Schulz e Porto (2012). 
Neste canal também se realizou ajuste manual da declividade. Foram realizados experimentos sem declividade e com a declividade máxima obtida no canal, de 3,5\%.

O outro canal usado possui paredes de concreto liso, referenciado neste trabalho como canal B, com 0,41 m de largura. Os ressaltos foram obtidos na região do canal compreendida entre uma soleira espessa de 0,23 m de altura e uma comporta. A Fig. 14 mostra uma visão da soleira espessa e da comporta no canal.

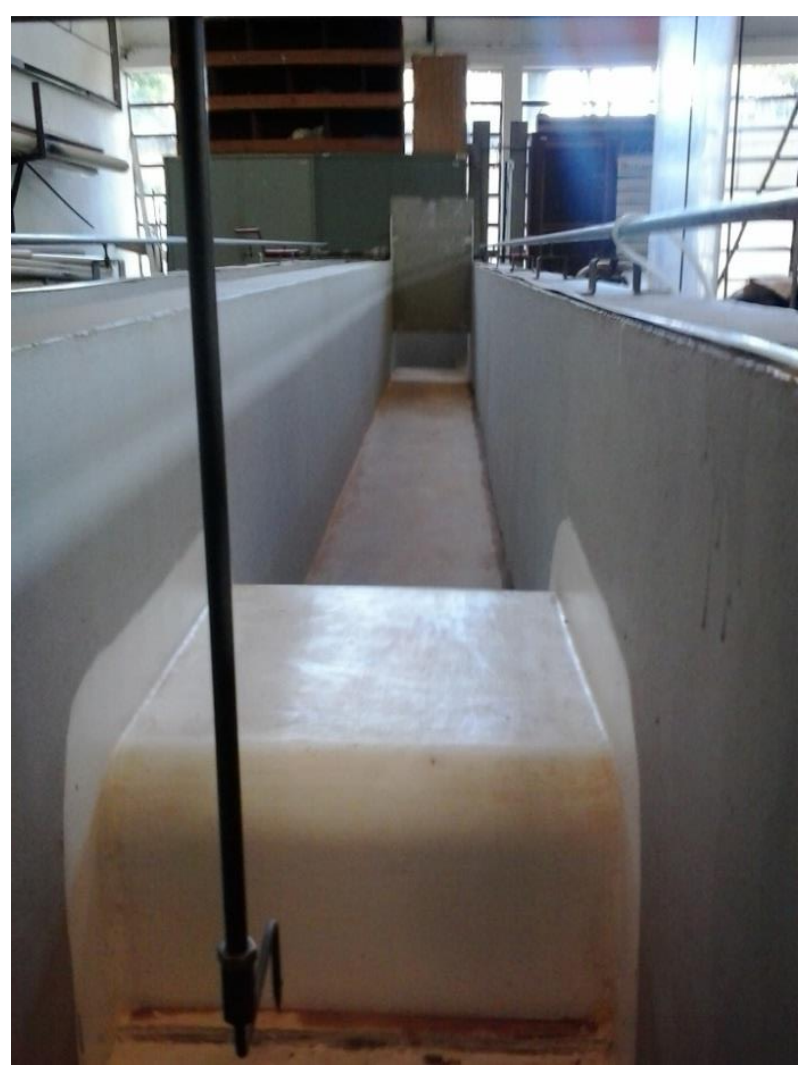

Figura 14. Canal B, soleira espessa e comporta ao final do canal.

\subsubsection{Etapa 2}

Esta etapa representa a operação dos canais e a fase de coleta de dados. Experimentos variando-se a vazão, declividade, uso de soleira espessa ou comporta plana e rugosidade de fundo foram analisados para o canal A. Nos experimentos com comporta plana, esta foi mantida a uma altura fixa de $1,5 \mathrm{~cm}$.

No canal A, uma câmera (SONY DSC-WX7) foi posicionada a uma distância de 1,3 m da lateral do canal, para filmar os experimentos e auxiliar na coleta e análise dos dados referentes ao ressalto, com captura de 30 quadros por segundo e resolução de vídeo 1920 x 1080. O tempo de amostragem foi de 35 segundos, resultando em 1050 quadros por experimento. 
No canal B, usou-se um sensor ultrassônico para medição das profundidades ao longo do comprimento do canal, partindo-se do início do ressalto e seguindo por um comprimento de aproximadamente $3,25 \mathrm{~m}$, com medições a cada $2 \mathrm{~cm}$. Em cada posição foi usada taxa de amostragem de $20 \mathrm{~Hz}$, durante 150 segundos, gerando 3000 amostras. Conforme mostra a Fig. 15, o sensor foi fixado em uma placa de madeira reconstituída retangular, com uso de fita dupla face, e o processo de posicionamento do sensor em cada ponto foi realizado manualmente, com auxílio de uma fita métrica colada em uma das paredes do canal. $\mathrm{O}$ desenho esquemático do canal B é apresentado na Fig. 16.

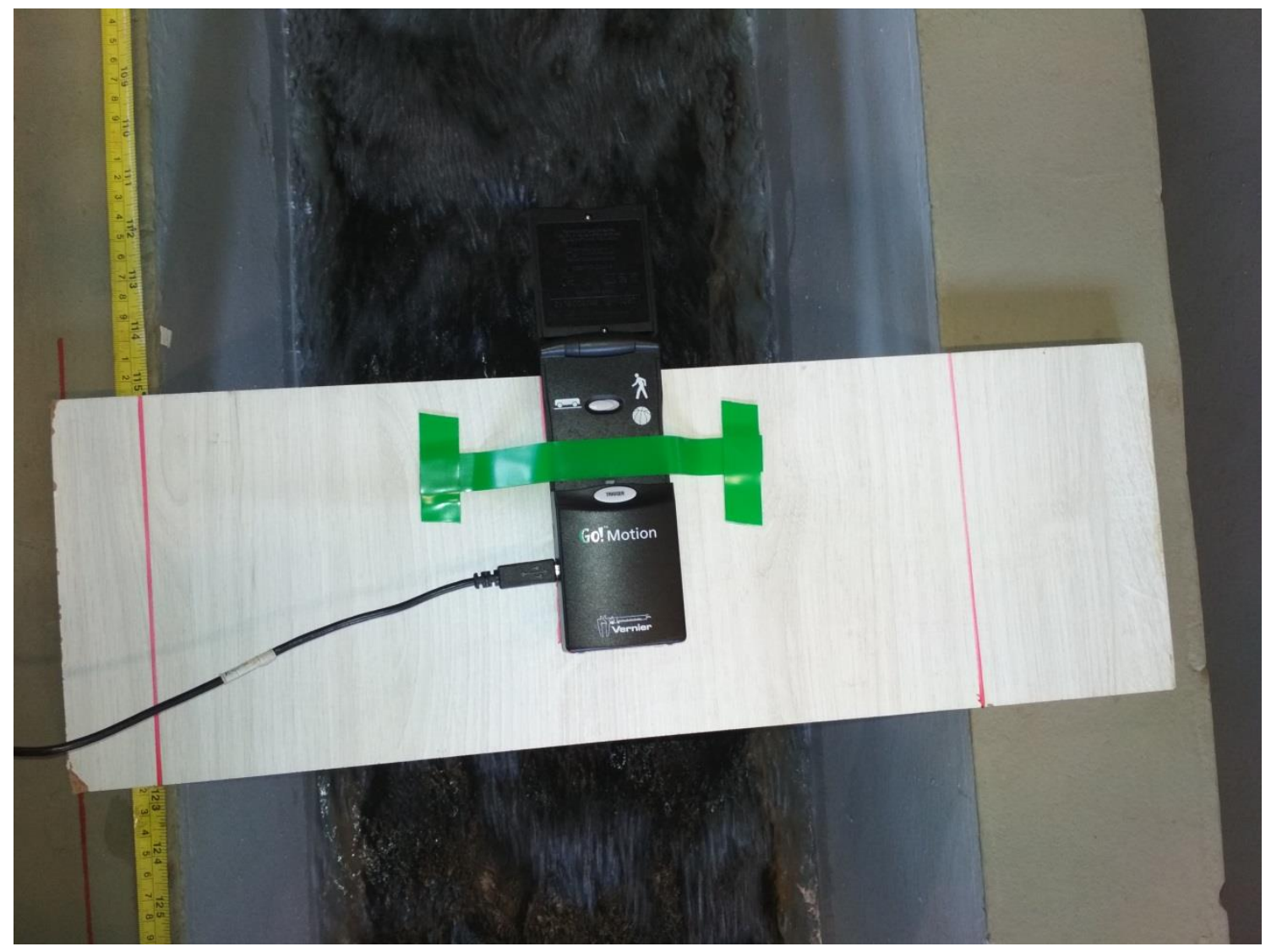

Figura 15. Sensor ultrassônico utilizado para medição das profundidades.

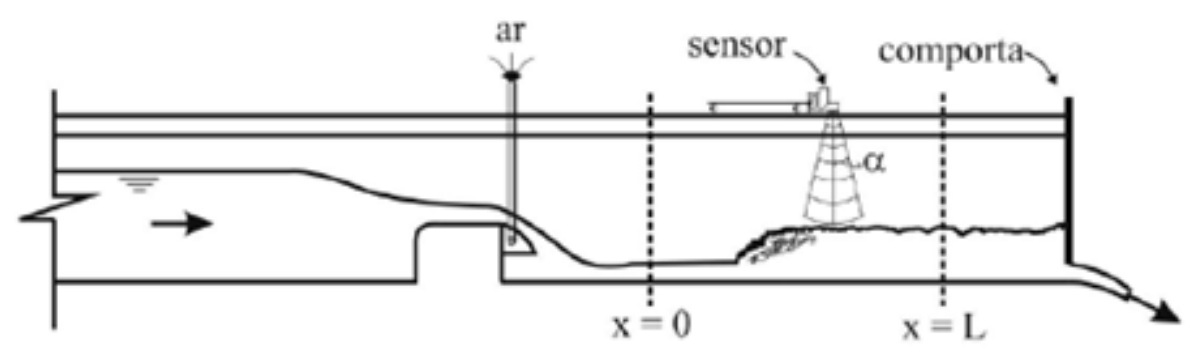

Figura 16. Desenho esquemático do aparato experimental do canal B. Fonte: Simões, Schulz e Porto (2010). 


\subsubsection{Medição da vazão}

Para o canal A, a vazão foi aferida por meio de um medidor eletrônico analógico acoplado a tubulação, fornecendo medidas em miliampéres para cada vazão correspondente.

Nóbrega (2014) havia realizado a última calibração no medidor eletrônico, encontrando uma relação entre a vazão e a corrente elétrica $Q / i=9,25$, com $i$ em mA e $Q$ em L/s. No intuito de garantir a precisão nas medidas de vazão, uma nova calibração foi realizada, utilizando-se do mesmo método deste autor. O método consistiu em achar o coeficiente de relação linear entre a corrente elétrica medida e a vazão real.

A nova calibração do medidor eletrônico foi feita com uso de um medidor de vazão ultrassônico doppler, sendo este último ligado a tubulação de recirculação. A curva de calibração pode ser observada na Fig. 17. A razão encontrada entre a vazão e a corrente elétrica foi $Q / i=9,51$, Eq. (20), e a vazão máxima registrada para o canal foi de aproximadamente $9,64 \mathrm{~L} / \mathrm{s}$.

$Q=9,51 . i$

Eq. 20

Com $i$ em miliampéres e $Q$ em L/s.

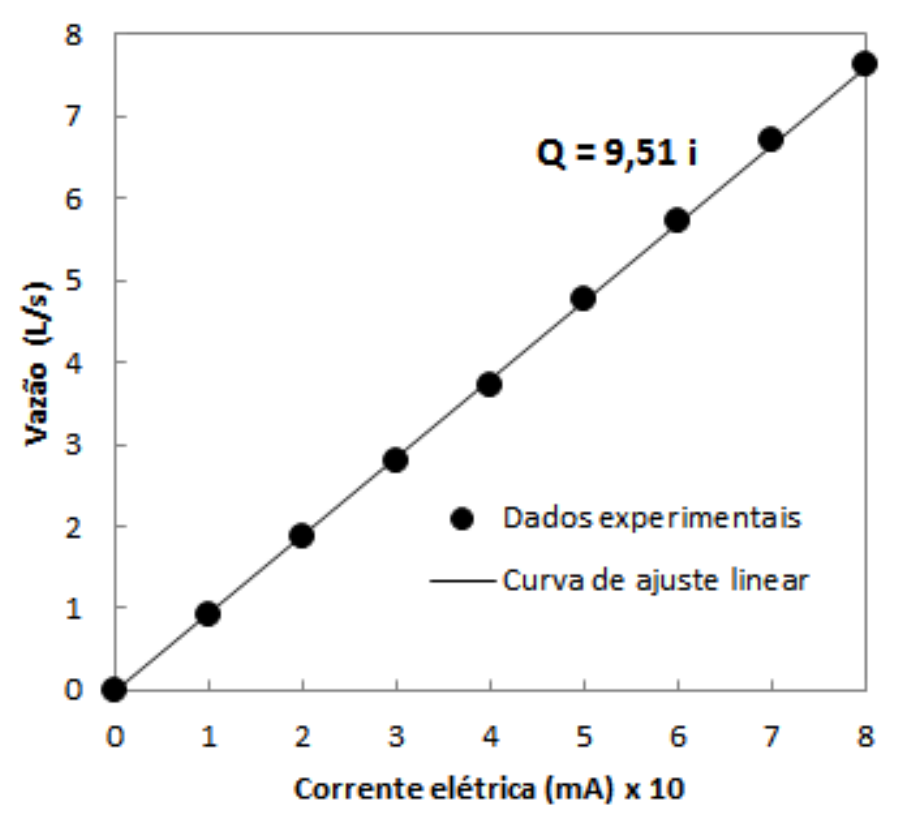

Figura 17. Curva de calibração para o medidor eletrônico de vazão.

Para o canal B, utilizou-se um vertedor triangular de parede delgada, Fig. 18, a montante do canal para o cálculo da vazão. A equação usada foi a de Thomson 
(LENCASTRE, 1969), em que a vazão é função da carga hidráulica acima do vertedor, e a carga foi determinada através de um piezómetro localizado na lateral do canal.

$$
Q=1,4 h^{5 / 2}
$$

Eq. 21

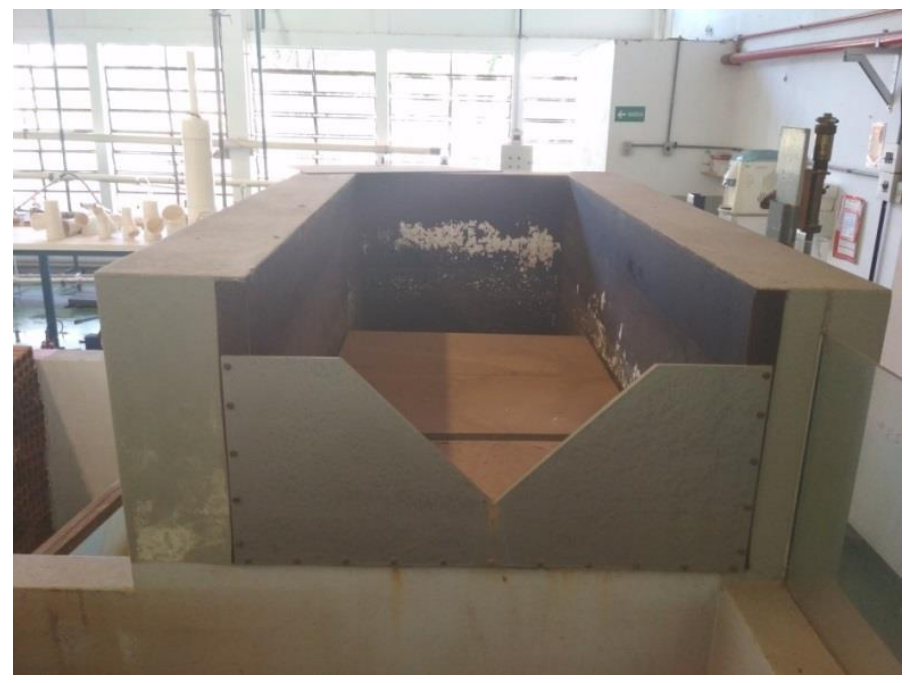

Figura 18. Vertedor triangular de parede delgada para aferição da vazão no canal B.

Na Eq. (21), $h$ representa a carga acima do vertedor triangular, em metros, com $h_{0}=$ 0,993 m. A medição da carga foi realizada por meio de piezômetro, Fig. 19.

]

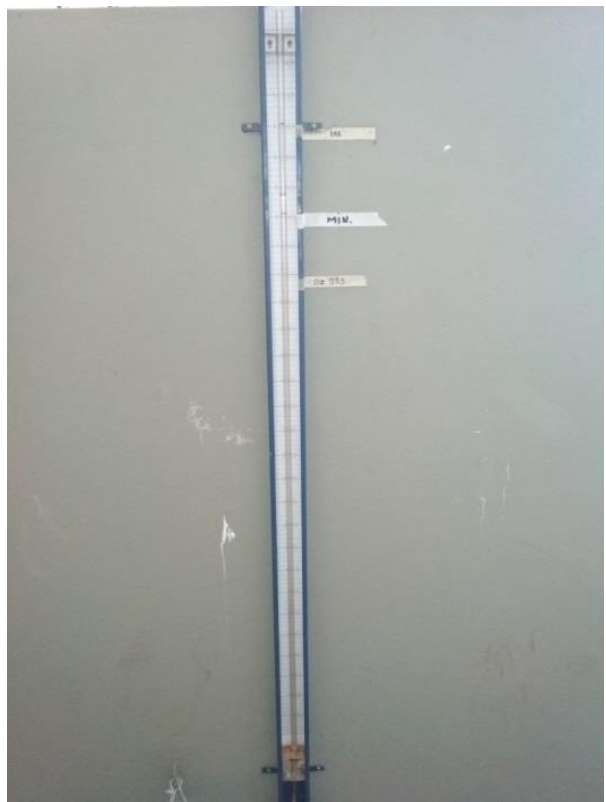

Figura 19. Piezômetro usado para medição da carga no vertedor triangular. 


\subsubsection{Número de Froude}

Na Eq. (22) é apresentado o cálculo para o número de Froude na seção de início do ressalto hidráulico, em ambos os canais.

$$
F_{1}=\frac{V_{1}}{\sqrt{g y_{1}}}
$$

$V_{l}$ é a velocidade supercrítica, $g$ é a aceleração da gravidade e $y_{l}$ é altura na seção supercrítica.

\subsubsection{Declividade}

O canal A, com paredes de vidro, permite um ajuste manual da inclinação, conforme pode ser observado na Fig. 20, gerando um ressalto do tipo E, ou seja, toda a extensão do canal é inclinada. A manivela circular na imagem serve para fixar o canal após o ajuste da inclinação desejada. A declividade foi calculada por relação trigonométrica simples, como mostra a Fig. 21 e Eq. (23). A máxima declividade obtida no canal através do regulador foi 3,5\%. Já para o canal B, de concreto, não houve alteração da declividade.

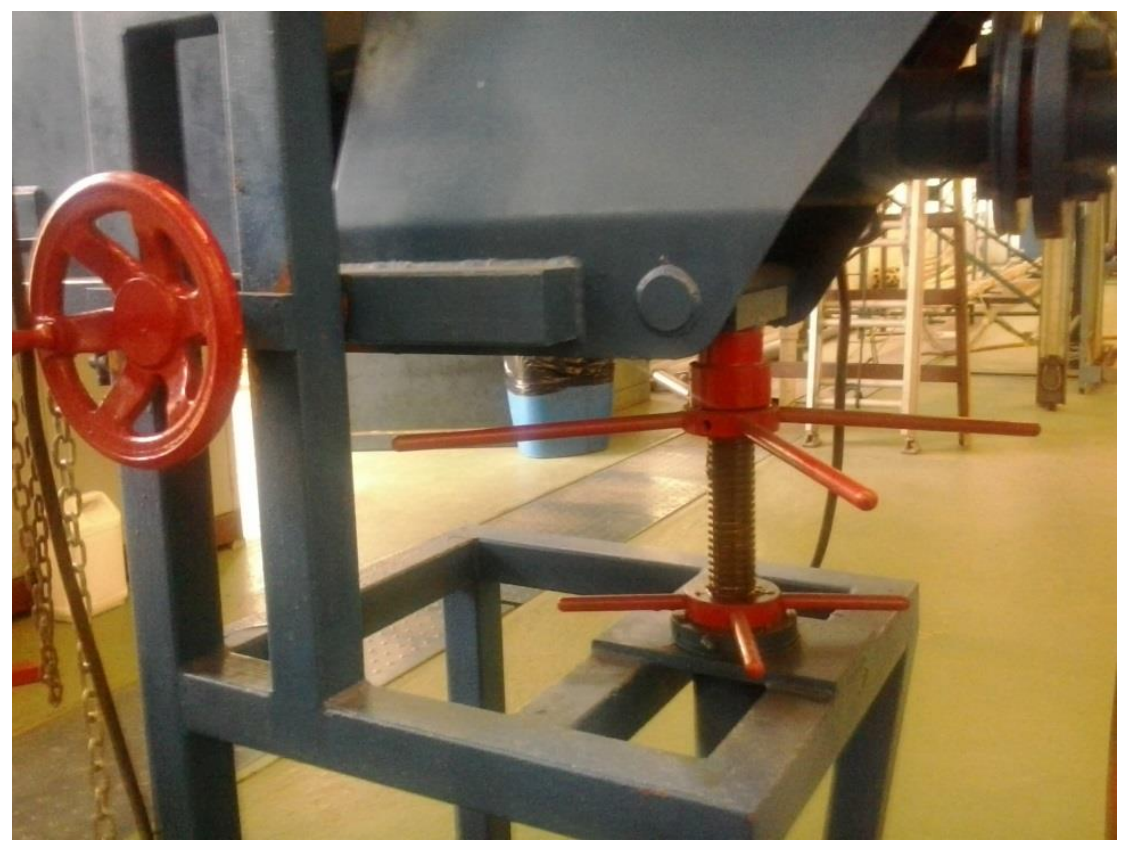

Figura 20. Regulador para controle manual da inclinação no canal. 


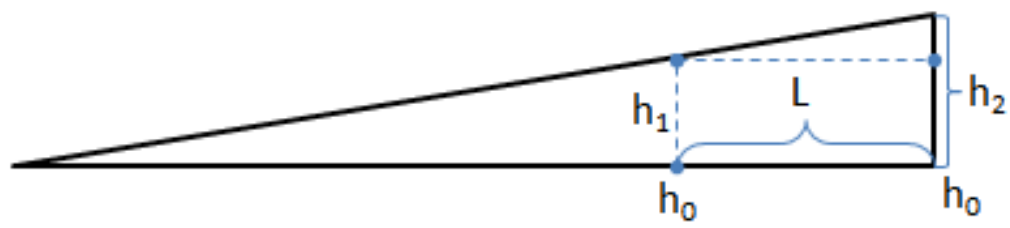

Figura 21. Esquema para ilustrar a medição da declividade.

$$
S=100 *\left|h_{2}-h_{1}\right| / L \quad \text { Eq. } 23
$$

Tomando-se dois pontos distintos numa seção horizontal de referência pertencente ao canal, quando o mesmo não possui inclinação: $h_{o}$ é a altura do piso até a seção horizontal de referência; $h_{2} e h_{1}$ são as alturas medidas em relação a $h_{o}$, em dois pontos distintos escolhidos, após a inclinação do canal; $L$ é a distância horizontal entre os dois pontos distintos; $S$ é a declividade, em porcentagem.

\subsubsection{Posição do ressalto hidráulico}

As medidas geométricas do ressalto hidráulico sofrem algumas flutuações ao longo do tempo, sendo observados os valores médios dessas medidas. O mesmo ocorre com a posição inicial do ressalto do canal.

A posição de início do ressalto foi medida visualmente nos canais estudados, assim como por meio dos dados experimentais, considerando a seção onde ocorre brusca mudança de comportamento da linha d'água. Essa posição pode ser controlada em ambos os canais, por meio de uma comporta ao final do canal.

Para os experimentos com comporta plana no canal A, o ressalto foi localizado a cerca de $60 \mathrm{~cm}$ a jusante da comporta, e nos experimentos com vertedor, tanto para o canal A como para o canal B, o ressalto foi posicionado na seção de menor contração da lâmina d'água para cada vazão.

A Fig. 22 apresenta um esquema da posição de início do ressalto para os dois canais. 

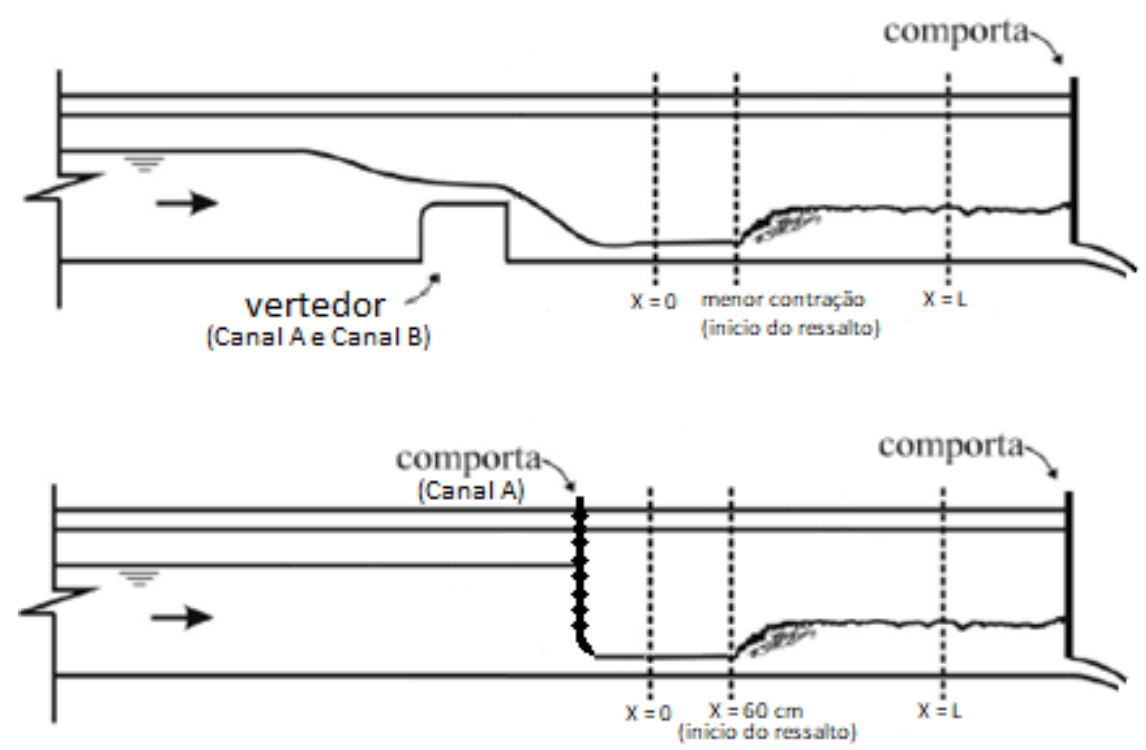

Figura 22. Esquema para a posição de início do ressalto nos canais estudados.

\subsubsection{Rugosidade de fundo}

A rugosidade no fundo nos canais foi controlada com o uso de material emborrachado (Canal B) e de peças Lego com placas base para as mesmas (Canal A e B). A escolha desse material se deve à facilidade de obtenção e, para o Lego, variedade de posicionamento das peças, possibilitando fácil reprodução da configuração usada.

\section{Canal A}

No canal A, realizou-se experimentos com o fundo liso e com fundo rugoso, por meio de um conjunto de placas base para Lego e peças Lego de bricks $2 \times 4$. As placas base possuem 9,6 x 25,5 cm e 0,32 cm de altura (incluindo a altura de $0,16 \mathrm{~cm}$ do botão de encaixe) com 12 x 32 botões de encaixe, para acoplar no fundo do canal que possui $10 \mathrm{~cm}$ de largura, e usadas numa extensão de $153 \mathrm{~cm}$ do canal (6 placas de 9,6 x 25,5 cm), totalizando 12 x 192 botões. Nos experimentos com peças Lego, estas foram dispostas de modo a formar pares de blocos de $1,6 \mathrm{~cm}$ x 3,2 cm e 1,28 cm de altura (incluindo nesse valor $0,16 \mathrm{~cm}$ de altura do botão de encaixe e $0,16 \mathrm{~cm}$ da altura da placa base), distantes um do outro $1,6 \mathrm{~cm}$ na seção transversal ao canal, e com espaçamento de $6,4 \mathrm{~cm}$ até o próximo par na seção longitudinal do canal. A Fig. 23, Fig. 24, Fig. 25 mostra detalhes do arranjo da configuração por placa base e peças Lego. A Tab. 3 mostra um resumo das configurações de fundo estudadas no canal A. 


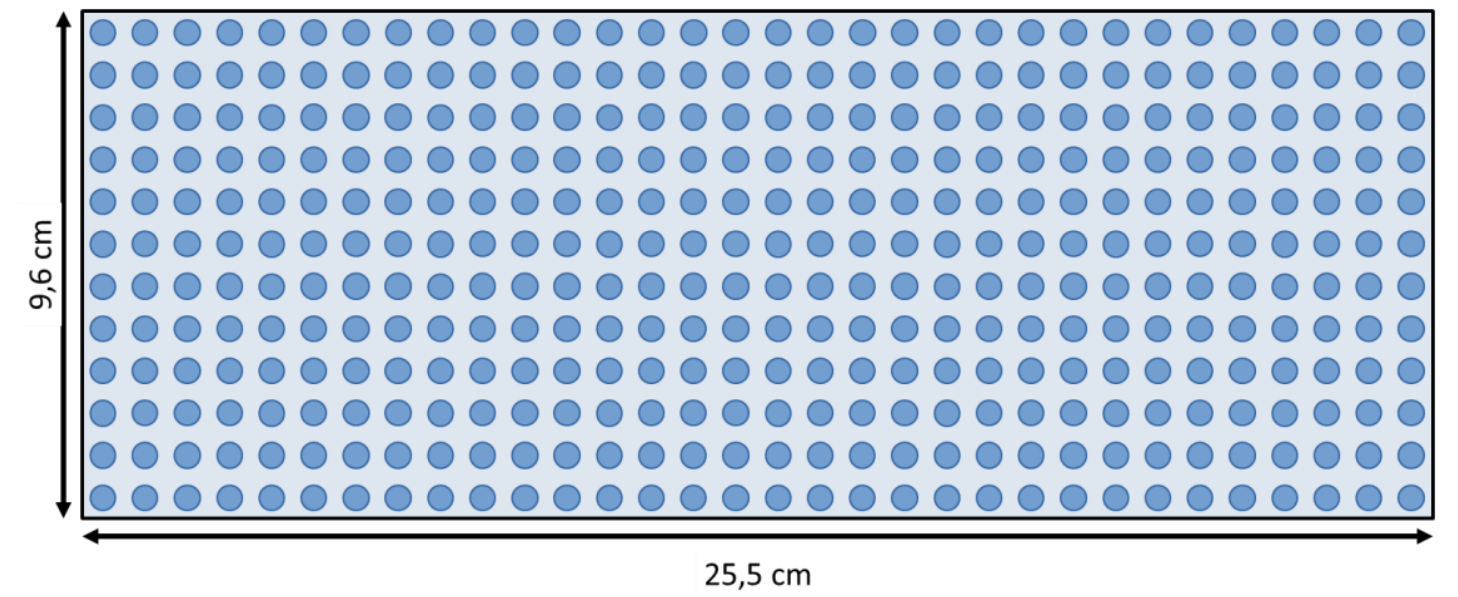

$0,32 \mathrm{~cm}$

19

Figura 23. Esquema da visão frontal e lateral para uma placa base.

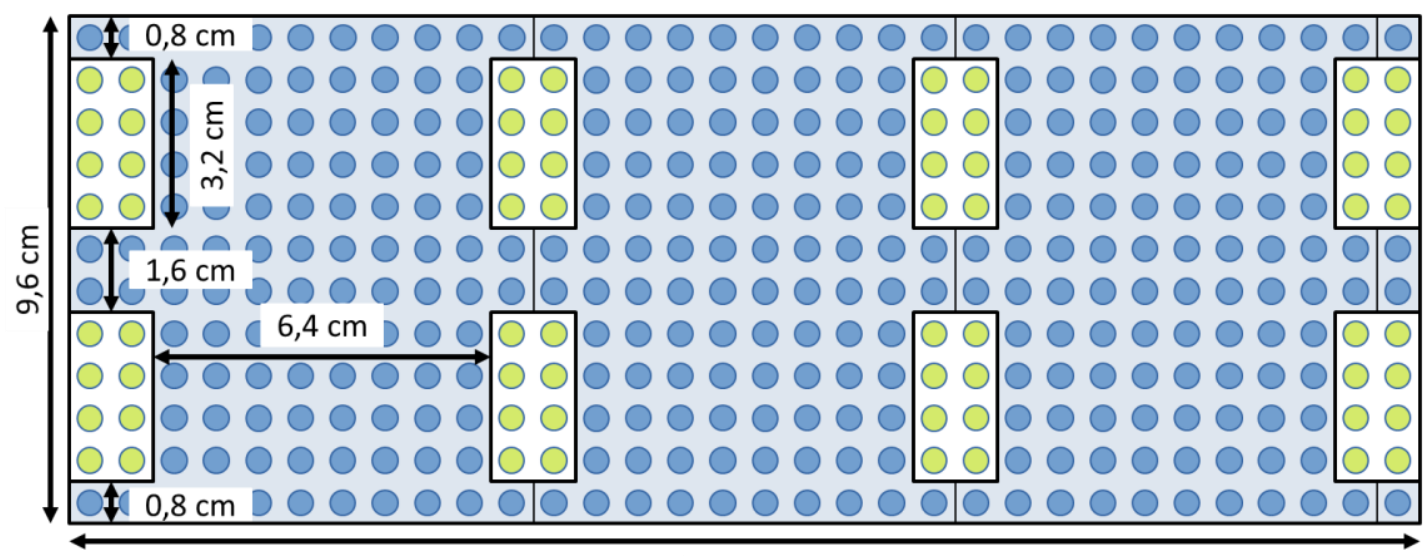

$25,5 \mathrm{~cm}$

$1,28 \mathrm{~cm}$

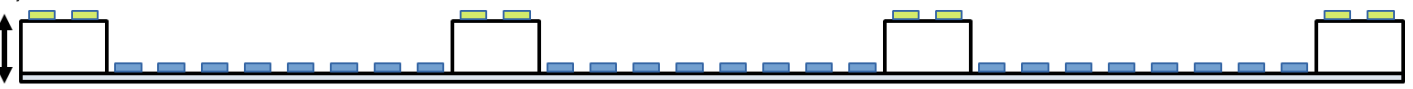

Figura 24. Esquema da disposição das peças Lego ao longo de uma placa base.
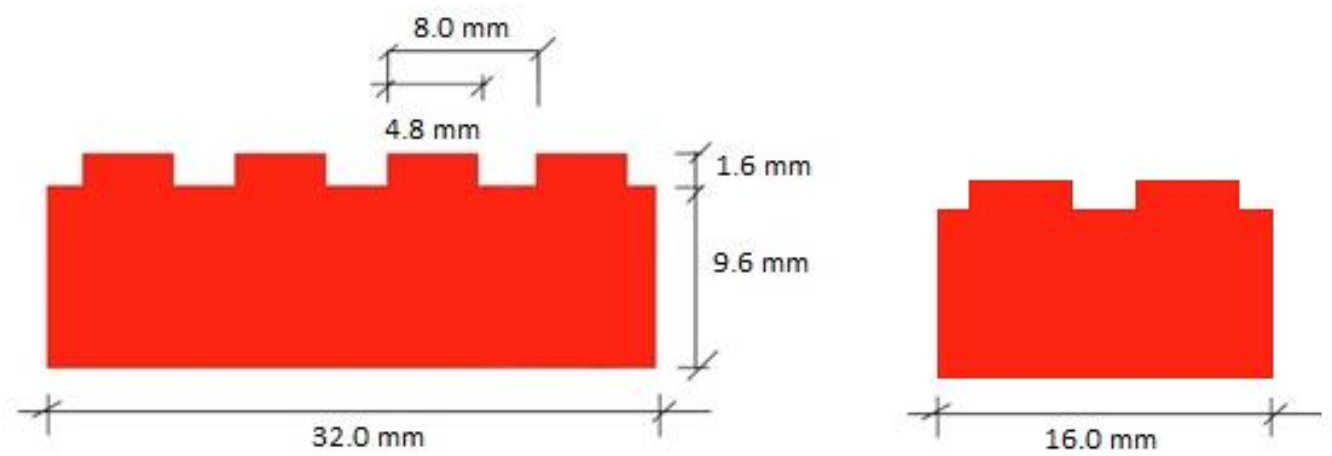

Figura 25. Dimensões dos bricks 2x4 utilizados. 
Tabela 3. Características das diferentes configurações de fundo para o canal A.

\section{Fundo "liso"}

Não houve acoplamento de peças ao fundo

\section{Fundo com placa base e peças Lego (brick 2x4)}

\begin{tabular}{c|c}
\hline Altura da placa (s/ botão de encaixe) & $0,16 \mathrm{~cm}$ \\
\hline Altura do botão de encaixe na placa & $0,16 \mathrm{~cm}$ \\
\hline Diâmetro do botão de encaixe na placa & $0,48 \mathrm{~cm}$ \\
\hline Altura do brick (s/ botão de encaixe) & $0,96 \mathrm{~cm}$ \\
\hline Altura do botão de encaixe no brick & $0,16 \mathrm{~cm}$ \\
\hline Diâmetro do botão de encaixe no brick & $0,48 \mathrm{~cm}$ \\
\hline Número de bricks por placa & $8 *$ \\
\hline Número de placas em série & 6 \\
\hline \multicolumn{2}{c}{ Extensão do fundo rugoso } \\
\hline Experimentos com comporta plana tiveram a primeira coluna de peças removida para a primeira placa
\end{tabular}

A partir do conceito de "densidade de rugosidade" (ALHAMID \& NEGM, 1996), analisou-se o efeito da distribuição dos elementos de rugosidade sobre as características do ressalto. A "densidade de rugosidade", em porcentagem, define-se como a razão entre a área plana projetada do total de elementos de rugosidade pela área plana relacionada a extensão do fundo rugoso.

A localização do início das placas base e peças no canal se manteve fixa tanto para os experimentos com vertedor como para os experimentos com comporta plana, com uma distância de $4 \mathrm{~cm}$ a jusante desta primeira, e $60 \mathrm{~cm}$ a jusante da última.

Nos experimentos com vertedor, a montagem das peças e placas base foi realizada conforme a Fig. 26. Todavia, nos experimentos com comporta plana, o primeiro par de peças foi retirado, já que a localização do início do ressalto e da placa base coincidia. Como o ressalto obtido com uso da comporta era devido a jatos de fundo, o primeiro par de peças impedia a localização do ressalto na posição desejada. 


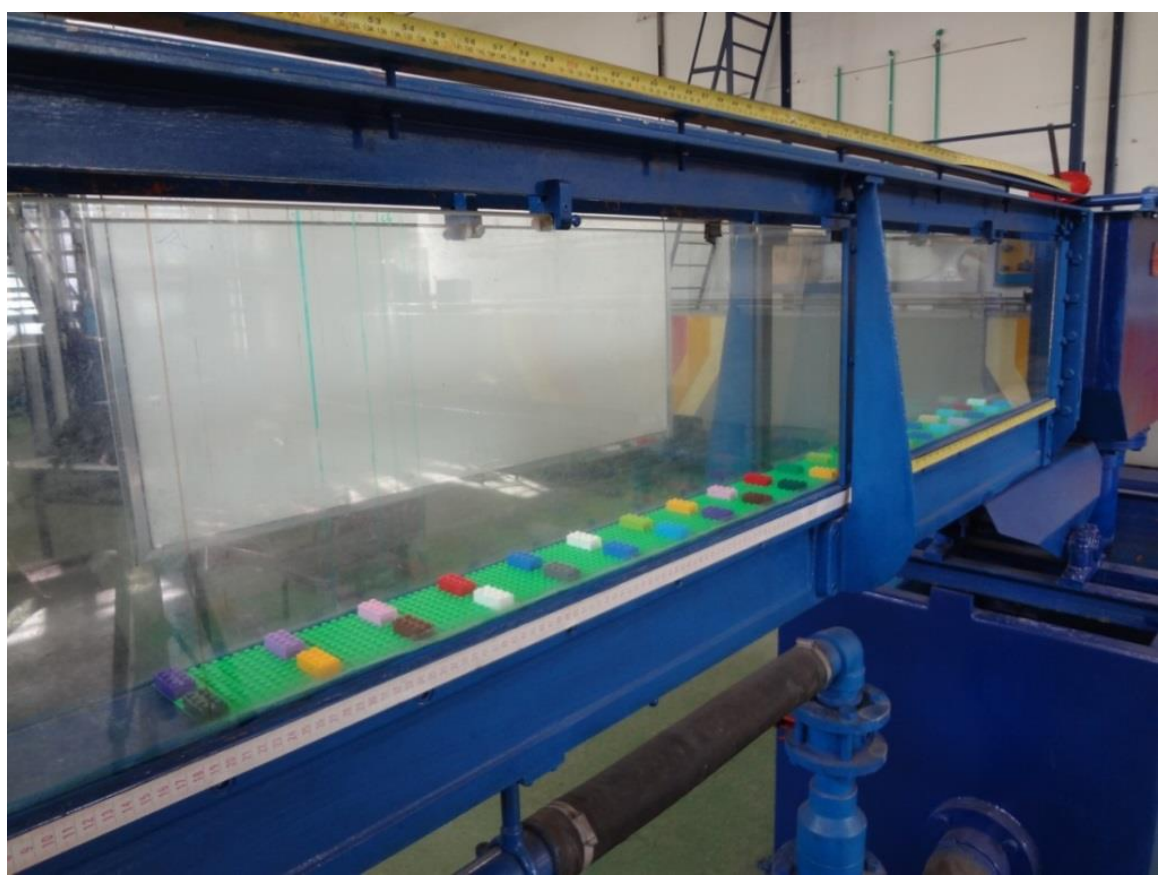

Figura 26. Arranjo com placas base e peças Lego em experimentos com vertedor, no canal A.

\section{Canal B}

No canal B foram realizados experimentos com fundo "liso", com material emborrachado e placas base com peças Lego. Diferente das placas usadas no canal A, para o canal B as placas tinham dimensões de bricks $2 \times 4$ de Lego, acopladas em cada brick para facilitar a fixação das peças no fundo do canal.

Usaram-se 6 placas de emborrachado antiderrapante, com $0,38 \mathrm{~m} \times 0,5 \mathrm{~m}$ de comprimento e largura cada, e $0,45 \mathrm{~cm}$ de altura, dos quais $0,25 \mathrm{~cm}$ é referente a placa e 0,2 $\mathrm{cm}$ da pastilha. A pastilha possui $2,0 \mathrm{~cm}$ de diâmetro. Cada placa contém 13x17 pastilhas, distantes 0,94 cm uma da outra. A Fig. 27 mostra um esquema de uma placa de emborrachado e a Fig. 28 mostra as placas já acopladas no fundo do canal B. 

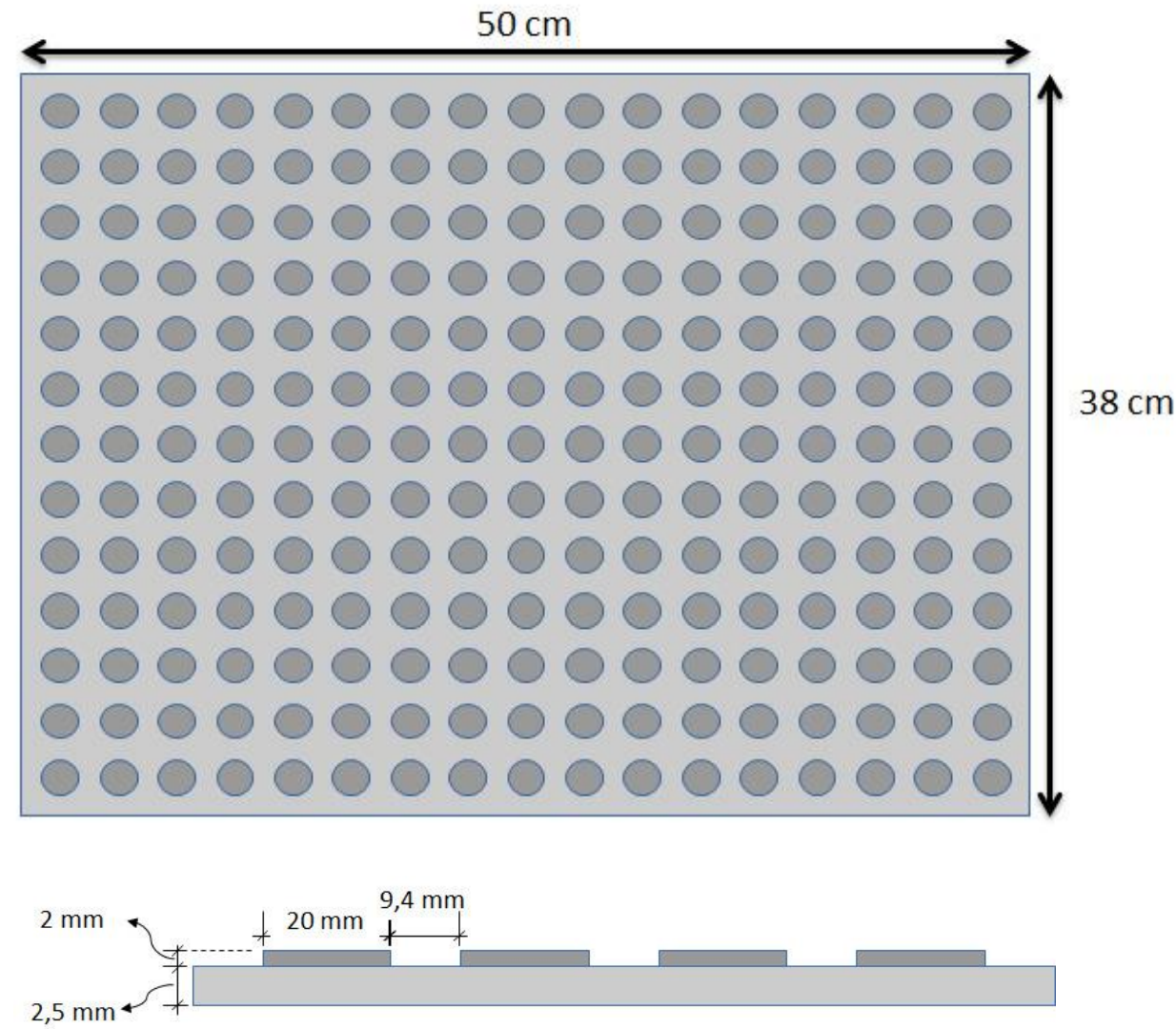

Figura 27. Visão frontal e lateral de cada placa de material emborrachado.

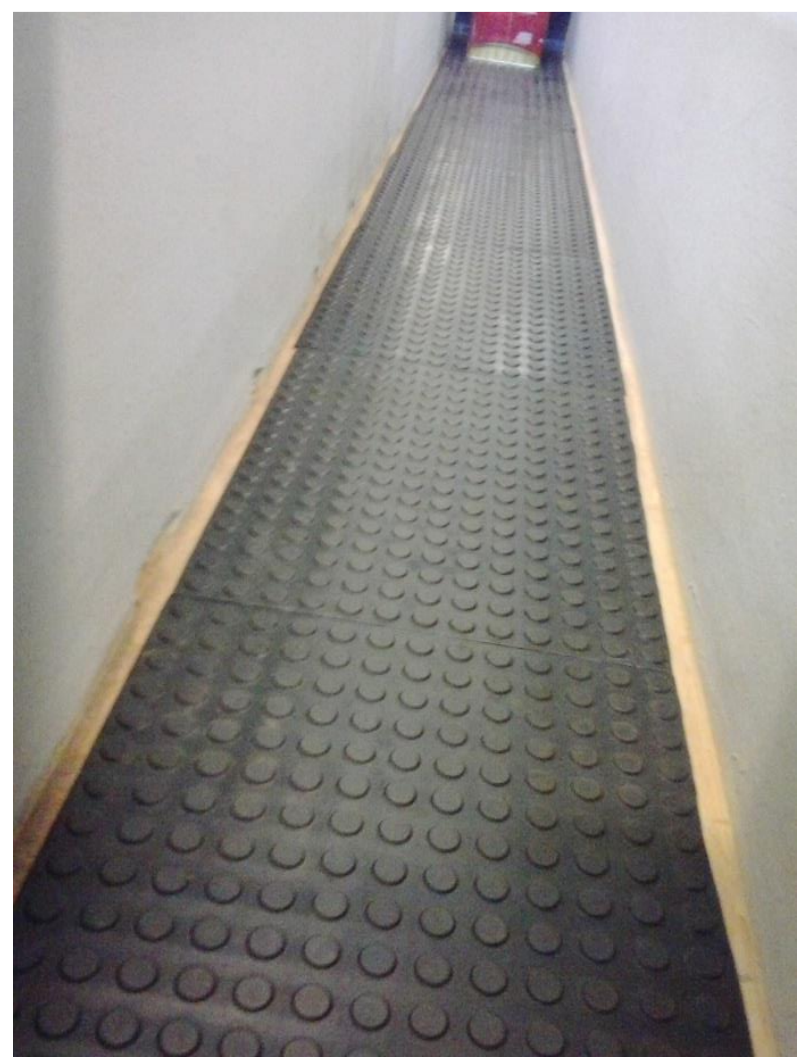

Figura 28. Placas de material emborrachado acopladas ao fundo do canal B. 
Cada brick 2x4 possui dimensões já apresentadas na Figura 25.

Para o canal B, as placas de lego foram cortadas, de modo a ter o mesmo comprimento e largura de um brick $2 \times 4$, isto é, $1,6 \times 3,2 \mathrm{~cm}$. O uso dessas placas garantia uma maior adesão no fundo do canal, evitando que as peças Lego fossem arrastadas pela água.

Foram elaboradas quatro diferentes configurações utilizando-se peças Lego e placas base, chamadas de LEGO1, LEGO2, LEGO3 e LEGO4, apresentadas na Fig. 29, Fig. 30, Fig. 31 e Fig. 32. Na Fig. 33 é mostrada foto de cada configuração.

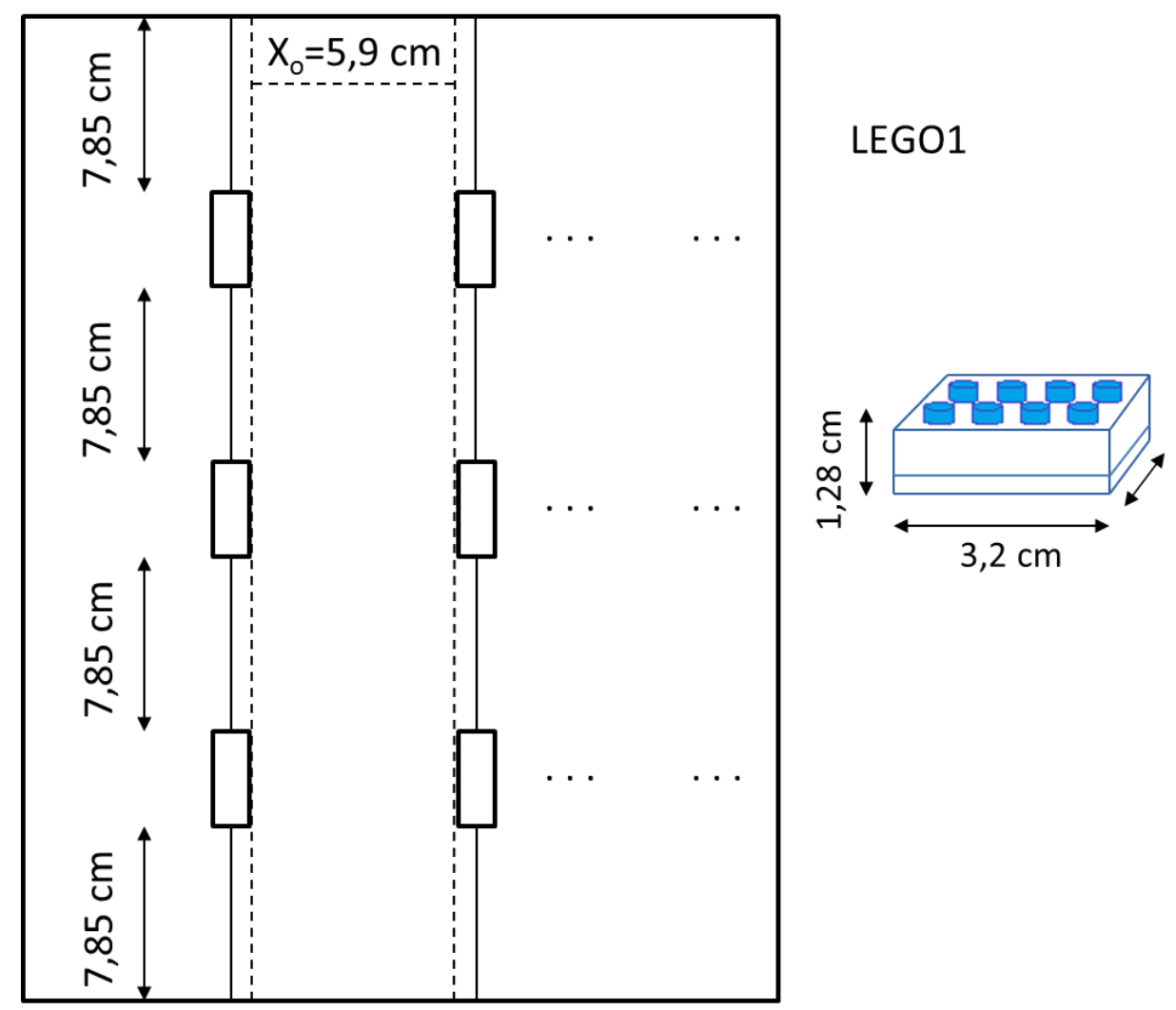

Figura 29. Configuração LEGO1 para o canal B. 


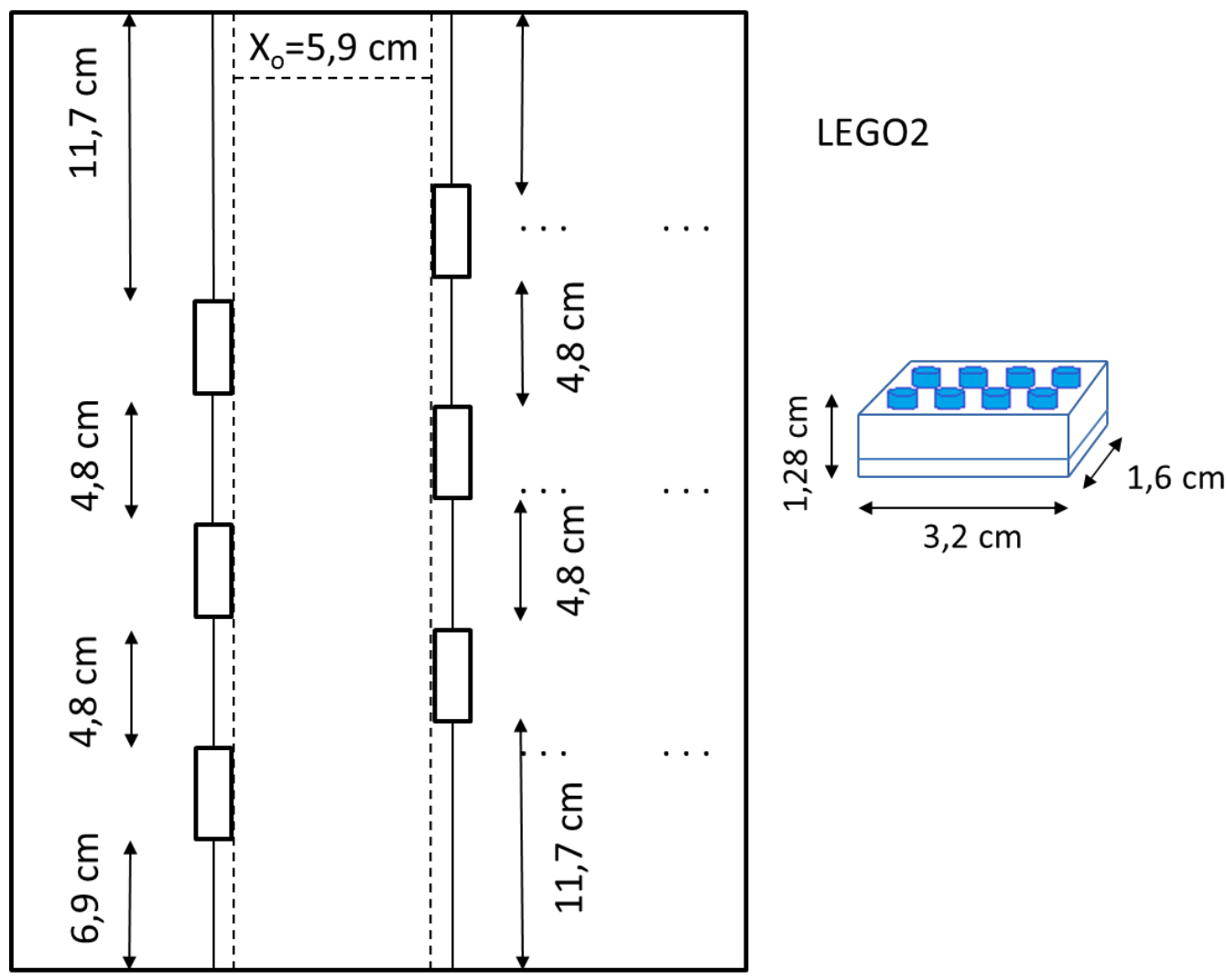

Figura 30. Configuração LEGO2 para o canal B.

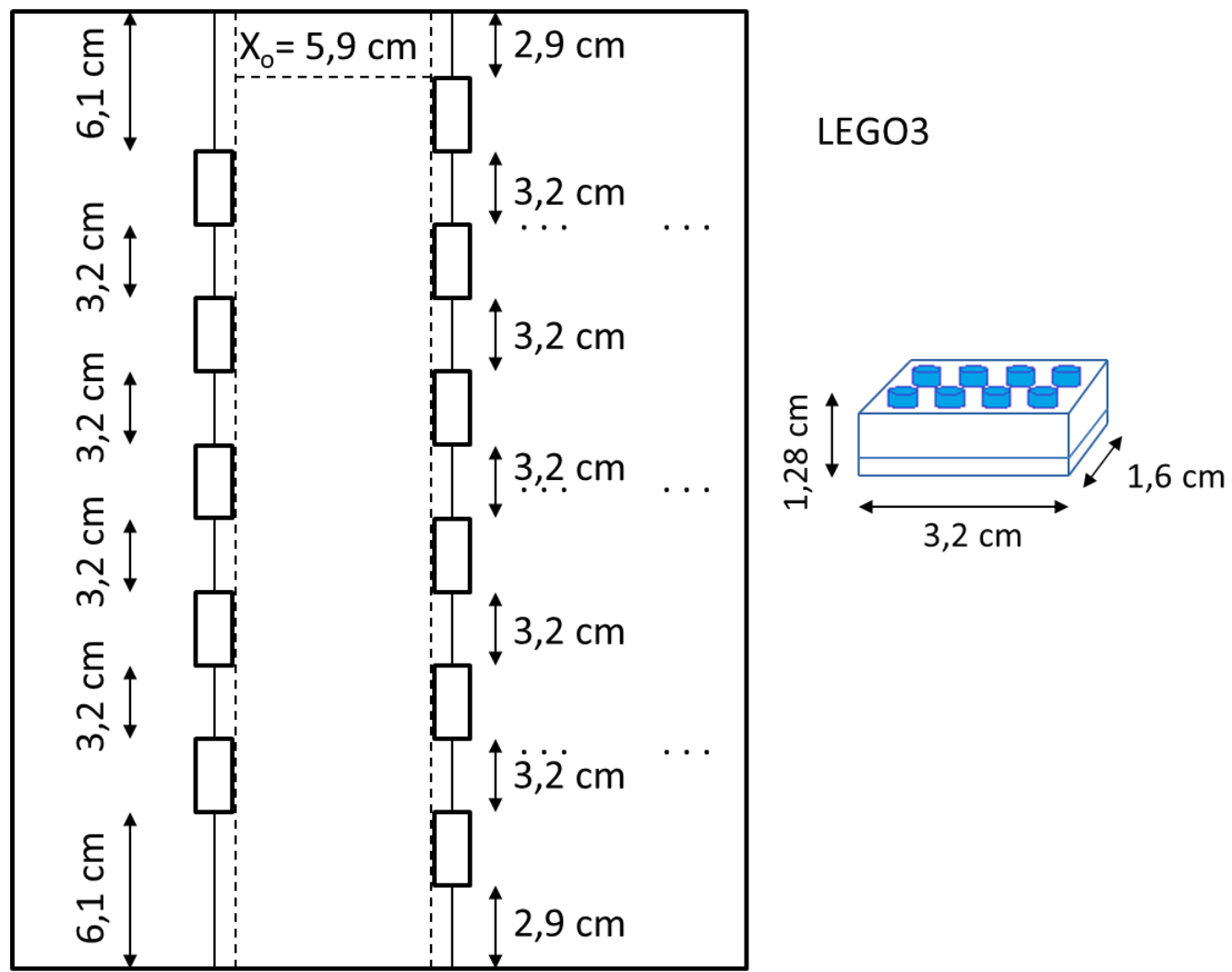

Figura 31. Configuração LEGO3 para o canal B. 


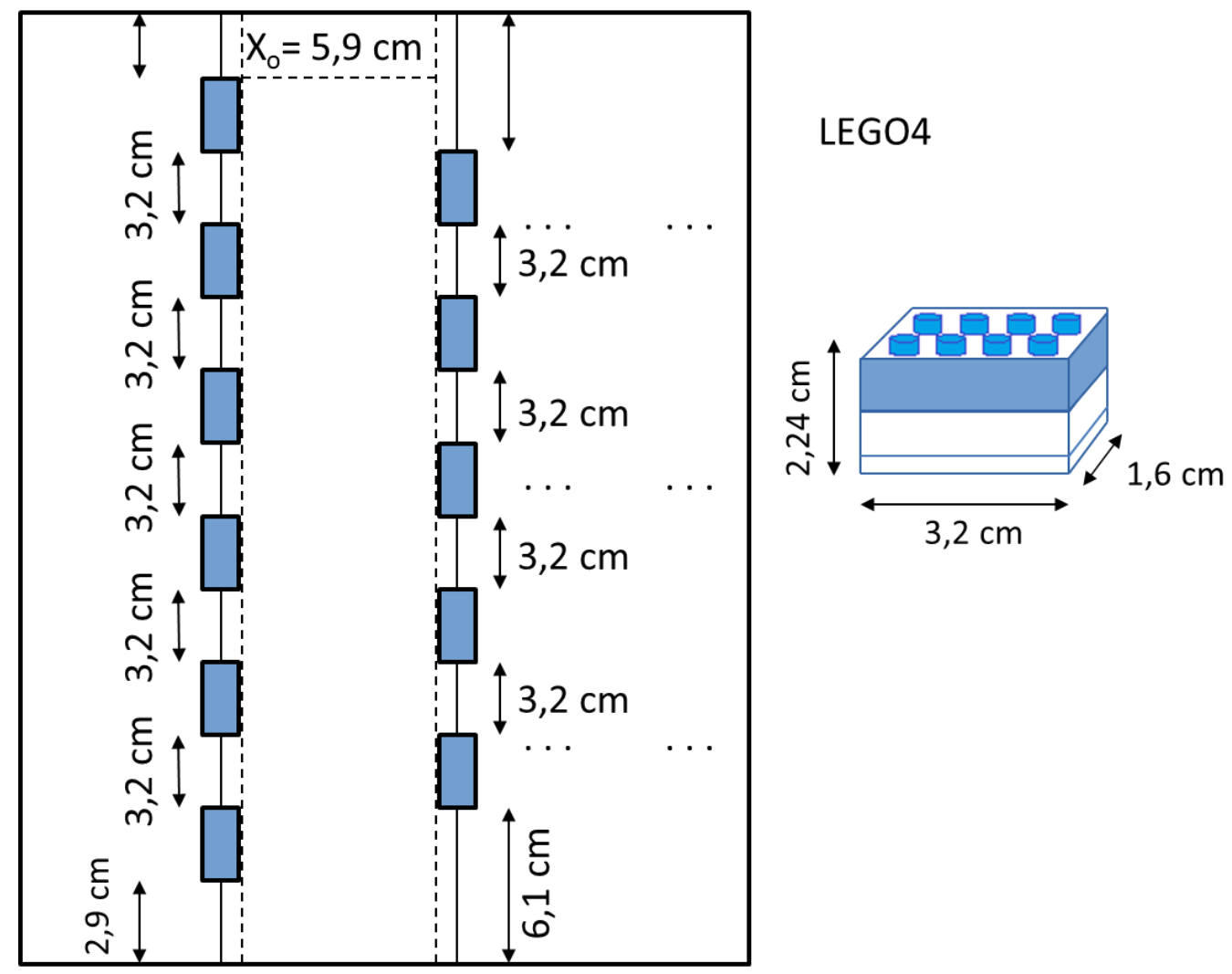

Figura 32. Configuração LEGO4 para o canal B.

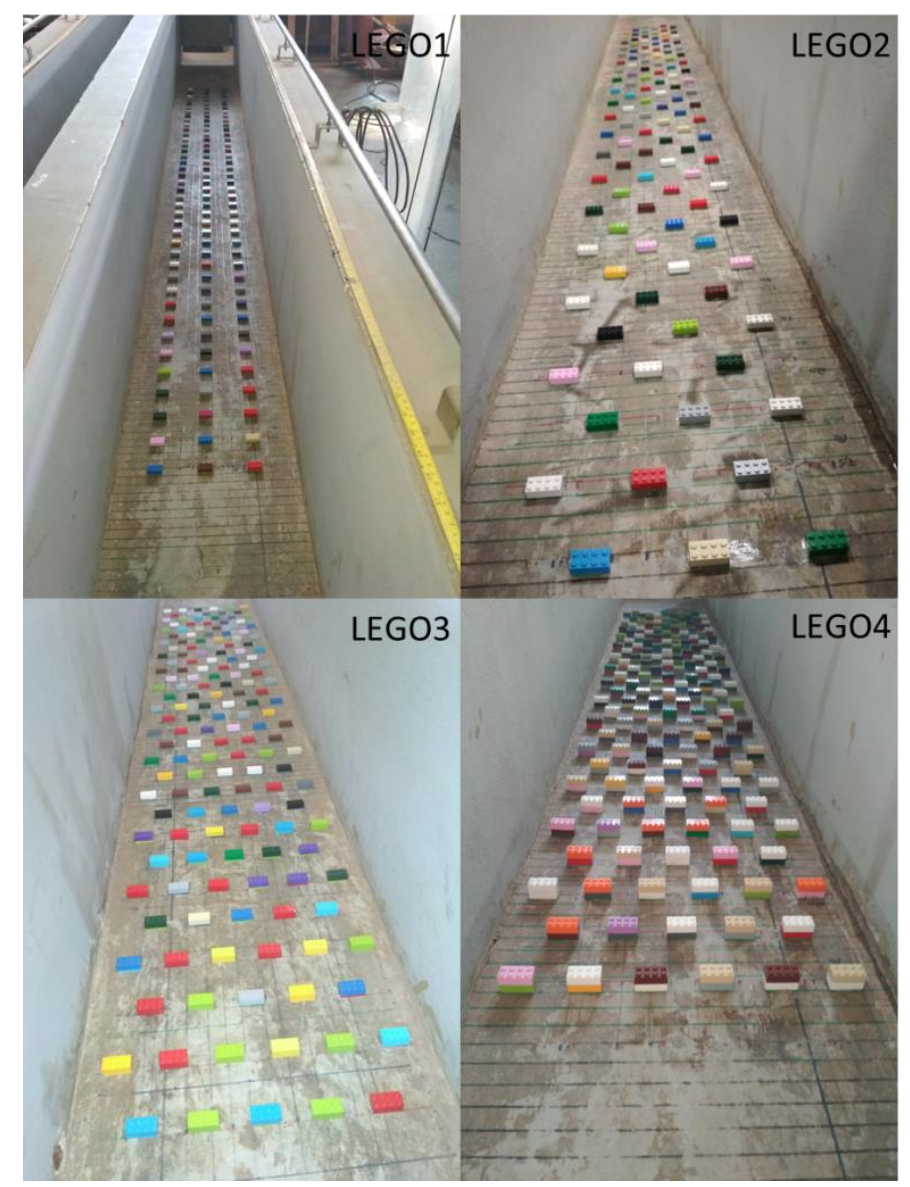

Figura 33. Imagens das 4 configurações elaboradas com peças Lego e placas base no canal B. 
A configuração LEGO1 apresenta fileiras de 3 bricks alinhadas, num total de 40 fileiras e 120 conjuntos de bricks + placa base. A configuração LEGO2 apresenta fileira alternadas de 3 bricks, num total de 40 fileiras e 120 conjuntos de bricks + placa base. A configuração LEGO3 é formada por um conjunto de duas fileiras alternadas com 5 e 6 peças Lego + placa base, conforme Fig. 31, num total de 165 peças Lego + placa base. A configuração LEGO4 é formada por um conjunto de duas fileiras alternadas com 6 e 5 peças Lego + placa base, conforme Fig. 32, num total 165 peças Lego + placa, e se diferencia da configuração LEGO 3 devido a ordem das fileiras estar invertida, e por utilizar conjuntos de bricks sobrepostos.

As características das diferentes configurações de fundo para o canal B são apresentadas na Tab. 4.

Tabela 4. Características das diferentes configurações de fundo para o canal B.

\section{Fundo "liso"}

Não houve acoplamento de peças ao fundo

Fundo com material emborrachado

\begin{tabular}{c|c}
\hline Altura da placa (s/ pastilha) & $0,25 \mathrm{~cm}$ \\
\hline Altura da pastilha na placa & $0,2 \mathrm{~cm}$ \\
\hline Diâmetro da pastilha na placa & $2,0 \mathrm{~cm}$ \\
\hline Números de placas em série & 6 \\
\hline Extensão do fundo rugoso & $300 \mathrm{~cm}$ \\
\hline
\end{tabular}

Fundo com configuração LEGO1

\begin{tabular}{c|c}
\hline Altura do conjunto Lego + placa & $1,28 \mathrm{~cm}$ \\
\hline Altura do botão de encaixe no brick & $0,16 \mathrm{~cm}$ \\
\hline Diâmetro do botão de encaixe no brick & $0,48 \mathrm{~cm}$ \\
\hline Número de peças do conjunto Lego + placa & 120 \\
\hline Extensão do fundo rugoso & $292,5 \mathrm{~cm}$ \\
\hline
\end{tabular}




\section{Fundo com configuração LEGO2}

\begin{tabular}{c|c}
\hline Altura do conjunto Lego + placa & $1,28 \mathrm{~cm}$ \\
\hline Altura do botão de encaixe no brick & $0,16 \mathrm{~cm}$ \\
\hline Diâmetro do botão de encaixe no brick & $0,48 \mathrm{~cm}$ \\
\hline Número de peças do conjunto Lego + placa & 120 \\
\hline Extensão do fundo rugoso & $292,5 \mathrm{~cm}$ \\
\hline
\end{tabular}

Fundo com configuração LEGO3

\begin{tabular}{c|c}
\hline Altura do conjunto Lego + placa & $1,28 \mathrm{~cm}$ \\
\hline Altura do botão de encaixe no brick & $0,16 \mathrm{~cm}$ \\
\hline Diâmetro do botão de encaixe no brick & $0,48 \mathrm{~cm}$ \\
\hline Número de peças do conjunto Lego + placa & 165 \\
\hline Extensão do fundo rugoso & $217,5 \mathrm{~cm}$ \\
\hline
\end{tabular}

\section{Fundo com configuração LEGO4}

\begin{tabular}{c|c}
\hline Altura do conjunto Lego + placa & $1,28 \mathrm{~cm}$ \\
\hline Altura do botão de encaixe no brick & $0,16 \mathrm{~cm}$ \\
\hline Diâmetro do botão de encaixe no brick & $0,48 \mathrm{~cm}$ \\
\hline Número de peças do conjunto Lego + placa & 120 \\
\hline Extensão do fundo rugoso & $217,5 \mathrm{~cm}$ \\
\hline
\end{tabular}

\subsubsection{Profundidades conjugadas}

\section{Canal A}

A rotina para obtenção dos dados de profundidade, de comprimento do rolo e do ressalto é apresentada de forma resumida na Fig. 34. 


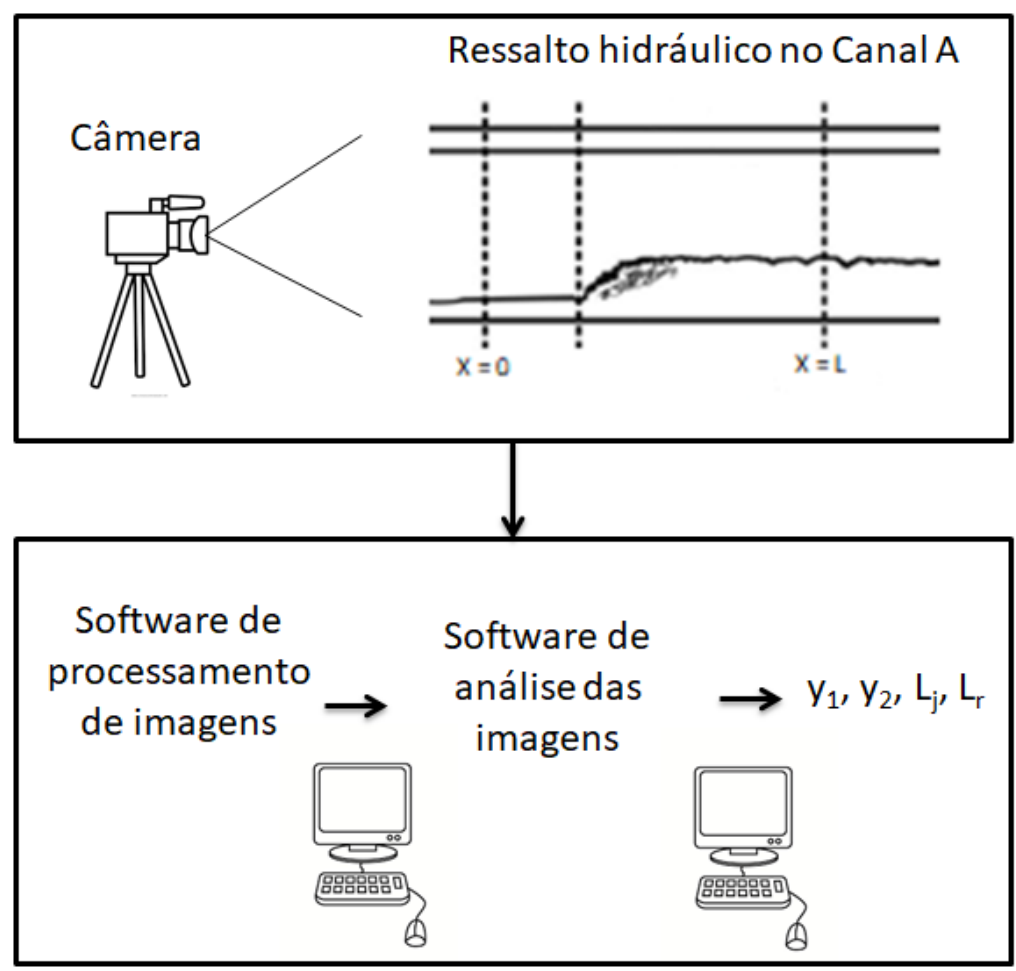

Figura 34. Resumo do procedimento para obtenção das medidas no canal A.

No canal A, as profundidades conjugadas foram medidas a partir da análise da filmagem dos experimentos, por sobreposição de imagens, realizada no software de edição de imagens Dynamic-Photo HDR. A imagem obtida pela sobreposição dos quadros da filmagem para cada experimento foi usada no software de análise de vídeos e ferramenta de modelagem Tracker, para determinar as profundidades conjugadas. Para tanto foi realizado um ajuste de escala nas imagens, através do próprio software.

Uma imagem da interface do software Tracker é apresentada na Fig. 35. Era realizada uma calibração da escala na imagem sobreposta dos quadros, e inserção de um eixo de origem coincidindo com a seção de início do ressalto. Após ajustada a escala e o eixo de referência, foram gerados pontos nas seções a montante e a jusante do ressalto com posições conhecidas, no fundo do canal e na superfície livre, determinando-se assim as profundidades conjugadas.

Nos experimentos com declividade, as profundidades conjugadas foram obtidas a partir da observação da distância do fundo do canal, seguindo uma linha perpendicular a partir deste até a superfície livre do escoamento. 


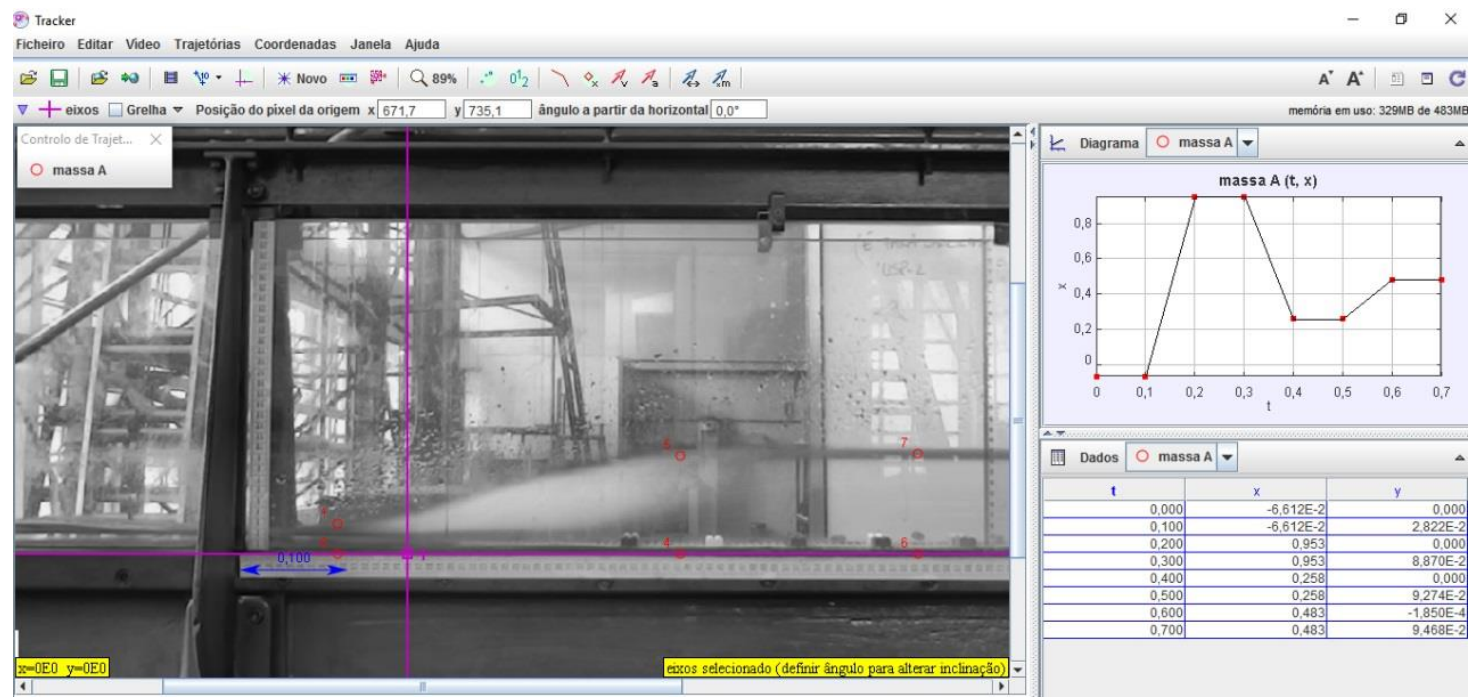

Figura 35. Interface do software Tracker, usado para a medição das profundidades conjugadas.

Experimento CA-14 no canal A com comporta plana, vazão de $2,7 \mathrm{~L} / \mathrm{s}, \mathrm{F}_{1}=1,84, \mathrm{y}_{1}=2,8 \mathrm{~cm}, \mathrm{y}_{2}=8,9$, sem declividade, fundo rugoso.

Observa-se na Fig. 35 que o perfil da superfície livre possui uma linha espessa, mostrando que o método de sobreposição usado uniu as diversas linhas da superfície em cada quadro da filmagem. $\mathrm{O}$ fato de a região do ressalto apresentar um tom mais claro se deve, provavelmente, a junção das bolhas de ar de cada quadro.

\section{Canal $B$}

No canal B as profundidades foram determinadas por meio de um sensor ultrassônico (Go!Motion Vernier®), como se observa na Fig. 15. O sensor mede a distância do sensor até o objeto ou obstáculo mais próximo. A distância é medida por meio do tempo que uma onda emitida pelo sensor leva até atingir um objeto e retornar, com base na velocidade do som no ar. O transdutor possui, de acordo com dados do fabricante, resolução de $1 \mathrm{~mm}$, acurácia de 2 mm e a frequência das ondas de ultrassom de $50 \mathrm{kHz}$. As ondas formam uma área em forma de cone com ângulo de abertura entre $15^{\circ}$ a $20^{\circ}$ e capacidade de detecção de objetos a uma distância de $0,15 \mathrm{~m}$ a $6 \mathrm{~m}$ do transdutor.

Inicialmente foi realizada uma medição das profundidades com canal vazio, desse modo foi possível obter a altura de coluna d'água nos experimentos a partir da diferença entre a altura medida com canal vazio e altura medida durante cada experimentação. Todas as medições foram realizadas a partir de uma altura fixa de $0,58 \mathrm{~cm}$ do sensor até o fundo do canal. 
Na Fig. 36 é mostrada a interface do software Logger Lite ${ }^{\circledR}$, utilizado em conjunto com o sensor ultrassônico para a coleta dos dados de profundidade. Ajustou-se a coleta de 20 dados por segundo, num intervalo de $150 \mathrm{~s}$, totalizando 3000 medições em cada ponto da seção longitudinal do canal.

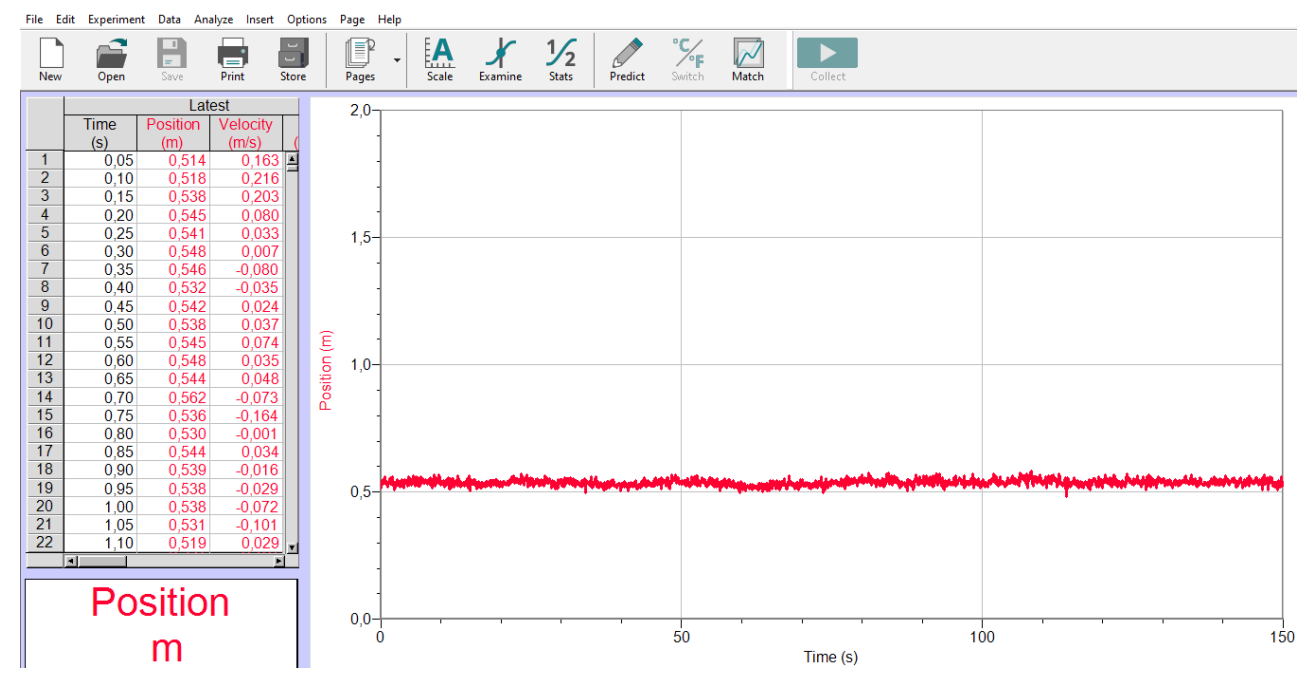

Figura 36. Interface do software Logger Lite ${ }^{\circledR}$.

\subsubsection{Comprimento do rolo}

As medidas do comprimento do rolo nos experimentos em cada canal foram obtidas visualmente.

O rolo do ressalto foi avaliado como a região compreendida desde o início do ressalto até o ponto médio de estagnação na superfície livre, e o seu comprimento, $\mathrm{L}_{\mathrm{r}}$, medido de acordo esta definição (CAROLLO, FERRO \& PAMPALONE, 2012).

O comprimento do ressalto, $\mathrm{L}_{\mathrm{j}}$, foi entendido neste estudo como a distância horizontal entre a seção de início do ressalto e a seção após o final do rolo, em que a superfície livre tende a se tornar horizontal, sem grandes flutuações de nível. Para os experimentos com declividade, considerou-se o comprimento do ressalto como sendo igual ao comprimento do rolo, como sugerido por Kindstaver (1944).

Especificamente para o canal B, como não era possível observar o escoamento pelas laterais do canal, já que eram de concreto, a zona de estagnação na superfície livre foi determinada com auxílio de um barbante preso a um pequeno anel de plástico, como mostra a Fig. 37. 


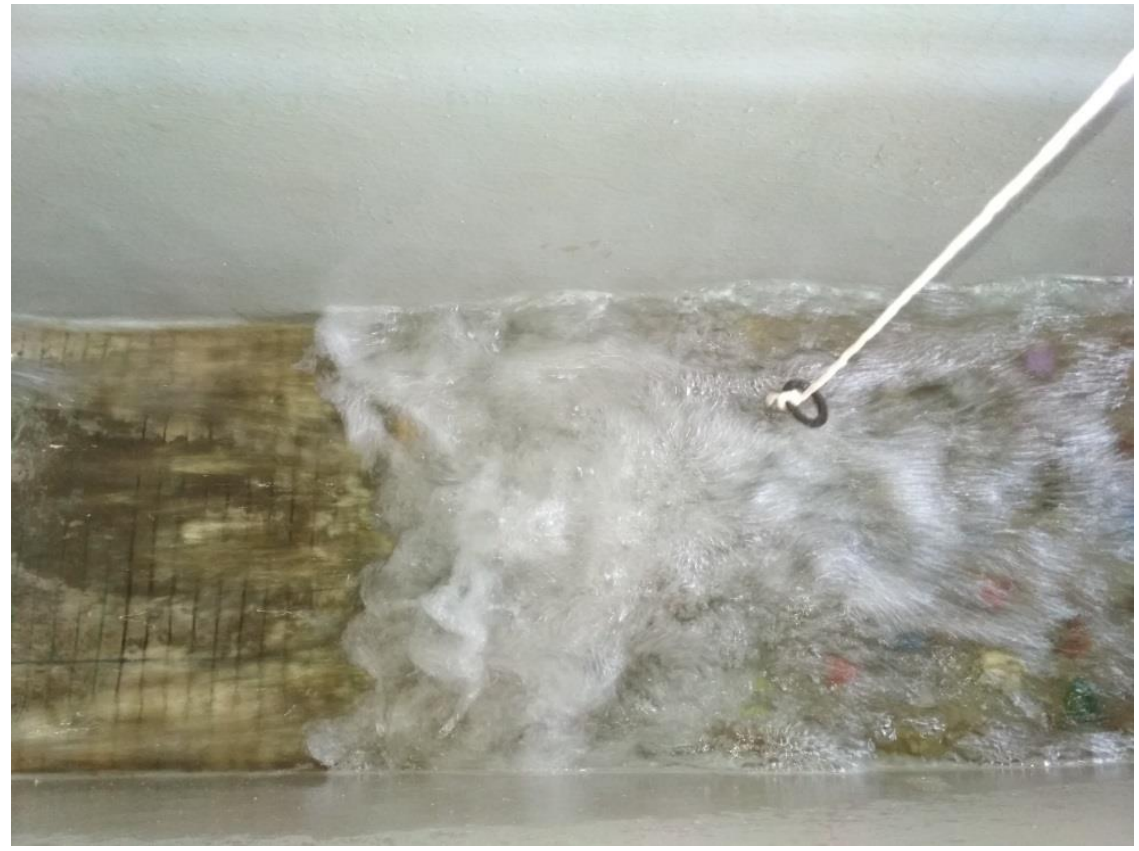

Figura 37. Barbante e anel de plástico usados para determinar a zona de estagnação da superfície livre.

\subsubsection{Etapa 3}

No capítulo 5, foi feita a análise e processamento dos dados experimentais, e proposição de equações de previsão para os casos analisados, considerando a formulação proposta por Schulz et al. (2015a), a fim de estender o estudo dos conceitos teóricos considerando a dissipação global de energia. 


\section{RESULTADOS E DISCUSSÃO}

\subsection{CANAL A}

\subsubsection{Dados medidos e análise de $y_{2} / y_{1}$}

As Tab. 5 e Tab. 6 mostram os resultados organizados dos experimentos realizados no canal A, nas diferentes condições experimentais aqui consideradas (soleira espessa e comporta vertical com suavização do escoamento junto ao fundo). A partir do estabelecimento da vazão, tipo de fundo e declividade (S) foi possível realizar medições de $\mathrm{y}_{1}$, $\mathrm{y}_{2}, \mathrm{~V}_{1}, \mathrm{~F}_{\mathrm{r}}$ (número de Froude na seção supercrítica), $\mathrm{L}_{\mathrm{r}}$ e $\mathrm{L}_{\mathrm{j}}$, para cada experimento.

Tabela 5. Dados dos experimentos para a soleira espessa no canal A.

\section{Canal A - Soleira espessa}

\begin{tabular}{|c|c|c|c|c|c|c|c|c|c|c|}
\hline Código & $\begin{array}{c}\text { Vazão } \\
{[\mathrm{L} / \mathrm{s}]}\end{array}$ & $\begin{array}{c}\mathrm{y}_{1} \\
{[\mathrm{~cm}]}\end{array}$ & $\begin{array}{c}\mathrm{y}_{2} \\
{[\mathrm{~cm}]}\end{array}$ & $\mathrm{y}_{2} / \mathrm{y}_{1}$ & $\begin{array}{c}\mathrm{V}_{1} \\
{[\mathrm{~m} / \mathrm{s}]}\end{array}$ & $\mathrm{F}_{\mathrm{r}}$ & $\begin{array}{l}\text { Tipo de } \\
\text { fundo }\end{array}$ & $\begin{array}{c}\mathrm{S} \\
(\mathrm{m} / \mathrm{m})\end{array}$ & $\begin{array}{c}\mathrm{L}_{\mathrm{r}} \\
{[\mathrm{cm}]}\end{array}$ & $\begin{array}{c}\mathrm{L}_{\mathrm{j}} \\
{[\mathrm{cm}]}\end{array}$ \\
\hline SA-1 & 2,8 & 2,7 & 9,1 & 3,37 & 1,04 & 2,02 & Liso & 0 & 27 & 44 \\
\hline SA-2 & 4,8 & 4,0 & 11,2 & 2,80 & 1,20 & 1,92 & Liso & 0 & 36 & 57 \\
\hline SA-3 & 2,8 & 2,4 & $\begin{array}{c}9,5\left(\mathrm{y}_{\mathrm{t}}\right) \\
11,0\end{array}$ & 4,58 & 1,17 & 2,40 & Liso & 0,035 & 30 & 30 \\
\hline SA-4 & 4,8 & 3,4 & $\begin{array}{c}12,7\left(y_{t}\right) \\
14,4\end{array}$ & 4,23 & 1,41 & 2,44 & Liso & 0,035 & 42 & 42 \\
\hline SA-5 & 2,8 & 3,2 & $\begin{array}{c}9,1\left(\mathrm{y}_{\mathrm{t}}\right) \\
10,9\end{array}$ & 3,41 & 0,875 & 1,56 & Rugoso & 0,035 & 17 & 17 \\
\hline SA-6 & 4,8 & 5,2 & $\begin{array}{c}13,7\left(\mathrm{y}_{\mathrm{t}}\right) \\
15,4\end{array}$ & 2,96 & 0,923 & 1,29 & Rugoso & 0,035 & 25 & 25 \\
\hline SA-7 & 2,8 & 3,5 & 8,7 & 2,49 & 0,800 & 1,37 & Rugoso & 0 & 14 & 25 \\
\hline SA-8 & 4,8 & 5,0 & 11,0 & 2,20 & 0,960 & 1,37 & Rugoso & 0 & 20 & 34 \\
\hline
\end{tabular}


Tabela 6. Dados dos experimentos para a comporta vertical no canal A.

\section{Canal A - Comporta vertical}

\begin{tabular}{|c|c|c|c|c|c|c|c|c|c|c|}
\hline Código & $\begin{array}{c}\text { Vazão } \\
{[\mathrm{L} / \mathrm{s}]}\end{array}$ & $\begin{array}{c}\mathrm{y}_{1} \\
{[\mathrm{~cm}]}\end{array}$ & $\begin{array}{c}\mathrm{y}_{2} \\
{[\mathrm{~cm}]}\end{array}$ & $\mathrm{y}_{2} / \mathrm{y}_{1}$ & $\begin{array}{c}\mathrm{V}_{1} \\
{[\mathrm{~m} / \mathrm{s}]}\end{array}$ & $\mathrm{F}_{\mathrm{r}}$ & $\begin{array}{l}\text { Tipo de } \\
\text { fundo }\end{array}$ & $\begin{array}{c}\mathrm{S} \\
(\mathrm{m} / \mathrm{m})\end{array}$ & $\begin{array}{c}\mathrm{L}_{\mathrm{r}} \\
{[\mathrm{cm}]}\end{array}$ & $\begin{array}{c}\mathrm{L}_{\mathrm{j}} \\
{[\mathrm{cm}]}\end{array}$ \\
\hline CA-1 & 1,9 & 1,8 & 6,7 & 3,72 & 1,06 & 2,51 & Liso & 0 & 14 & 28 \\
\hline CA-2 & 2,3 & 2,0 & 7,4 & 3,70 & 1,15 & 2,60 & Liso & 0 & 20 & 35 \\
\hline CA-3 & 2,5 & 2,2 & 8,1 & 3,68 & 1,14 & 2,45 & Liso & 0 & 26 & 44 \\
\hline CA-4 & 2,7 & 2,3 & 8,4 & 3,65 & 1,17 & 2,47 & Liso & 0 & 34 & 55 \\
\hline CA-5 & 1,9 & 1,8 & $\begin{array}{c}6,7\left(\mathrm{y}_{\mathrm{t}}\right) \\
9,5\end{array}$ & 5,28 & 1,06 & 2,51 & Liso & 0,035 & 17 & 17 \\
\hline CA-6 & 2,3 & 1,9 & $\begin{array}{c}8,0\left(\mathrm{y}_{\mathrm{t}}\right) \\
10,0\end{array}$ & 5,26 & 1,21 & 2,80 & Liso & 0,035 & 27 & 27 \\
\hline CA-7 & 2,5 & 2,1 & $\begin{array}{c}8,8\left(\mathrm{y}_{\mathrm{t}}\right) \\
11,0\end{array}$ & 5,24 & 1,19 & 2,62 & Liso & 0,035 & 34 & 34 \\
\hline CA-8 & 2,7 & 2,2 & $\begin{array}{c}10,0\left(\mathrm{y}_{\mathrm{t}}\right) \\
11,5\end{array}$ & 5,22 & 1,23 & 2,64 & Liso & 0,035 & 41 & 41 \\
\hline CA-9 & 1,9 & 2,0 & $\begin{array}{c}6,8\left(\mathrm{y}_{\mathrm{t}}\right) \\
8,2\end{array}$ & 4,1 & 0,95 & 2,14 & Rugoso & 0,035 & 16 & 16 \\
\hline CA-10 & 2,3 & 2,1 & $\begin{array}{c}8,2\left(\mathrm{y}_{\mathrm{t}}\right) \\
9,2\end{array}$ & 4,38 & 1,10 & 2,41 & Rugoso & 0,035 & 23 & 23 \\
\hline CA-11 & 2,7 & 2,4 & $\begin{array}{c}9,8\left(\mathrm{y}_{\mathrm{t}}\right) \\
10,9\end{array}$ & 4,54 & 1,13 & 2,31 & Rugoso & 0,035 & 32 & 32 \\
\hline CA-12 & 2,3 & 2,4 & 7,3 & 3,04 & 0,958 & 1,98 & Rugoso & 0 & 18 & 35 \\
\hline CA-13 & 2,5 & 2,6 & 8,0 & 3,08 & 0,962 & 1,90 & Rugoso & 0 & 20 & 38 \\
\hline CA-14 & 2,7 & 2,8 & 8,9 & 3,18 & 0,964 & 1,84 & Rugoso & 0 & 26 & 48 \\
\hline
\end{tabular}


Em todos os experimentos a velocidade $\mathrm{V}_{1}$ foi calculada dividindo a vazão medida pela área da seção transversal supercrítica, e o correspondente número de Froude $\mathrm{F}_{\mathrm{r}}$ foi calculado utilizando esta velocidade e $\mathrm{y}_{1}$. Nas Tab. 5 e Tab. $6 \mathrm{y}_{\mathrm{t}}$ é a altura do final do rolo.

Para as condições experimentais desenvolvidas, o número de Froude supercrítico variou de 1,29 a 2,80. Compreendendo casos de ressalto ondular $\left(\mathrm{F}_{1}<1,7\right)$, ressalto fraco $(1,7$ $\left.<\mathrm{F}_{1}<2,5\right)$ e ressalto oscilante $\left(2,5<\mathrm{F}_{1}<4,5\right)$.

Em termos comparativos, uma primeira análise foi feita entre a razão das alturas conjugadas observada e a razão das alturas conjugadas da equação de Bélanger. A Tab. 7 apresenta os valores calculados e a Fig. 38 mostra a relação entre os dois conjuntos de valores (Observado x Bélanger) para as duas configurações de geração de ressalto.

Tabela 7. Razão entre alturas conjugadas observadas x Bélanger obtidas no canal A.

\begin{tabular}{c|c|c|c|c|c|c|c}
\hline \multicolumn{4}{c}{ Canal A Vertedor } & \multicolumn{4}{c}{ Canal A Comporta } \\
\hline \multirow{2}{*}{ Código } & y2/y1 & y2/y1 & \multirow{2}{*}{ Erro (\%) } & \multirow{2}{*}{ Código } & y2/y1 & y2/y1 & \multirow{2}{*}{$\begin{array}{c}\text { Erro } \\
(\%)\end{array}$} \\
\cline { 2 - 3 } & Observado & Bélanger & & & Observado & Bélanger & \\
\hline SA-1 & 3,37 & 2,39 & 29,1 & CA-1 & 3,72 & 3,09 & 16,9 \\
\hline SA-2 & 2,80 & 2,25 & 19,6 & CA-2 & 3,70 & 3,21 & 13,2 \\
\hline SA-3 & 4,58 & 2,94 & 35,8 & CA-3 & 3,68 & 2,30 & 37,5 \\
\hline SA-4 & 4,24 & 2,99 & 29,5 & CA-4 & 3,65 & 3,03 & 17,0 \\
\hline SA-5 & 3,41 & 1,76 & 48,4 & CA-5 & 5,28 & 3,09 & 41,5 \\
\hline SA-6 & 2,96 & 1,39 & 53,0 & CA-6 & 5,26 & 3,50 & 33,5 \\
\hline SA-7 & 2,49 & 1,39 & 44,2 & CA-7 & 5,24 & 3,24 & 38,2 \\
\hline SA-8 & 2,20 & 1,49 & 32,3 & CA-8 & 5,23 & 3,27 & 37,5 \\
\hline & & & & CA-9 & 4,10 & 2,57 & 37,3 \\
\hline & & & & CA-10 & 4,38 & 2,95 & 32,6 \\
\hline & & & & CA-11 & 4,54 & 2,82 & 37,9 \\
\hline & & & & CA-12 & 3,04 & 2,34 & 23,0 \\
\hline & & & & CA-13 & 3,08 & 2,24 & 27,3 \\
\hline & & & & CA-14 & 3,18 & 2,15 & 32,4 \\
\hline
\end{tabular}




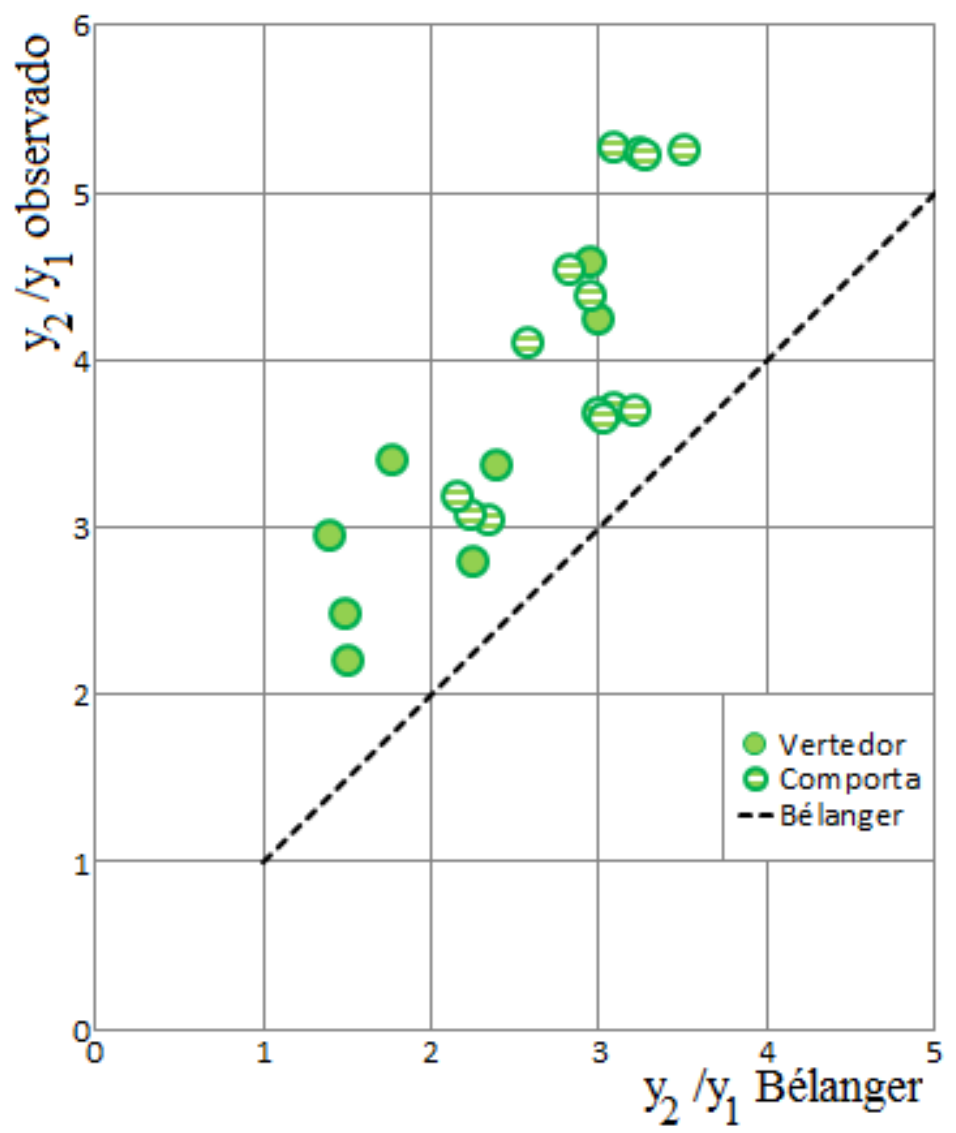

Figura 38. Razão entre alturas conjugadas observadas x Bélanger obtidas no canal A.

\subsubsection{Análise comparativa de $y_{2} / y_{1}$ com dados de estudos anteriores}

A Tab. 7 e Fig. 38 mostram que a equação de Bélanger subestima os valores de $y_{2} / y_{1}$ para o canal A, para qualquer uma das declividades de trabalho adotadas e na faixa experimental de números de Froude estudada. Em estudo anterior também Nóbrega (2014), utilizando o mesmo canal A, obteve esta tendência para ambas as configurações (vertedor e comporta), embora não a tenha evidenciado em suas discussões. As Tab. 8 e Tab. 9 mostram os valores obtidos por Nóbrega (2014). A Fig. 39 mostra os dados conjuntos de Nóbrega (2014) e do presente estudo. Nota-se que para soleira espessa os dados de Nóbrega (2014) se aproximaram mais da previsão da equação de Bélanger, porém mantendo valores acima daquela previsão, similarmente ao obtido no presente estudo. Os dados para comporta, por outro lado, mostram valores semelhantes para os dois conjuntos de experimentos independentes. Nas condições experimentais estudadas pela autora citada, $\mathrm{F}_{\mathrm{r}}$ variou de 1,94 a 3,51 , compreendendo casos de ressalto fraco $\left(1,7<F_{1}<2,5\right)$ e ressalto oscilante $\left(2,5<F_{1}<\right.$ $4,5)$. 
Tabela 8. Dados para a soleira espessa no canal A obtidos por Nóbrega (2014).

\begin{tabular}{|c|c|c|c|c|c|c|}
\hline \multicolumn{7}{|c|}{ Canal A - Soleira espessa, liso, horizontal - Nóbrega (2014) } \\
\hline Vazão & $\mathrm{y}_{1}$ & $\mathrm{y}_{2}$ & \multirow{2}{*}{$\mathrm{y}_{2} / \mathrm{y}_{1}$} & $\mathrm{U}_{1}$ & \multirow{2}{*}{$\mathrm{F}_{1}$} & \multirow{2}{*}{$\begin{array}{c}\mathrm{y} 2 / \mathrm{y}_{1} \\
\text { (Bélanger) }\end{array}$} \\
\hline$[\mathrm{L} / \mathrm{s}]$ & [cm] & [cm] & & {$[\mathrm{m} / \mathrm{s}]$} & & \\
\hline 2,8 & 2,2 & 7,9 & 3,59 & 1,27 & 2,74 & 3,41 \\
\hline 3,3 & 2,5 & 8,7 & 3,48 & 1,32 & 2,67 & 3,30 \\
\hline 3,7 & 2,8 & 9,5 & 3,39 & 1,32 & 2,52 & 3,10 \\
\hline 4,6 & 3,4 & 10,8 & 3,18 & 1,35 & 2,34 & 2,85 \\
\hline 5,6 & 3,9 & 12,1 & 3,10 & 1,44 & 2,32 & 2,82 \\
\hline 6,5 & 4,7 & 13,5 & 2,87 & 1,38 & 2,04 & 2,42 \\
\hline 7,4 & 5,3 & 14,5 & 2,74 & 1,40 & 1,94 & 2,28 \\
\hline
\end{tabular}

Tabela 9. Dados para a comporta vertical no canal A obtidos por Nóbrega (2014).

\begin{tabular}{|c|c|c|c|c|c|c|}
\hline \multicolumn{7}{|c|}{ Canal A - Comporta vertical, liso, horizontal - Nóbrega (2014) } \\
\hline Vazão & $\mathrm{y}_{1}$ & $\mathrm{y}_{2}$ & \multirow{2}{*}{$\mathrm{y}_{2} / \mathrm{y}_{1}$} & $\mathrm{U}_{1}$ & \multirow{2}{*}{$\mathrm{F}_{1}$} & \multirow{2}{*}{$\begin{array}{c}\mathrm{y}_{2} / \mathrm{y}_{1} \\
\text { (Bélanger) }\end{array}$} \\
\hline$[\mathrm{L} / \mathrm{s}]$ & {$[\mathrm{cm}]$} & {$[\mathrm{cm}]$} & & {$[\mathrm{m} / \mathrm{s}]$} & & \\
\hline 1,1 & 1,0 & 5,9 & 5,90 & 1,1 & 3,51 & 4,49 \\
\hline 1,7 & 1,4 & 7,8 & 5,57 & 1,21 & 3,28 & 4,16 \\
\hline 4,6 & 2,9 & 13,2 & 4,55 & 1,59 & 2,97 & 3,74 \\
\hline
\end{tabular}

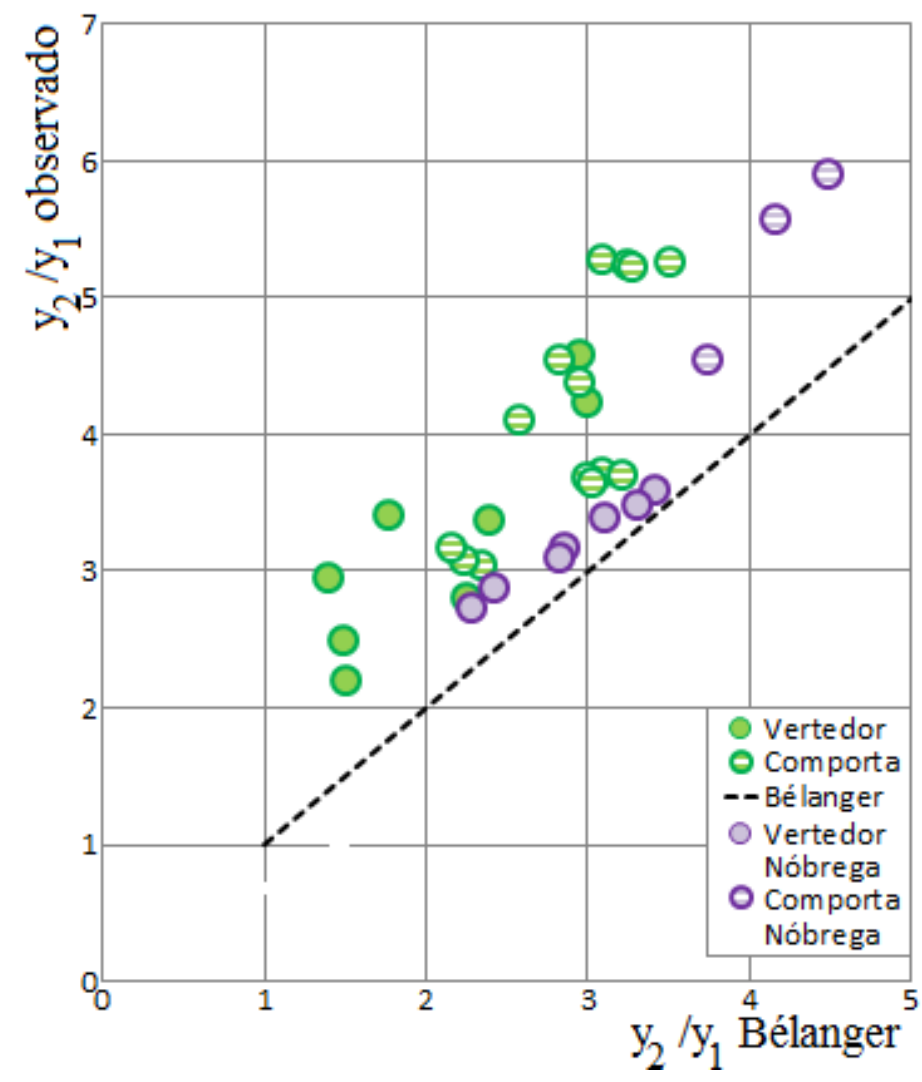

Figura 39. Dados $\mathrm{y}_{2} / \mathrm{y}_{1}$ de Nóbrega (2014) e deste estudo x Bélanger para o canal A. 
No sentido de estabelecer uma melhor comparação entre os experimentos independentes (Nóbrega, 2014, e o presente estudo), foi feita uma análise comparativa restrita apenas para os dados coletados para a condição de canal liso e sem declividade, conforme indicados nas Tab. 8 e Tab. 9. Os dados de Nóbrega (2014) foram utilizados em sua integralidade, uma vez que apenas a condição "liso e sem declividade" foi considerada pela autora citada. Para esta condição obteve-se que os dados de ambos os experimentos estão bem mais próximos, conforme mostra a Fig. 40. Esta proximidade é importante para assegurar a repetitividade dos experimentos e para viabilizar uma generalização eventual das conclusões do presente estudo.

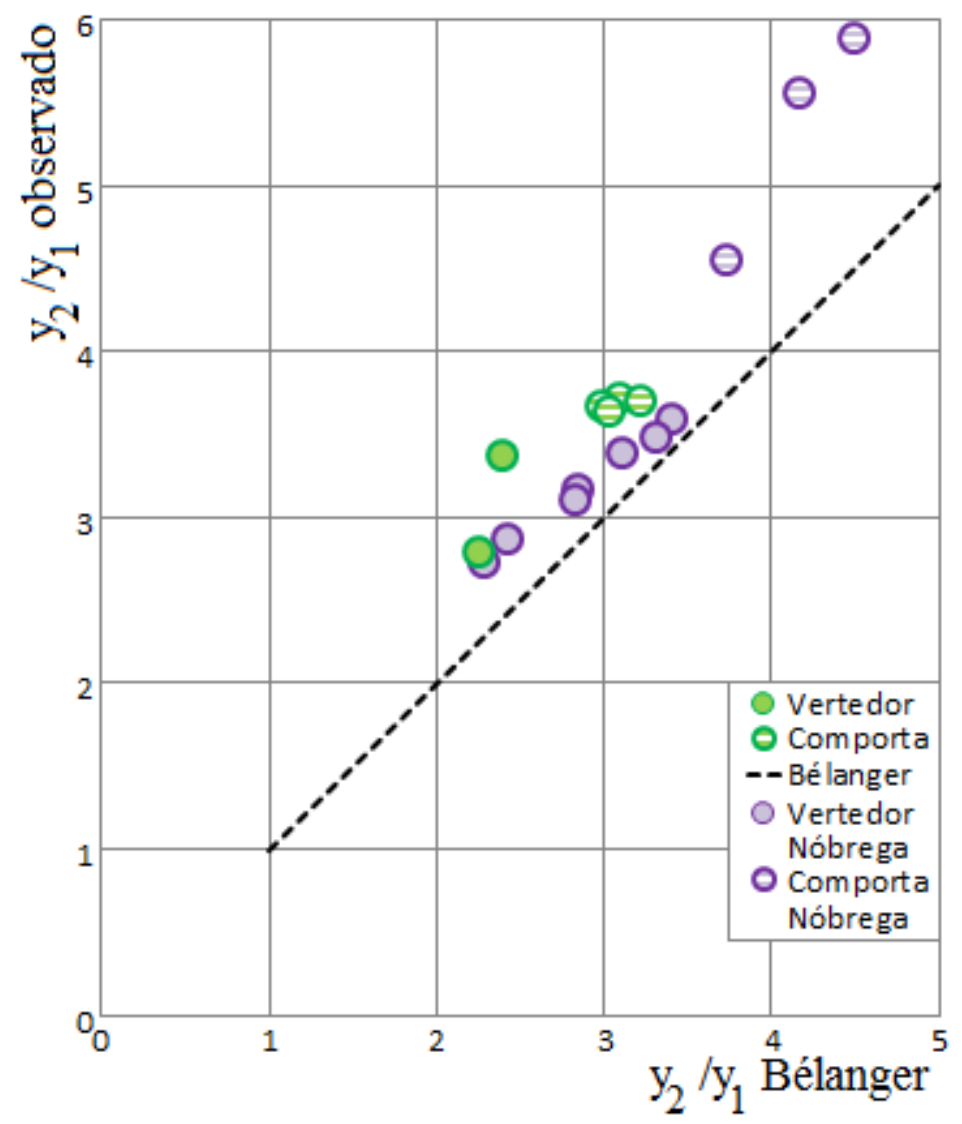

Figura 40. Dados $\mathrm{y}_{2} / \mathrm{y}_{1}$ de Nóbrega (2014) e deste estudo para o Canal A na condição "liso e sem declividade" em comparação com a equação de Bélanger.

$\mathrm{Na}$ continuidade da análise, verificou-se que, para as condições experimentais exploradas, houve menor variação dos resultados para a associação entre diferentes rugosidades e diferentes estruturas hidráulicas (vertedor ou comporta) do que para diferentes declividades. A Tab. 10 apresenta os dados de $\mathrm{y}_{2} / \mathrm{y}_{1}$ para o canal A horizontal, com e sem rugosidade, para vertedor e comporta. A tabela foi construída com os dados deste estudo e de Nóbrega (2014). A Tab. 11 apresenta os dados de $\mathrm{y}_{2} / \mathrm{y}_{1}$ para o canal A inclinado, com e sem rugosidade, vertedor e comporta. Nesse caso, apenas dados deste estudo foram usados. 
Tabela 10. Dados do Canal A para condição horizontal, liso e rugoso.

\begin{tabular}{c|c|c|c|c|c|c|c}
\hline Código & Vazão & $\mathrm{y}_{1}$ & $\mathrm{y}_{2}$ & $\mathrm{y}_{2} / \mathrm{y}_{1}$ & $\mathrm{U}_{1}$ & $\mathrm{~F}_{1}$ & $\mathrm{y}_{2} / \mathrm{y}_{1}$ \\
\hline & {$[\mathrm{L} / \mathrm{s}]$} & {$[\mathrm{cm}]$} & {$[\mathrm{cm}]$} & Medido & {$[\mathrm{m} / \mathrm{s}]$} & & Bélanger \\
\hline $\mathrm{NVH}$ & 2,8 & 2,2 & 7,9 & 3,59 & 1,27 & 2,74 & 3,41 \\
\hline $\mathrm{NVH}$ & 3,3 & 2,5 & 8,7 & 3,48 & 1,32 & 2,67 & 3,30 \\
\hline $\mathrm{NVH}$ & 3,7 & 2,8 & 9,5 & 3,39 & 1,32 & 2,52 & 3,10 \\
\hline $\mathrm{NVH}$ & 4,6 & 3,4 & 10,8 & 3,18 & 1,35 & 2,34 & 2,85 \\
\hline $\mathrm{NVH}$ & 5,6 & 3,9 & 12,1 & 3,10 & 1,44 & 2,32 & 2,82 \\
\hline $\mathrm{NVH}$ & 6,5 & 4,7 & 13,5 & 2,87 & 1,38 & 2,04 & 2,42 \\
\hline $\mathrm{NVH}$ & 7,4 & 5,3 & 14,5 & 2,74 & 1,40 & 1,94 & 2,28 \\
\hline $\mathrm{NCH}$ & 1,1 & 1 & 5,9 & 5,90 & 1,10 & 3,51 & 4,49 \\
\hline $\mathrm{NCH}$ & 1,7 & 1,4 & 7,8 & 5,57 & 1,21 & 3,28 & 4,16 \\
\hline $\mathrm{NCH}$ & 4,6 & 2,9 & 13,2 & 4,55 & 1,59 & 2,97 & 3,74 \\
\hline PVLH & 2,8 & 2,7 & 9,1 & 3,37 & 1,04 & 2,02 & 2,39 \\
\hline PVLH & 4,8 & 4 & 11,2 & 2,80 & 1,20 & 1,92 & 2,25 \\
\hline PVRH & 2,8 & 3,5 & 8,7 & 2,49 & 0,80 & 1,37 & 1,49 \\
\hline PVRH & 4,8 & 5 & 11 & 2,20 & 0,96 & 1,37 & 1,50 \\
\hline PCLH & 1,9 & 1,8 & 6,7 & 3,72 & 1,06 & 2,51 & 3,09 \\
\hline PCLH & 2,3 & 2 & 7,4 & 3,70 & 1,15 & 2,60 & 3,21 \\
\hline PCLH & 2,5 & 2,2 & 8,1 & 3,68 & 1,14 & 2,45 & 3,00 \\
\hline PCLH & 2,7 & 2,3 & 8,4 & 3,65 & 1,17 & 2,47 & 3,03 \\
\hline PCRH & 2,3 & 2,4 & 7,3 & 3,04 & 0,958 & 1,98 & 2,34 \\
\hline PCRH & 2,5 & 2,6 & 8 & 3,08 & 0,962 & 1,90 & 2,24 \\
\hline PCRH & 2,7 & 2,8 & 8,9 & 3,18 & 0,964 & 1,84 & 2,15 \\
\hline
\end{tabular}

NVH: Nóbrega Vertedor Horizontal; NCH: Nóbrega Comporta Horizontal; PVLH: Presente Vertedor Liso Horizontal; PVRH: Presente Vertedor Rugoso Horizontal; PCLH: Presente Comporta Liso Horizontal; PCRH: Presente Comporta Rugoso Horizontal. 
Tabela 11. Dados do Canal A para condição inclinado, liso e rugoso.

\begin{tabular}{c|c|c|c|c|c|c|c}
\hline Código & Vazão & $\mathrm{y}_{1}$ & $\mathrm{y}_{2}$ & $\mathrm{y}_{2} / \mathrm{y}_{1}$ & $\mathrm{U}_{1}$ & $\mathrm{~F}_{1}$ & $\mathrm{y} 2 / \mathrm{y} 1$ \\
\hline & {$[\mathrm{L} / \mathrm{s}]$} & {$[\mathrm{cm}]$} & {$[\mathrm{cm}]$} & Medido & {$[\mathrm{m} / \mathrm{s}]$} & & Bélanger \\
\hline PVLI & 2,8 & 2,4 & 11 & 4,58 & 1,17 & 2,40 & 2,94 \\
\hline PVLI & 4,8 & 3,4 & 14,4 & 4,24 & 1,41 & 2,45 & 2,99 \\
\hline PVRI & 2,8 & 3,2 & 10,9 & 3,41 & 0,875 & 1,56 & 1,76 \\
\hline PVRI & 4,8 & 5,2 & 15,4 & 2,96 & 0,923 & 1,29 & 1,39 \\
\hline PCLI & 1,9 & 1,8 & 9,5 & 5,28 & 1,06 & 2,51 & 3,09 \\
\hline PCLI & 2,3 & 1,9 & 10 & 5,26 & 1,21 & 2,80 & 3,50 \\
\hline PCLI & 2,5 & 2,1 & 11 & 5,24 & 1,19 & 2,62 & 3,24 \\
\hline PCLI & 2,7 & 2,2 & 11,5 & 5,23 & 1,23 & 2,64 & 3,27 \\
\hline PCRI & 1,9 & 2 & 8,2 & 4,1 & 0,95 & 2,14 & 2,57 \\
\hline PCRI & 2,3 & 2,1 & 9,2 & 4,38 & 1,10 & 2,41 & 2,95 \\
\hline PCRI & 2,7 & 2,4 & 10,9 & 4,54 & 1,13 & 2,32 & 2,82 \\
\hline
\end{tabular}

PVLI: Presente Vertedor Liso Inclinado; PVRI: Presente Vertedor Rugoso Inclinado; PCLI: Presente Comporta Liso Inclinado; PCRI: Presente Comporta Rugoso Inclinado.

As Fig. 41 e Fig. 42 mostram os dados de $\mathrm{y}_{2} / \mathrm{y}_{1}$ das Tab. 10 e Tab. 11, respectivamente. Observa-se que a inclinação representa de fato o aspecto geométrico que acarreta a maior segregação dos dados. Não se afirma que os outros aspectos geométricos não modifiquem os valores e tendências de $\mathrm{y}_{2} / \mathrm{y}_{1}$ quando comparados com as previsões da equação de Bélanger, mas que na presente análise, com a presente quantidade de dados, a declividade mostra uma influência mais relevante. 


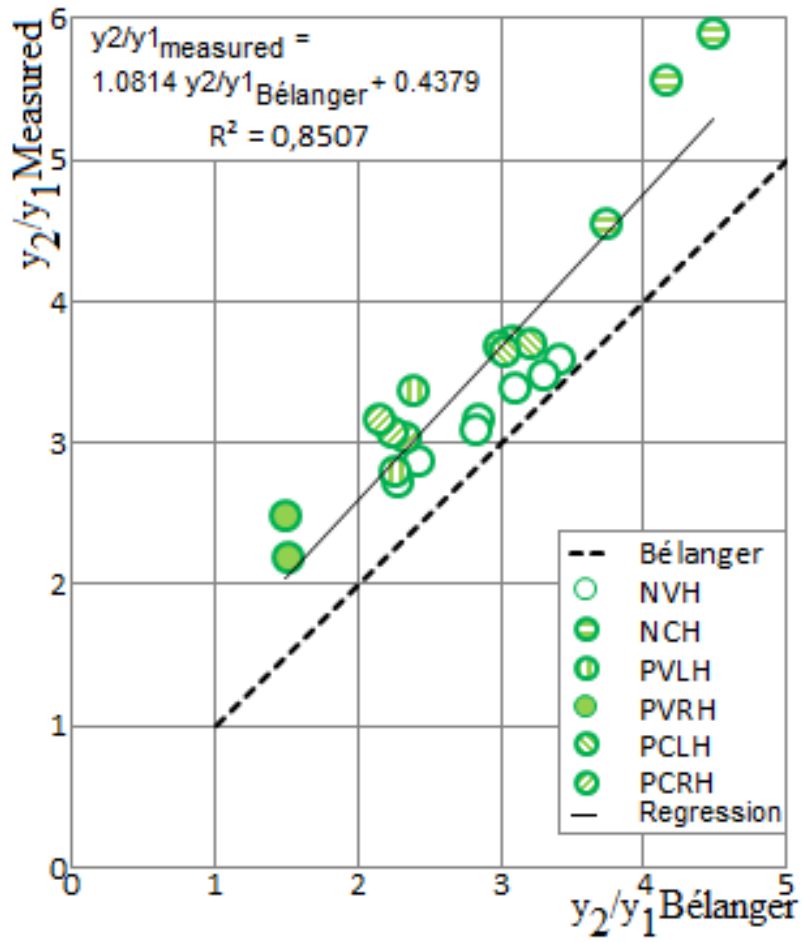

Figura 41. Dados para canal liso e rugoso, vertedor e comporta, horizontal.

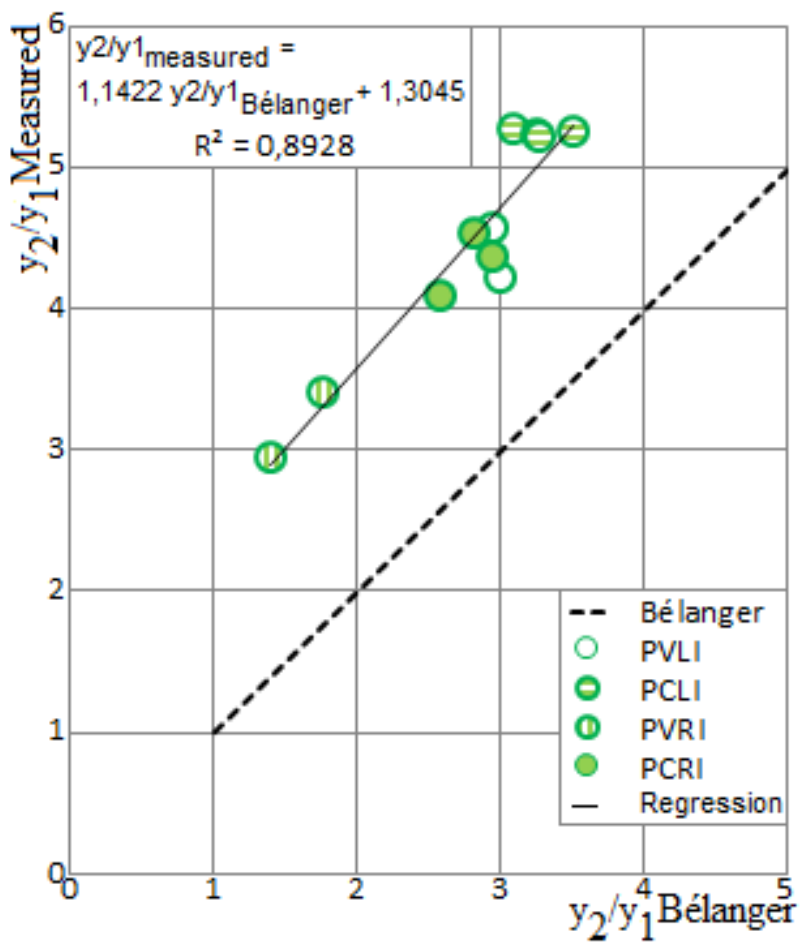

Figura 42. Dados para canal liso e rugoso, vertedor e comporta, inclinado.

As equações de regressão fornecidas nas Fig. 41 e Fig. 42 visam evidenciar a diferença entre os conjuntos de dados para as situações "horizontal" e "inclinado". No segundo caso, tanto o coeficiente angular como o termo independente são maiores do que no primeiro caso, 
mostrando que a distância para as previsões da equação de Bélanger são maiores e aumenta a uma taxa maior.

Entende-se que a equação de Bélanger é condicionada à situação de canais largos. Uma vez que o número de Froude de referência nesta equação é Froude supercrítico $\left(\mathrm{F}_{1}\right)$, vale mencionar que a razão de aspecto na seção do Froude supercrítico nos experimentos aqui conduzidos foi sempre inferior ou igual a 0,52 para o vertedor; e sempre inferior ou igual a 0,28 para a comporta (a razão de aspecto calculada como a profundidade supercrítica $\mathrm{y}_{1}$ dividida pela largura do canal). Em outras palavras, para o vertedor a largura do canal foi maior que o dobro da profundidade supercrítica na maioria dos experimentos, enquanto que para a comporta a largura do canal foi maior que quatro vezes a profundidade supercrítica na maioria dos experimentos. Para os experimentos de Nóbrega (2014) valem as respectivas razões de aspecto: 0,53 e 0,29, o que mostra que também Nóbrega (2014) trabalhou preferencialmente em condições nas quais a largura era maior que o dobro (vertedor) ou quatro vezes (comporta) a profundidade supercrítica.

Com base nos resultados apresentados, verifica-se que:

$\mathrm{i}$ - A equação de Bélanger subestima $\mathrm{y}_{2} / \mathrm{y}_{1}$ para as condições geométricas do Canal A, em qualquer das condições de operação testadas.

ii - As diferentes condições de operação induzem diferentes resultados, tendo-se gerado um maior espalhamento dos dados do que aquele de experimentos anteriores (Nóbrega, 2014) efetuados para condição única de fundo liso horizontal.

iii - Diferentes séries de experimentos nas mesmas condições de operação geraram valores de $\mathrm{y}_{2} / \mathrm{y}_{1}$ compatíveis entre si (Nóbrega, 2014, e o presente trabalho).

iv - O presente conjunto de dados para esta geometria permite observar uma maior influência da declividade na determinação de $\mathrm{y}_{2} / \mathrm{y}_{1}$.

\subsubsection{Comparações de $y_{2} / y_{1}$ com propostas conceituais mais abrangentes}

No presente item considera-se a equação fornecida por Schulz et al. (2015a) para a razão entre profundidades conjugadas, obtida para forças resistivas normais e tangenciais (cisalhantes), que, na notação da presente tese, é escrita como:

$$
\frac{y_{2}}{y_{1}}=\alpha F_{1}^{2} \pm \sqrt{\left(\alpha F_{1}^{2}\right)^{2}+\beta F_{1}^{2}}
$$


$\alpha$ e $\beta$ são coeficientes a ajustar, dependentes das condições experimentais. Para efetuar o ajuste de modo mais imediato, a Eq. (24) foi rearranjada, efetuando-se o seu quadrado, obtendo-se:

$$
\begin{aligned}
& \left(\frac{y_{2}}{y_{1}}\right)^{2}-2 \alpha F_{1}^{2}\left(\frac{y_{2}}{y_{1}}\right)-\beta F_{1}^{2}=0 \\
& \text { Definindo } \varphi_{3}=\left(\frac{y_{2}}{y_{1}}\right)^{2}, \quad \varphi_{2}=F_{1}^{2}, \quad \varphi_{1}=F_{1}^{2}\left(\frac{y_{2}}{y_{1}}\right), \text { tem-se, para a Eq. } 25
\end{aligned}
$$
forma:

$$
\varphi_{3}-\beta \varphi_{2}-2 \alpha \varphi_{1}=0
$$

Os valores de $\varphi_{1}, \varphi_{2}, \varphi_{3}$ são conhecidos das medições feitas, sendo possível obter $\alpha$ e $\beta$ através de regressão multilinear com o método dos mínimos quadrados. Esta metodologia foi seguida aplicando a ferramenta de regressão multilinear "proj.lin" da planilha Excel, parte integrante do pacote de trabalhos da Microsoft. Note-se que, como mencionado em Schulz et al. (2015a), a maneira de rearranjar as parcelas na equação resultante interfere na quantificação das constantes $\alpha$ e $\beta$, sendo que uma regressão não-linear pode ser opção talvez mais conveniente para esse tipo de problema. Esta variação em $\alpha$ e $\beta$ decorre da distribuição dos erros de cada variável. O procedimento não-linear não foi seguido aqui porque o ajuste de coeficientes na raiz quadrada leva, nos processos iterativos, a raízes complexas que dificultam exageradamente a programação da solução, exigindo um tempo bem maior do que aquele disponível para a conclusão dos presentes trabalhos. O procedimento seguido foi o de buscar o modo mais adequado de rearranjar as parcelas de maneira a produzir altos coeficientes de determinação $r^{2}$ tanto para a regressão multilinear (ferramenta proj.lin) como para o ajuste linear feito em seguida entre os valores de $\mathrm{y}_{2} / \mathrm{y}_{1}$ medidos e calculados.

A Eq. (26) foi utilizada diretamente com a ferramenta Proj.lin.

Como já foi observado nas Fig. 41 e Fig. 42, os dados já se mostram segregados pela declividade. Portanto as regressões multilineares foram feitas já respeitando esta segregação.

Para o canal A horizontal, após várias tentativas de agrupamento dos dados para obter boas correlações e ajustes dos coeficientes $\alpha$ e $\beta$, observou-se que dois agrupamentos se mostraram mais coesos, sendo diferenciados pela estrutura hidráulica que produziu o ressalto, ou seja, um agrupamento para o vertedor e outro agrupamento para a comporta vertical. 
O agrupamento de dados para o vertedor e canal horizontal está mostrado na Tab. 12, enquanto que o agrupamento para a comporta e canal horizontal está mostrado na Tab. 13.

Tabela 12. Dados do Canal A para vertedor, horizontal, liso e rugoso.

\begin{tabular}{c|c|c|c|c|c|c}
\hline Código & Vazão & $\mathrm{y}_{1}$ & $\mathrm{y}_{2}$ & $\mathrm{y}_{2} / \mathrm{y}_{1}$ & $\mathrm{U}_{1}$ & $\mathrm{~F}_{1}$ \\
\hline & {$[\mathrm{L} / \mathrm{s}]$} & {$[\mathrm{cm}]$} & {$[\mathrm{cm}]$} & Medido & {$[\mathrm{m} / \mathrm{s}]$} & \\
\hline $\mathrm{NVH}$ & 2,8 & 2,2 & 7,9 & 3,59 & 1,27 & 2,74 \\
\hline $\mathrm{NVH}$ & 3,3 & 2,5 & 8,7 & 3,48 & 1,32 & 2,67 \\
\hline $\mathrm{NVH}$ & 3,7 & 2,8 & 9,5 & 3,39 & 1,32 & 2,52 \\
\hline $\mathrm{NVH}$ & 4,6 & 3,4 & 10,8 & 3,18 & 1,35 & 2,34 \\
\hline $\mathrm{NVH}$ & 5,6 & 3,9 & 12,1 & 3,10 & 1,44 & 2,32 \\
\hline $\mathrm{NVH}$ & 6,5 & 4,7 & 13,5 & 2,87 & 1,38 & 2,04 \\
\hline $\mathrm{NVH}$ & 7,4 & 5,3 & 14,5 & 2,74 & 1,40 & 1,94 \\
\hline PVLH & 2,8 & 2,7 & 9,1 & 3,37 & 1,04 & 2,02 \\
\hline PVLH & 4,8 & 4 & 11,2 & 2,8 & 1,2 & 1,92 \\
\hline PVRH & 2,8 & 3,5 & 8,7 & 2,49 & 0,8 & 1,37 \\
\hline PVRH & 4,8 & 5 & 11 & 2,2 & 0,96 & 1,37 \\
\hline
\end{tabular}

Tabela 13. Dados do Canal A para comporta, horizontal, liso e rugoso.

\begin{tabular}{c|c|c|c|c|c|c}
\hline $\mathrm{NCH}$ & 1,1 & 1 & 5,9 & 5,9 & 1,1 & 3,51 \\
\hline $\mathrm{NCH}$ & 1,7 & 1,4 & 7,8 & 5,57 & 1,21 & 3,28 \\
\hline $\mathrm{NCH}$ & 4,6 & 2,9 & 13,2 & 4,55 & 1,59 & 2,97 \\
\hline PCLH & 1,9 & 1,8 & 6,7 & 3,72 & 1,06 & 2,51 \\
\hline PCLH & 2,3 & 2 & 7,4 & 3,7 & 1,15 & 2,60 \\
\hline PCLH & 2,5 & 2,2 & 8,1 & 3,68 & 1,14 & 2,45 \\
\hline PCLH & 2,7 & 2,3 & 8,4 & 3,65 & 1,17 & 2,47 \\
\hline PCRH & 2,3 & 2,4 & 7,3 & 3,04 & 0,958 & 1,98 \\
\hline PCRH & 2,5 & 2,6 & 8 & 3,08 & 0,962 & 1,90 \\
\hline PCRH & 2,7 & 2,8 & 8,9 & 3,18 & 0,964 & 1,84 \\
\hline
\end{tabular}

As Fig. 43 e Fig. 44 mostram comparações entre as razões $\mathrm{y}_{2} / \mathrm{y}_{1}$ medidas e graficadas em relação ao número de Froude supercrítico, em conjunto com a equação previsiva obtida com os coeficientes $\alpha$ e $\beta$ ajustados pela regressão multilinear. 


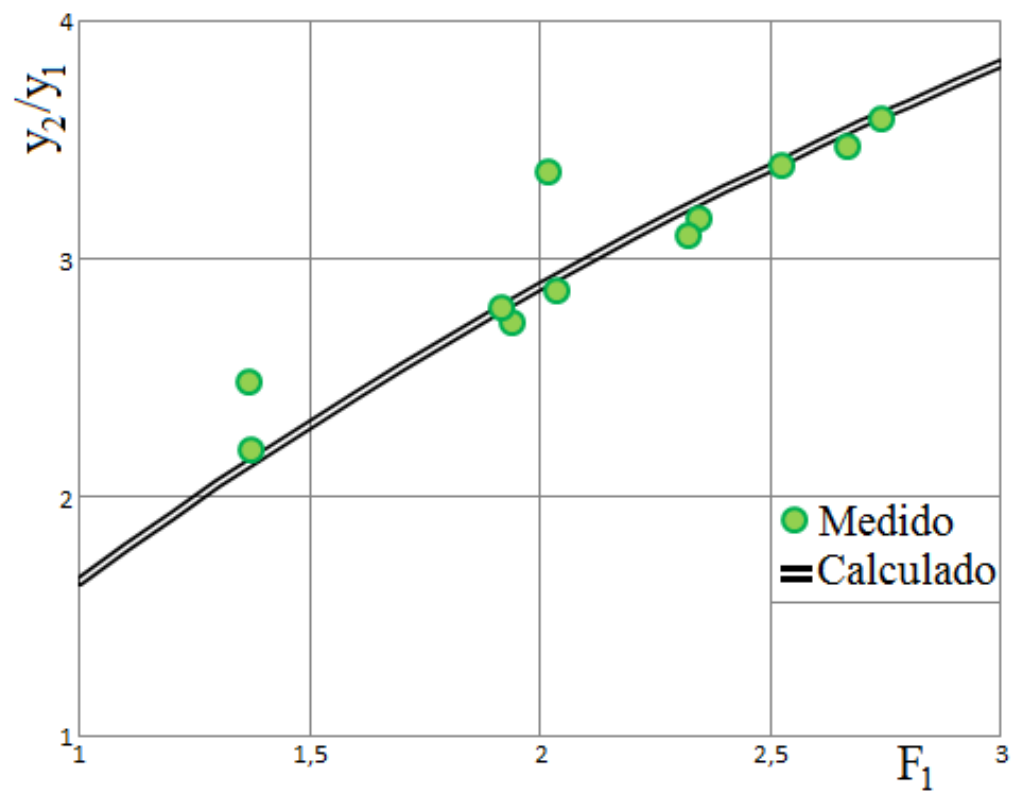

Figura 43. Medições e previsão utilizando a Eq. (24) $\operatorname{com} \alpha=-0,2489$ e $\beta=3,526 . r^{2}=0,991$ na regressão multilinear.

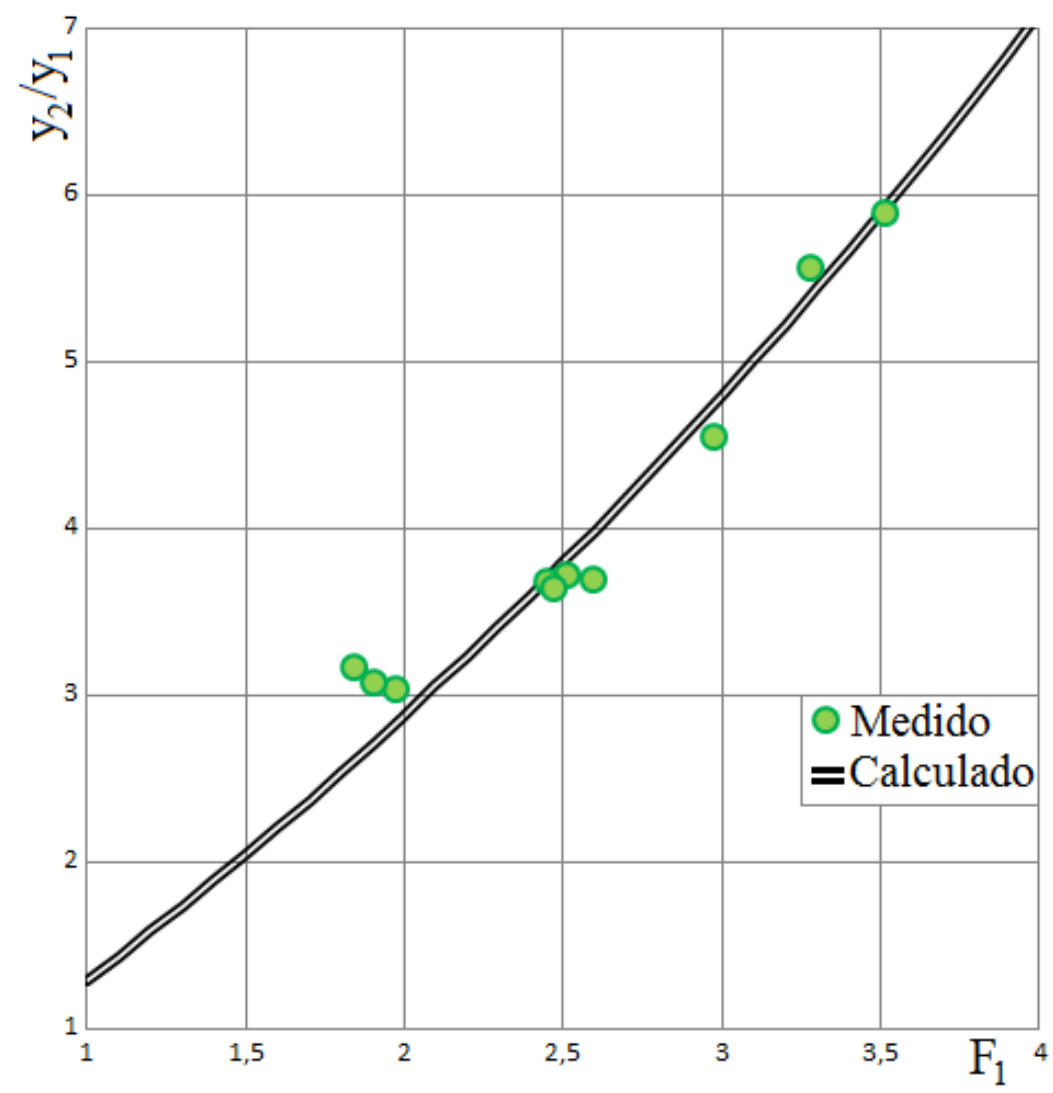

Figura 44. Medições e previsão utilizando a Eq. (24) $\operatorname{com} \alpha=0,1262$ e $\beta=1,353 \cdot r^{2}=0,995$ na regressão multilinear

A formulação de Schulz et al. (2015a) mostrou-se versátil para as diferentes condições de trabalho. Verifica-se, nas Fig. 43 e Fig. 44 que para a faixa de $F_{1}$ estudada, o vertedor gerou uma função com concavidade "para baixo", enquanto que a comporta gerou uma 
função com concavidade "para cima". A Fig. 45 amplia a faixa de $F_{1}$ para se observar melhor o comportamento das duas tendências.

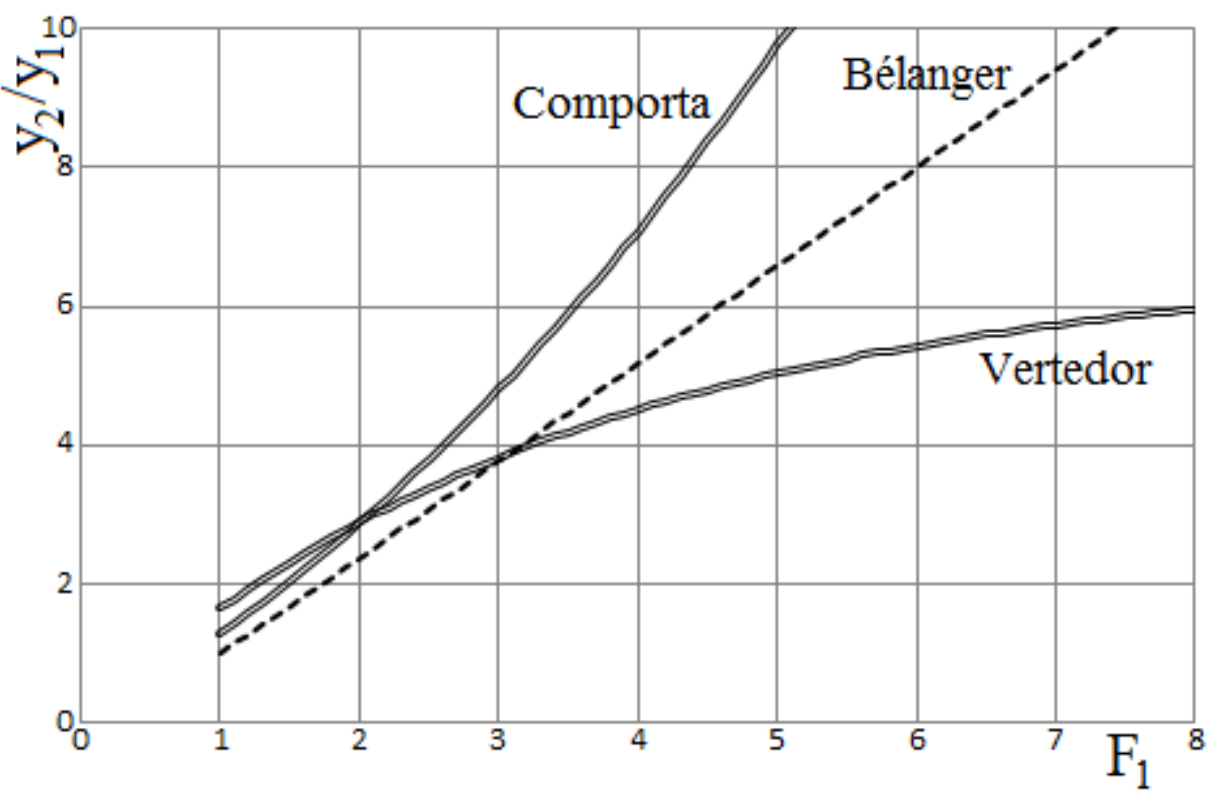

Figura 45. Os diferentes comportamentos que a formulação em teste permite cobrir.

Vale mencionar que as duas tendências de evolução (concavidade para cima com $\alpha$ > 0 e para baixo com $\alpha<0$ ) são observadas em dados reportados na literatura, assim como valores acima e abaixo da previsão da equação de Bélanger (Schulz et al., 2015a). No caso da solução de Schulz et al. (2015a) obtém-se a tendência linear quando $\alpha=0$.

Foram buscados os mesmos agrupamentos de dados (vertedor e comporta) para o canal inclinado, porque esta segregação se mostrou adequada ao canal horizontal. As tendências gerais foram compatíveis com aquelas observadas para o canal horizontal. Entretanto, devido ao pequeno número de dados para a estrutura hidráulica do vertedor, entende-se que os valores das constantes $\alpha$ e $\beta$ aqui apresentados ainda constituem apenas uma primeira aproximação.

O agrupamento de dados para o vertedor e canal inclinado está mostrado na Tab. 13, enquanto que o agrupamento para a comporta e canal inclinado está mostrado na Tab. 14. Os gráficos correspondentes às duas situações são fornecidos nas Fig. 46 e Fig. 47, respectivamente. 
Tabela 14. Dados do Canal A para vertedor, inclinado, liso e rugoso.

\begin{tabular}{c|c|c|c|c|c|c}
\hline Código & Vazão & $\mathrm{y}_{1}$ & $\mathrm{y}_{2}$ & $\mathrm{y}_{2} / \mathrm{y}_{1}$ & $\mathrm{U}_{1}$ & $\mathrm{~F}_{1}$ \\
\hline & {$[\mathrm{L} / \mathrm{s}]$} & {$[\mathrm{cm}]$} & {$[\mathrm{cm}]$} & Medido & {$[\mathrm{m} / \mathrm{s}]$} & \\
\hline PVLI & 2,8 & 2,4 & 11 & 4,58 & 1,17 & 2,40 \\
\hline PVLI & 4,8 & 3,4 & 14,4 & 4,24 & 1,41 & 2,449 \\
\hline PVRI & 2,8 & 3,2 & 10,9 & 3,41 & 0,875 & 1,56 \\
\hline PVRI & 4,8 & 5,2 & 15,4 & 2,96 & 0,923 & 1,29 \\
\hline
\end{tabular}

Tabela 15. Dados do Canal A para comporta, inclinado, liso e rugoso.

\begin{tabular}{c|c|c|c|c|c|c}
\hline Código & Vazão & $\mathrm{y}_{1}$ & $\mathrm{y}_{2}$ & $\mathrm{y}_{2} / \mathrm{y}_{1}$ & $\mathrm{U}_{1}$ & $\mathrm{~F}_{1}$ \\
\hline & {$[\mathrm{L} / \mathrm{s}]$} & {$[\mathrm{cm}]$} & {$[\mathrm{cm}]$} & Medido & {$[\mathrm{m} / \mathrm{s}]$} & \\
\hline PCLI & 1,9 & 1,8 & 9,5 & 5,28 & 1,06 & 2,51 \\
\hline PCLI & 2,3 & 1,9 & 10 & 5,26 & 1,21 & 2,80 \\
\hline PCLI & 2,5 & 2,1 & 11 & 5,24 & 1,19 & 2,62 \\
\hline PCLI & 2,7 & 2,2 & 11,5 & 5,23 & 1,23 & 2,64 \\
\hline PCRI & 1,9 & 2 & 8,2 & 4,1 & 0,95 & 2,14 \\
\hline PCRI & 2,3 & 2,1 & 9,2 & 4,38 & 1,10 & 2,41 \\
\hline PCRI & 2,7 & 2,4 & 10,9 & 4,54 & 1,13 & 2,32 \\
\hline
\end{tabular}

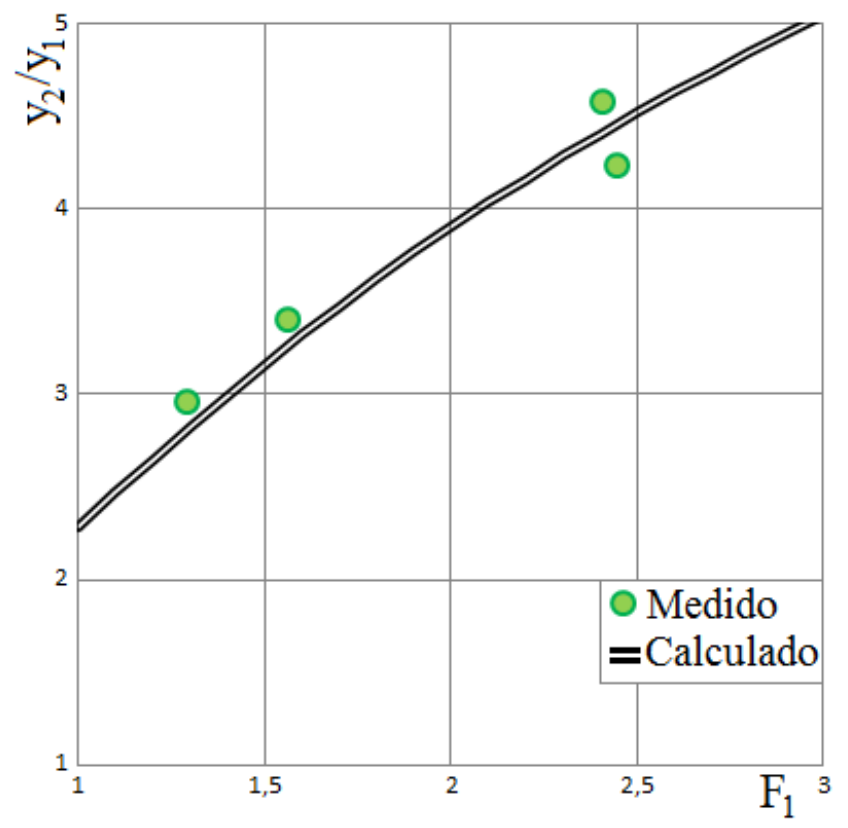

Figura 46. Medições e previsão utilizando a equação (24) com $\alpha=-0,4319$ e $\beta=7,181 \cdot r^{2}=0,981$ na regressão multilinear, para experimentos no canal inclinado. 


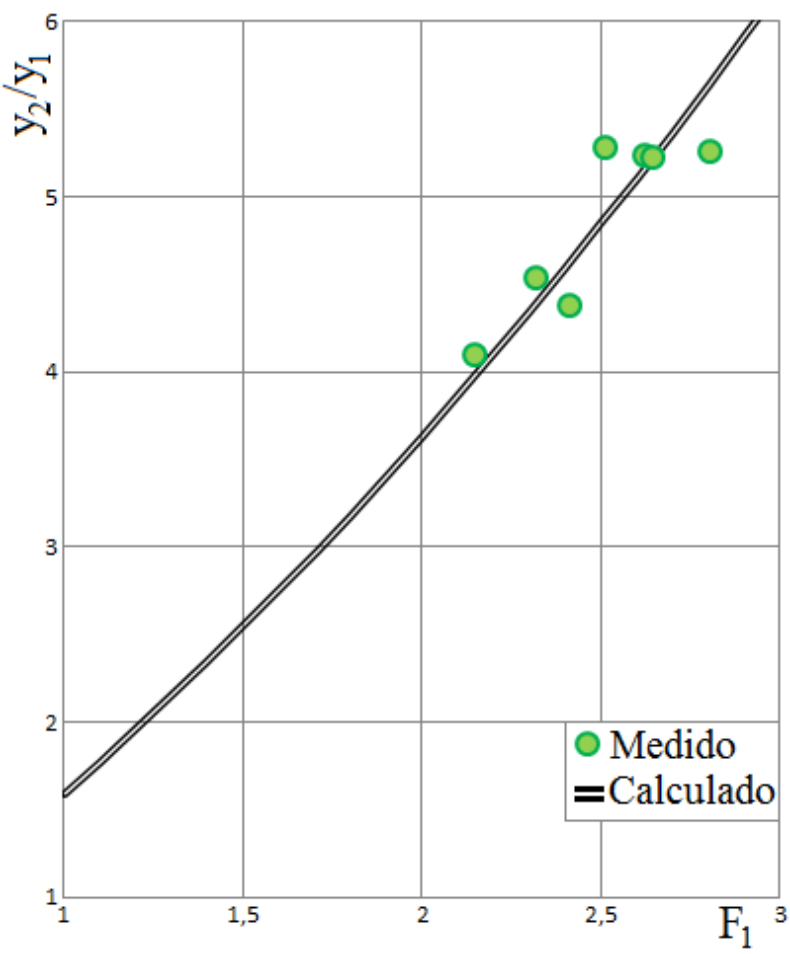

Figura 47. Medições e previsão utilizando a equação (24) com $\alpha=0,1908$ e $\beta=1,907 . r^{2}=0,994$ na regressão multilinear, para experimentos no canal inclinado.

Com base nos resultados apresentados, verifica-se que:

$\mathrm{i}$ - A solução de Schulz et al. (2015a) permite que as evoluções de $\mathrm{y}_{2} / \mathrm{y}_{1}$ para com $\mathrm{F}_{1}$ sejam adequadamente representadas ajustando-se os coeficientes $\alpha$ e $\beta$.

ii - Os comportamentos calculados acompanham bem os comportamentos medidos na faixa de números de Froude estudadas.

iii - Dois tipos de comportamento dos dados e dos cálculos foram observados; concavidade para cima, quando $\alpha>0$, e concavidade para baixo, quando $\alpha<0$. Da formulação testada sabe-se que há tendência linear para $\alpha=0$. Todos esses compor atamentos são encontrados na literatura, mostrando que o equacionamento é versátil para abranger as diferentes tendências.

iv - Os valores de $\alpha$ e $\beta$ e as características comportamentais para as diferentes condições experimentais do canal A são apresentadas na Tab. 16. 
Tabela 16. Valores de $\alpha$ e $\beta$ para as diferentes condições experimentais no canal A.

\begin{tabular}{c|c|c|c|c}
\hline & \multicolumn{2}{|c|}{ Horizontal } & \multicolumn{2}{c}{ Inclinado } \\
\hline & Vertedor & Comporta & Vertedor & Comporta \\
\hline$\alpha$ & $-0,2489$ & 0,1262 & $-0,4319$ & 0,1908 \\
\hline$\beta$ & 3,526 & 1,353 & 7,181 & 1,907 \\
\hline Concavidade & P/ baixo & P/ cima & P/ baixo & P/ cima \\
\hline
\end{tabular}

v-A Tab. 16 mostra:

- Valores absolutos das constantes maiores para a condição inclinada do que para a condição horizontal. A segregação por inclinação mostra-se, portanto, adequada.

- Valores absolutos das constantes maiores para a estrutura hidráulica do vertedor do que para a estrutura hidráulica da comporta. A segregação por geometria do tipo de estrutura mostra-se, portanto, também adequada.

- Concavidades semelhantes para estruturas semelhantes, também apontando para a adequação da separação por geometria da estrutura hidráulica.

vi - O presente conjunto de dados não permitiu quantificar o efeito da rugosidade no contexto da sobreposição das diferentes variáveis utilizadas nos experimentos (inclinação, tipo de estrutura hidráulica, rugosidade). Por outro lado, permitiu observar de forma bastante detalhada o efeito do tipo de estrutura e da inclinação. Sugere-se a execução de experimentos específicos, com maior densidade de dados, para melhor quantificar $\alpha$ e $\beta$ para as diferentes rugosidades.

Em termos visuais, a Tab. 16 permite gerar o gráfico da Fig. 48, que indica a evolução dos coeficientes $\alpha$ e $\beta$ com a declividade, considerando a estrutura hidráulica utilizada. 


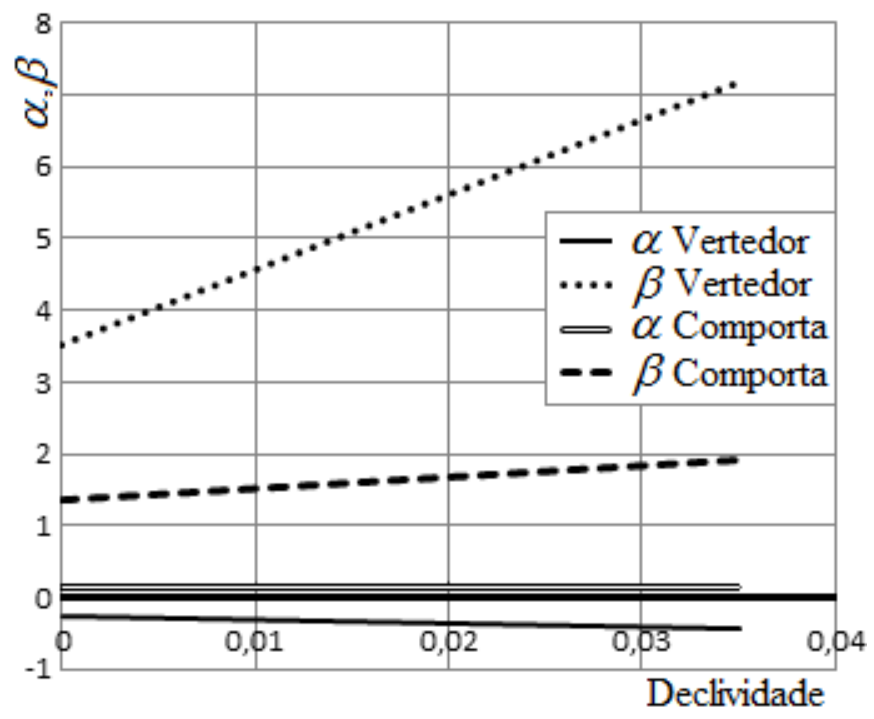

Figura 48. Tendências dos coeficientes $\alpha$ e $\beta$ nas condições experimentais do canal A.

Adicionalmente, o uso dos coeficientes conforme a Tab. 16 e a Fig. 48 produz a Fig. 49 relacionando resultados medidos e previstos.

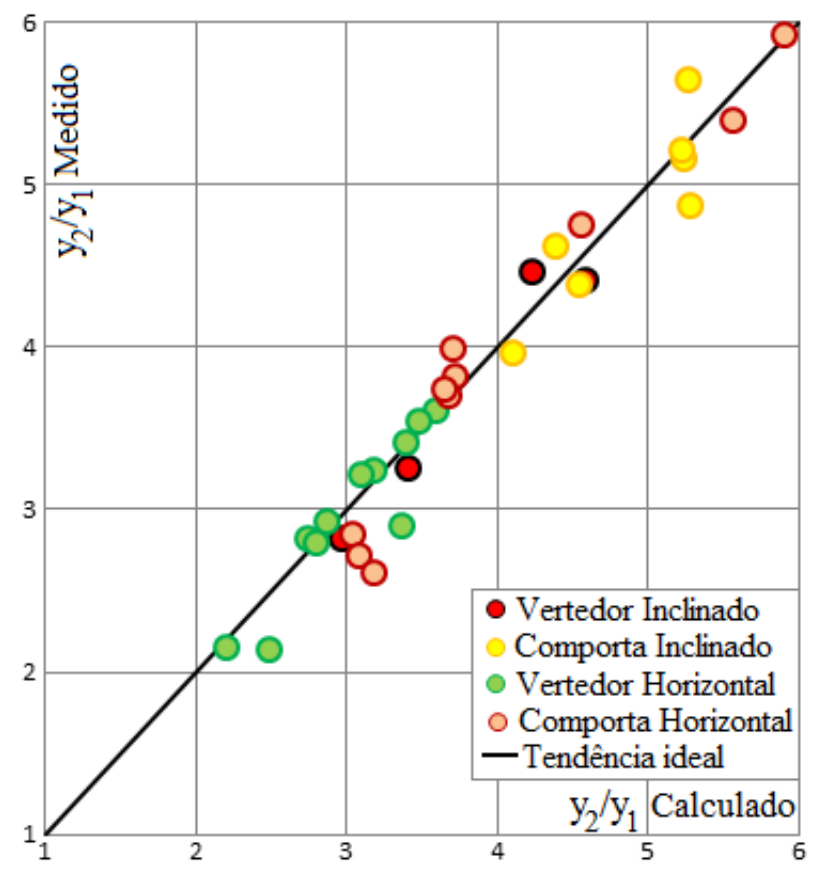

Figura 49. $y_{2} / y_{1}$ medidos e calculados considerando os coeficientes $\alpha$ e $\beta$.

\subsubsection{Análises dos comprimentos do rolo no canal A}

No presente item são analisados os resultados obtidos para o comprimento do rolo no canal A já apresentados nas Tab. 5 e Tab. 6. Pelo fato de o comprimento do rolo também ser definido como o comprimento do ressalto em canais inclinados, apenas a análise comparativa 
para o comprimento do rolo é feita. Nesse caso, são utilizados os valores $y_{t}$ para a profundidade da água no final do rolo apresentados nas Tab. 5 e Tab. 6.

Os resultados dos comprimentos de rolos se mostraram mais coesos com relação às diferentes condições experimentais, ou seja, não se observou tendência clara de segregação dos dados devido a uma ou outra variável controlada, como por exemplo, a declividade (que foi evidente para os dados de $\mathrm{y}_{2} / \mathrm{y}_{1}$ ). A Fig. 50 apresenta os dados do presente estudo em conjunto com os dados de Nóbrega (2014), apresentados na Tab. 17. Novamente se observa maior espalhamento dos dados obtidos no presente estudo em decorrência das diferentes condições experimentais que aqui foram testadas. Entretanto, como já comentado, não há diferenciação evidente para as diferentes condições (rugosidade, declividade e estrutura geradora do ressalto).

Tabela 17. Dados de Nóbrega (2014) para comprimento do rolo no canal A.

\begin{tabular}{c|c|c|c|c|c}
\hline \multicolumn{6}{c}{ Canal A - Vertedor, liso, horizontal - Nóbrega (2014) } \\
\cline { 1 - 4 } Vazão & $\mathrm{y}_{1}$ & $\mathrm{y}_{2}$ & $\mathrm{U}_{1}$ & \multirow{2}{*}{$\mathrm{F}_{1}$} & \multirow{2}{*}{$\mathrm{L}_{\mathrm{r}}(\mathrm{cm})$} \\
\cline { 1 - 4 }$[\mathrm{L} / \mathrm{s}]$ & {$[\mathrm{cm}]$} & {$[\mathrm{cm}]$} & {$[\mathrm{m} / \mathrm{s}]$} & & \\
\hline 2,8 & 2,2 & 7,9 & 1,27 & 2,74 & 23,96 \\
\hline 3,3 & 2,5 & 8,7 & 1,32 & 2,67 & 26,26 \\
\hline 3,7 & 2,8 & 9,5 & 1,32 & 2,52 & 27,1 \\
\hline 4,6 & 3,4 & 10,8 & 1,35 & 2,34 & 29,11 \\
\hline 5,6 & 3,9 & 12,1 & 1,44 & 2,32 & 31,82 \\
\hline 6,5 & 4,7 & 13,5 & 1,38 & 2,04 & 33,81 \\
\hline 7,4 & 5,3 & 14,5 & 1,40 & 1,94 & 34,63 \\
\hline
\end{tabular}

Canal A - Comporta, liso, horizontal - Nóbrega (2014)

\begin{tabular}{c|c|c|c|c|c}
\hline 1,1 & 1 & 5,9 & 1,1 & 3,51 & 19,89 \\
\hline 1,7 & 1,4 & 7,8 & 1,21429 & 3,28 & 24,96 \\
\hline 4,6 & 2,9 & 13,2 & 1,58621 & 2,97 & 41,54 \\
\hline
\end{tabular}

A Fig. 48 relaciona os valores de $L_{r} / y_{1}$ medidos e calculados segundo a Eq. (27), apresentada por Schulz et al. (2015a) e cujos coeficientes $\gamma$ e $\delta$ são ajustados de acordo com as condições experimentais.

$$
\frac{L_{r}}{y_{1}}=\gamma \frac{F_{1}}{\sqrt{\frac{y_{1}}{y_{2}-y_{1}}}}+\delta F_{1}^{3} \sqrt{\frac{y_{1}}{y_{2}-y_{1}}}
$$


Esta equação segue procedimentos dedutivos vinculados à realidade física da dissipação de energia no rolo e na base do escoamento (parede do canal). Os coeficientes $\gamma$ e $\delta$ dependem de condições não modeladas, como geometria da estrutura geradora do ressalto, rugosidade, declividade, geometria do canal distinta da retangular, etc. As variáveis $L_{r} / y_{1}$, $F_{1} / \sqrt{ }\left[y_{1} /\left(y_{2}-y_{1}\right)\right]$ e $F_{1}^{3} \sqrt{ }\left[y_{1} /\left(y_{2}-y_{1}\right)\right]$ são calculadas a partir dos dados medidos e $\gamma$ e $\delta$ são obtidos por regressão multilinear, seguindo o procedimento descrito para os cálculo de $y^{2} / y^{1}$. A Fig. 50 mostra que as previsões obtidas aplicando a Eq. (27) acompanham a distribuição observada nos dados medidos, produzindo uma boa correlação expressa pelo valor de $r^{2}=$ 0,79 .

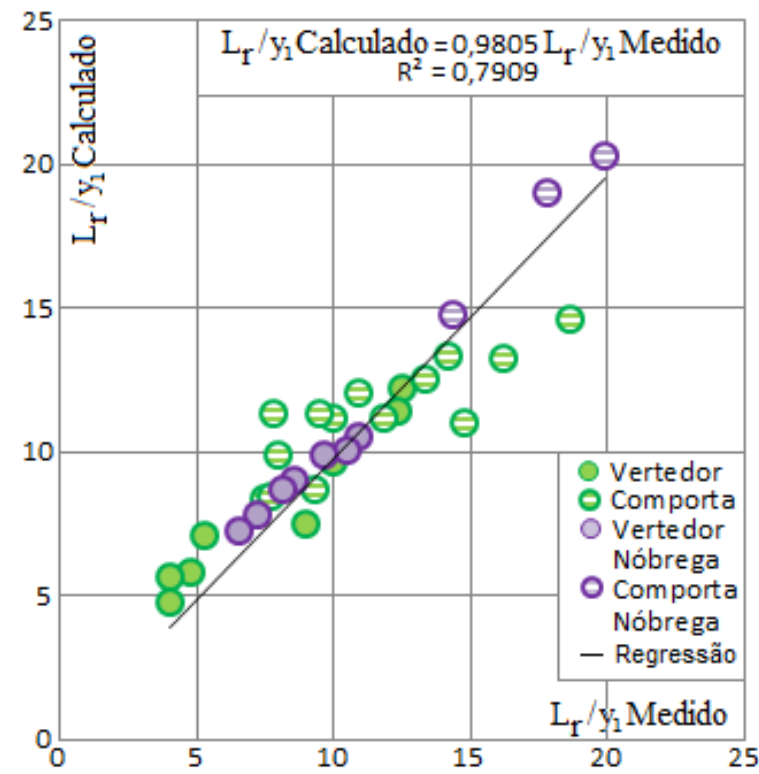

Figura 50. Conjunto completo de $L_{r} / y_{1}$ medido e calculado utilizando $\gamma=4,137$ e $\delta=-0,6050$.

Entre os resultados em condições experimentais específicas, uma condição que se mostrou bastante coesa foi aquela que utilizou a estrutura hidráulica do vertedor, independentemente da rugosidade e declividade. A Fig. 51 mostra esta condição com $r^{2}=0,86$. 


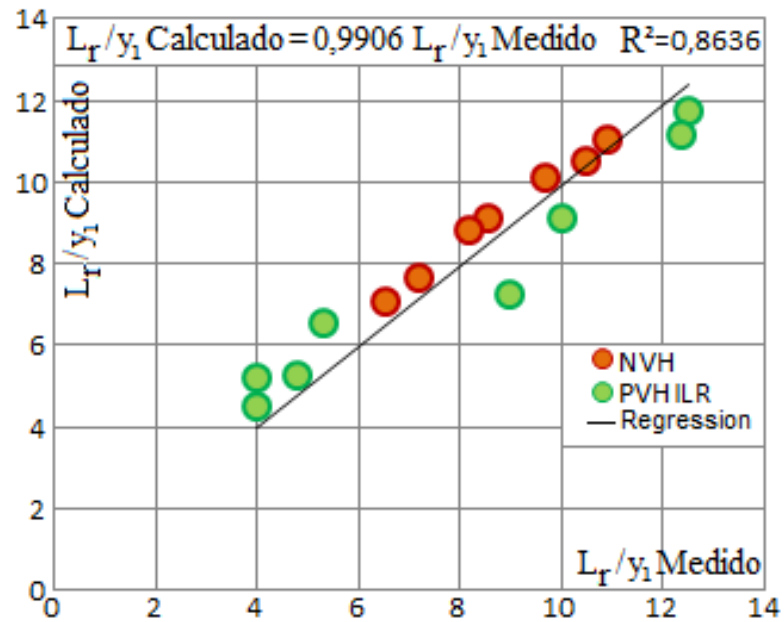

Figura 51. $L_{r} / y_{1}$ medido e calculado para estrutura hidráulica do vertedor, liso, rugoso, inclinado e horizontal, utilizando $\gamma=3,570$ e $\delta=-0,3700$. NVH=Nóbrega, Vertedor, Horizontal; PVHILR=Presente, Vertedor, Horizontal, Inclinado, Liso, Rugoso.

Observa-se que há modificação dos coeficientes quando se considera a comporta como estrutura geradora do ressalto, mas havendo diminuição da qualidade da previsão, como mostra a Fig. 52, na qual $r^{2}=0,60$.

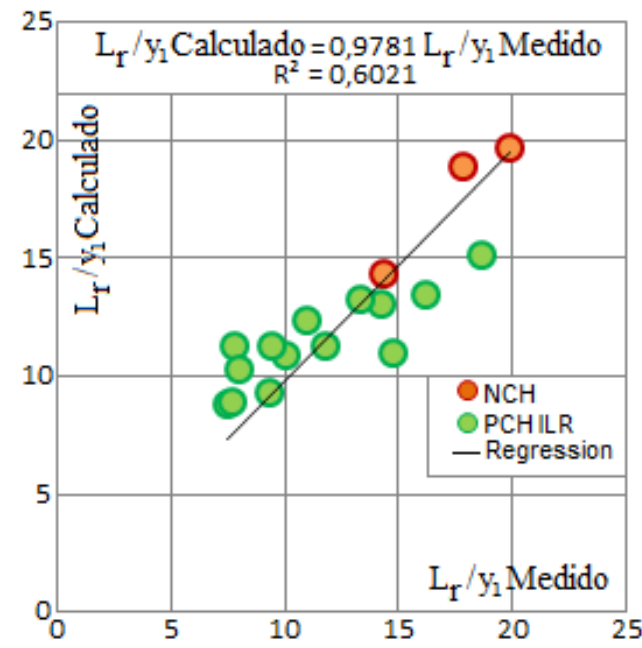

Figura 52. $L_{r} / y_{1}$ medido e calculado para estrutura hidráulica de comporta, liso, rugoso, inclinado e horizontal, utilizando $\gamma=4,903$ e $\delta=-0,9401$.

Os coeficientes $\gamma$ e $\delta$ obtidos estão apresentados na Tab. 18, tendo sido usados também para gerar o gráfico da Fig. 53. Observa-se que o uso discriminado dos coeficientes melhorou a correlação final obtida, representada pelo valor $r^{2}=0,81$, um pouco maior que o valor $r^{2}=0,79$ apresentado na Fig. 50. Isto mostra que, apesar do espalhamento dos dados, há um efeito de segregação que melhora a correlação em se considerando as diferentes estruturas hidráulicas responsáveis pela geração do ressalto. 
Tabela 18. Valores de $\gamma$ e $\delta$ para as diferentes condições experimentais no canal A.

\begin{tabular}{c|c|c}
\hline & Vertedor & Comporta \\
\hline$\gamma$ & 3,570 & 4,903 \\
\hline$\delta$ & $-0,37009$ & $-0,9401$ \\
\hline
\end{tabular}

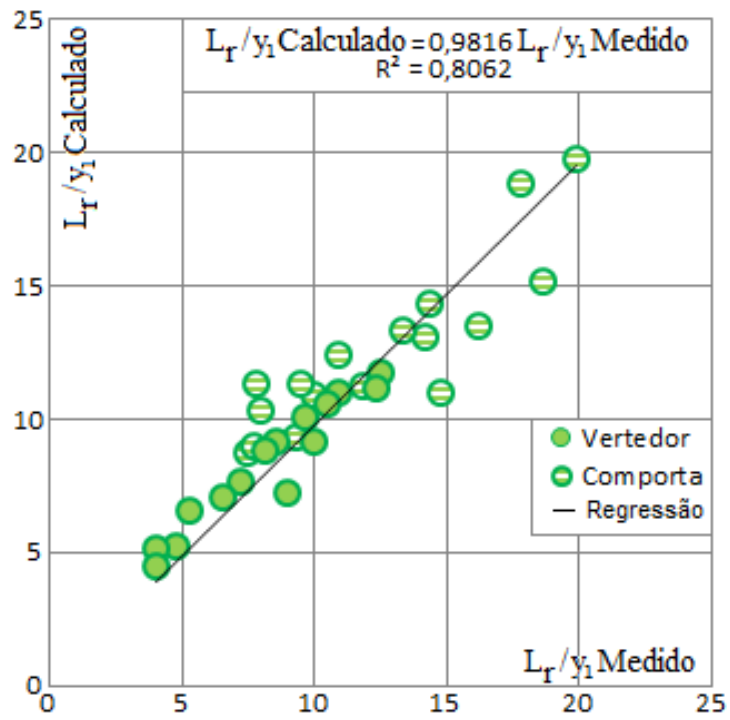

Figura 53. Ajuste para os dados de $L_{r} / y_{1}$ medido e calculado, utilizando os dados da Tab. 18.

Vale a menção do fenômeno observado que se caracterizou pelo aparecimento de ondas laterais nos jatos entre a seção da comporta e do ressalto, como também relatado por Nóbrega (2014), que podem ter influenciado a altura média da profundidade supercrítica e, dessa forma, haver induzido um efeito não computado nas medições de $\mathrm{y}_{1}$ para a comporta. Esta menção é feita no sentido de permitir comparações com outros dados de literatura que eventualmente descrevam o mesmo fenômeno.

Com base nos resultados apresentados, verifica-se que:

i - A solução de Schulz et al. (2015) permite analisar adequadamente as evoluções de $\mathrm{L}_{\mathrm{r}} / \mathrm{y}_{1}$, envolvendo informações de $\mathrm{F}_{1} \mathrm{e}$ informações adicionais das profundidades conjugadas.

ii - Os comportamentos calculados acompanham bem os comportamentos medidos na faixa de números de Froude estudadas, permitindo ajustar os coeficientes $\gamma$ e $\delta$.

iii - A segregação por geometria do tipo de estrutura foi observada. Os valores de $\gamma$ e $\delta$ para as diferentes estruturas de geração de ressaltos hidráulicos no canal A são apresentadas na Tab. 18 no texto. 
iv - A Tab. 18 mostra valores absolutos das constantes maiores para a estrutura hidráulica da comporta do que para a estrutura hidráulica do vertedor.

v - Sugere-se a execução de experimentos específicos, com maior densidade de dados, para melhor quantificar $\gamma$ e $\delta$ para as diferentes condições experimentais, com ênfase para a rugosidade.

\subsubsection{Análise da dissipação de energia}

A dissipação de energia foi obtida em termos da perda de energia relativa $\Delta \mathrm{E} / \mathrm{E}_{1}$ para no canal A, em conjunto com os dados de Nóbrega (2014) para este mesmo canal.

Palermo e Pagliara (2018) buscaram uma relação para a dissipação de energia, em canais com declividade e fundo rugoso, com grande correlação para uma enorme quantidade de dados experimentais. As Eq. (28), (29), (30), (31) e (32) mostram a equação definida pelos autores, considerando o intervalo de número de Froude $F_{1}>1,5$ e declividade no intervalo $0,3 \leq \mathrm{S} \leq 0,15$.

$$
\Delta E_{r}^{*}=\frac{\left(E_{1}-E_{2}\right)}{\left(E_{1}-y_{2}\right)}=\frac{2 \lambda \tan (\alpha)+2(1-Y)+\frac{F_{1}^{2}}{\cos (\alpha)}\left(1-Y^{-2}\right)}{\frac{F_{1}^{2}}{\cos (\alpha)}+2+2 \lambda \tan (\alpha)}
$$

Em que:

$\Delta \mathrm{E}_{\mathrm{r}}^{*}=$ é a perda de energia relativa;

$\alpha=$ ângulo de inclinação no canal;

$\mathrm{Y}=\mathrm{y}_{2} / \mathrm{y}_{1}$ e definido como

$\lambda=4,616(Y-1)$

$Y=\frac{-1+\sqrt{1+8 G_{1}^{2}(1-\beta)}}{2}$

$$
G=3,32^{2,7 S} F_{1}
$$

Para $S \geq 0$

$\beta=-0,14\left[-\exp \left(2,38 \frac{K_{S}}{K}\right)\right]$

$\beta$ representa um déficit de momento

$\mathrm{K}_{\mathrm{s}}$ é a altura dos elementos de rugosidade

$\mathrm{K}$ é a profundidade crítica 
A Tab. 19 apresenta os dados de energia relativa calculada com a Eq. (28). Vale mencionar que, devido a restrição da Eq. (28) para $F_{1}$ maiores que 1,5, dois experimentos PCLH com $\mathrm{F}_{1}=1,37$ e um PVRI com $\mathrm{F}_{1}=1,29$, não foram incluídos na análise.

Tabela 19. Dados de $\Delta \mathrm{E} / \mathrm{E}_{1}$ calculados para o canal A, por meio da Eq (28).

\begin{tabular}{|c|c|c|c|c|c|c|c|c|c|c|c|}
\hline Código & $\begin{array}{c}\mathrm{Q} \\
{[\mathrm{L} / \mathrm{s}]}\end{array}$ & $\mathrm{Fr}$ & $\begin{array}{c}\text { B } \\
{[\mathrm{m}]}\end{array}$ & $\begin{array}{c}\mathrm{y}_{1} \\
{[\mathrm{~cm}]}\end{array}$ & $\begin{array}{c}\mathrm{y}_{2} \\
{[\mathrm{~cm}]}\end{array}$ & $\begin{array}{c}\mathrm{S} \\
{[\%]}\end{array}$ & $\begin{array}{l}\text { Ks } \\
{[\mathrm{m}]}\end{array}$ & $\mathrm{y}_{2} / \mathrm{y}_{1}$ & $\begin{array}{c}\mathrm{v}_{1} \\
{[\mathrm{~m} / \mathrm{s}]}\end{array}$ & $\begin{array}{c}\mathrm{v}_{2} \\
{[\mathrm{~m} / \mathrm{s}]}\end{array}$ & $\Delta \mathrm{E} / \mathrm{E}_{1}$ \\
\hline $\mathrm{NVH}$ & 2,8 & 2,74 & 0,1 & 2,2 & 7,9 & 0 & 0 & 3,59 & 1,27 & 0,35 & 0,215608 \\
\hline $\mathrm{NVH}$ & 3,3 & 2,67 & 0,1 & 2,5 & 8,7 & 0 & 0 & 3,48 & 1,32 & 0,38 & 0,204082 \\
\hline $\mathrm{NVH}$ & 3,7 & 2,52 & 0,1 & 2,8 & 9,5 & 0 & 0 & 3,39 & 1,32 & 0,39 & 0,17896 \\
\hline $\mathrm{NVH}$ & 4,6 & 2,34 & 0,1 & 3,4 & 10,8 & 0 & 0 & 3,18 & 1,35 & 0,43 & 0,148318 \\
\hline $\mathrm{NVH}$ & 5,6 & 2,32 & 0,1 & 3,9 & 12,1 & 0 & 0 & 3,1 & 1,44 & 0,46 & 0,144901 \\
\hline $\mathrm{NVH}$ & 6,5 & 2,04 & 0,1 & 4,7 & 13,5 & 0 & 0 & 2,87 & 1,38 & 0,48 & 0,097626 \\
\hline $\mathrm{NVH}$ & 7,4 & 1,94 & 0,1 & 5,3 & 14,5 & 0 & 0 & 2,74 & 1,4 & 0,51 & 0,081423 \\
\hline $\mathrm{NCH}$ & 1,1 & 3,51 & 0,1 & 1 & 5,9 & 0 & 0 & 5,9 & 1,1 & 0,19 & 0,33068 \\
\hline $\mathrm{NCH}$ & 1,7 & 3,28 & 0,1 & 1,4 & 7,8 & 0 & 0 & 5,57 & 1,21 & 0,22 & 0,298754 \\
\hline $\mathrm{NCH}$ & 4,6 & 2,97 & 0,1 & 2,9 & 13,2 & 0 & 0 & 4,55 & 1,59 & 0,35 & 0,25236 \\
\hline PVLH & 2,8 & 2,02 & 0,1 & 2,7 & 9,1 & 0 & 0 & 3,37 & 1,04 & 0,31 & 0,094341 \\
\hline PVLH & 4,8 & 1,92 & 0,1 & 4 & 11,2 & 0 & 0 & 2,8 & 1,2 & 0,43 & 0,078258 \\
\hline PCLH & 2,5 & 2,51 & 0,1 & 1,8 & 6,7 & 0 & 0 & 3,72 & 1,06 & 0,37 & 0,177268 \\
\hline PCLH & 2,7 & 2,6 & 0,1 & 2 & 7,4 & 0 & 0 & 3,7 & 1,15 & 0,36 & 0,192423 \\
\hline PVRH & 2,8 & 2,45 & 0,1 & 2,2 & 8,1 & 0 & 0,012 & 3,68 & 1,14 & 0,35 & 0,210781 \\
\hline PVRH & 4,8 & 2,47 & 0,1 & 2,3 & 8,4 & 0 & 0,012 & 3,65 & 1,17 & 0,57 & 0,197892 \\
\hline PCRH & 2,3 & 1,98 & 0,1 & 2,4 & 7,3 & 0 & 0,012 & 3,04 & 0,958 & 0,32 & 0,137273 \\
\hline PCRH & 2,5 & 1,9 & 0,1 & 2,6 & 8 & 0 & 0,012 & 3,08 & 0,962 & 0,31 & 0,11985 \\
\hline PCRH & 2,7 & 1,84 & 0,1 & 2,8 & 8,9 & 0 & 0,012 & 3,18 & 0,964 & 0,3 & 0,106749 \\
\hline PVLI & 2,8 & 2,4 & 0,1 & 2,4 & 11 & 0,035 & 0 & 4,58 & 1,17 & 0,25 & 0,156217 \\
\hline PVLI & 4,8 & 2,45 & 0,1 & 3,4 & 14,4 & 0,035 & 0 & 4,24 & 1,41 & 0,33 & 0,164393 \\
\hline PVRI & 2,8 & 1,56 & 0,1 & 3,2 & 10,9 & 0,035 & 0,012 & 3,41 & 0,875 & 0,26 & 0,062083 \\
\hline PCLI & 1,9 & 2,51 & 0,1 & 1,8 & 9,5 & 0,035 & 0 & 5,28 & 1,06 & 0,2 & 0,174143 \\
\hline PCLI & 2,3 & 2,8 & 0,1 & 1,9 & 10 & 0,035 & 0 & 5,26 & 1,21 & 0,23 & 0,219969 \\
\hline PCLI & 2,5 & 2,62 & 0,1 & 2,1 & 11 & 0,035 & 0 & 5,24 & 1,19 & 0,23 & 0,191805 \\
\hline PCLI & 2,7 & 2,64 & 0,1 & 2,2 & 11,5 & 0,035 & 0 & 5,23 & 1,23 & 0,23 & 0,194982 \\
\hline PCRI & 1,9 & 2,14 & 0,1 & 2 & 8,2 & 0,035 & 0,012 & 4,1 & 0,95 & 0,23 & 0,173626 \\
\hline PCRI & 2,3 & 2,41 & 0,1 & 2,1 & 9,2 & 0,035 & 0,012 & 4,38 & 1,1 & 0,25 & 0,208293 \\
\hline PCRI & 2,7 & 2,32 & 0,1 & 2,4 & 10,9 & 0,035 & 0,012 & 4,54 & 1,13 & 0,25 & 0,186414 \\
\hline
\end{tabular}


Tendo-se como base os agrupamentos feitos anteriormente nos itens 5.1.2 e 5.1.3, em estrutura hidráulica formadora do ressalto (comporta ou vertedor) e declividade ou horizontal,

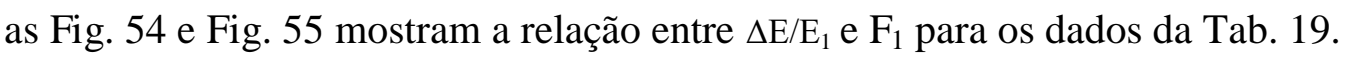

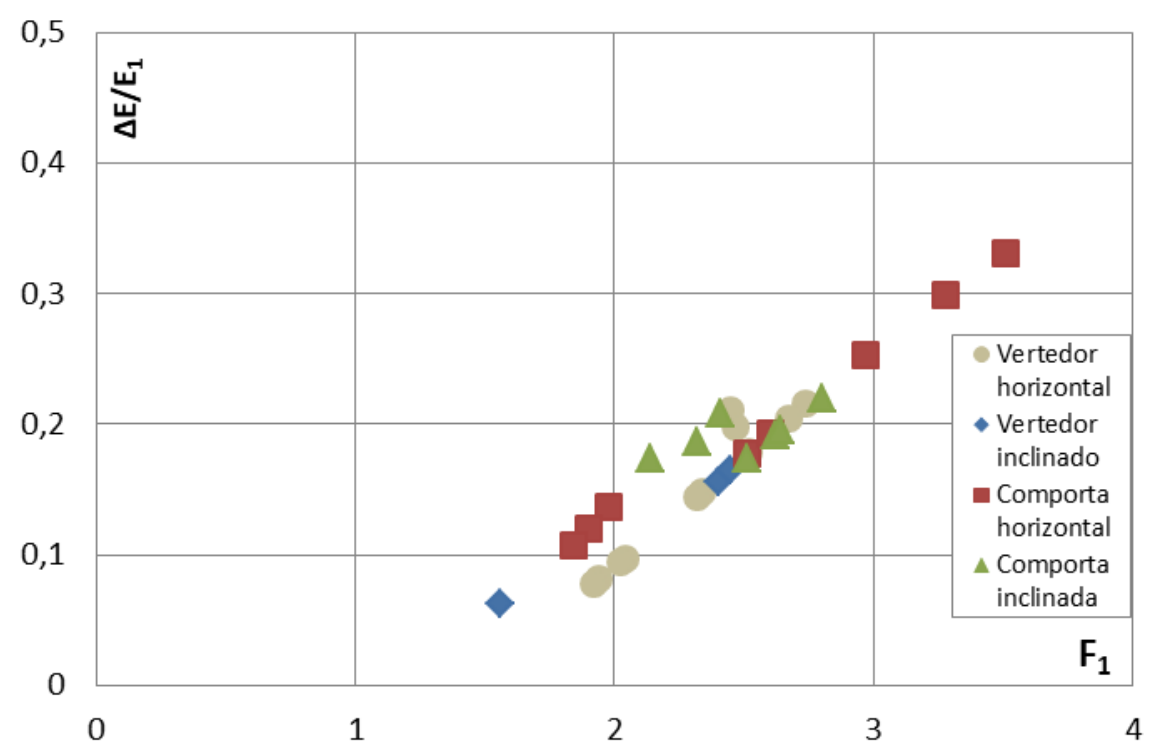

Figura 54. Energia relativa por $F_{1}$ para vertedor horizontal (liso e rugoso), vertedor inclinado (liso e rugoso), comporta horizontal (liso e rugoso) e comporta inclinada (liso e rugoso), utilizando os dados da Tab. 19.

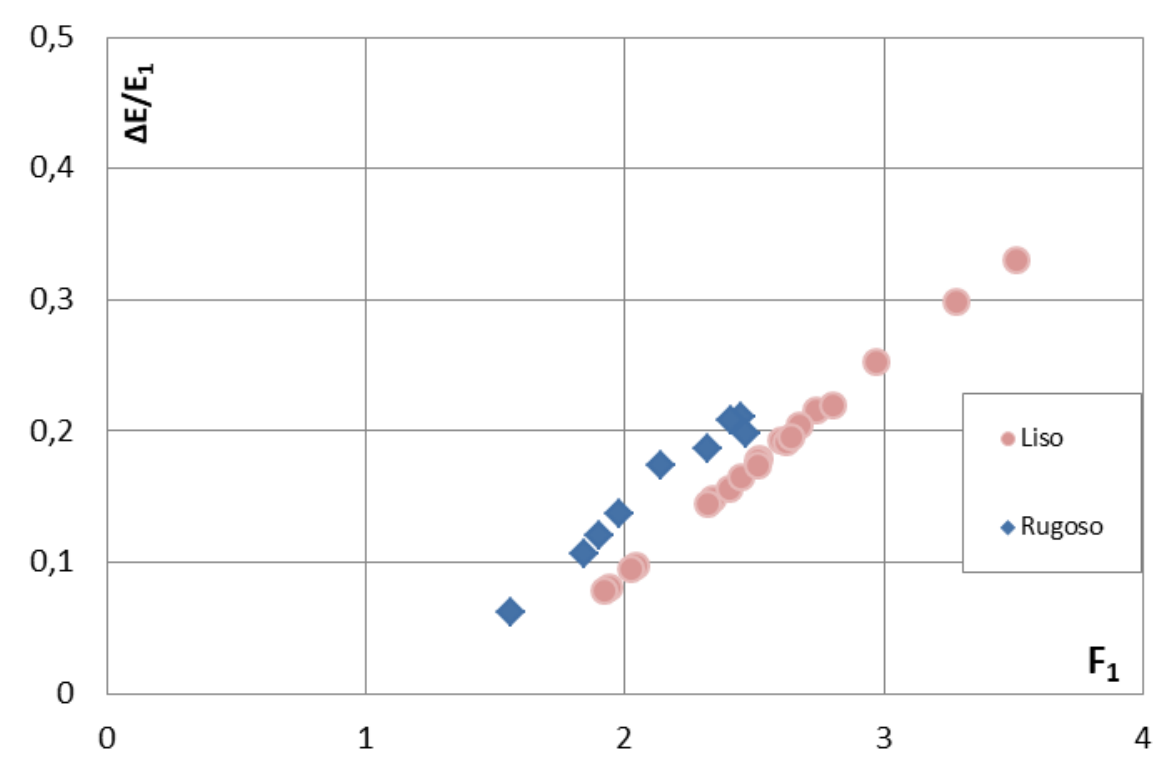

Figura 55. Energia relativa por $F_{1}$ para liso e rugoso, utilizando os dados da Tab. 19. 
Com base nos resultados apresentados, verifica-se que:

$\mathrm{i}$ - O comportamento entre $\Delta \mathrm{E} / \mathrm{E}_{1}$ e $\mathrm{F}_{1}$ se mostrou plausível, sendo a energia dissipada diretamente proporcional ao número de Froude supercrítico.

ii - Os comportamentos de $\Delta \mathrm{E} / \mathrm{E}_{1}$ calculados por formulação simples, derivada da equação Bélanger, Eq. (14), não se mostraram adequados e não foi incluído nos resultados, apresentando incongruências como valores de $\Delta \mathrm{E} / \mathrm{E}_{1}$ negativos ou relativamente altos.

iii - É possível observar na Fig. 53 uma segregação por rugosidade. Isso se deve a formulação da $\mathrm{Eq}$ (32), que considera um déficit de momento.

iv - Sugere-se a execução de experimentos específicos, com maior densidade de dados e faixa de número de Froude, para melhor quantificar o efeito das diferentes condições experimentais na dissipação de energia.

\subsection{CANAL B}

\subsubsection{Dados medidos de y2/yl e Lr/yl}

Inicialmente foram realizados experimentos com o fundo do canal B sem rugosidade (sem bricks Lego) a fim de permitir a posterior comparação entre as dissipações de energia com e sem rugosidade adicional no fundo. Os experimentos foram conduzidos para vazões de 20, 25, 30, 35 e 40 L/s. Esta escolha permitiu comparar os presentes dados com aqueles obtidos por Nóbrega (2014) no mesmo canal, embora apenas três experimentos para canal liso e vazões de 21,31 e $40 \mathrm{~L} / \mathrm{s}$ tenham sido realizados pela autora citada. A Tab. 20 mostra o resumo dos experimentos para o canal com fundo "liso" considerando as profundidades conjugadas e o comprimento do rolo. Vale mencionar que também foram efetuadas análises para a energia dissipada no ressalto, apresentadas no item 5.2.3.

Tabela 20. Variáveis relevantes medidas e $\mathrm{y}_{2} / \mathrm{y}_{1}$ e $\mathrm{L}_{\mathrm{r}} / \mathrm{y}_{1}$ medidos e calculados.

\begin{tabular}{|c|c|c|c|c|c|c|c|c|c|c|c|c|c|}
\hline Código & $\begin{array}{c}\mathrm{Q} \\
\mathrm{m}^{3} / \mathrm{s}\end{array}$ & $\mathrm{F} 1$ & $\begin{array}{c}\mathrm{B} \\
\mathrm{m}\end{array}$ & $\begin{array}{c}\mathrm{y}_{1} \\
\mathrm{~cm}\end{array}$ & $\begin{array}{c}\mathrm{y}_{2} \\
\mathrm{~cm}\end{array}$ & $\begin{array}{c}\mathrm{L}_{\mathrm{r}} \\
\mathrm{cm}\end{array}$ & $\begin{array}{c}\text { Material } \\
\text { no } \\
\text { fundo }\end{array}$ & $\begin{array}{c}\mathrm{y}_{2} / \mathrm{y}_{1} \\
\text { Exp. }\end{array}$ & $\begin{array}{c}\mathrm{v}_{1} \\
\mathrm{~m} / \mathrm{s}\end{array}$ & $\begin{array}{c}\mathrm{v}_{2} \\
\mathrm{~m} / \mathrm{s}\end{array}$ & $\begin{array}{c}\mathrm{L}_{\mathrm{r}} / \mathrm{y}_{1} \\
\text { Exp. }\end{array}$ & $\begin{array}{c}\mathrm{y}_{2} / \mathrm{y}_{1} \\
\text { Calc. }\end{array}$ & $\begin{array}{c}\mathrm{L}_{\mathrm{r}} / \mathrm{y}_{1} \\
\text { Calc. }\end{array}$ \\
\hline $\mathrm{J}-1$ & 0,021 & 4,14 & 0,41 & 2,5 & 14,2 & 53 & - & 5,68 & 2,05 & 0,361 & 21,22 & 5,77 & 21,05 \\
\hline $\mathrm{J}-2$ & 0,031 & 3,69 & 0,41 & 3,5 & 17,4 & 62 & - & 4,97 & 2,16 & 0,435 & 17,85 & 5,28 & 18,54 \\
\hline $\mathrm{J}-3$ & 0,040 & 2,79 & 0,41 & 5,0 & 21,4 & 64 & - & 4,28 & 1,95 & 0,456 & 12,88 & 4,09 & 14,21 \\
\hline $\mathrm{CB}-1$ & 0,020 & 3,34 & 0,41 & 2,8 & 14,4 & 54 & - & 5,14 & 1,75 & 0,340 & 19,29 & 4,75 & 18,10 \\
\hline $\mathrm{CB}-2$ & 0,025 & 3,57 & 0,41 & 3,1 & 16,1 & 58 & - & 5,19 & 1,97 & 0,379 & 18,71 & 5,07 & 18,84 \\
\hline $\mathrm{CB}-3$ & 0,030 & 3,15 & 0,41 & 3,8 & 17,4 & 60 & - & 4,58 & 1,93 & 0,421 & 15,79 & 4,58 & 16,17 \\
\hline $\mathrm{CB}-4$ & 0,035 & 3,07 & 0,41 & 4,3 & 19,0 & 66 & - & 4,42 & 1,99 & 0,451 & 15,35 & 4,48 & 15,50 \\
\hline $\mathrm{CB}-5$ & 0,040 & 2,78 & 0,41 & 5,0 & 20,0 & 74 & - & 4,00 & 1,95 & 0,487 & 14,80 & 4,12 & 13,53 \\
\hline CB-6 & 0,020 & 2,73 & 0,41 & 3,2 & 13,3 & 48 & Borr. & 4,16 & 1,53 & 0,367 & 15,00 & 3,87 & 15,24 \\
\hline
\end{tabular}




\begin{tabular}{|c|l|l|l|l|l|l|l|l|l|l|l|l|l|}
\hline CB-7 & 0,025 & 2,85 & 0,41 & 3,6 & 14,9 & 58 & Borr. & 4,14 & 1,69 & 0,409 & 16,11 & 4,02 & 15,74 \\
\hline CB-8 & 0,030 & 3,03 & 0,41 & 3,9 & 16,4 & 65 & Borr. & 4,21 & 1,88 & 0,446 & 16,67 & 4,33 & 16,74 \\
\hline CB-9 & 0,035 & 3,07 & 0,41 & 4,3 & 18,2 & 70 & Borr. & 4,23 & 1,99 & 0,470 & 16,28 & 4,39 & 16,96 \\
\hline CB-10 & 0,040 & 3,05 & 0,41 & 4,7 & 19,0 & 80 & Borr. & 4,04 & 2,07 & 0,512 & 17,02 & 4,22 & 16,37 \\
\hline CB-11 & 0,020 & 3,94 & 0,41 & 2,5 & 12,8 & 50 & LEGO1 & 5,12 & 1,96 & 0,383 & 20,00 & 5,16 & 19,26 \\
\hline CB-12 & 0,025 & 3,57 & 0,41 & 3,1 & 14,8 & 56 & LEGO1 & 4,77 & 1,97 & 0,412 & 18,06 & 4,70 & 19,32 \\
\hline CB-13 & 0,030 & 3,42 & 0,41 & 3,6 & 16,3 & 60 & LEGO1 & 4,53 & 2,03 & 0,449 & 16,67 & 4,49 & 17,99 \\
\hline CB-14 & 0,035 & 3,42 & 0,41 & 4,0 & 17,6 & 68 & LEGO1 & 4,40 & 2,14 & 0,486 & 17,00 & 4,40 & 17,22 \\
\hline CB-15 & 0,040 & 2,95 & 0,41 & 4,8 & 18,4 & 78 & LEGO1 & 3,83 & 2,03 & 0,529 & 16,25 & 3,93 & 13,49 \\
\hline CB-16 & 0,020 & 3,53 & 0,41 & 2,7 & 12,7 & 35 & LEGO2 & 4,70 & 1,82 & 0,386 & 12,96 & 4,62 & 14,98 \\
\hline CB-17 & 0,025 & 3,57 & 0,41 & 3,1 & 14,8 & 44 & LEGO2 & 4,77 & 1,97 & 0,412 & 14,19 & 4,73 & 15,53 \\
\hline CB-18 & 0,030 & 3,42 & 0,41 & 3,6 & 15,6 & 55 & LEGO2 & 4,33 & 2,03 & 0,469 & 15,28 & 4,20 & 13,30 \\
\hline CB-19 & 0,035 & 3,69 & 0,41 & 3,8 & 17,3 & 64 & LEG02 & 4,55 & 2,25 & 0,495 & 16,84 & 4,71 & 16,74 \\
\hline CB-20 & 0,040 & 3,61 & 0,41 & 4,2 & 18,9 & 72 & LEGO2 & 4,50 & 2,32 & 0,515 & 17,15 & 4,57 & 15,67 \\
\hline CB-21 & 0,020 & 3,53 & 0,41 & 2,7 & 12,6 & 33 & LEG03 & 4,67 & 1,82 & 0,389 & 12,22 & 4,54 & 13,19 \\
\hline CB-22 & 0,025 & 3,94 & 0,41 & 2,9 & 14,3 & 37 & LEGO3 & 4,93 & 2,10 & 0,426 & 12,79 & 4,99 & 12,51 \\
\hline CB-23 & 0,030 & 3,42 & 0,41 & 3,6 & 16,2 & 44 & LEG03 & 4,50 & 2,03 & 0,452 & 12,22 & 4,45 & 12,97 \\
\hline CB-24 & 0,035 & 2,77 & 0,41 & 4,6 & 17,8 & 51 & LEG03 & 3,87 & 1,86 & 0,481 & 11,09 & 3,74 & 11,49 \\
\hline CB-25 & 0,040 & 3,25 & 0,41 & 4,5 & 18,6 & 64 & LEGO3 & 4,13 & 2,16 & 0,523 & 14,22 & 4,33 & 12,27 \\
\hline CB-26 & 0,030 & 3,42 & 0,41 & 3,6 & 15,6 & 38 & LEGO4 & 4,33 & 2,03 & 0,469 & 10,56 & 4,27 & 12,24 \\
\hline CB-27 & 0,035 & 3,55 & 0,41 & 3,9 & 17,1 & 47 & LEGO4 & 4,38 & 2,20 & 0,501 & 12,05 & 4,44 & 11,24 \\
\hline CB-28 & 0,040 & 3,25 & 0,41 & 4,5 & 18,0 & 60 & LEGO4 & 4,00 & 2,16 & 0,541 & 13,33 & 4,01 & 12,40 \\
\hline
\end{tabular}

Na Tab. 20 os códigos J-1, J-2 e J-3 referem-se aos três experimentos em canal liso efetuados por Nóbrega (2014). Na coluna "Material de fundo" o hífen “-” representa canal liso, o termo "Borr." representa o canal revestido com borracha anti-derrapante e os termos "LEGO 1, 2, 3 e 4" representam as quatro diferentes configurações de bricks Lego no fundo do canal.

No item 4.2.2.5 foi feita uma descrição dos tipos de rugosidade adotados no presente estudo. Para o Canal B, as rugosidades utilizadas podem ser assim descritas:

Canal Liso: O material com revestimento em argamassa de cimento e areia.

Material antiderrapante (borracha): como observado na Fig. 27, as placas de borracha antiderrapante possuem uma rugosidade constituída de protuberâncias circulares com $2 \mathrm{~mm}$ de altura, com diâmetro de 20 mm e distância de 29,4 mm entre centros de círculos vizinhos. A disposição dos círculos gera uma malha retangular de pontos centrais equidistantes.

Lego 1: como observado na Fig. 29, os bricks geram uma rugosidade de protuberâncias com dimensões com 11,2 mm de altura (12,8 mm com botão de encaixe), 16 $\mathrm{mm}$ de largura e $32 \mathrm{~mm}$ de comprimento. A distância entre centros de bricks vizinhos foi de $75 \mathrm{~mm}$ no sentido longitudinal e 110,5 mm no sentido transversal. A disposição dos bricks gera uma malha retangular de bricks alinhados. 
Lego 2: como observado na Fig. 30, os bricks geram uma rugosidade de protuberâncias com dimensões com 11,2 mm de altura (12,8 mm com botão de encaixe), 16 mm de largura e $32 \mathrm{~mm}$ de comprimento. A distância entre centros de bricks vizinhos foi de $150 \mathrm{~mm}$ no sentido longitudinal e $80 \mathrm{~mm}$ no sentido transversal. A disposição dos bricks gera uma malha retangular de bricks intercalados.

Lego 3: como observado na Fig. 31, os bricks geram uma rugosidade de protuberâncias com dimensões com 11,2 $\mathrm{mm}$ de altura (12,8 mm com botão de encaixe), 16 mm de largura e $32 \mathrm{~mm}$ de comprimento. A distância entre centros de bricks vizinhos foi de $150 \mathrm{~mm}$ no sentido longitudinal e $64 \mathrm{~mm}$ no sentido transversal. A disposição dos bricks gera uma malha retangular de bricks intercalados.

Lego 4: Os bricks geram uma rugosidade de protuberâncias com dimensões com 20,8 $\mathrm{mm}$ de altura (22,4 $\mathrm{mm}$ com botão de encaixe), $16 \mathrm{~mm}$ de largura e $32 \mathrm{~mm}$ de comprimento. A distância entre centros de bricks vizinhos foi de $150 \mathrm{~mm}$ no sentido longitudinal e $64 \mathrm{~mm}$ no sentido transversal. A disposição dos bricks gera uma malha retangular de bricks intercalados.

Vale ressaltar que em todos os experimentos com peças Lego, o maior comprimento da base dos bricks $(32 \mathrm{~mm})$ estava alinhado com a seção transversal. As malhas para as configurações de fundo rugoso são apresentadas na Fig. 56. 


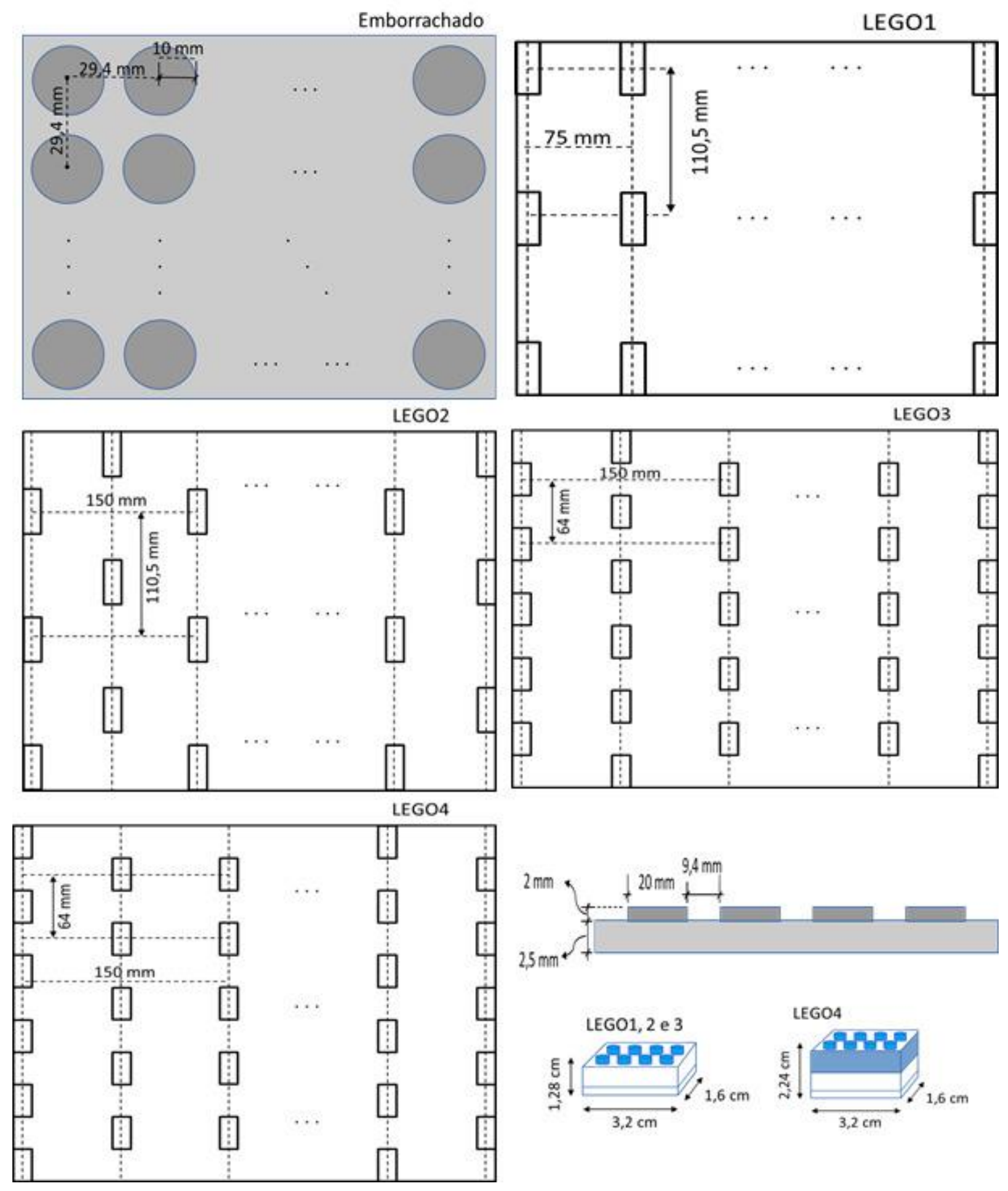

Figura 56. Malhas das diferentes configurações de fundo rugoso para o canal B.

Foram feitos registros da posição média da superfície livre para todos os experimentos. A Fig. 57 e Fig. 58 mostram a evolução da superfície para os experimentos CB - 1 a 5 e $\mathrm{CB}-6$ a 10, respectivamente. Registros semelhantes foram feitos para cada experimento, constituindo a informação essencial para a análise das características dos ressaltos hidráulicos aqui gerados. 


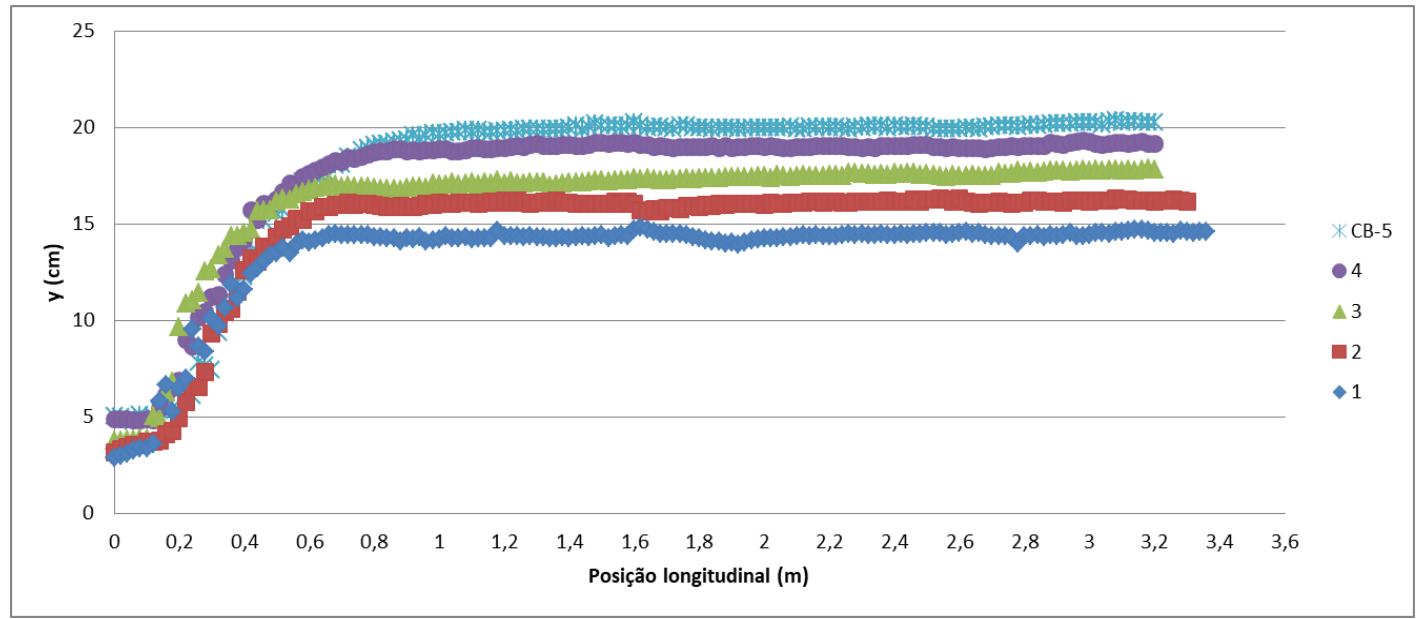

Figura 57. Diferentes evoluções da superfície da água para o canal liso.

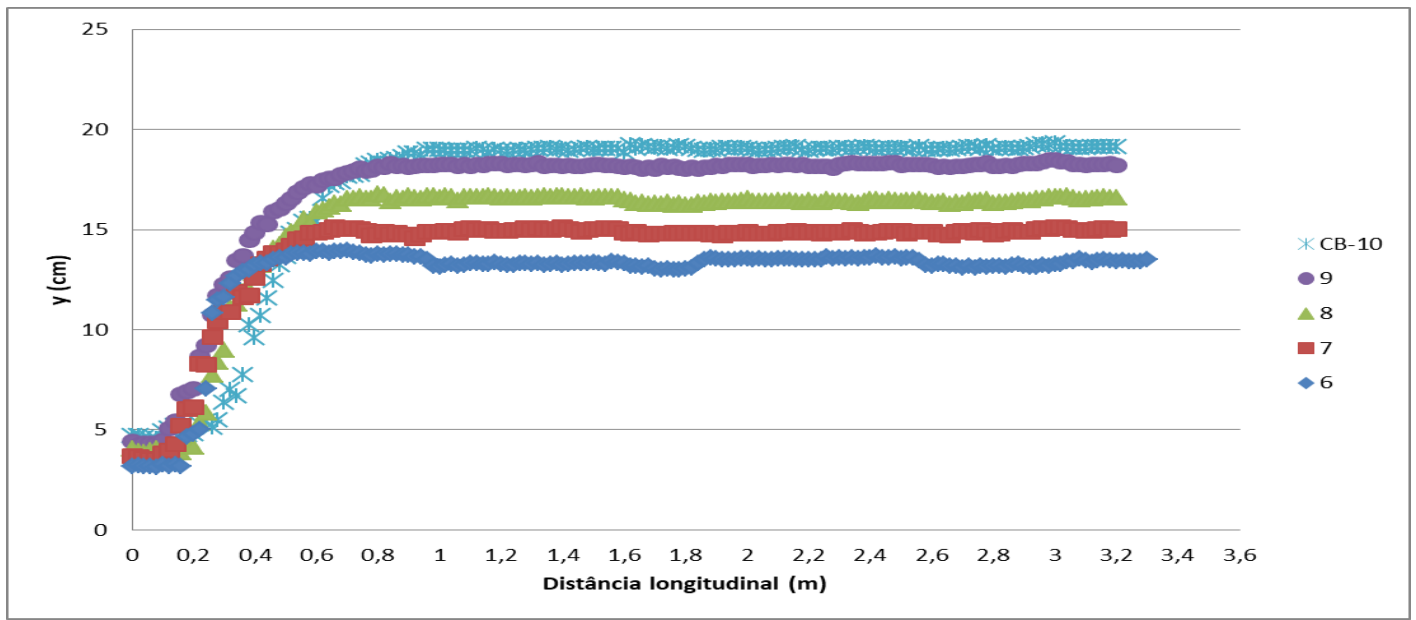

Figura 58. Diferentes evoluções da superfície da água para com material emborrachado.

As Fig. 57 e Fig. 58 permitem observar a esperada influência da vazão no estabelecimento das profundidades conjugadas. Visualmente observa-se que a presença da rugosidade do material anti-derrapante produziu profundidades $y_{2}$ ligeiramente menores que para o caso liso.

\subsubsection{Profundidades conjugadas $y_{2} / y_{1}$}

Os dados da Tab. 20 foram analisados utilizando a Eq. (24) para o cálculo dos coeficientes $\alpha$ e $\beta$. Os dados dos experimentos do canal liso, $\mathrm{J}-1$ a 3 e $\mathrm{CB}-1$ a 5 , foram analisados em conjunto. Os dados seguintes, CB - 6 a 10, CB - 11 a 15, CB - 16 a 20, CB 21 a 25 e CB - 26 a 28 foram analisados cada qual separadamente, por constituírem rugosidades diferentes entre si. 
A Fig. 59 mostra a comparação entre os resultados medidos e os resultados calculados após o ajuste dos coeficientes $\alpha$ e $\beta$, sem fazer a discriminação entre os diferentes grupos de rugosidade.

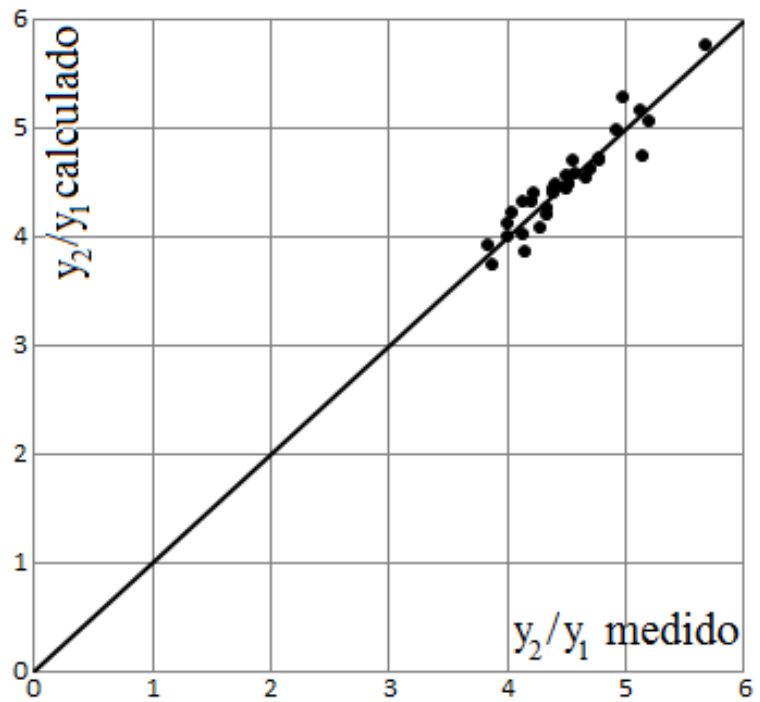

Figura 59. Razões $\mathrm{y}_{2} / \mathrm{y}_{1}$ medidas e calculadas, sem distinção de experimentos.

A Fig. 60 mostra os resultados da razão entre as profundidades conjugadas medidas e calculadas, graficados em relação ao número de Froude supercrítico $\left(\mathrm{F}_{1}\right)$, em conjunto com as previsões da equação de Bélanger.

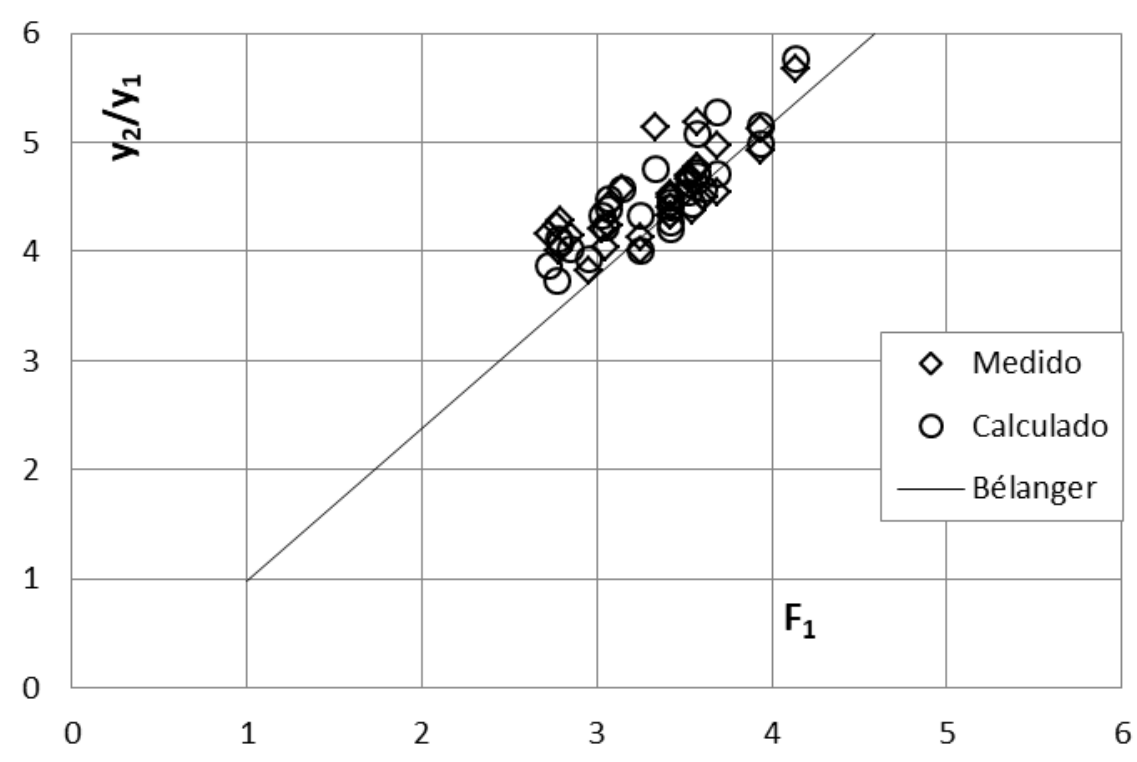

Figura 60. Razões $\mathrm{y}_{2} / \mathrm{y}_{1}$ medidas e calculadas sem distinção de experimentos e equação de Bélanger em relação a $\mathrm{F}_{1}$. 
As Fig. 59 e Fig. 60 mostram que a Eq. (24) reproduz os dados medidos. Notadamente a Fig. 60 mostra boa reprodução para características de rugosidade que geram comportamentos distintos dos demais grupos experimentais. As Fig. 61 e Fig. 62 mostram os mesmos resultados das Fig. 59 e Fig. 60, respectivamente, considerando a distinção dos diferentes tipos de rugosidade.

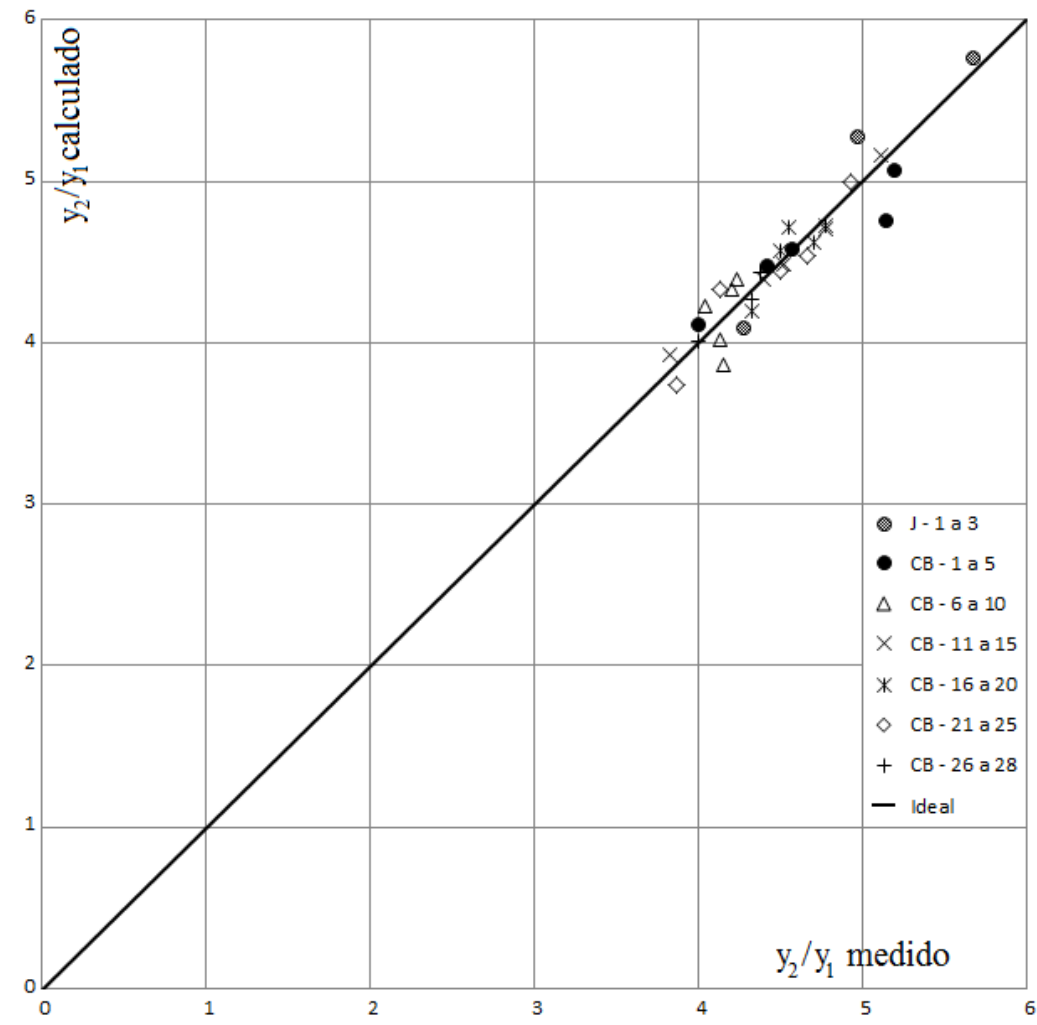

Figura 61. Razões $\mathrm{y}_{2} / \mathrm{y}_{1}$ medidas e calculadas fazendo a distinção de experimentos. 


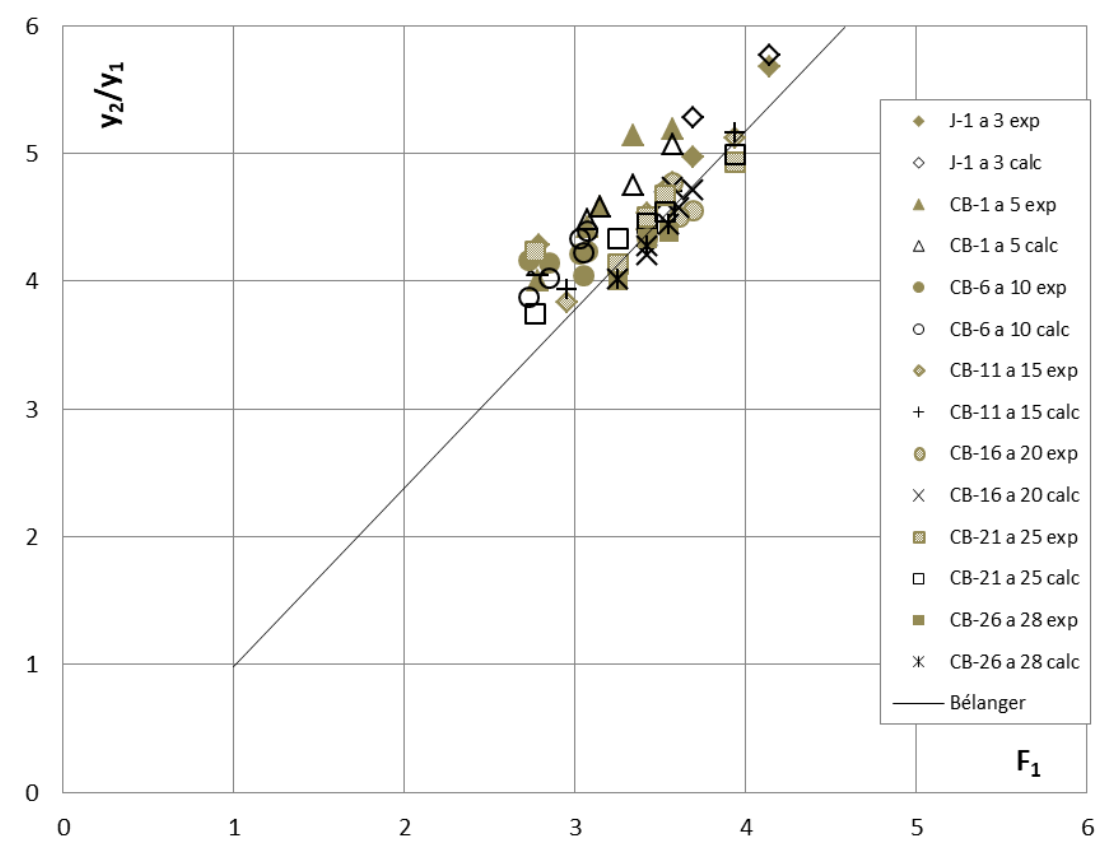

Figura 62. Razões $\mathrm{y}_{2} / \mathrm{y}_{1}$ medidas e calculadas com distinção de experimentos e equação de Bélanger em relação da $F_{1}$.

\subsubsection{1. $\quad$ Valores de $\alpha$ e $\beta$}

A Tabela 21 mostra os valores de $\alpha$ e $\beta$ obtidos para os dados da Tabela 20. Observase que os valores para canal liso, Lego 1 e Lego 3 mostram valores que guardam uma relação de semelhança maior entre si. Para esses experimentos os números de Froude alcançados com as vazões preestabelecidas mostraram variações maiores.

Tabela 21. $\alpha$ e $\beta$ obtidos e variação experimental do número de Froude.

\begin{tabular}{l|r|c|c}
\hline & \multicolumn{1}{|c|}{$\alpha$} & $\beta$ & $\Delta \mathrm{F}_{1}$ \\
\hline Liso & $-0,07533$ & 2,795727 & 1,36 \\
\hline Borr. & 0,376915 & $-1,16218$ & 0,331 \\
\hline LEGO 1 & 0,00691 & 1,650448 & 0,99 \\
\hline LEGO 2 & 0,2815 & $-0,93297$ & 0,441 \\
\hline LEGO 3 & $-0,16287$ & 3,210116 & 1,06 \\
\hline LEGO 4 & 0,047574 & 1,142087 & 0,384 \\
\hline
\end{tabular}

Observa-se que o tipo de rugosidade afeta os coeficientes da equação para a razão entra as profundidades conjugadas. Considerando os experimentos em que houve variação acima de 0,5 para número de Froude supercrítico (experimentos para canal liso, Lego 1 e Lego 3), as curvas traçadas com os valors de $\alpha$ e $\beta$ mostram uma evolução muito compatível com as medidas feitas. A Fig. 63 mostra as curvas teóricas e os dados experimentais. Evitou- 
se utilizar na análise comparativa da evolução das curvas, aquelas funções obtidas com excessivamente pequenas variações de $\mathrm{F}_{1}\left(\Delta \mathrm{F}_{1}=0,331,0,384\right.$ e 0,441 , portanto todas menores que 0,5$)$, evitando que a dispersão de dados em torno de um valor quase "pontual" de $F_{1}$ interferisse na visualização dos resultados globais.

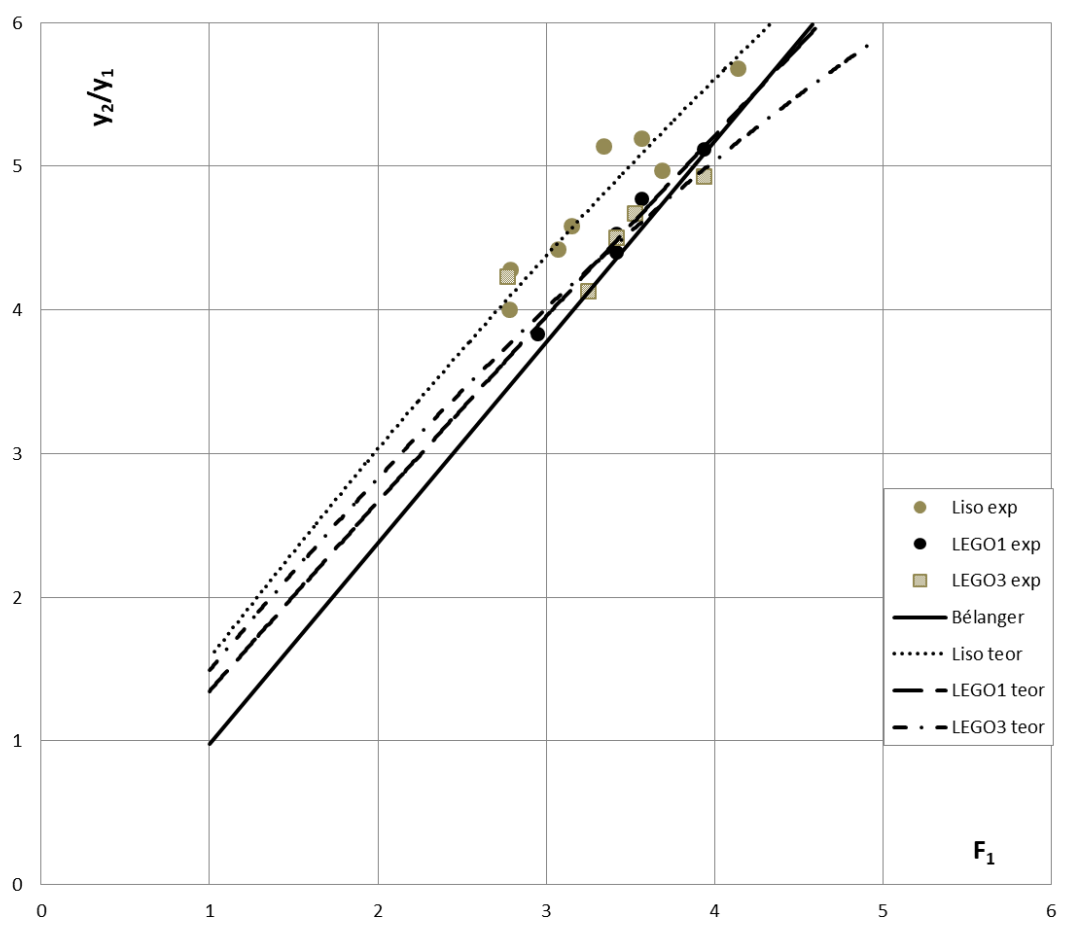

Figura 63. Dados experimentais e curvas teóricas obtidas com os valores de $\alpha$ e $\beta$ ajustados para a equação (24).

Para quantificar o efeito da rugosidade no fundo do canal, Maatooq e Taleb (2018) consideraram o uso do adimensional $I$, chamado de percentual de intensidade da rugosidade e definido de acordo com a Eq. (28).

$$
I=100 \frac{A N}{B X_{r}} \quad \text { Eq. } 28
$$

Em que: $\mathrm{I}=$ percentual de intensidade da rugosidade

$\mathrm{A}=$ área projetada de um elemento de rugosidade

$\mathrm{N}=$ número de elementos de rugosidade

$\mathrm{B}=$ largura do canal

$\mathrm{X}_{\mathrm{r}}=$ comprimento da extensão rugosa

A intensidade de rugosidade pode ser entendida como uma "densidade" em termos de área, entre a área plana ocupada pelos elementos de rugosidade no fundo do canal dividida pela área total em que esses elementos ficam compreendidos, para uma extensão $X_{\mathrm{r}}$ de elementos, num canal com largura B. 
A Tab. 22 mostra as características geométricas para cada tipo de fundo rugoso no canal B, considerando as informações da Tab. 4, Fig. 52 e usando a Eq (28).

Tabela 22. Características geométricas dos diferentes fundos rugosos para o canal B.

\begin{tabular}{|c|c|c|c|c|c|c|c|c|c|c|}
\hline Código & $\mathrm{N}$ & $\begin{array}{l}\mathrm{I} \\
\%\end{array}$ & $\begin{array}{c}\mathrm{a} \\
\mathrm{mm}\end{array}$ & $\begin{array}{c}\mathrm{b} \\
\mathrm{mm}\end{array}$ & $\begin{array}{c}\mathrm{C} \\
\mathrm{mm}\end{array}$ & $c / a$ & $\mathrm{~b} / \mathrm{a}$ & $\begin{array}{c}\text { № de } \\
\text { linhas } \\
\text { na } \\
\text { malha }\end{array}$ & $\begin{array}{c}\text { № de } \\
\text { colunas } \\
\text { na } \\
\text { malha }\end{array}$ & $\begin{array}{c}\text { Rugosi- } \\
\text { dade }\end{array}$ \\
\hline CB-6 & 1326 & 33,87 & 2 & 20 & 20 & 10 & 10 & 13 & 17 & Borr. \\
\hline CB-7 & 1326 & 33,87 & 1 & 21 & 21 & 21 & 21 & 13 & 17 & Borr. \\
\hline CB-8 & 1326 & 33,87 & 1 & 21 & 21 & 21 & 21 & 13 & 17 & Borr. \\
\hline CB-9 & 1326 & 33,87 & 1 & 21 & 21 & 21 & 21 & 13 & 17 & Borr. \\
\hline CB-10 & 1326 & 33,87 & 1 & 21 & 21 & 21 & 21 & 13 & 17 & Borr. \\
\hline CB-11 & 120 & 5,08 & 12,8 & 32 & 16 & 1,25 & 2,5 & 3 & 40 & LEG01 \\
\hline CB-12 & 120 & 5,08 & 12,8 & 32 & 16 & 1,25 & 2,5 & 3 & 40 & LEGO1 \\
\hline CB-13 & 120 & 5,08 & 12,8 & 32 & 16 & 1,25 & 2,5 & 3 & 40 & LEGO1 \\
\hline CB-14 & 120 & 5,08 & 12,8 & 32 & 16 & 1,25 & 2,5 & 3 & 40 & LEGO1 \\
\hline CB-15 & 120 & 5,08 & 12,8 & 32 & 16 & 1,25 & 2,5 & 3 & 40 & LEGO1 \\
\hline CB-16 & 120 & 5,08 & 12,8 & 32 & 16 & 1,25 & 2,5 & 3 & 40 & LEGO2 \\
\hline CB-17 & 120 & 5,08 & 12,8 & 32 & 16 & 1,25 & 2,5 & 3 & 40 & LEGO2 \\
\hline CB-18 & 120 & 5,08 & 12,8 & 32 & 16 & 1,25 & 2,5 & 3 & 40 & LEGO2 \\
\hline CB-19 & 120 & 5,08 & 12,8 & 32 & 16 & 1,25 & 2,5 & 3 & 40 & LEGO2 \\
\hline CB-20 & 120 & 5,08 & 12,8 & 32 & 16 & 1,25 & 2,5 & 3 & 40 & LEGO2 \\
\hline CB-21 & 165 & 9,47 & 12,8 & 32 & 16 & 1,25 & 2,5 & 11 & 15 & LEGO3 \\
\hline CB-22 & 165 & 9,47 & 12,8 & 32 & 16 & 1,25 & 2,5 & 11 & 15 & LEGO3 \\
\hline CB-23 & 165 & 9,47 & 12,8 & 32 & 16 & 1,25 & 2,5 & 11 & 15 & LEGO3 \\
\hline CB-24 & 165 & 9,47 & 12,8 & 32 & 16 & 1,25 & 2,5 & 11 & 15 & LEGO3 \\
\hline CB-25 & 165 & 9,47 & 12,8 & 32 & 16 & 1,25 & 2,5 & 11 & 15 & LEGO3 \\
\hline CB-26 & 165 & 9,47 & 22,4 & 32 & 16 & 0,71 & 1,43 & 11 & 15 & LEGO4 \\
\hline CB-27 & 165 & 9,47 & 22,4 & 32 & 16 & 0,71 & 1,43 & 11 & 15 & LEGO4 \\
\hline CB-28 & 165 & 9,47 & 22,4 & 32 & 16 & 0,71 & 1,43 & 11 & 15 & LEGO4 \\
\hline
\end{tabular}

$a, b, c$ são as dimensões de altura, largura transversal e comprimento, respectivamente, dos elementos do fundo rugoso no canal B. 
A Fig. 64 mostra os resultados da razão entre as profundidades conjugadas medidas e calculadas, graficados em relação ao número de Froude supercrítico $\left(\mathrm{F}_{1}\right)$, em conjunto com as previsões da equação de Bélanger, separados por grupos de dados com diferentes intensidades de rugosidade.

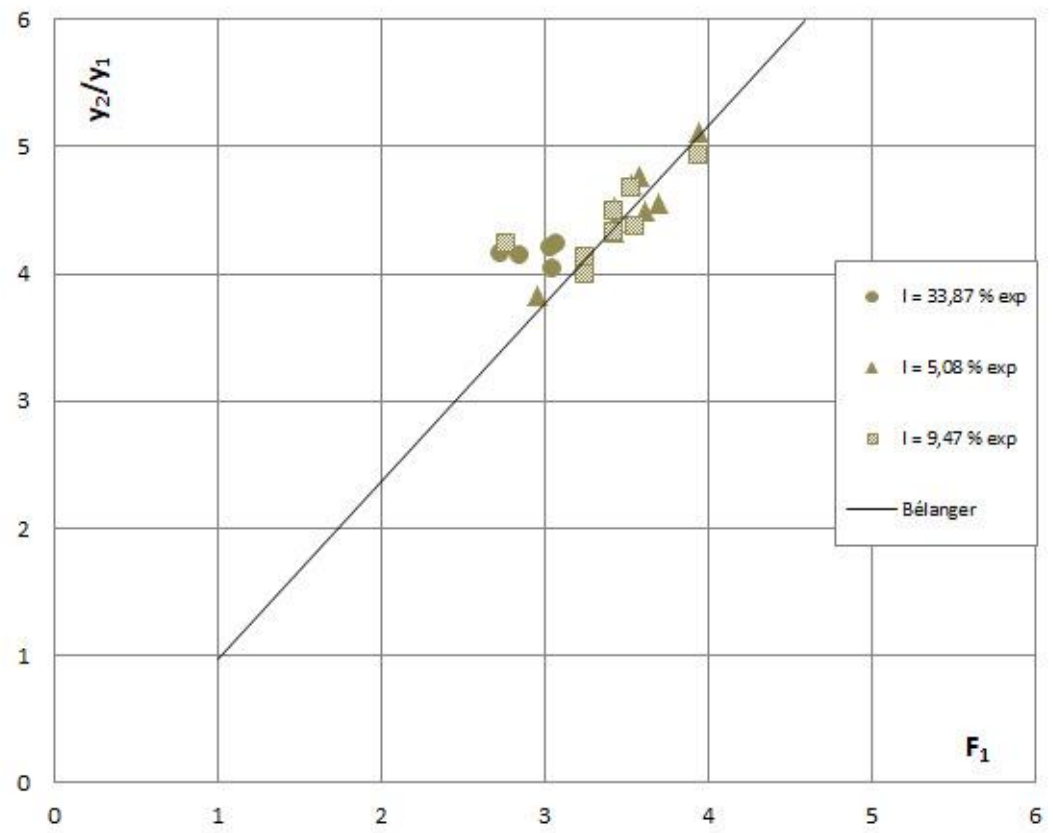

Figura 64. Razões $\mathrm{y}_{2} / \mathrm{y}_{1}$ medidas, separados nas intensidades de rugosidade $(I)$ e equação de Bélanger em relação a $\mathrm{F}_{1}$.

O grupo com $I=33,87 \%$ representa os experimentos com material emborrachado antiderrapante, com razão de comprimento por altura $=b / a=c / a=10$. O grupo com $I=5,08$ \% representa os experimentos com configuração LEGO1 e LEGO2, e relação $b / a=2,5, c / a=$ 1,25. O grupo com $I=9,47 \%$ representa os experimentos com configuração LEGO3 e LEGO4, e relação $b / a=1,43, c / a=0,71$.

Em todos os grupos, não se observa uma variação apreciável da relação $\mathrm{y}_{2} / \mathrm{y}_{1} \mathrm{com}$ a variação da intensidade $I$. O ajuste dos grupos de dados de intensidade com o uso da Eq (24) fornece a Fig. 65. Vale ressaltar, como já comentado anteriormente e observado na Tab. 21 e Fig 63, que se evitou comparar dados com baixa variação de $F_{1}$, e o grupo $I=33,87 \%$ coincide com o grupo de experimentos com emborrachado. Na Tab. 23 são mostrados os coeficientes $\alpha$ e $\beta$ resultantes para os grupos de intensidade. 
Tabela 23. $\alpha$ e $\beta$ obtidos e variação experimental do número de Froude para os grupos de intensidade.

\begin{tabular}{c|c|c|c}
\hline $\mathrm{I}(\%)$ & $\alpha$ & $\beta$ & $\Delta \mathrm{F}_{1}$ \\
\hline 5,08 & 0,052517 & 1,191987 & 1,21 \\
\hline 9,47 & $-0,02151$ & 1,843286 & 1,17 \\
\hline
\end{tabular}

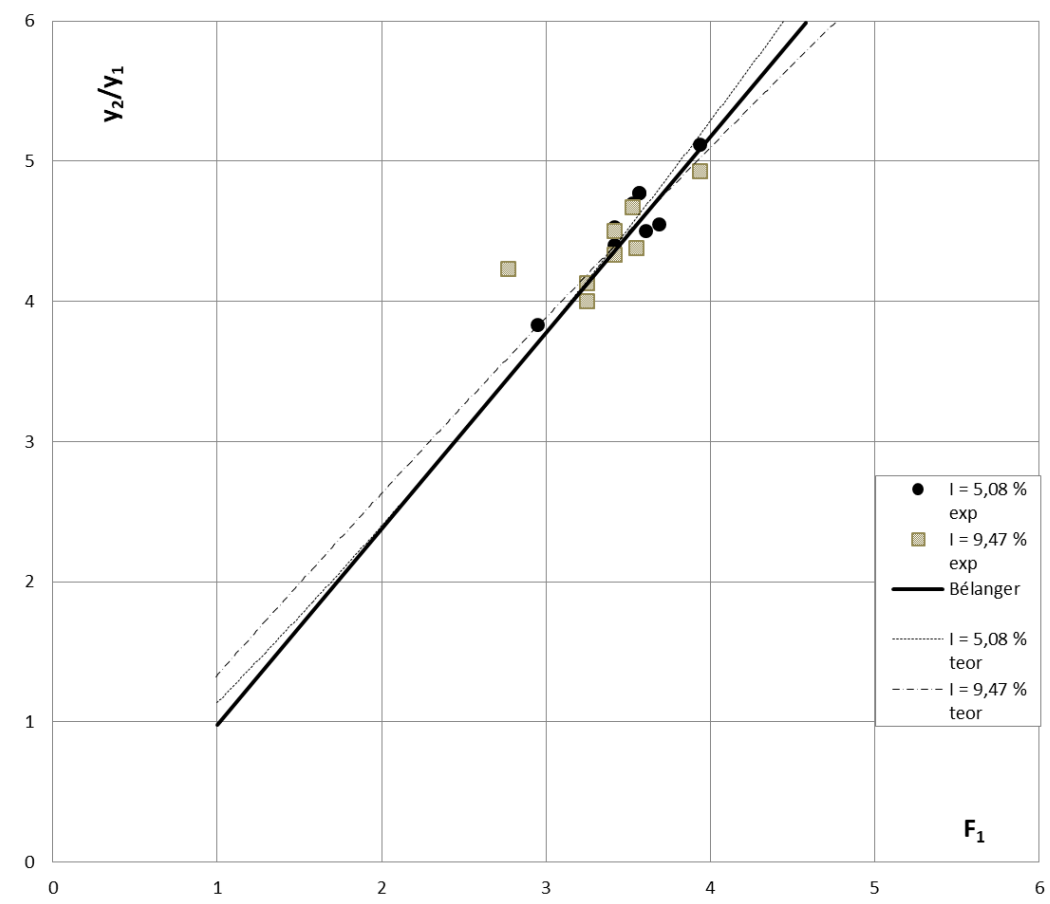

Figura 65. Dados experimentais e curvas teóricas obtidas com os valores de $\alpha$ e $\beta$ ajustados para a equação (24).

Com base nos resultados apresentados, verifica-se que:

i - Também para o canal B a solução de Schulz et al. (2015) produziu evoluções de $\mathrm{y}_{2} / \mathrm{y}_{1}$ para com $\mathrm{F}_{1}$ adequadas efetuando o ajuste dos coeficientes $\alpha$ e $\beta$.

ii - Como observado no canal A, os comportamentos calculados acompanham bem os comportamentos medidos na faixa de números de Froude estudadas.

iii - No caso do canal B, os dados com fundo "liso" e LEGO1 produziram $\alpha<0$, ou seja, a concavidade da curva obtida foi "para baixo". Similarmente, o grupo com maior intensidade de rugosidade apresentou $\alpha<0$, isto é, concavidade da curva para baixo, enquanto que o grupo com menor valor de intensidade teve $\alpha>0$, ou seja, a concavidade da curva resultante apontava para cima.

iv - Os valores de $\alpha$ e $\beta$ em todos os casos estudados estão mostrados na Tab. $21 \mathrm{e}$ Tab. 23, evidenciando que diferentes rugosidades produzem diferentes coeficientes na 
equação (24) e geram diferentes comportamentos para a evolução da razão entre as profundidades conjugadas.

v - As Fig. 63 e Fig. 65 permitem enfatizar o comentário do item iv para aqueles experimentos em que a variação de $\mathrm{F}_{1}$ foi maior que 0,5 .

vi - No caso do canal B, o presente conjunto de dados permitiu observar diferentes evoluções da razão entre as profundidades conjugadas e quantificar o efeito da rugosidade nos parâmetros $\alpha$ e $\beta$. Entretanto, devido à característica de se gerar variações reduzidas de $\mathrm{F}_{1} \mathrm{em}$ alguns casos de rugosidade, sugere-se a execução de experimentos com maior variação do número de Froude, para melhor quantificar $\alpha$ e $\beta$ para diferentes condições de rugosidade.

\subsubsection{Comprimento do rolo $L_{r} / y_{1}$}

Os dados da Tab. 20 foram também analisados utilizando a Eq. (27) para o cálculo dos coeficientes $\gamma$ e $\delta$. Semelhante ao procedimento seguido para as profundidades conjugadas, os dados dos experimentos do canal liso, $\mathrm{J}-1$ a 3 e $\mathrm{CB}-1$ a 5 , foram analisados em conjunto. Os dados seguintes, $\mathrm{CB}-6$ a 10, CB - 11 a $15, \mathrm{CB}-16$ a 20, CB - 21 a 25 e CB - 26 a 28 foram analisados cada qual separadamente.

A Fig. 66 mostra a comparação entre os resultados medidos e os resultados calculados após o ajuste dos coeficientes $\gamma$ e $\delta$, sem fazer a discriminação entre os diferentes grupos de rugosidade. Observa-se que a nuvem de pontos segue a declividade ideal de $45^{\circ}$ esperada, embora o espalhamento dos pontos seja maior. Isso decorre da maior dificuldade de determinar o comprimento do rolo devido à turbulência na superfície do ressalto. 


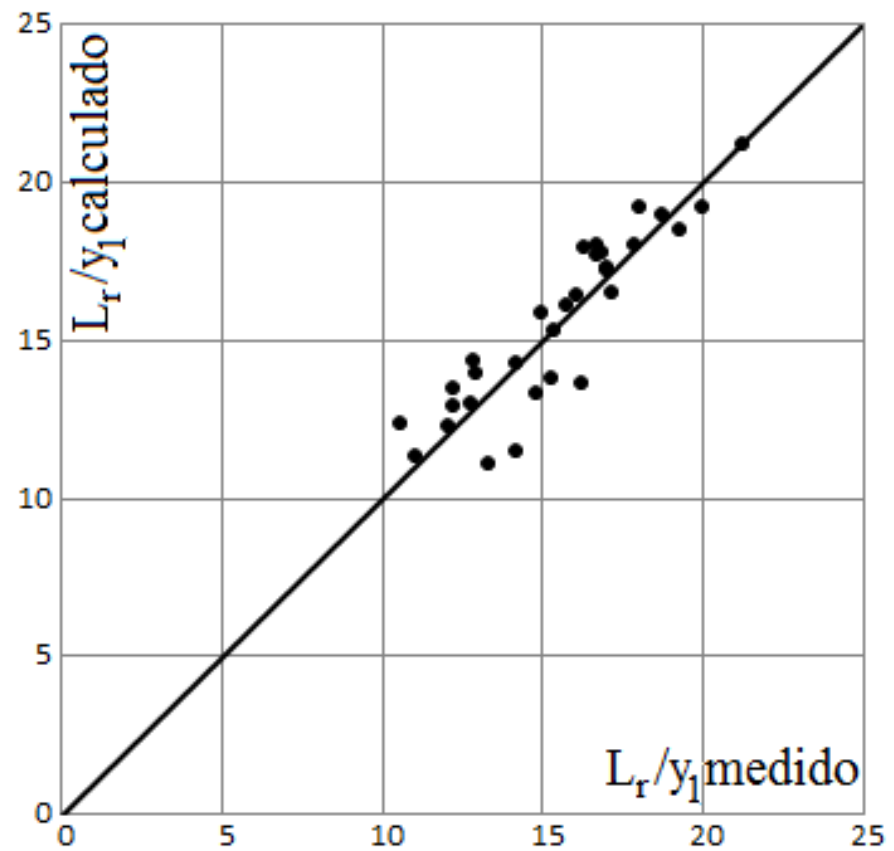

Figura 66. $\mathrm{L}_{\mathrm{r}} / \mathrm{y}_{1}$ medidos e calculados, sem distinção de experimentos.

A Fig. 65 mostra os resultados dos comprimentos relativos medidos e calculados graficados em relação ao número de Froude supercrítico $\left(\mathrm{F}_{1}\right)$. O maior espalhamento da Fig. 66 é refletido na Fig. 67 pelo maior distanciamento entre os pontos medidos e calculados para um mesmo número de Froude. Não obstante este aspecto de maior distanciamento, a nuvem de pontos calculados segue o formato da nuvem de pontos medidos.

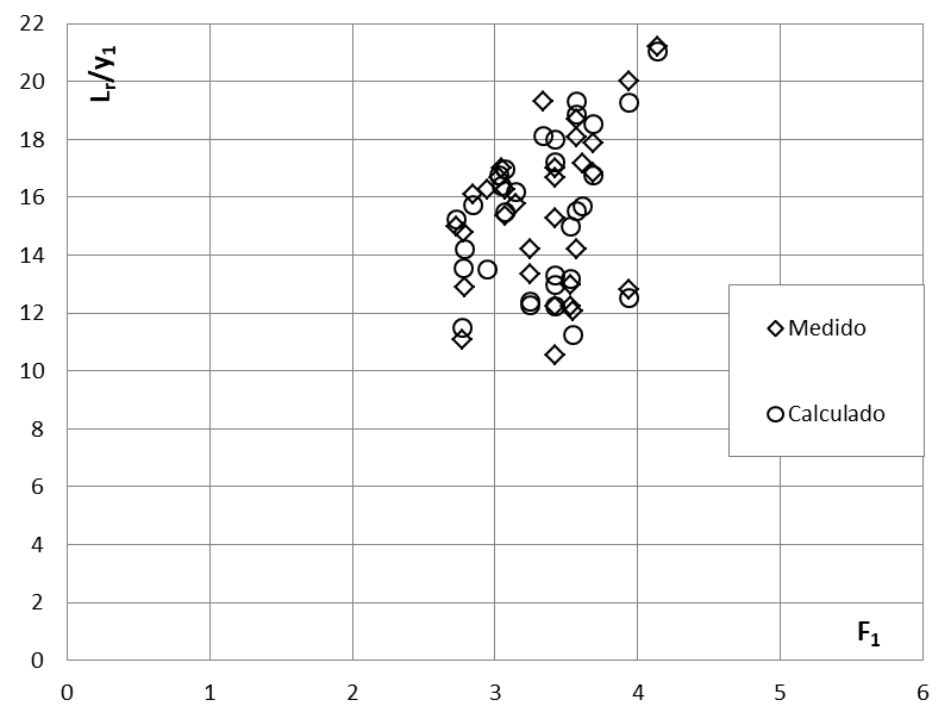

Figura 67. $\mathrm{L}_{\mathrm{r}} / \mathrm{y}_{1}$ medidos e calculados em relação ao número de Froude $\mathrm{F}_{1}$, sem distinção de experimentos. 
A Fig. 68 mostra os mesmos resultados da Fig. 66 considerando a distinção dos diferentes tipos de rugosidade. A Eq (27) mostra-se adequada para agrupar todos os pontos medidos em torno da reta ideal.

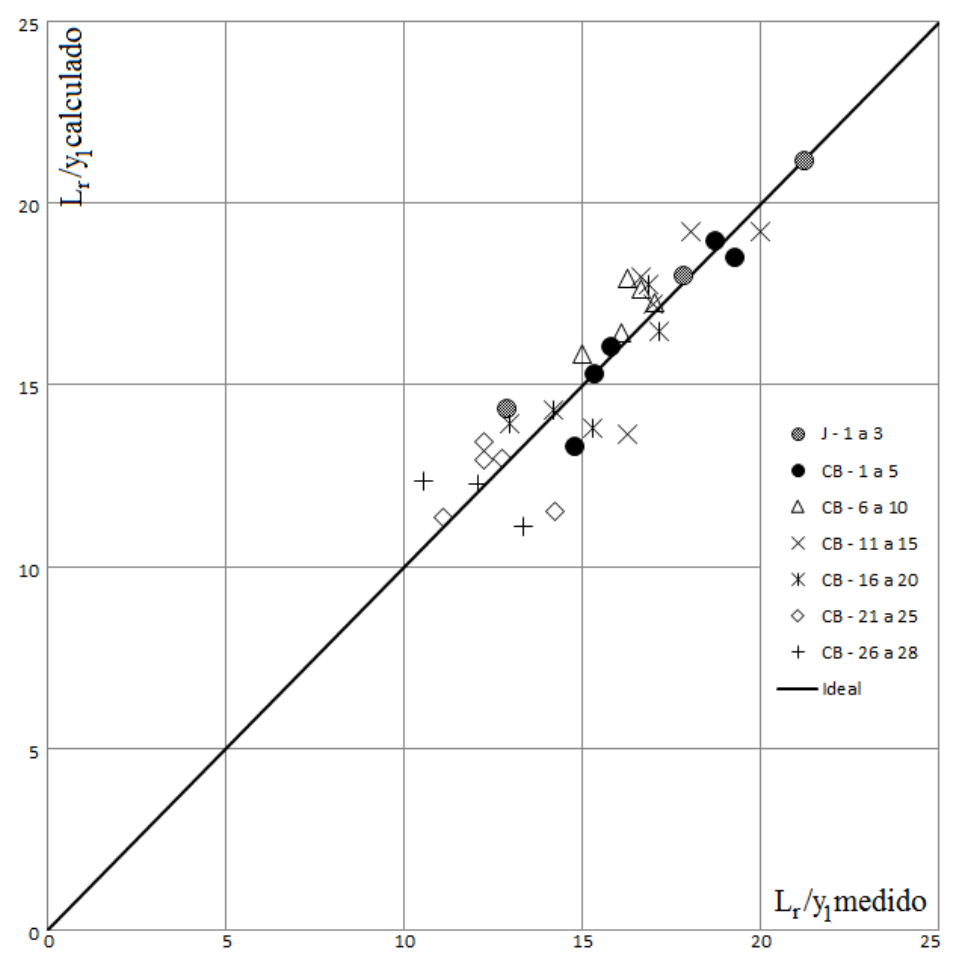

Figura 68. $\mathrm{L}_{\mathrm{r}} / \mathrm{y}_{1}$ medidos e calculados com distinção de experimentos.

\subsubsection{1. $\quad$ Valores de $\gamma$ e $\delta$}

A Tab. 24 mostra os valores de $\gamma$ e $\delta$ obtidos para os dados da Tab. 20. Nesse caso os valores para canal liso e LEGO3 mostram valores mais semelhantes entre si. Embora algo mais distante, os valores para Lego 1 apresentam sinais compatíveis para os dois coeficientes em relação ao canal liso e a LEGO3. Essas três rugosidades são consideradas com mais detalhe porque, como já mencionado na análise de $\mathrm{y}_{2} / \mathrm{y}_{1}$, os números de Froude $\mathrm{F}_{1}$ tiveram variações superiores a 0,5 para cada conjunto de dados, permitindo uma maior confiabilidade da análise de regressão.

Tabela 24. $\gamma$ e $\delta$ obtidos e variação experimental do número de Froude

\begin{tabular}{c|c|c|c}
\hline & $\gamma$ & $\delta$ & $\Delta \mathrm{F}_{1}$ \\
\hline Liso & 3,72364 & $-0,37069$ & 1,36 \\
\hline Borr. & 3,16396 & $-0,02433$ & 0,331 \\
\hline Lego1 & 5,311586 & $-0,76571$ & 0,99 \\
\hline Lego2 & $-1,5155$ & 1,06185 & 0,441 \\
\hline Lego3 & 4,00427 & $-0,59335$ & 1,06 \\
\hline Lego4 & 3,68492 & $-0,48594$ & 0,384 \\
\hline
\end{tabular}


Como ocorreu para as profundidades conjugadas, observa-se que o tipo de rugosidade afeta os coeficientes da equação para o comprimento relativo. Considerando os experimentos em que houve variação acima de 0,5 para número de Froude supercrítico (experimentos para canal liso, Lego 1 e Lego 3), as curvas traçadas com os valores de $\gamma$ e $\delta$ mostram uma evolução compatível com as medidas feitas. A Fig. 69 mostra as curvas teóricas e os dados experimentais. Aqui se utilizou, para o cálculo de $\mathrm{y}_{1} /\left(\mathrm{y}_{2}-\mathrm{y}_{1}\right)$, a informação que consta em Schulz et al. (2015), de que:

$$
\frac{y_{1}}{y_{2}-y_{1}}=\frac{1}{\frac{y_{2}}{y_{1}}-1}
$$

Para o cálculo das curvas teóricas foram utilizadas as soluções já calculadas para $\mathrm{y}_{2} / \mathrm{y}_{1}$ como função do número de Froude (Eq. (27)) com os respectivos coeficientes para cada rugosidade estudada). As curvas teóricas sobrepõem-se adequadamente aos dados calculados. Na Fig. 69 as curvas foram traçadas até atingirem seu ponto de máximo. Foi considerado aqui que é preciso realizar experimentos com uma maior variação do número de Froude para poder fazer afirmações definitivas sobre o ponto de máximo para cada rugosidade ensaiada.

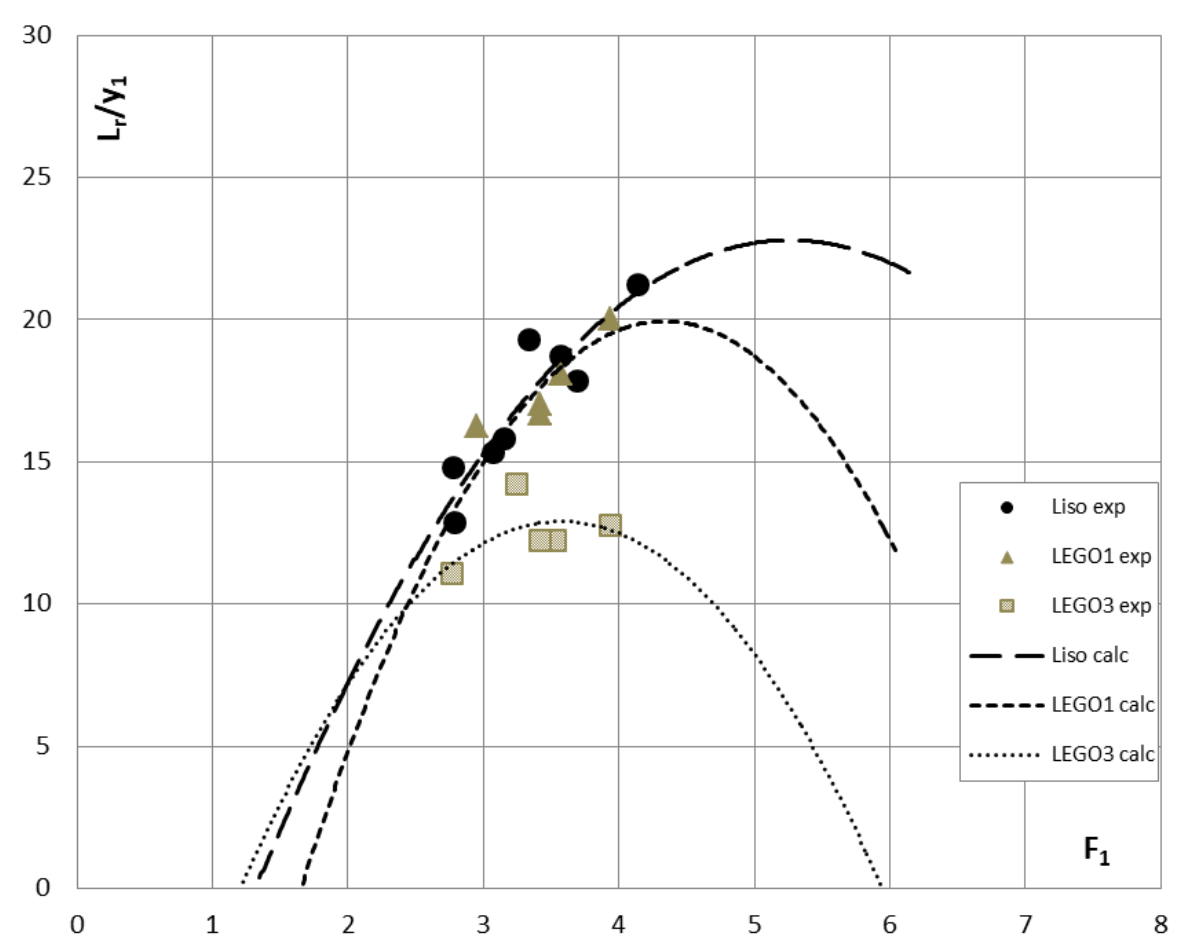

Figura 69. Dados experimentais e curvas teóricas obtidas com os valores de $\gamma$ e $\delta$ ajustados para a Eq. (27).

Com base nos resultados apresentados, verifica-se que: 
i - A solução teórica de Schulz et al. (2015) para $\mathrm{L}_{\mathrm{r}} / \mathrm{y}_{1}$, dependente de dois coeficientes, $\gamma$ e $\delta$, é adequada para o cálculo do comprimento relativo do rolo para diferentes condições de rugosidade.

ii - Os valores de $\gamma$ e $\delta$ aqui obtidos estão mostrados na Tab. 24, evidenciando que diferentes rugosidades produzem diferentes coeficientes na Eq. (27) e geram diferentes comportamentos para a evolução do comprimento relativo do rolo.

iii - A Fig. 69 permite enfatizar o comentário do item iv para aqueles experimentos em que a variação de $\mathrm{F}_{1}$ foi maior que 0,5 .

iv - Devido à característica de terem sido geradas variações reduzidas de $F_{1}$ em alguns casos de rugosidade, sugere-se a execução de experimentos com maior variação do número de Froude, para melhor quantificar $\gamma$ e $\delta$ para diferentes condições de rugosidade.

\subsubsection{Energia dissipada}

A energia relativa dissipada foi determinada conforme a Eq. (14) e Eq. (16), para os experimentos no canal B do presente estudo e no estudo de Nóbrega (2014). A Tab. 25 apresenta a energia relativa determinada pelos dados experimentais, e calculada a partir da Eq. (24). A Fig. 70 mostra uma comparação da energia relativa com base em dados experimentais e calculada, sem distinção de experimentos. Nota-se que a nuvem de pontos segue a declividade ideal de $45^{\circ}$ esperada, com menor espalhamento a medida que o número de Froude $\mathrm{F}_{1}$ cresce e, consequentemente, a energia relativa.

Tabela 25. Dados relevantes medidos e valores de $\Delta \mathrm{E} / \mathrm{E}_{1}$ experimentais e calculados para o canal $\mathrm{B}$, com base na $\mathrm{Eq}(27)$.

\begin{tabular}{c|c|c|c|c|c|c|c|c|c|c|c|c}
\hline Código & $\begin{array}{c}\mathrm{Q} \\
\mathrm{m}^{3} / \mathrm{s}\end{array}$ & $\mathrm{F} 1$ & $\begin{array}{c}\mathrm{B} \\
\mathrm{m}\end{array}$ & $\begin{array}{c}\mathrm{y}_{1} \\
\mathrm{~cm}\end{array}$ & $\begin{array}{c}\mathrm{y}_{2} \\
\mathrm{~cm}\end{array}$ & $\begin{array}{c}\text { Rugosi- } \\
\text { dade }\end{array}$ & $\begin{array}{c}\mathrm{y}_{2} / \mathrm{y}_{1} \\
\mathrm{Exp} .\end{array}$ & $\begin{array}{c}\mathrm{v}_{1} \\
\mathrm{~m} / \mathrm{s}\end{array}$ & $\begin{array}{c}\mathrm{v}_{2} \\
\mathrm{~m} / \mathrm{s}\end{array}$ & $\begin{array}{c}\mathrm{y}_{2} / \mathrm{y}_{1} \\
\mathrm{Calc}\end{array}$ & $\begin{array}{c}\Delta \mathrm{E} / \mathrm{E}_{1} \\
\text { exp }\end{array}$ & $\begin{array}{c}\Delta \mathrm{E} / \mathrm{E}_{1} \\
\text { calc }\end{array}$ \\
\hline $\mathrm{J}-1$ & 0,021 & 4,14 & 0,41 & 2,5 & 14,2 & - & 5,68 & 2,05 & 0,361 & 5,77 & 0,377956 & 0,368539 \\
\hline $\mathrm{J}-2$ & 0,031 & 3,69 & 0,41 & 3,5 & 17,4 & - & 4,97 & 2,16 & 0,435 & 5,28 & 0,327038 & 0,287457 \\
\hline $\mathrm{J}-3$ & 0,040 & 2,79 & 0,41 & 5,0 & 21,4 & - & 4,28 & 1,95 & 0,456 & 4,09 & 0,079724 & 0,118651 \\
\hline CB-1 & 0,020 & 3,34 & 0,41 & 2,8 & 14,4 & - & 5,14 & 1,75 & 0,340 & 4,75 & 0,179788 & 0,239998 \\
\hline CB-2 & 0,025 & 3,57 & 0,41 & 3,1 & 16,1 & - & 5,19 & 1,97 & 0,379 & 5,07 & 0,262417 & 0,279201 \\
\hline CB-3 & 0,030 & 3,15 & 0,41 & 3,8 & 17,4 & - & 4,58 & 1,93 & 0,421 & 4,58 & 0,193692 & 0,193516 \\
\hline CB-4 & 0,035 & 3,07 & 0,41 & 4,3 & 19,0 & - & 4,42 & 1,99 & 0,451 & 4,48 & 0,178734 & 0,167909 \\
\hline CB-5 & 0,040 & 2,78 & 0,41 & 5,0 & 20,0 & - & 4,00 & 1,95 & 0,487 & 4,12 & 0,1308 & 0,106215 \\
\hline CB-6 & 0,020 & 2,73 & 0,41 & 3,2 & 13,3 & Borr. & 4,16 & 1,53 & 0,367 & 3,87 & 0,070343 & 0,131232 \\
\hline CB-7 & 0,025 & 2,85 & 0,41 & 3,6 & 14,9 & Borr. & 4,14 & 1,69 & 0,409 & 4,02 & 0,135467 & 0,158955 \\
\hline CB-8 & 0,030 & 3,03 & 0,41 & 3,9 & 16,4 & Borr. & 4,21 & 1,88 & 0,446 & 4,33 & 0,202665 & 0,180368 \\
\hline CB-9 & 0,035 & 3,07 & 0,41 & 4,3 & 18,2 & Borr. & 4,23 & 1,99 & 0,470 & 4,39 & 0,207747 & 0,179987 \\
\hline CB-10 & 0,040 & 3,05 & 0,41 & 4,7 & 19,0 & Borr. & 4,04 & 2,07 & 0,512 & 4,22 & 0,236952 & 0,205671 \\
\hline CB-11 & 0,020 & 3,94 & 0,41 & 2,5 & 12,8 & LEGo1 & 5,12 & 1,96 & 0,383 & 5,16 & 0,381865 & 0,3773 \\
\hline
\end{tabular}




\begin{tabular}{c|c|c|c|c|c|c|c|c|c|c|c|c}
\hline CB-12 & 0,025 & 3,57 & 0,41 & 3,1 & 14,8 & LEGO1 & 4,77 & 1,97 & 0,412 & 4,70 & 0,313511 & 0,32359 \\
\hline CB-13 & 0,030 & 3,42 & 0,41 & 3,6 & 16,3 & LEGO1 & 4,53 & 2,03 & 0,449 & 4,49 & 0,29724 & 0,302756 \\
\hline CB-14 & 0,035 & 3,42 & 0,41 & 4,0 & 17,6 & LEGO1 & 4,40 & 2,14 & 0,486 & 4,40 & 0,309213 & 0,309213 \\
\hline CB-15 & 0,040 & 2,95 & 0,41 & 4,8 & 18,4 & LEGO1 & 3,83 & 2,03 & 0,529 & 3,93 & 0,23294 & 0,214995 \\
\hline CB-16 & 0,020 & 3,53 & 0,41 & 2,7 & 12,7 & LEGO2 & 4,70 & 1,82 & 0,386 & 4,62 & 0,304329 & 0,316017 \\
\hline CB-17 & 0,025 & 3,57 & 0,41 & 3,1 & 14,8 & LEGO2 & 4,77 & 1,97 & 0,412 & 4,73 & 0,313511 & 0,319515 \\
\hline CB-18 & 0,030 & 3,42 & 0,41 & 3,6 & 15,6 & LEGO2 & 4,33 & 2,03 & 0,469 & 4,20 & 0,321809 & 0,341277 \\
\hline CB-19 & 0,035 & 3,69 & 0,41 & 3,8 & 17,3 & LEGO2 & 4,55 & 2,25 & 0,495 & 4,71 & 0,371956 & 0,3517 \\
\hline CB-20 & 0,040 & 3,61 & 0,41 & 4,2 & 18,9 & LEGO2 & 4,50 & 2,32 & 0,515 & 4,57 & 0,360971 & 0,351697 \\
\hline CB-21 & 0,020 & 3,53 & 0,41 & 2,7 & 12,6 & LEGO3 & 4,67 & 1,82 & 0,389 & 4,54 & 0,308881 & 0,326567 \\
\hline CB-22 & 0,025 & 3,94 & 0,41 & 2,9 & 14,3 & LEGO3 & 4,93 & 2,10 & 0,426 & 4,99 & 0,401299 & 0,394576 \\
\hline CB-23 & 0,030 & 3,42 & 0,41 & 3,6 & 16,2 & LEGO3 & 4,50 & 2,03 & 0,452 & 4,45 & 0,30078 & 0,308081 \\
\hline CB-24 & 0,035 & 2,77 & 0,41 & 4,6 & 17,8 & LEGO3 & 3,87 & 1,86 & 0,481 & 3,74 & 0,143584 & 0,170487 \\
\hline CB-25 & 0,040 & 3,25 & 0,41 & 4,5 & 18,6 & LEGO3 & 4,13 & 2,16 & 0,523 & 4,33 & 0,2971 & 0,266 \\
\hline CB-26 & 0,030 & 3,42 & 0,41 & 3,6 & 15,6 & LEGO4 & 4,33 & 2,03 & 0,469 & 4,27 & 0,321809 & 0,331056 \\
\hline CB-27 & 0,035 & 3,55 & 0,41 & 3,9 & 17,1 & LEGO4 & 4,38 & 2,20 & 0,501 & 4,44 & 0,351327 & 0,3437 \\
\hline CB-28 & 0,040 & 3,25 & 0,41 & 4,5 & 18,0 & LEGO4 & 4,00 & 2,16 & 0,541 & 4,01 & 0,314845 & 0,313264 \\
\hline
\end{tabular}

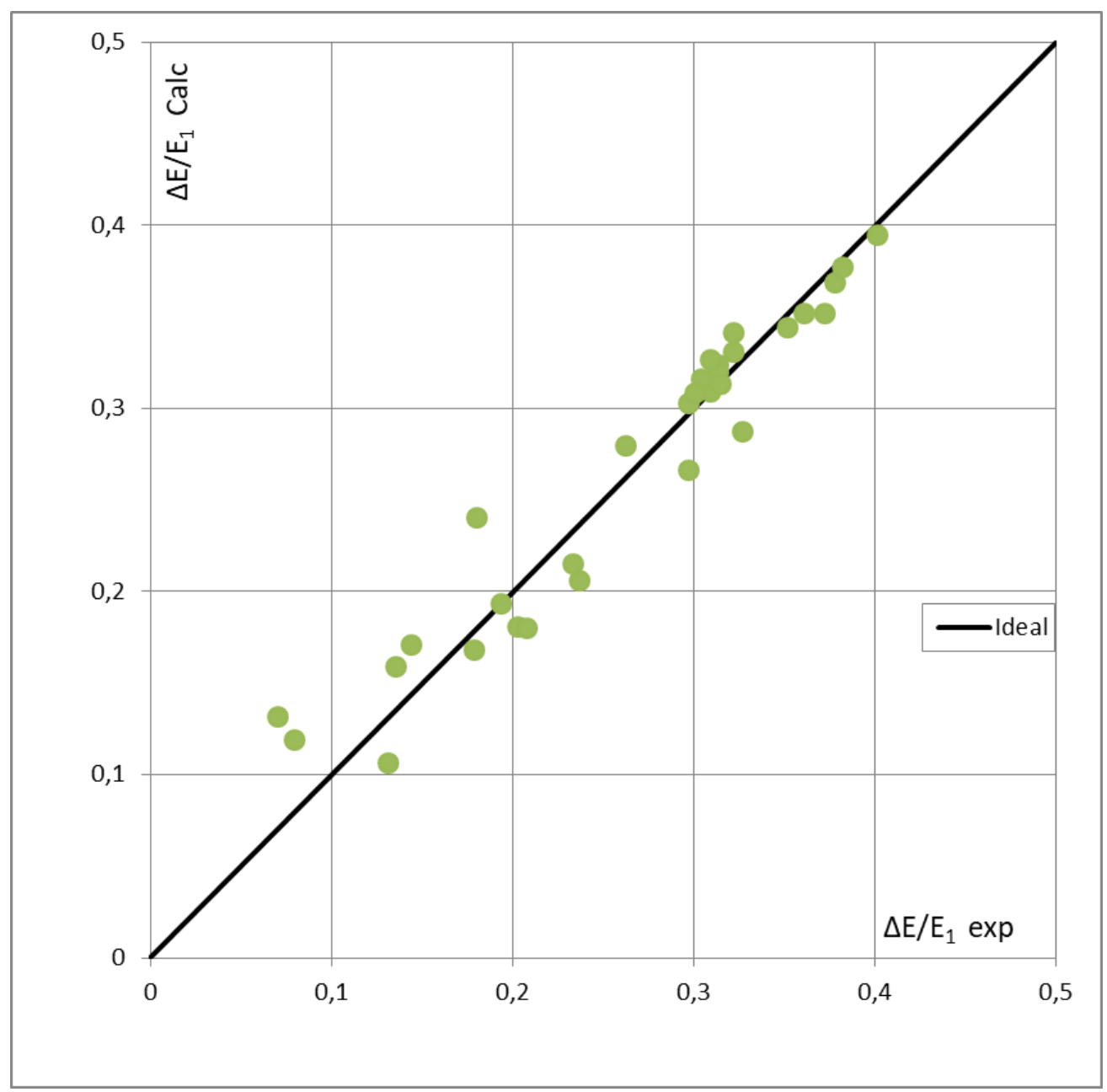

Figura 70. Comparação da energia relativa determinada por dados experimentais e através dos dados de $\mathrm{y}_{2} / \mathrm{y}_{1}$ ajustados pela Eq. (24).

A Fig. 71 mostra as energias relativas em relação ao número de Froude $F_{1}$, para os diferentes tipos de rugosidade no fundo. Nota-se que para valores semelhantes de número de 
Froude, as configurações com algum tipo de fundo rugoso mostraram uma maior dissipação de energia em relação ao fundo liso.

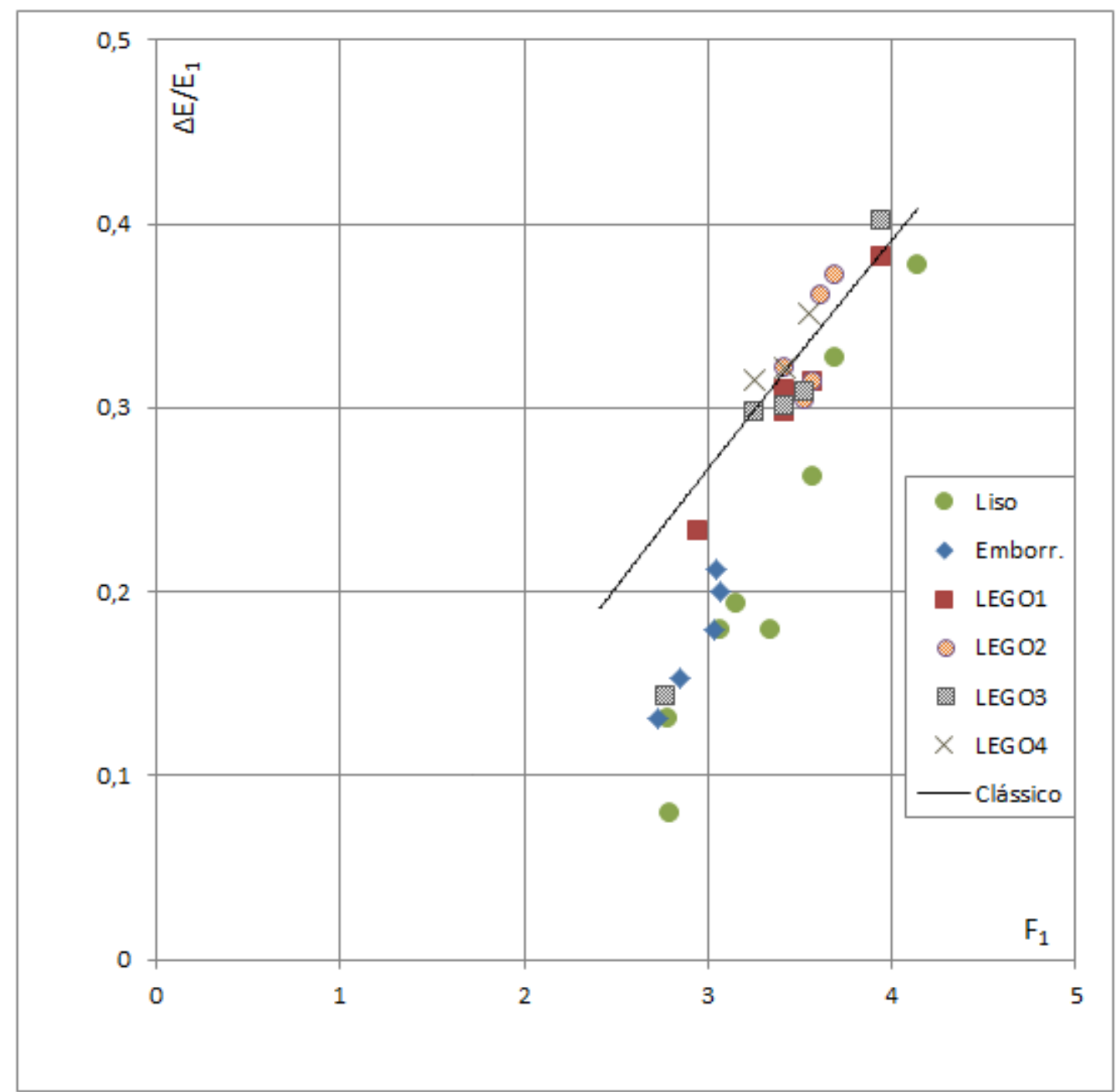

Figura 71. Energia relativa $\Delta \mathrm{E} / \mathrm{E}_{1} \times \mathrm{F}_{1}$ para as diferentes rugosidades de fundo no canal $\mathrm{B}$.

Considerando os grupos de intensidade mostrados na Tab. 23 foi obtida a Fig. 72, em que se relaciona a energia relativa dissipada x número de Froude. 


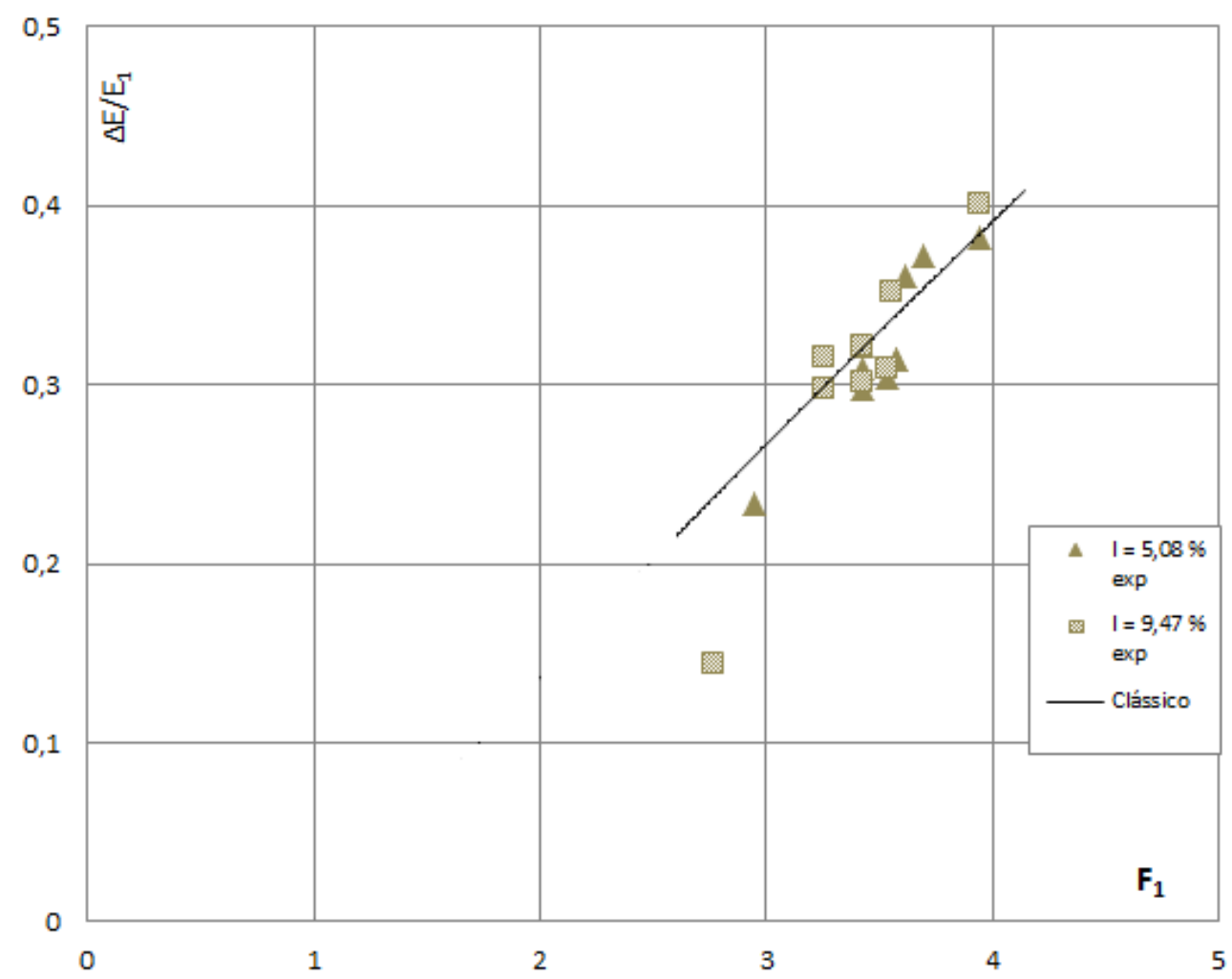

Figura 72. Energia relativa $\Delta E / E_{1} \times F_{1}$ para as os grupos de intensidade fornecidos na Tab. 23.

Com base nos resultados apresentados, verifica-se que:

i - A solução teórica de Schulz et al. (2015) para $\mathrm{y}_{2} / \mathrm{y}_{1}$, dependente de dois coeficientes, $\alpha$ e 8 , é adequada para o cálculo indireto da energia relativa $\Delta \mathrm{E} / \mathrm{E}_{1}$ em diferentes condições de rugosidade.

ii - A Tab. 25 mostra que as maiores dissipações observadas ocorreram nos experimentos CB-11 e CB-22 (ambos com $F_{1}=3,94$ ), com valores de $\Delta \mathrm{E}_{2} \mathrm{E}_{1}$ iguais a 0,382 e 0,401 , respectivamente.

iii - Novamente, devido à característica de terem sido geradas variações reduzidas de $\mathrm{F}_{1}$ em alguns casos de rugosidade, sugere-se a execução de experimentos com maior variação do número de Froude para melhor quantificar a variação de $\Delta \mathrm{E} / \mathrm{E}_{1}$ nas diferentes condições de rugosidade, especialmente na faixa 4,5 $<\mathrm{F}_{\mathrm{r}}<9,0$, que compreende o tipo de ressalto estável, bastante usado como dissipador de energia em bacias de dissipação. 


\section{CONCLUSÕES E RECOMENDAÇÕES}

Resultados experimentais foram obtidos utilizando duas metodologias para medição das profundidades conjugadas e comprimentos do rolo de ressalto hidráulico, sobreposição de quadros de filmagem dos experimentos e uso de sensor ultrassônico determinação das profundidades ao longo do escoamento. A primeira se mostrou uma metodologia de fácil e rápida aplicação, porém sua qualidade está sujeita as especificações da câmera utilizada. O uso de sensor ultrassônico, por sua vez se mostrou como método robusto e simples na determinação das medições realizadas.

Nesse sentido, a comparação dos dados obtidos com estudos anteriores, nos mesmos canais, e posterior verificação da compatibilidade dos dados para as mesmas condições experimentais, serviu para assegurar a repetitividade dos experimentos e a efetividade da metodologia usada para as medições.

No total, cinquenta configurações experimentais distintas foram realizadas, gerando-se ressaltos a jusante de comporta plana e vertedor de soleira espessa, com números de Froude supercríticos variando de 1,29 a 3,94, declividade nula e de 0,035, fundo "liso", fundo com emborrachado antiderrapante e fundo com configurações de peças Lego. Os dados resultantes obtidos compreenderam profundidades conjugadas, comprimentos do rolo, perfil de superfície livre, intensidade de rugosidade e energia relativa dissipada.

Os dados experimentais foram usados para validação e ajuste de coeficientes da proposta semi-empírica de Schulz et al. (2015a), para evolução do comportamento de $\mathrm{y}_{2} / \mathrm{y}_{1}$ e de $\mathrm{L}_{\mathrm{r}} / \mathrm{y}_{1}$ em relação ao $\mathrm{F}_{1}$. Os resultados mostraram uma boa correlação e permitiram as seguintes conclusões para o conjunto de dados em cada canal:

- No canal A, os coeficientes ajustados $\alpha$ e $\beta$ para Eq (24) e suas características comportamentais apontaram uma adequação para a segregação por declividade, e por geometria do tipo de estrutura, com concavidades da curva semelhantes para estruturas também semelhantes;

- No canal B, os coeficientes ajustados $\alpha$ para Eq (24) mostrou um comportamento de concavidade "para baixo" nos experimentos com fundo liso e LEGO1, assim como para o grupo de experimentos com intensidade de rugosidade igual a 9,47\%;

- Os coeficientes ajustados $\gamma$ e $\delta$ para Eq. (27) também apontaram para uma segregação por geometria do tipo de estrutura, no canal A. 
Para a análise de dissipação de energia, notou-se uma relação direta entre o número de Froude $\mathrm{F}_{1}$ e o $\Delta \mathrm{E} / \mathrm{E}_{1}$. O maior valor de $\Delta \mathrm{E} / \mathrm{E}_{1}$ foi de 0,401 , para o experimento $\mathrm{CB}-22$.

Os resultados e conclusões divulgados aqui neste estudo são importantes para a avaliação do comportamento e adequação da solução proposta por Schulz et al. (2015a), em diferentes condições experimentais, e servem como material para análise e comparação para demais pesquisadores interessados no tema.

De um modo geral, para futuros estudos sugere-se ampliar a faixa de $\mathrm{F}_{\mathrm{r}}$ nas diferentes condições de rugosidade, em especial para ressalto estável, em vertedor e em comporta, para evidenciar as influências dessas características geométricas com maior detalhamento, assim como elaborar uma maior densidade de dados para analisar os comportamentos das equações de previsão relacionados às diferentes condições experimentais. 


\section{REFERÊNCIAS}

ALVES, A. A. M. (2008). Caracterização das solicitações hidrodinâmicas em bacias de dissipação por ressalto hidráulico com baixo número de Froude. Dissertação (mestrado em Recursos Hídricos e Saneamento Ambiental). Universidade Federal do Rio Grande do Sul, Porto Alegre, 2008.

ALHAMID, A. A.; NEGM, A. M. (1996). Depth ratio of hydraulic jump in rectangular stilling basins. Journal of Hydraulic Research, Vol. 34, No. 5, 1996.

BEIRAMI, M. K.; CHAMANI, M. R. (2006). Hydraulic jumps in sloping channels: sequent depth ratio. Journal of Hydraulic Engineering, v. 132, p. 1061-1068, 2006.

BEIRAMI, M. K.; CHAMANI, M. R. (2010). Hydraulic jumps in sloping channels: roller length and energy loss. Canadian Journal of Civil Engineering, v. 37, p. 535-543, 2010.

CAROLlO, F.G., FERRO, V. (2004). Determination of Conjugated Heights Emphasis on Free Smooth Surface and Rough, Journal of Agricultural Engineering, Vol. 4, p. 1-12. 2004.

CAROLlO, F. G.; FERRO, V.; PAMPALONE, V. (2007). Hydraulic jumps on rough beds. Journal of Hydraulic Engineering, v. 133, p.989-999, 2007.

CAROLlO, F. G.; FERRO, V.; PAMPALONE, V. (2012). New expression of the hydraulic jump roller length. Journal of Hydraulic Engineering, v. 138. P. 995-999, 2012.

CARVALHO, P. D. (1997). Aeração de escoamentos de alta velocidade em canais de forte declividade. Tese (doutorado em Ciências - Hidráulica e Saneamento). Escola de Engenharia de São Carlos, Universidade de São Paulo, São Carlos, 1997.

CHANSON, H. (2011). Hydraulic jumps: turbulence and air bubble entrainment. La Houille Blanche, v. 3, p. 5-16, 2011.

CHOW, V.T. (1959). Open channel hydraulics. 680 p., McGraw-Hill, New York, 1959.

HAGER, W. H.; BREMEN, R.; KAWAGOSHI, N. (1990). Classical hydraulic jump: length of roller. Journal of Hydraulic Research, v. 28, n. 5, p. 591-608, 1990.

HAGER, W. H. (1992). Energy dissipators and hydraulic jump. Water Science and Technology Library, Kluwer Academic Publishers, 289 p., 1992. 
HUGHES, W. C.; FLACK, J. E. (1984). Hydraulic jump properties over a rough bed. Journal of Hydraulic Engineering, v. 110, n. 12, p. 1755-1771, 1984.

KINDSVATER, C. E. (1944). The hydraulic jump in sloping channels. Trans., ASCE, v. 109, p. 1107-1120, 1944.

LOBOSCO, R. J.; SCHULZ, H.E. (2010). Análise computacional do escoamento em estruturas de vertedouros em degraus. Mecánica Computacional, v. XXIX, p. 3593-3600, 2010.

MAATOOQ, J.; TALEB, E. (2018). The performance of hydraulic jump over rough bed stilling basin consisting of cubic-shape elements. MATEC Web of Conferences, v. 162, 2018.

NELUWALA, N. G. P. B.; KARUNANAYAKE, K. T. S.; SANDARUWAN, K. B. G. PATHIRANA, M. \& K. P. P. (2013). Characteristics of Hydraulic Jumps over Rough Beds - An Experimental Study. ENGINEER, Vol. XXXXVI, No 03, p. 1-7, 2013.

NÓBREGA, J. D. (2014). Metodologia Teórica e Experimental para Determinação das Características do Ressalto Hidráulico Clássico. Dissertação (mestrado em Engenharia Hidráulica e Saneamento). Escola de Engenharia de São Carlos, Universidade de São Paulo, São Carlos, 2014.

ORTIZ, J. P. (1981). Macroturbulência de escoamentos a jusante de estruturas de dissipação por ressalto. Dissertação (mestrado em Engenharia Civil) - Escola Politécnica da Universidade de São Paulo, São Paulo, 1981.

PALERMO, M.; PAGLIARA, S. (2018). Semi-theoretical approach for energy dissipation estimation at hydraulic jumps in rough sloped channels. Journal of Hydraulic Research, 2018.

PETERKA, A. J. (1963). Hydraulic design of Stilling basins and Energy Dissipators. Engineering Monograph, Número 25, U.S. Bureau of Reclamation, Denver, 1963.

PETERKA, A. J. (1984). Hydraulic Design of Stilling Basins and Energy Dissipators. United States Department of the Interior. Bureau of Reclamation, Water Resources Technical Publication, Engineering Monography, n. 25, Eitghth Printing. Denver, 1984.

PORTO, R. M. (2006). Hidráulica Básica. 540 p., 4ª Ed. Projeto Reenge. Escola de Engenharia de São Carlos, Universidade de São Paulo, São Carlos, 2006. 
RAJARATNAM, N. (1965). The hydraulic jump as a wall jet. Journal of Hydraulics Division. v. 91, p. 107-132, 1965.

RAJARATNAM, N. (1966). The hydraulic jump in sloping channels. J. Irrig. Pwr. India, v. 23, p. 137-149, 1966.

RAJARATNAM, N. (1967). Hydraulics jumps. In: CHOW, V. T. (Ed). Advances in Hydroscience. v. 4. New York: Academic Press, p. 197-280, 1967.

RAJARATNAM, N. (1968). Hydraulic jumps on rough beds. Trans. Eng. Inst. Canada, Vol. 11, p. 1-8, 1968.

SCHULZ, H. E.; NÓBREGA, J.D.; SIMÕES, A.L.A.; SCHULZ, H.; PORTO, R. M. (2015a). Details of Hydraulic Jumps for Design Criteria of Hydraulic Jumps for Design Criteria of Hydraulic Structures. Em: Schulz H.E, Hydrodynamics - Concepts and Experiments. $1^{\text {a }}$ Ed. InTech, 1-44, capítulo provisional acessado em DOI 10.13140/2.1.2552.5288,https://www.researchgate.net/publication/273632789_Details_of_Hy draulic_Jumps_for_Design_Criteria_of_Hydraulic_Structures, 2015.

SCHULZ, H. E.; SIMÕES, A. L. A.; NÓBREGA, J. D. (2015b). Roller lengths, sequent depths, surface profiles for pre-design of dissipation basins. $2^{\text {nd }}$ International Workshop on Hydraulic Structures: Data validation. Coimbra, 2015.

SIMÕES, A. L. A. (2008). Considerações sobre a hidráulica de vertedores em degraus: metodologias adimensionais para pré-dimensionamento. Dissertação (mestrado em Engenharia Hidráulica e Saneamento), Escola de Engenharia de São Carlos, Universidade de São Paulo, 2008.

SIMÕES, A. L. A. (2012). Escoamentos turbulentos em canais com o fundo em degraus: resultados experimentais, soluções numéricas e proposições teóricas. Tese (doutorado em Hidráulica e Saneamento), Escola de Engenharia de São Carlos, Universidade de São Paulo, 2012.

SIMÕES, A. L. A.; SCHULZ. H. E; PORTO, R. M. (2012). Superfície livre de escoamentos turbulentos em canais: vertedores em degraus e ressalto hidráulico. Revista Brasileira de Recursos Hídricos, v. 17, n. 4, p. 125-139. 2012.

SOUSA, P. M. B. M. (2011). Estudo da dissipação de energia por ressalto hidráulico a jusante de descarregadores não convencionais. Dissertação de mestrado. Mestrado 
Integrado em Engenharia Civil, Departamento de Engenharia Civil da Universidade do Porto, Portugal, 2011.

SULTANA, A. (2011). A study of hydraulic jump in a sloping channel with abrupt drop. Dissertação de mestrado. Departamento de Engenharia em Recursos Hídricos, Universidade de Bangladesh de Engenharia e Tecnologia, Dhaka, 2011.

TEIXEIRA, E. D. (2003). Previsão dos valores de pressão junto ao fundo em bacias de dissipação por ressalto hidráulico. Dissertação (mestrado em Recursos Hídricos e Saneamento Ambiental), Universidade Federal do Rio Grande do Sul, Porto Alegre, 2003.

U.S. ARMY CORPS OF ENGINEERS (1994). Engineering and Design: Hydraulic Design of Flood Control Channels. Engineer Manual, 110-2-1601, Washington.

UNITED STATES BUREAU OF RECLAMATION (1987). Design of Small Dams. Water Resources Technical Publication, 860 p., 1987.

WIEST, R. A. (2008) Avaliação do campo de pressões em ressalto hidráulico formado a jusante de um vertedouro com diferentes graus de submergência. Dissertação (mestrado em Recursos Hídricos e Saneamento Ambiental). Universidade Federal do Rio Grande do Sul, Porto Alegre, 2008. 


\section{APÊNDICES}

\subsection{APÊNDICE A - FOTOS DOS EXPERIMENTOS}

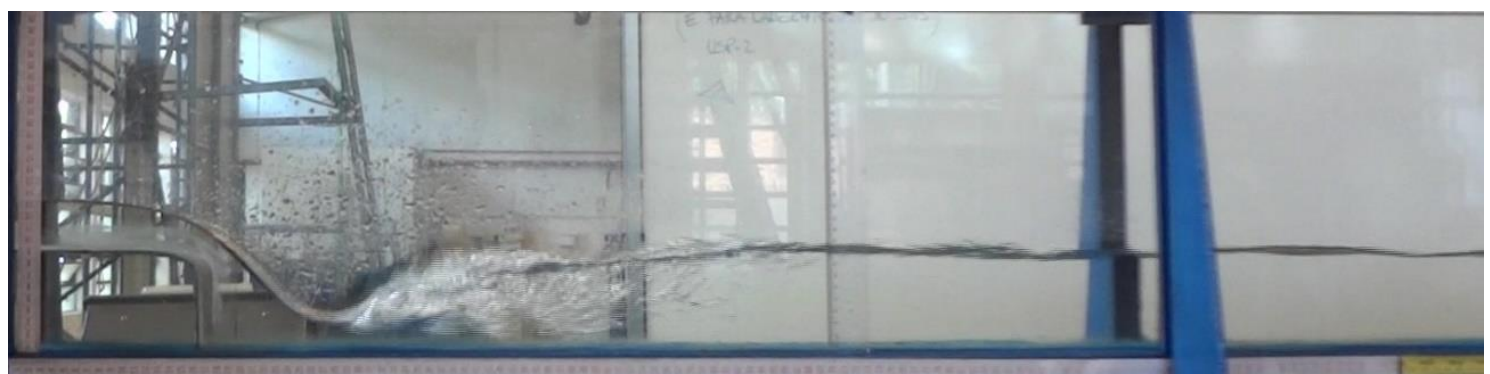

Experimento: SA-1. Vazão $=2,8 \mathrm{~L} / \mathrm{s} . \mathrm{y}_{1}=2,7 \mathrm{~cm} . \mathrm{y}_{2}=9,1 \mathrm{~cm} . \mathrm{F}_{1}=2,02$. Fundo liso, não inclinado.

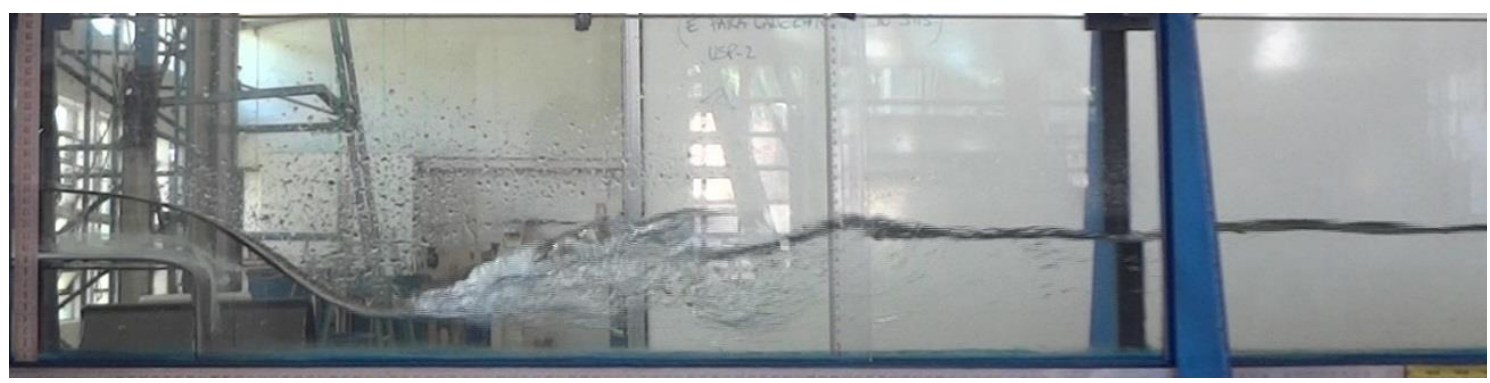

Experimento: SA-2. Vazão $=4,8 \mathrm{~L} / \mathrm{s} . \mathrm{y}_{1}=4,0 \mathrm{~cm} . \mathrm{y}_{2}=11,2 \mathrm{~cm} . \mathrm{F}_{1}=1,92$. Fundo liso, não inclinado.

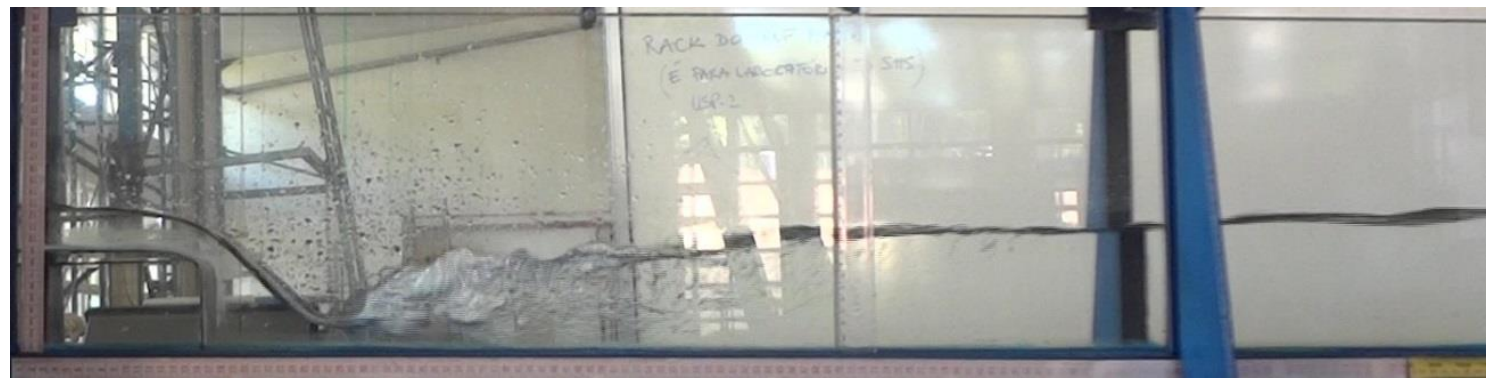

Experimento: SA-3. Vazão $=2,8 \mathrm{~L} / \mathrm{s} . \mathrm{y}_{1}=2,4 \mathrm{~cm} . \mathrm{y}_{2}=11,0 \mathrm{~cm} . \mathrm{F}_{1}=2,40$. Fundo liso, inclinado.

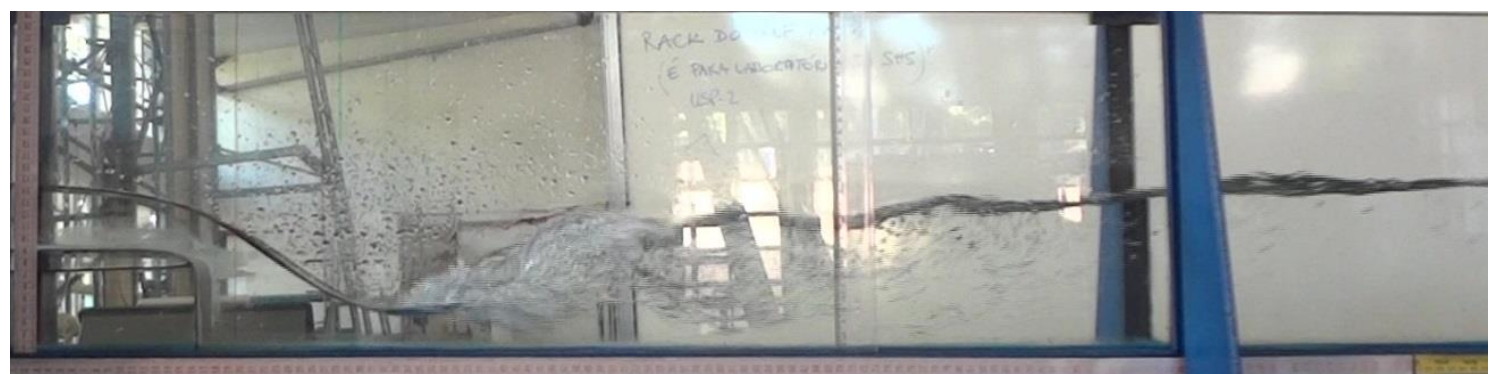

Experimento: SA-4. Vazão $=4,8 \mathrm{~L} / \mathrm{s} . \mathrm{y}_{1}=3,4 \mathrm{~cm} . \mathrm{y}_{2}=14,4 \mathrm{~cm} . \mathrm{F}_{1}=2,44$. Fundo liso, inclinado. 


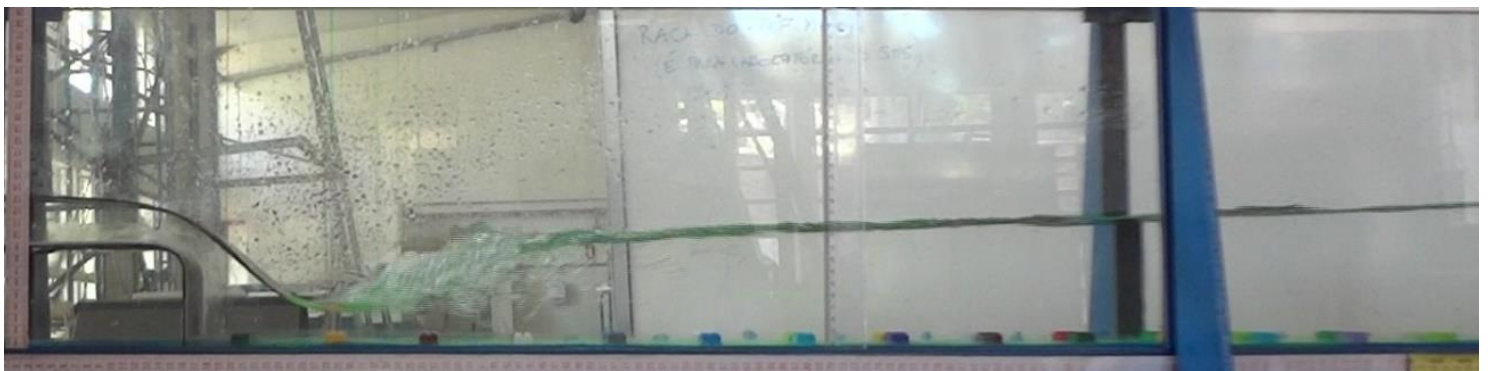

Experimento: SA-5. Vazão $=2,8 \mathrm{~L} / \mathrm{s} . \mathrm{y}_{1}=3,2 \mathrm{~cm} . \mathrm{y}_{2}=10,9 \mathrm{~cm} . \mathrm{F}_{1}=1,56$. Fundo rugoso, inclinado.

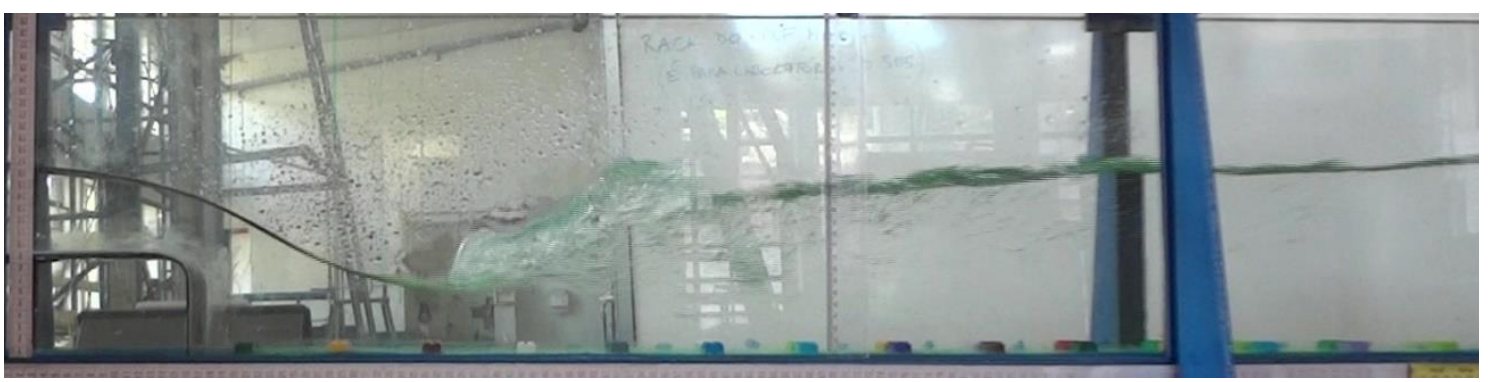

Experimento: SA-6. Vazão $=4,8$ L/s. $\mathrm{y}_{1}=5,2 \mathrm{~cm} . \mathrm{y}_{2}=15,4 \mathrm{~cm} . \mathrm{F}_{1}=1,29$. Fundo rugoso, inclinado.

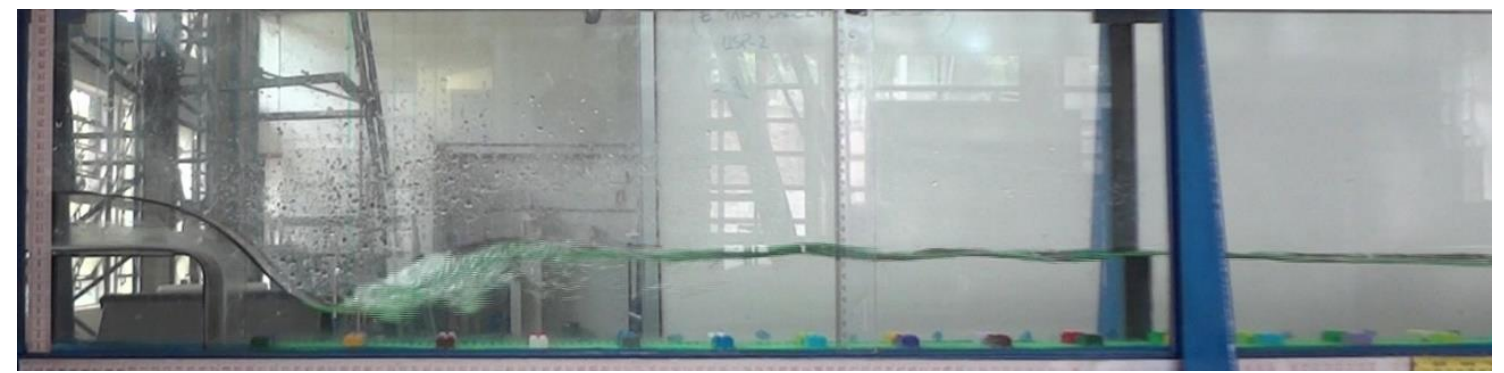

Experimento: SA-7. Vazão $=2,8 \mathrm{~L} / \mathrm{s} \cdot \mathrm{y}_{1}=3,5 \mathrm{~cm} \cdot \mathrm{y}_{2}=8,7 \mathrm{~cm} . \mathrm{F}_{1}=1,37$. Fundo rugoso, não inclinado.

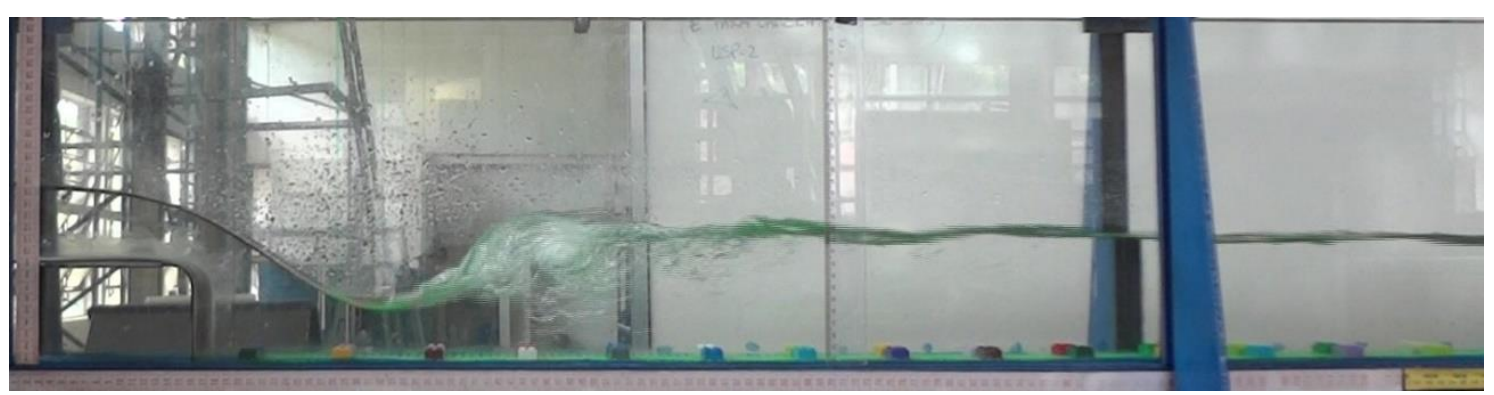

Experimento: SA-8. Vazão $=4,8 \mathrm{~L} / \mathrm{s} . \mathrm{y}_{1}=5,0 \mathrm{~cm} . \mathrm{y}_{2}=11,0 \mathrm{~cm} . \mathrm{F}_{1}=1,37$. Fundo rugoso, não inclinado. 


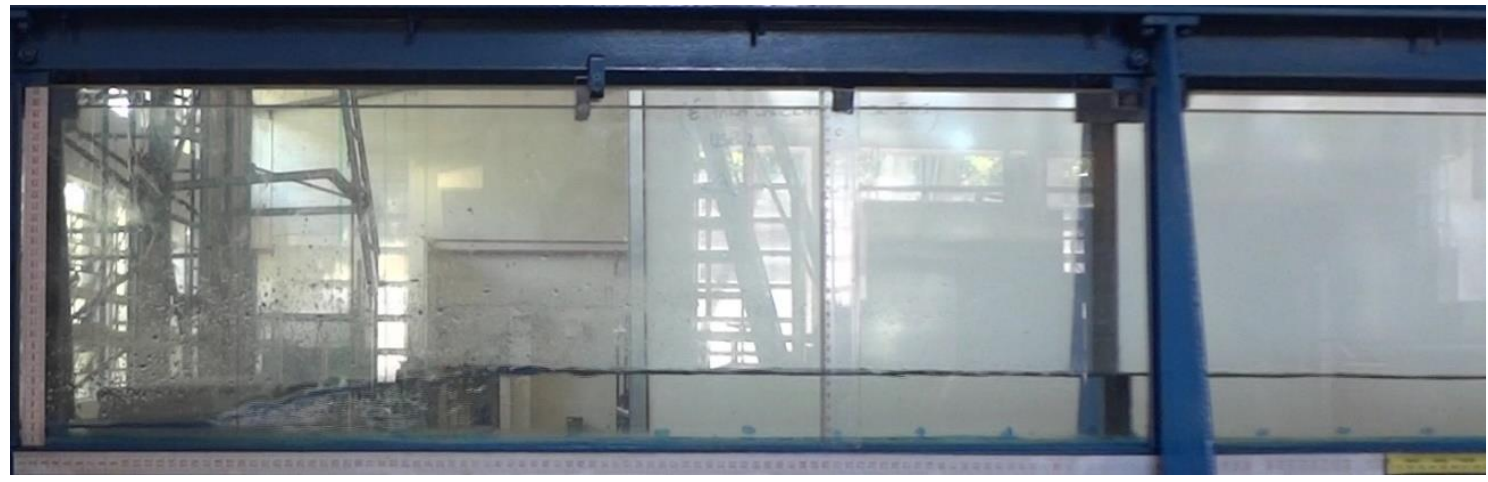

Experimento: CA-1. Vazão $=1,9 \mathrm{~L} / \mathrm{s} \cdot \mathrm{y}_{1}=1,8 \mathrm{~cm} \cdot \mathrm{y}_{2}=6,7 \mathrm{~cm} . \mathrm{F}_{1}=2,51$. Fundo liso, não inclinado.

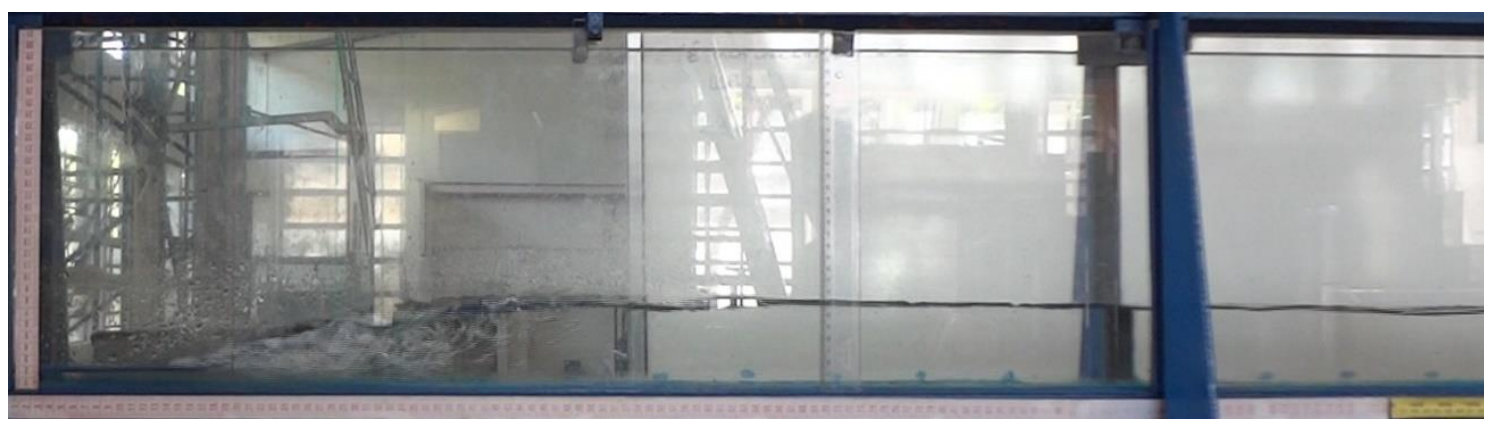

Experimento: CA-2. Vazão $=2,3 \mathrm{~L} / \mathrm{s} \cdot \mathrm{y}_{1}=2,0 \mathrm{~cm} \cdot \mathrm{y}_{2}=7,4 \mathrm{~cm} . \mathrm{F}_{1}=2,60$. Fundo liso, não inclinado.

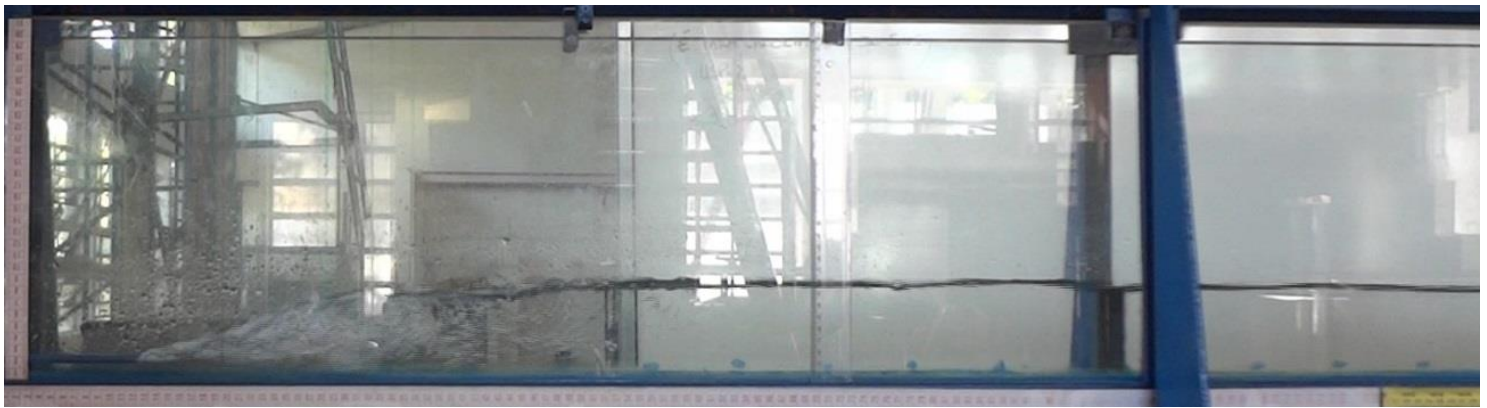

Experimento: CA-3. Vazão $=2,5 \mathrm{~L} / \mathrm{s} \cdot \mathrm{y}_{1}=2,2 \mathrm{~cm} \cdot \mathrm{y}_{2}=8,1 \mathrm{~cm} . \mathrm{F}_{1}=2,45$. Fundo liso, não inclinado.

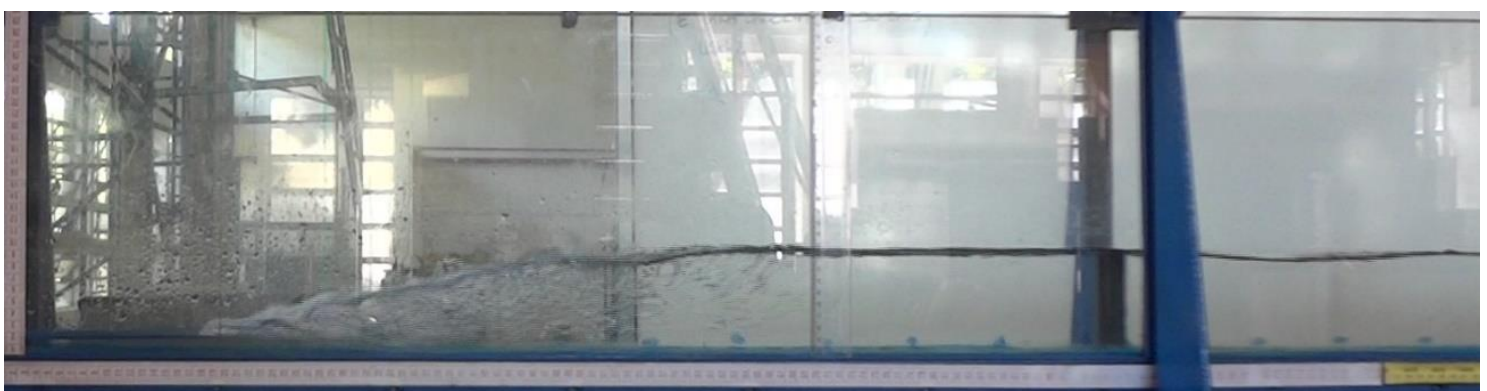

Experimento: CA-4. Vazão $=2,7 \mathrm{~L} / \mathrm{s} . \mathrm{y}_{1}=2,3 \mathrm{~cm} . \mathrm{y}_{2}=8,4 \mathrm{~cm} . \mathrm{F}_{1}=2,47$. Fundo liso, não inclinado. 


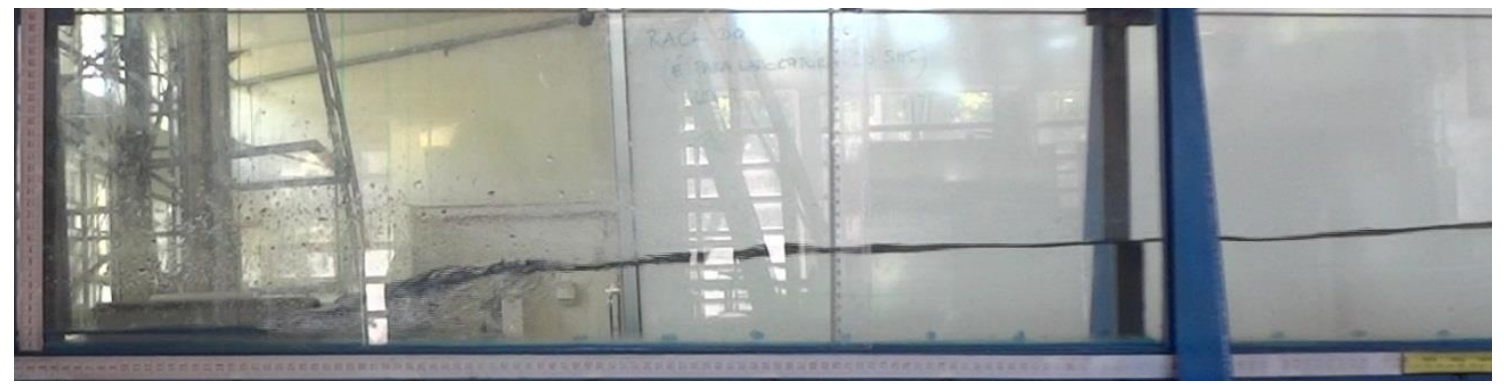

Experimento: CA-5. Vazão $=1,9 \mathrm{~L} / \mathrm{s} . \mathrm{y}_{1}=1,8 \mathrm{~cm} \cdot \mathrm{y}_{2}=9,5 \mathrm{~cm} . \mathrm{F}_{1}=2,51$. Fundo liso, inclinado.

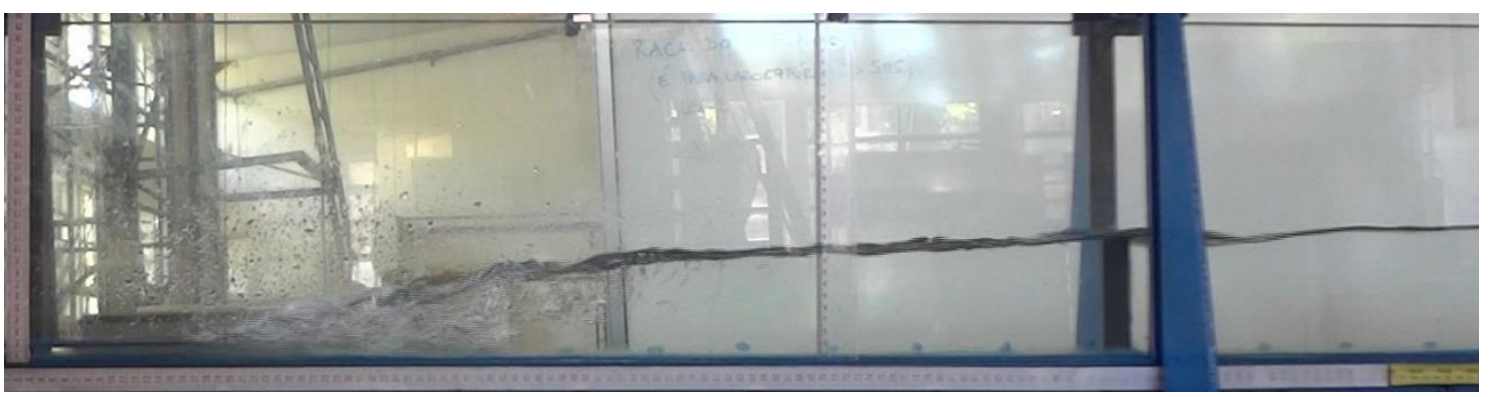

Experimento: CA-6. Vazão $=2,3 \mathrm{~L} / \mathrm{s} . \mathrm{y}_{1}=1,9 \mathrm{~cm} . \mathrm{y}_{2}=10,0 \mathrm{~cm} . \mathrm{F}_{1}=2,80$. Fundo liso, inclinado.

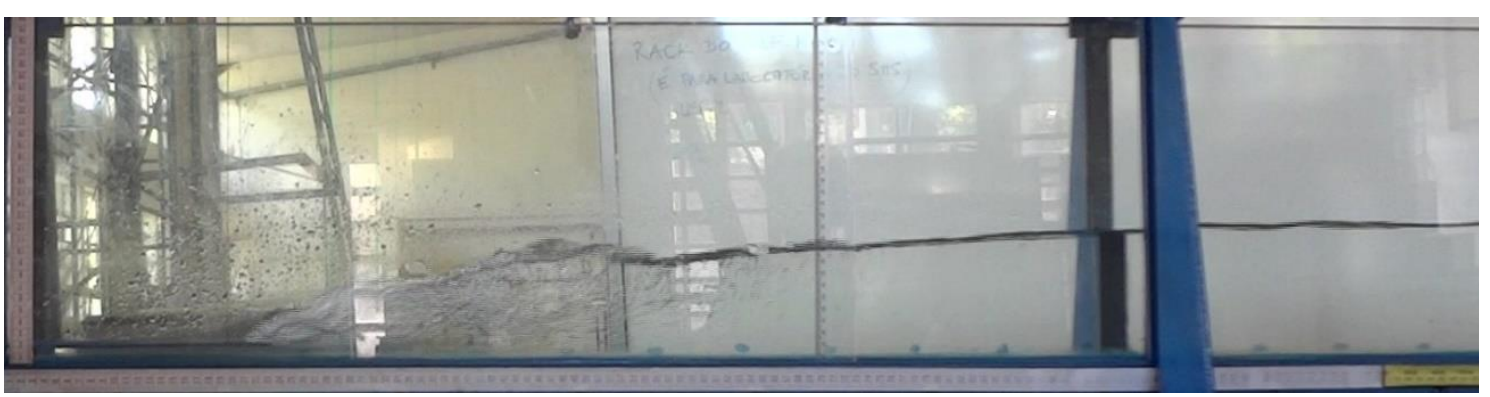

Experimento: CA-7. Vazão $=2,5 \mathrm{~L} / \mathrm{s} . \mathrm{y}_{1}=2,1 \mathrm{~cm} . \mathrm{y}_{2}=11,0 \mathrm{~cm} . \mathrm{F}_{1}=2,62$. Fundo liso, inclinado.

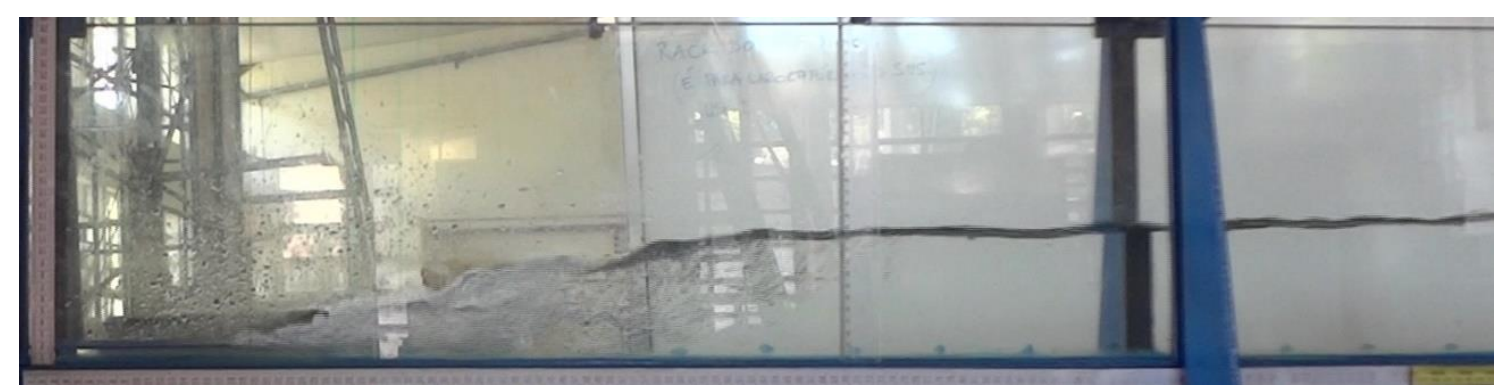

Experimento: CA-8. Vazão $=2,7 \mathrm{~L} / \mathrm{s} . \mathrm{y}_{1}=2,2 \mathrm{~cm} . \mathrm{y}_{2}=11,5 \mathrm{~cm} . \mathrm{F}_{1}=2,64$. Fundo liso, inclinado. 


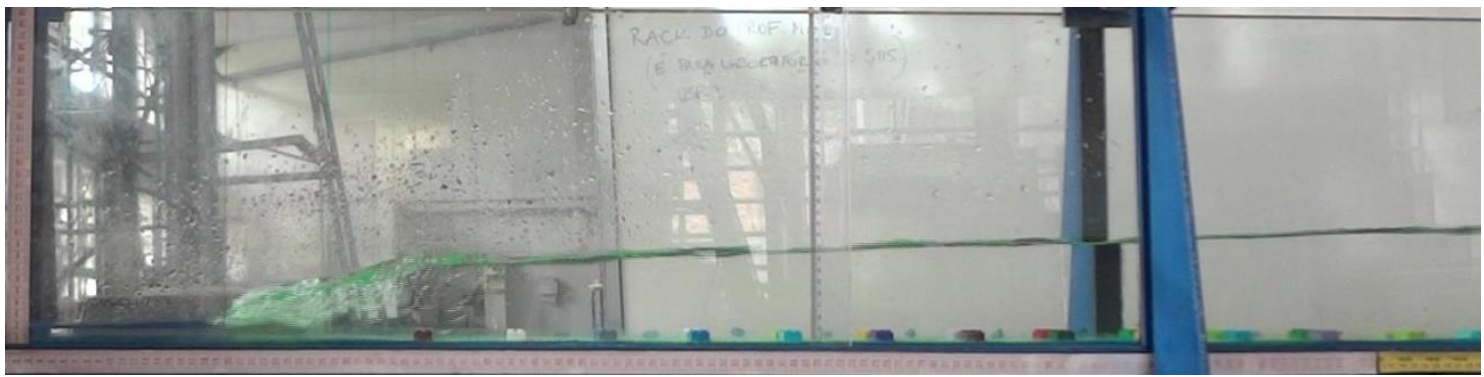

Experimento: CA-9. Vazão $=1,9$ L/s. $y_{1}=2,0 \mathrm{~cm} . \mathrm{y}_{2}=8,2 \mathrm{~cm} . \mathrm{F}_{1}=2,14$. Fundo rugoso, inclinado.

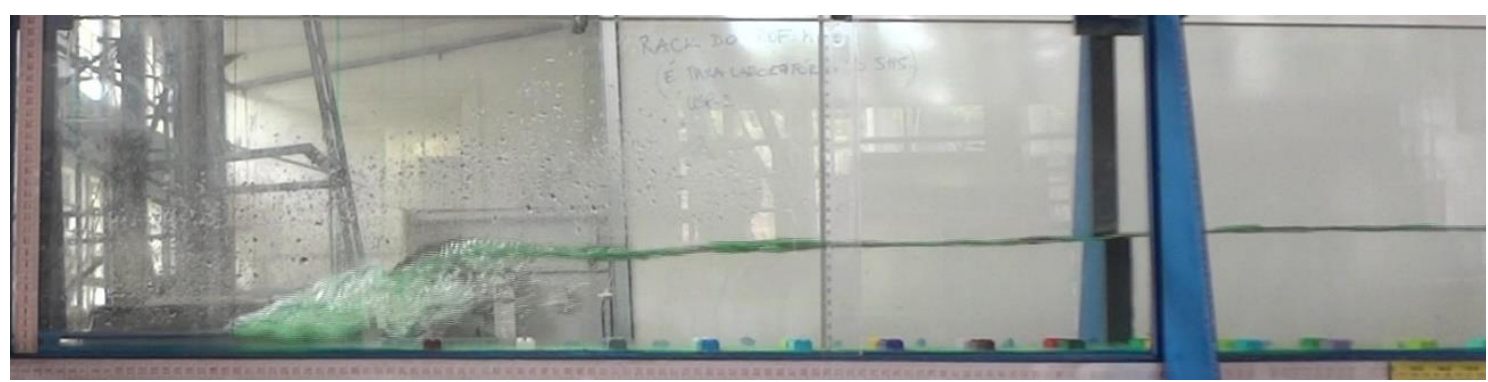

Experimento: CA-10. Vazão $=2,3 \mathrm{~L} / \mathrm{s} . \mathrm{y}_{1}=2,1 \mathrm{~cm} . \mathrm{y}_{2}=9,2 \mathrm{~cm} . \mathrm{F}_{1}=2,41$. Fundo rugoso, inclinado.

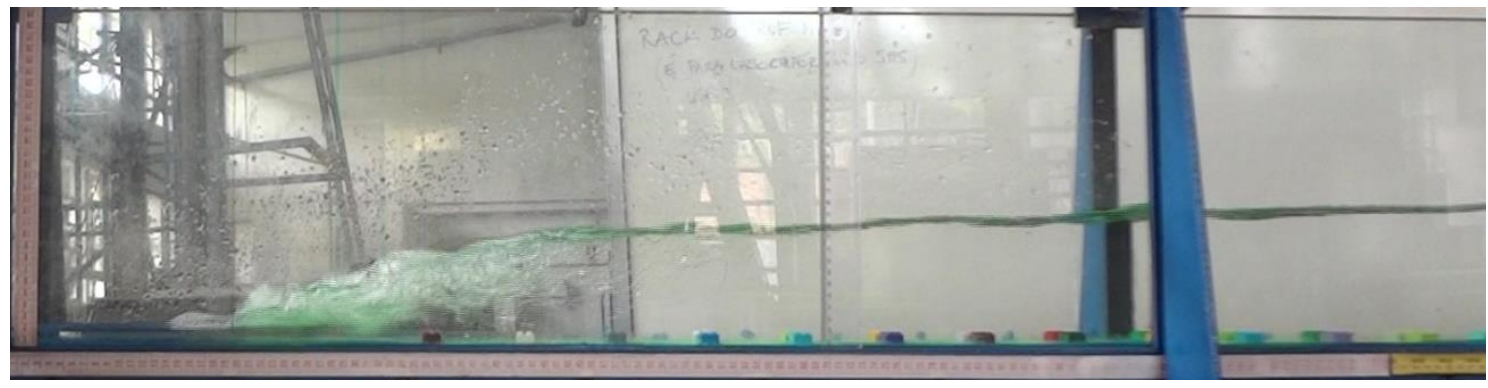

Experimento: CA-11. Vazão $=2,7 \mathrm{~L} / \mathrm{s} . \mathrm{y}_{1}=2,4 \mathrm{~cm} . \mathrm{y}_{2}=10,9 \mathrm{~cm} . \mathrm{F}_{1}=2,31$. Fundo rugoso, inclinado.

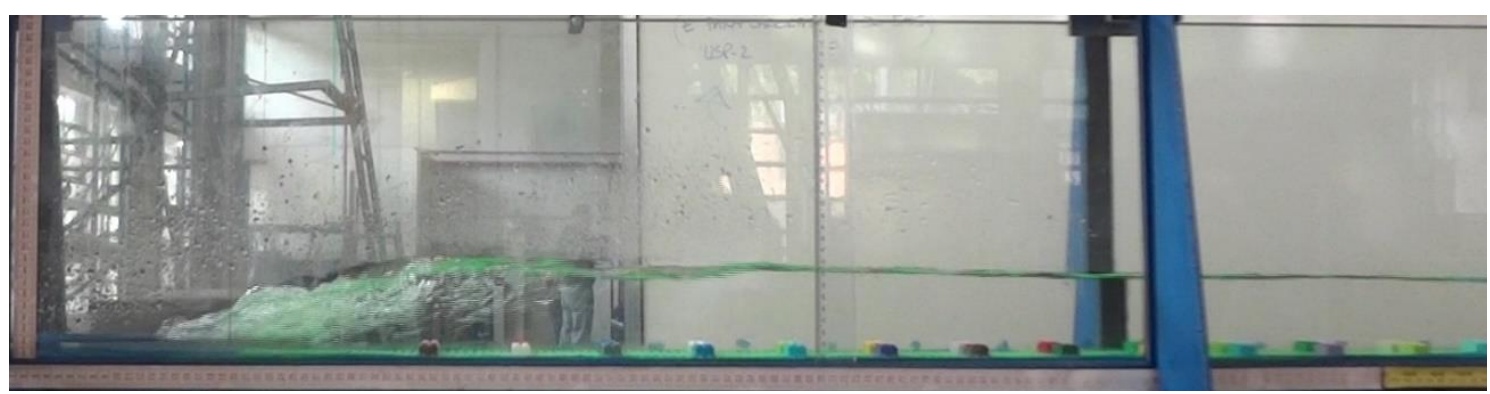

Experimento: CA-12. Vazão $=2,3 \mathrm{~L} / \mathrm{s} . \mathrm{y}_{1}=2,4 \mathrm{~cm} . \mathrm{y}_{2}=7,3 \mathrm{~cm} . \mathrm{F}_{1}=1,98$. Fundo rugoso, não inclinado. 


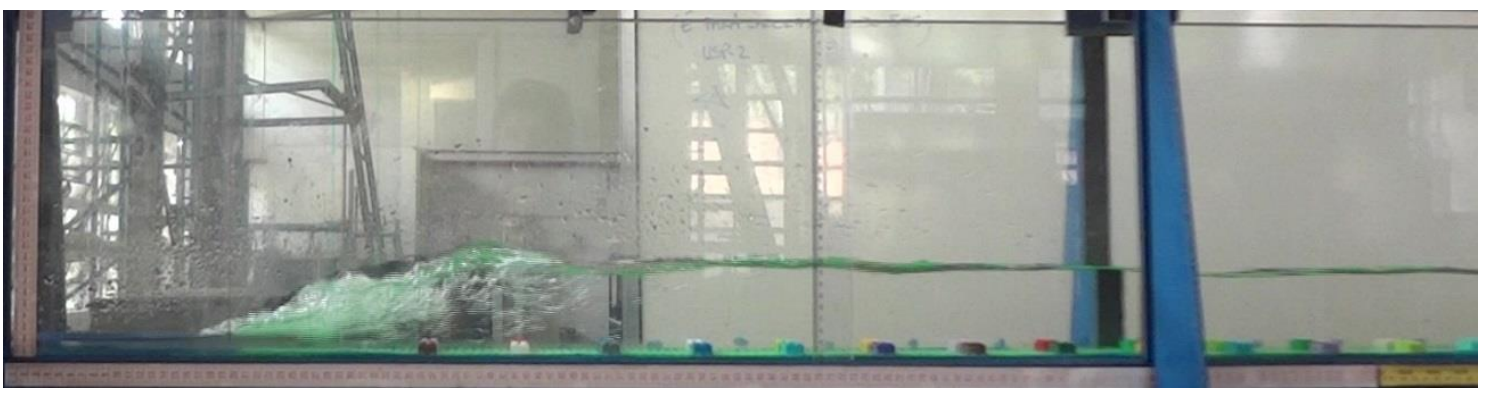

Experimento: CA-13. Vazão $=2,5 \mathrm{~L} / \mathrm{s} . \mathrm{y}_{1}=2,6 \mathrm{~cm} . \mathrm{y}_{2}=8,0 \mathrm{~cm} . \mathrm{F}_{1}=1,90$. Fundo rugoso, não inclinado.

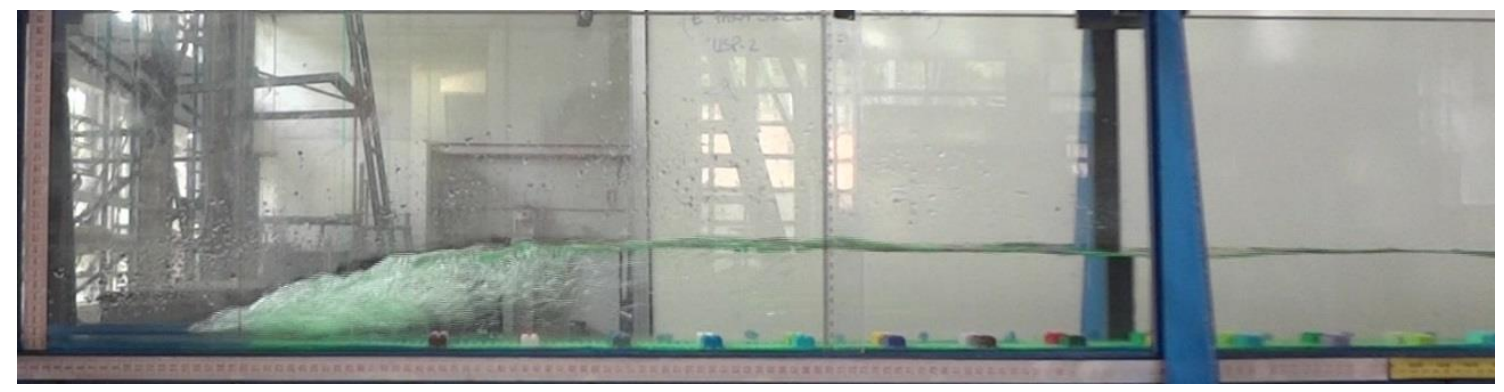

Experimento: CA-14. Vazão $=2,7 \mathrm{~L} / \mathrm{s} . \mathrm{y}_{1}=2,8 \mathrm{~cm} . \mathrm{y}_{2}=8,9 \mathrm{~cm} . \mathrm{F}_{1}=1,84$. Fundo rugoso, não inclinado.

\subsection{APÊNDICE B - SOBREPOSIÇÃO DOS QUADROS DA FILMAGEM PAR O CANAL A}

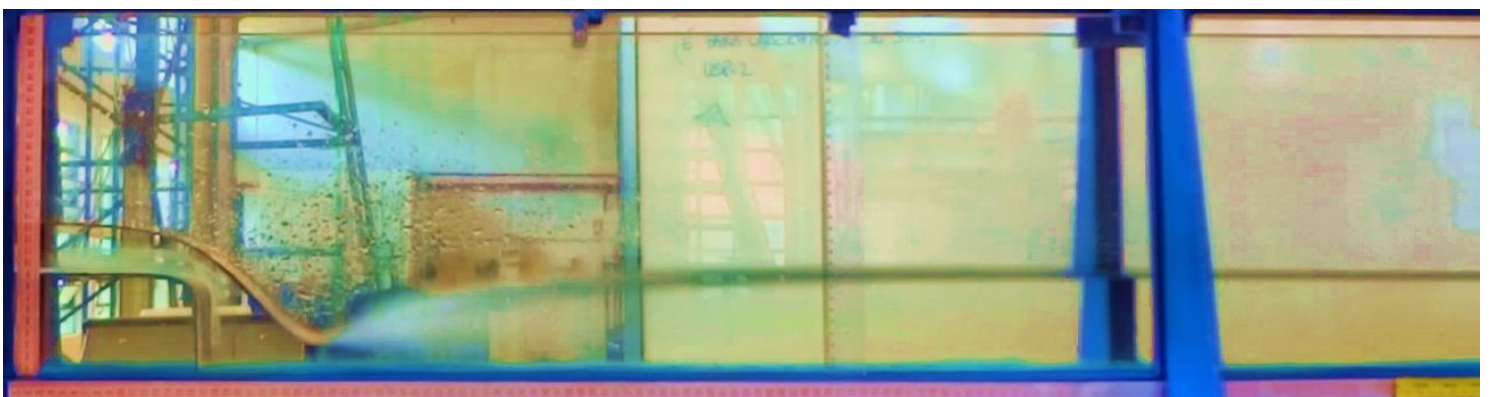

Experimento: SA-1. Vazão $=2,8 \mathrm{~L} / \mathrm{s} . \mathrm{y}_{1}=2,7 \mathrm{~cm} . \mathrm{y}_{2}=9,1 \mathrm{~cm} . \mathrm{F}_{1}=2,02$. Fundo liso, não inclinado.

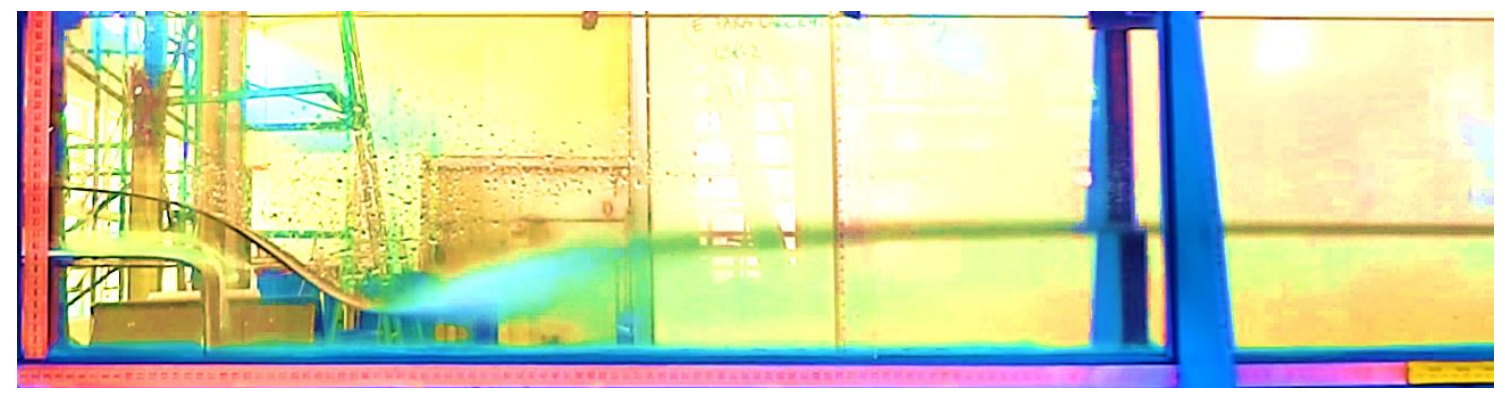

Experimento: SA-2. Vazão $=4,8 \mathrm{~L} / \mathrm{s} . \mathrm{y}_{1}=4,0 \mathrm{~cm} . \mathrm{y}_{2}=11,2 \mathrm{~cm} . \mathrm{F}_{1}=1,92$. Fundo liso, não inclinado. 


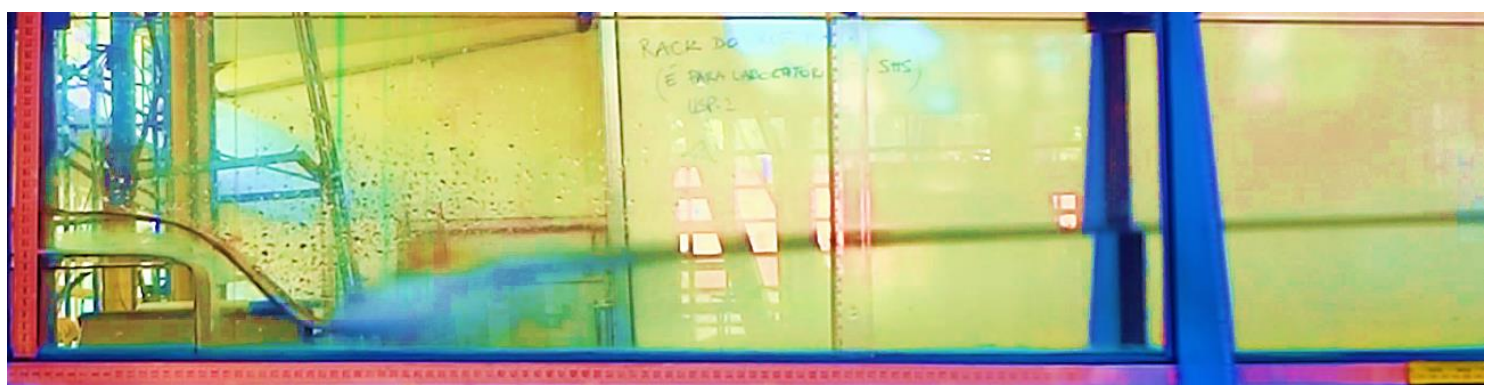

Experimento: SA-3. Vazão $=2,8 \mathrm{~L} / \mathrm{s} . \mathrm{y}_{1}=2,4 \mathrm{~cm} \cdot \mathrm{y}_{2}=11,0 \mathrm{~cm} . \mathrm{F}_{1}=2,40$. Fundo liso, inclinado.

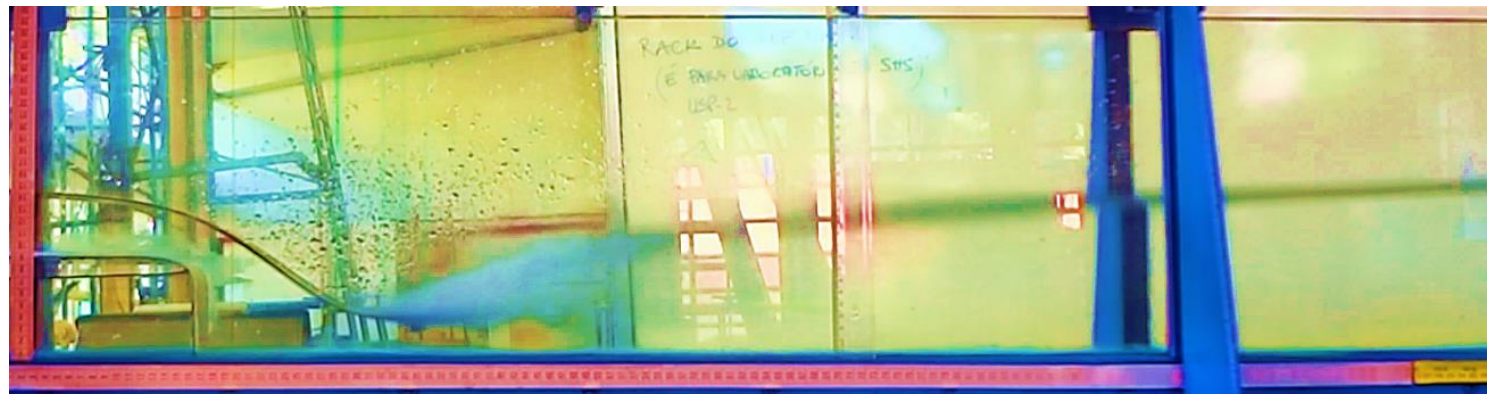

Experimento: SA-4. Vazão $=4,8 \mathrm{~L} / \mathrm{s} . \mathrm{y}_{1}=3,4 \mathrm{~cm} . \mathrm{y}_{2}=14,4 \mathrm{~cm} . \mathrm{F}_{1}=2,44$. Fundo liso, inclinado.

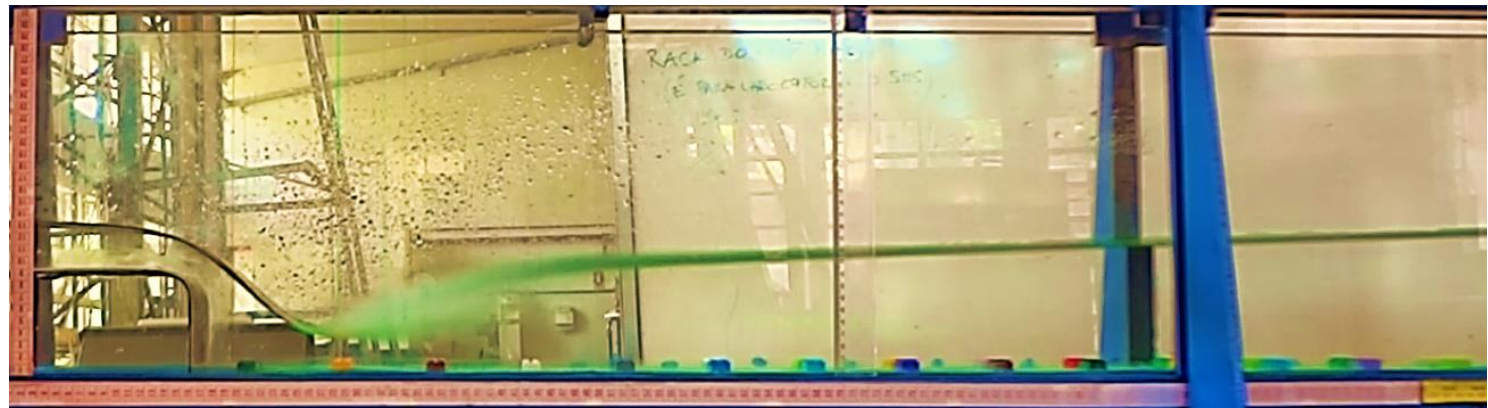

Experimento: SA-5. Vazão $=2,8 \mathrm{~L} / \mathrm{s} . \mathrm{y}_{1}=3,2 \mathrm{~cm} . \mathrm{y}_{2}=10,9 \mathrm{~cm} . \mathrm{F}_{1}=1,56$. Fundo rugoso, inclinado.

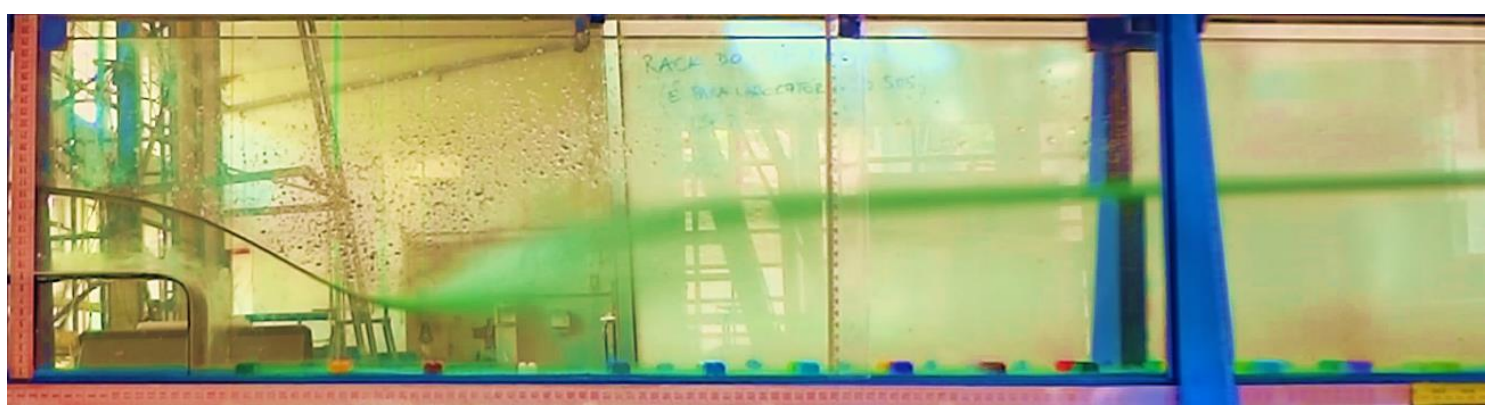

Experimento: SA-6. Vazão $=4,8 \mathrm{~L} / \mathrm{s} . \mathrm{y}_{1}=5,2 \mathrm{~cm} . \mathrm{y}_{2}=15,4 \mathrm{~cm} . \mathrm{F}_{1}=1,29$. Fundo rugoso, inclinado. 


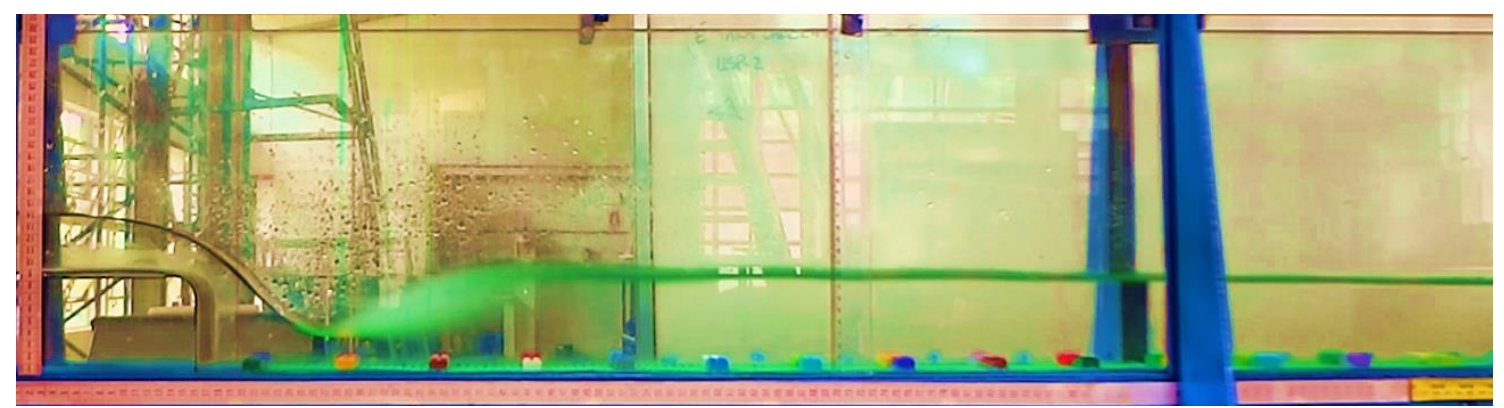

Experimento: SA-7. Vazão $=2,8 \mathrm{~L} / \mathrm{s} . \mathrm{y}_{1}=3,5 \mathrm{~cm} . \mathrm{y}_{2}=8,7 \mathrm{~cm} . \mathrm{F}_{1}=1,37$. Fundo rugoso, não inclinado.

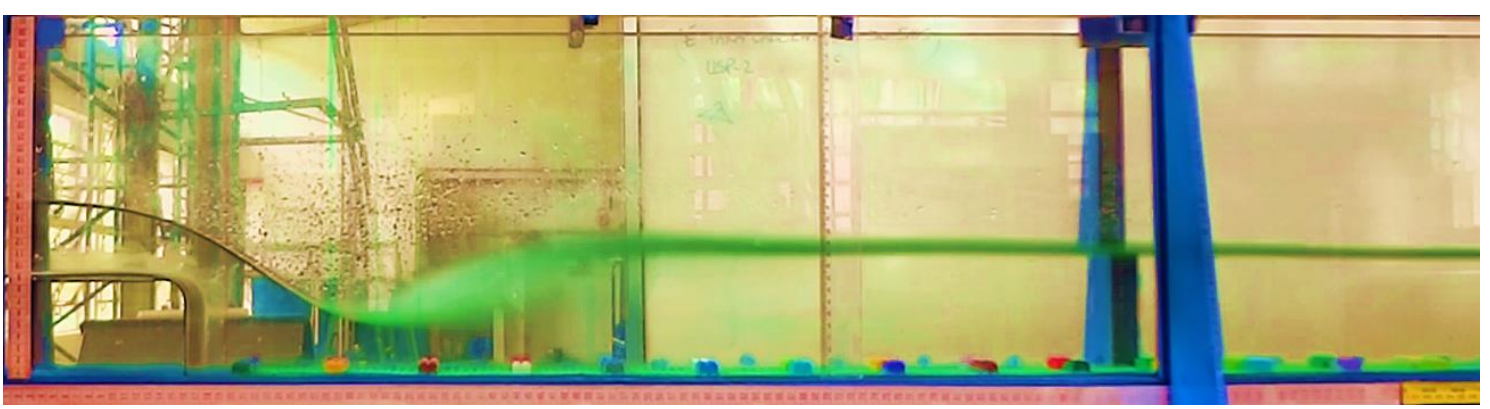

Experimento: SA-8. Vazão $=4,8 \mathrm{~L} / \mathrm{s} . \mathrm{y}_{1}=5,0 \mathrm{~cm} . \mathrm{y}_{2}=11,0 \mathrm{~cm} . \mathrm{F}_{1}=1,37$. Fundo rugoso, não inclinado.

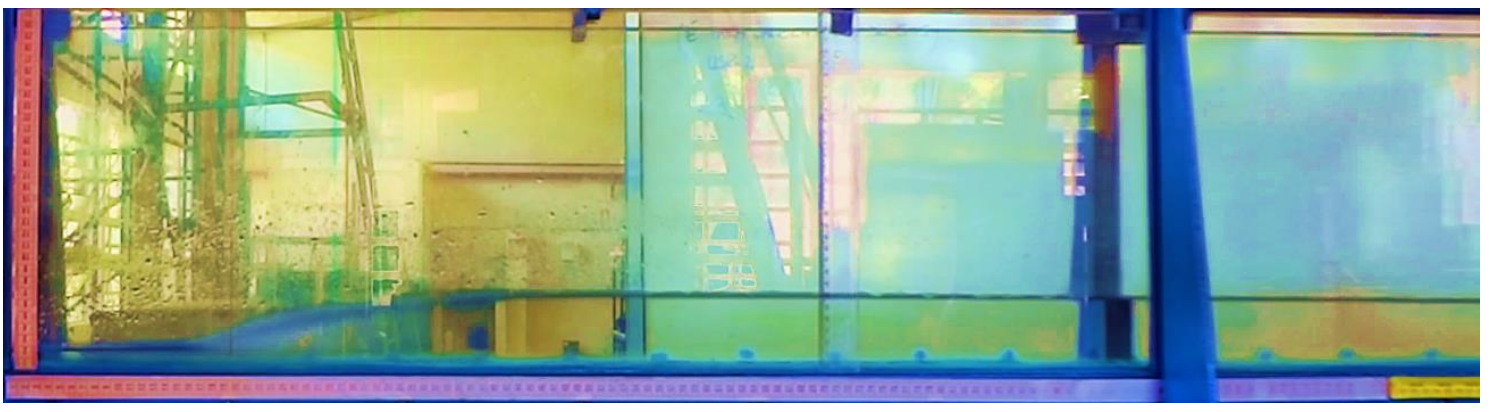

Experimento: CA-1. Vazão $=1,9$ L/s. $\mathrm{y}_{1}=1,8 \mathrm{~cm} . \mathrm{y}_{2}=6,7 \mathrm{~cm} . \mathrm{F}_{1}=2,51$. Fundo liso, não inclinado.

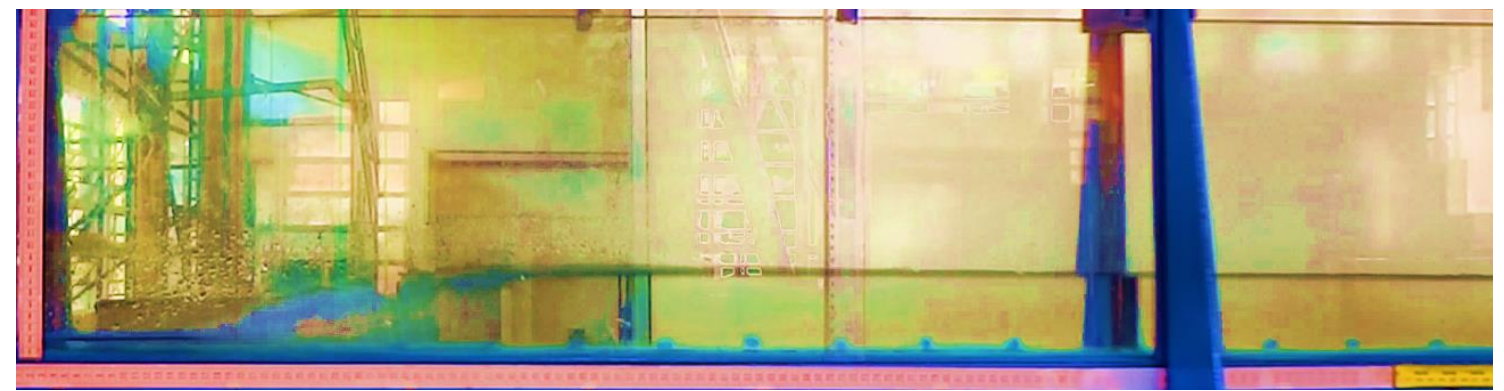

Experimento: CA-2. Vazão $=2,3 \mathrm{~L} / \mathrm{s} . \mathrm{y}_{1}=2,0 \mathrm{~cm} . \mathrm{y}_{2}=7,4 \mathrm{~cm} . \mathrm{F}_{1}=2,60$. Fundo liso, não inclinado. 


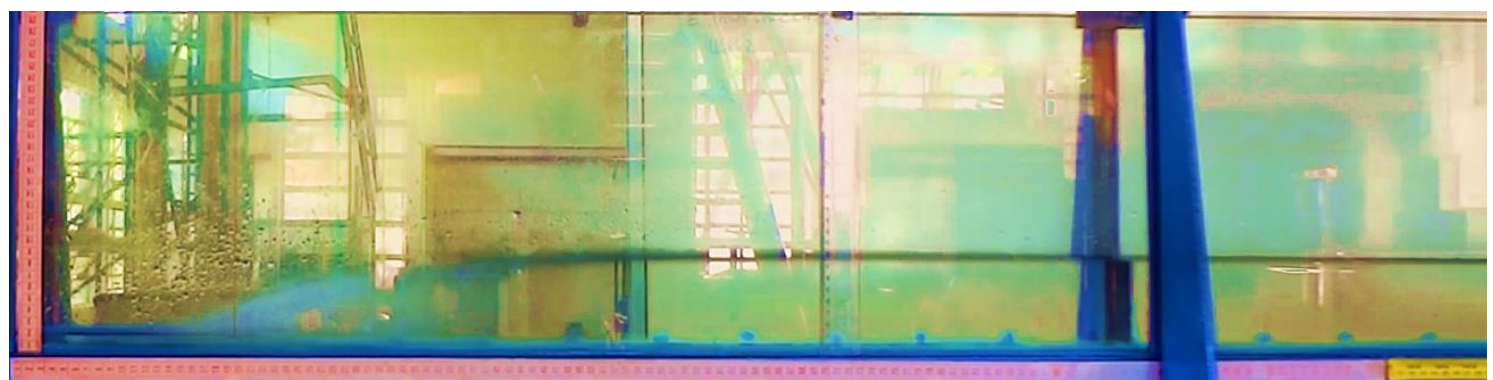

Experimento: CA-3. Vazão $=2,5 \mathrm{~L} / \mathrm{s} \cdot \mathrm{y}_{1}=2,2 \mathrm{~cm} \cdot \mathrm{y}_{2}=8,1 \mathrm{~cm} \cdot \mathrm{F}_{1}=2,45$. Fundo liso, não inclinado.

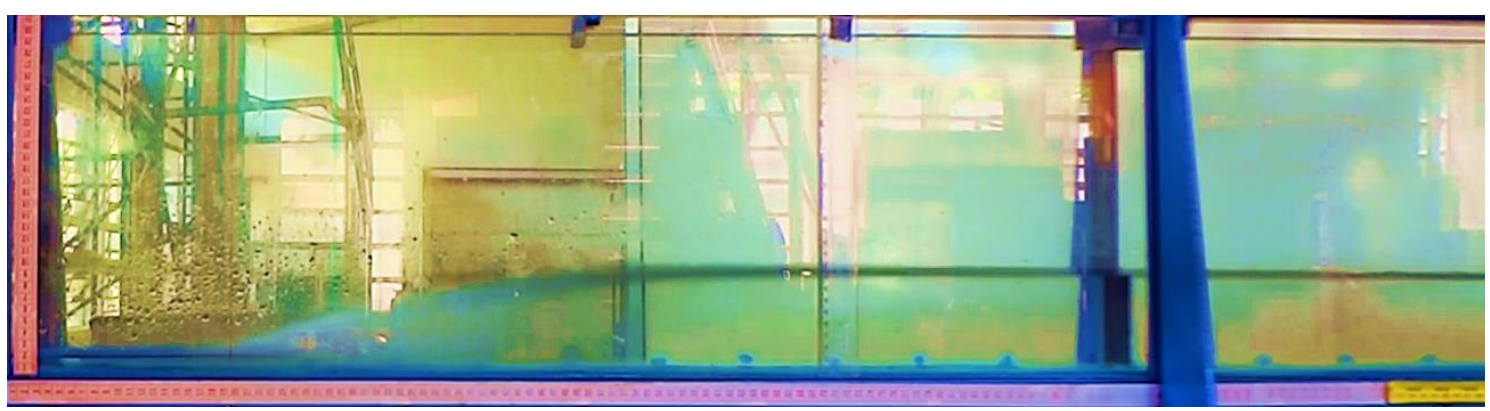

Experimento: CA-4. Vazão $=2,7 \mathrm{~L} / \mathrm{s} \cdot \mathrm{y}_{1}=2,3 \mathrm{~cm} \cdot \mathrm{y}_{2}=8,4 \mathrm{~cm} . \mathrm{F}_{1}=2,47$. Fundo liso, não inclinado.

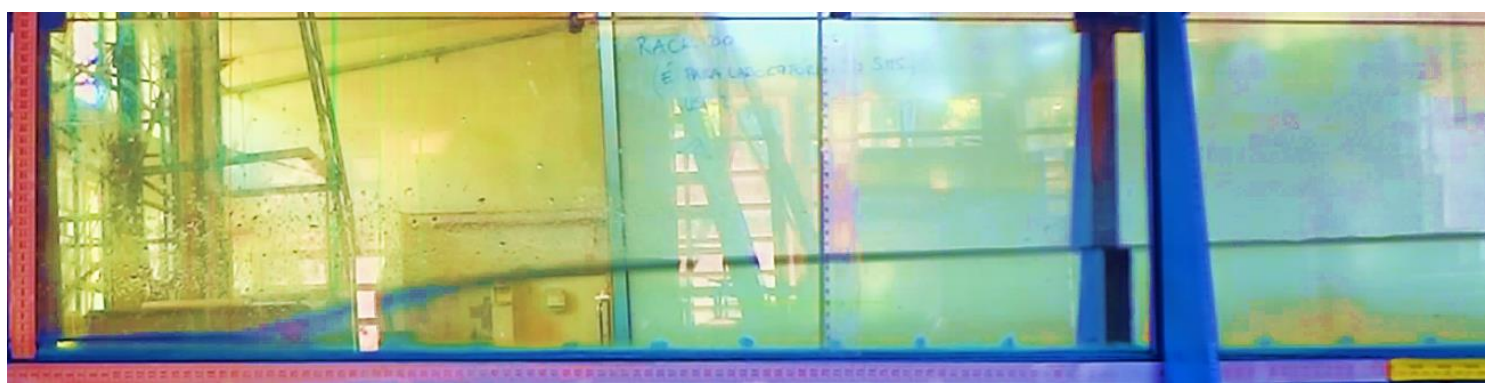

Experimento: CA-5. Vazão $=1,9 \mathrm{~L} / \mathrm{s} . \mathrm{y}_{1}=1,8 \mathrm{~cm} \cdot \mathrm{y}_{2}=9,5 \mathrm{~cm} . \mathrm{F}_{1}=2,51$. Fundo liso, inclinado.

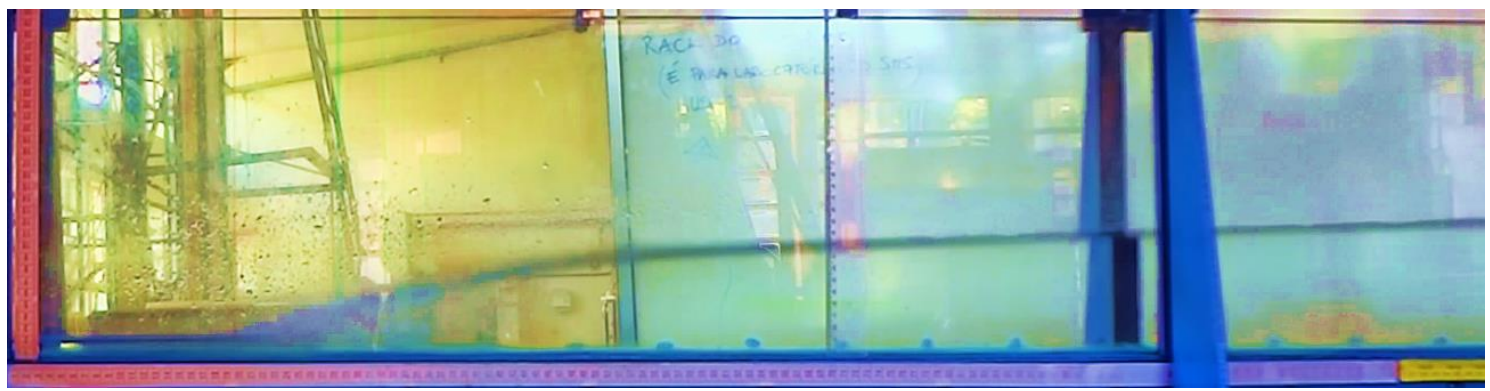

Experimento: CA-6. Vazão $=2,3 \mathrm{~L} / \mathrm{s} . \mathrm{y}_{1}=1,9 \mathrm{~cm} . \mathrm{y}_{2}=10,0 \mathrm{~cm} . \mathrm{F}_{1}=2,80$. Fundo liso, inclinado. 


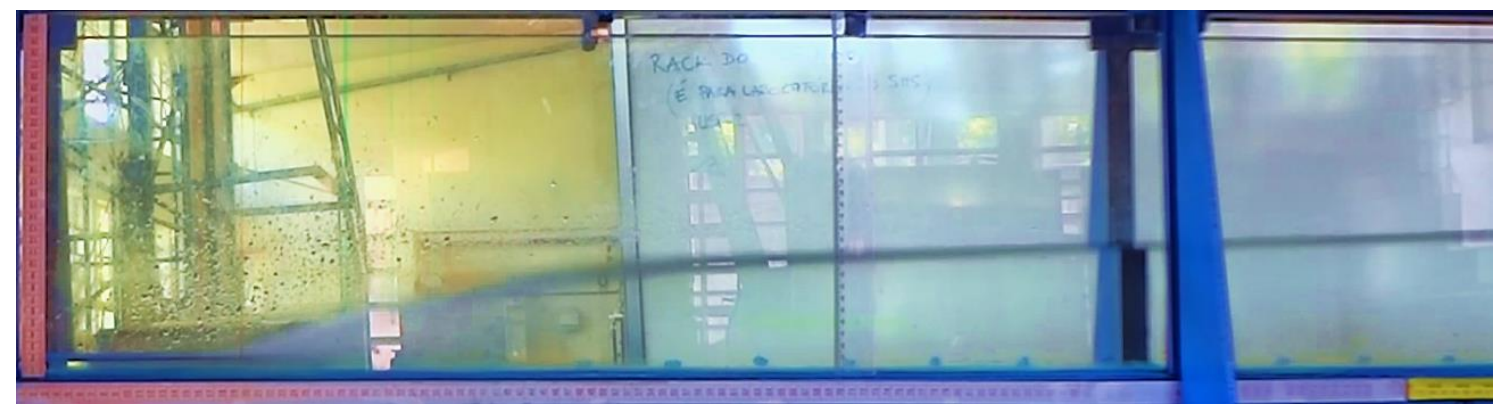

Experimento: CA-7. Vazão $=2,5 \mathrm{~L} / \mathrm{s} . \mathrm{y}_{1}=2,1 \mathrm{~cm} . \mathrm{y}_{2}=11,0 \mathrm{~cm} . \mathrm{F}_{1}=2,62$. Fundo liso, inclinado.

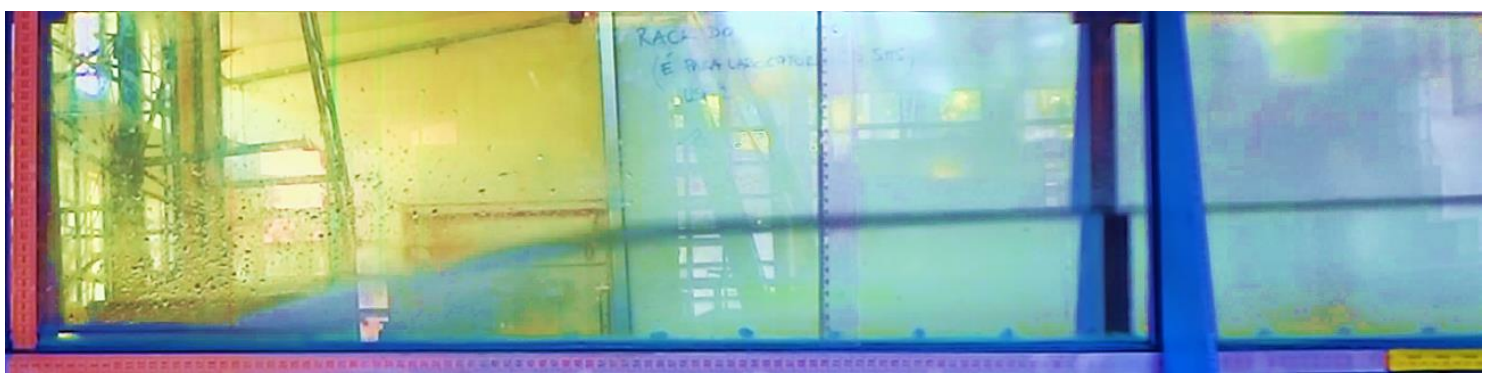

Experimento: CA-8. Vazão $=2,7 \mathrm{~L} / \mathrm{s} . \mathrm{y}_{1}=2,2 \mathrm{~cm} . \mathrm{y}_{2}=11,5 \mathrm{~cm} . \mathrm{F}_{1}=2,64$. Fundo liso, inclinado.

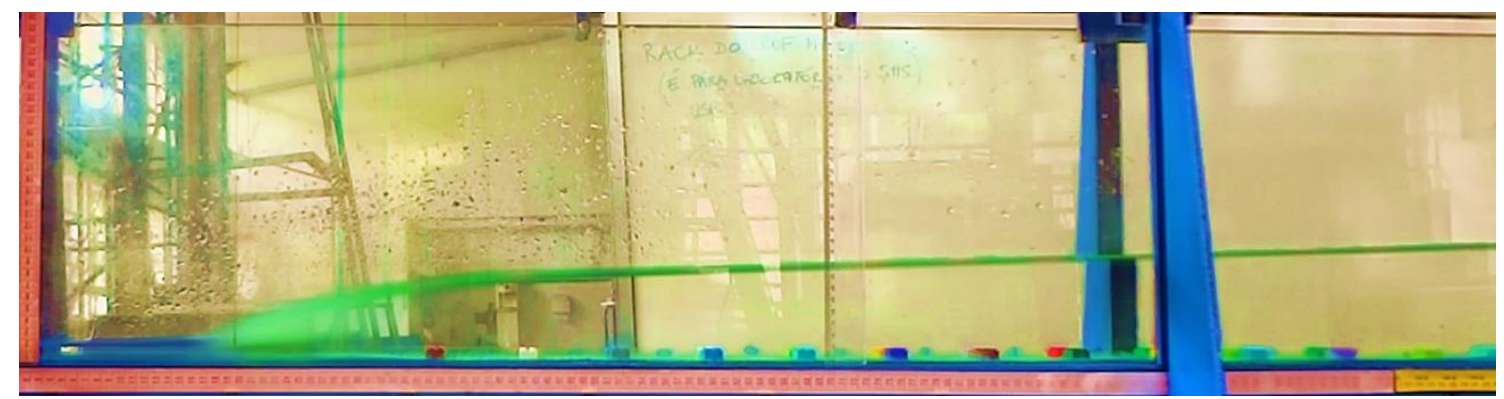

Experimento: CA-9. Vazão $=1,9$ L/s. $y_{1}=2,0 \mathrm{~cm} \cdot \mathrm{y}_{2}=8,2 \mathrm{~cm} . \mathrm{F}_{1}=2,14$. Fundo rugoso, inclinado.

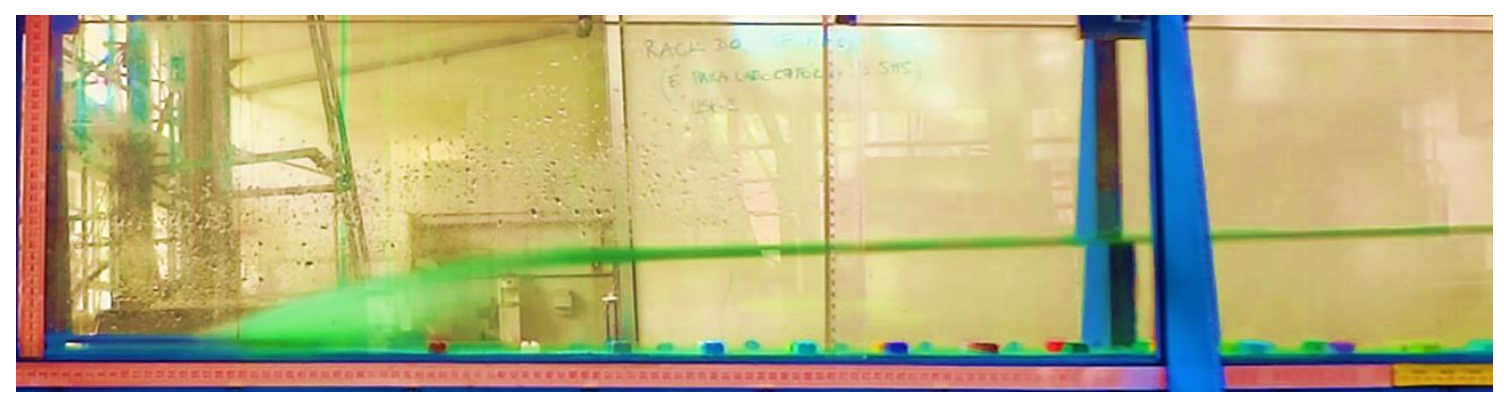

Experimento: CA-10. Vazão $=2,3 \mathrm{~L} / \mathrm{s} \cdot \mathrm{y}_{1}=2,1 \mathrm{~cm} \cdot \mathrm{y}_{2}=9,2 \mathrm{~cm} . \mathrm{F}_{1}=2,41$. Fundo rugoso, inclinado. 


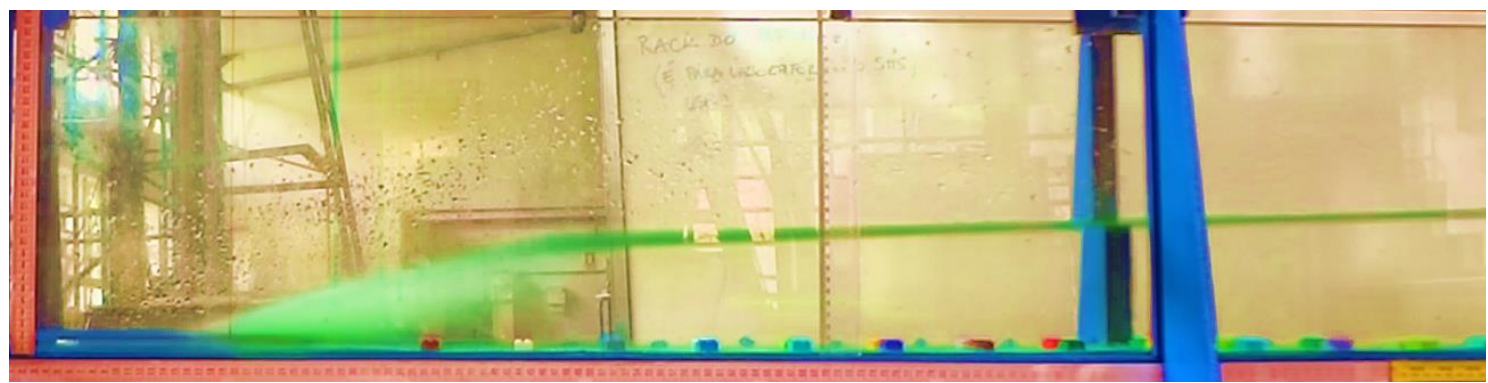

Experimento: CA-11. Vazão $=2,7 \mathrm{~L} / \mathrm{s} . \mathrm{y}_{1}=2,4 \mathrm{~cm} \cdot \mathrm{y}_{2}=10,9 \mathrm{~cm} . \mathrm{F}_{1}=2,31$. Fundo rugoso, inclinado.

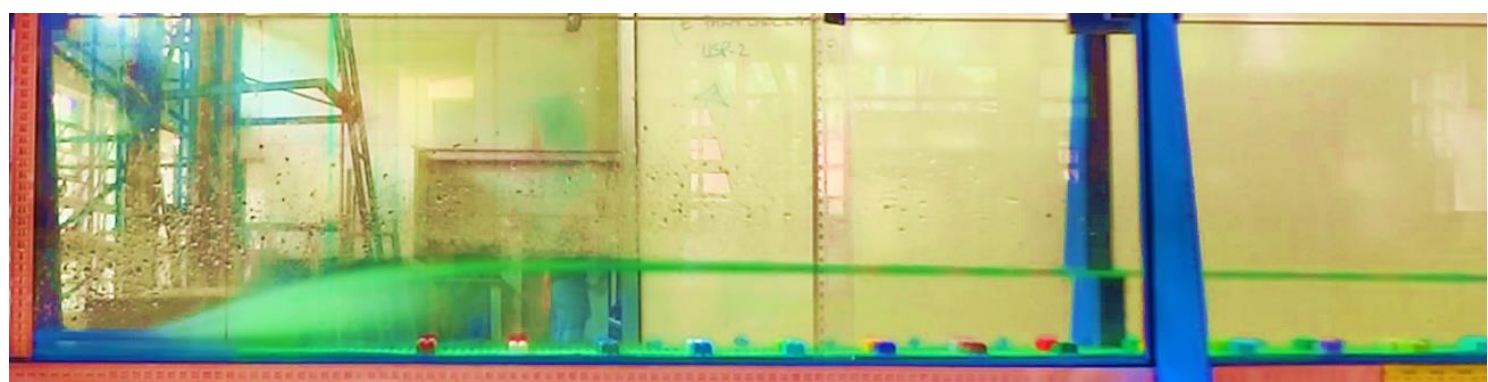

Experimento: CA-12. Vazão $=2,3 \mathrm{~L} / \mathrm{s} . \mathrm{y}_{1}=2,4 \mathrm{~cm} . \mathrm{y}_{2}=7,3 \mathrm{~cm} . \mathrm{F}_{1}=1,98$. Fundo rugoso, não inclinado.

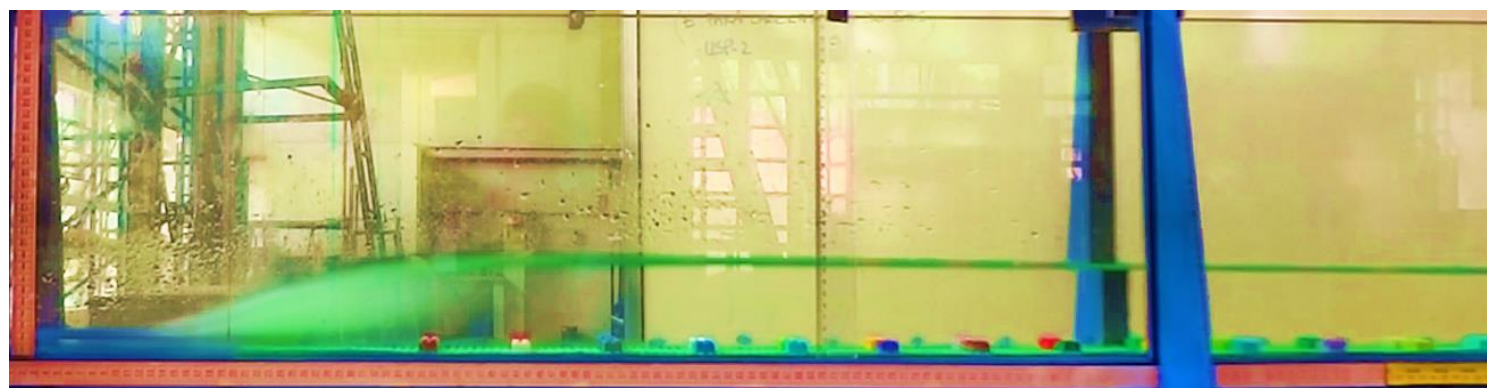

Experimento: CA-13. Vazão $=2,5 \mathrm{~L} / \mathrm{s} \cdot \mathrm{y}_{1}=2,6 \mathrm{~cm} . \mathrm{y}_{2}=8,0 \mathrm{~cm} . \mathrm{F}_{1}=1,90$. Fundo rugoso, não inclinado.

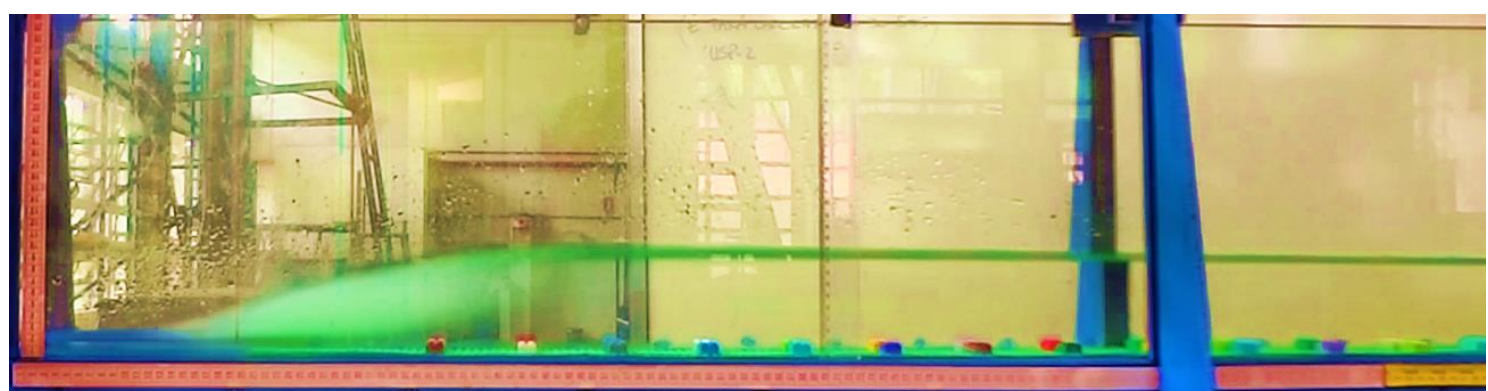

Experimento: CA-14. Vazão $=2,7 \mathrm{~L} / \mathrm{s} \cdot \mathrm{y}_{1}=2,8 \mathrm{~cm} \cdot \mathrm{y}_{2}=8,9 \mathrm{~cm} . \mathrm{F}_{1}=1,84$. Fundo rugoso, não inclinado. 
8.3. APÊNDICE C - PERFIL DE SUPERFÍCIE LIVRE PARA EXPERIMENTOS DO CANAL B

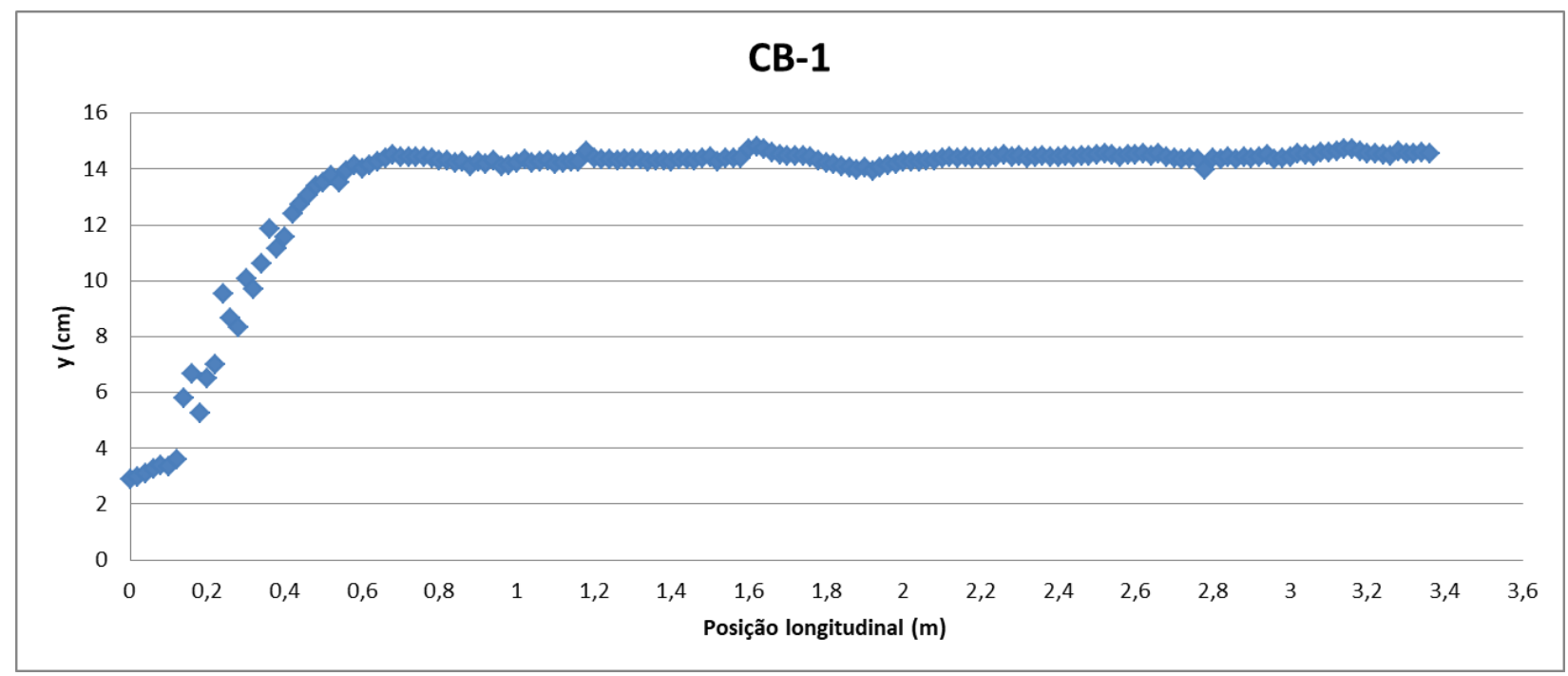

Experimento: CB-1. Vazão $=20 \mathrm{~L} / \mathrm{s} . \mathrm{y}_{1}=2,8 \mathrm{~cm} . \mathrm{y}_{2}=14,4 \mathrm{~cm} . \mathrm{F}_{1}=3,34$. Fundo liso.

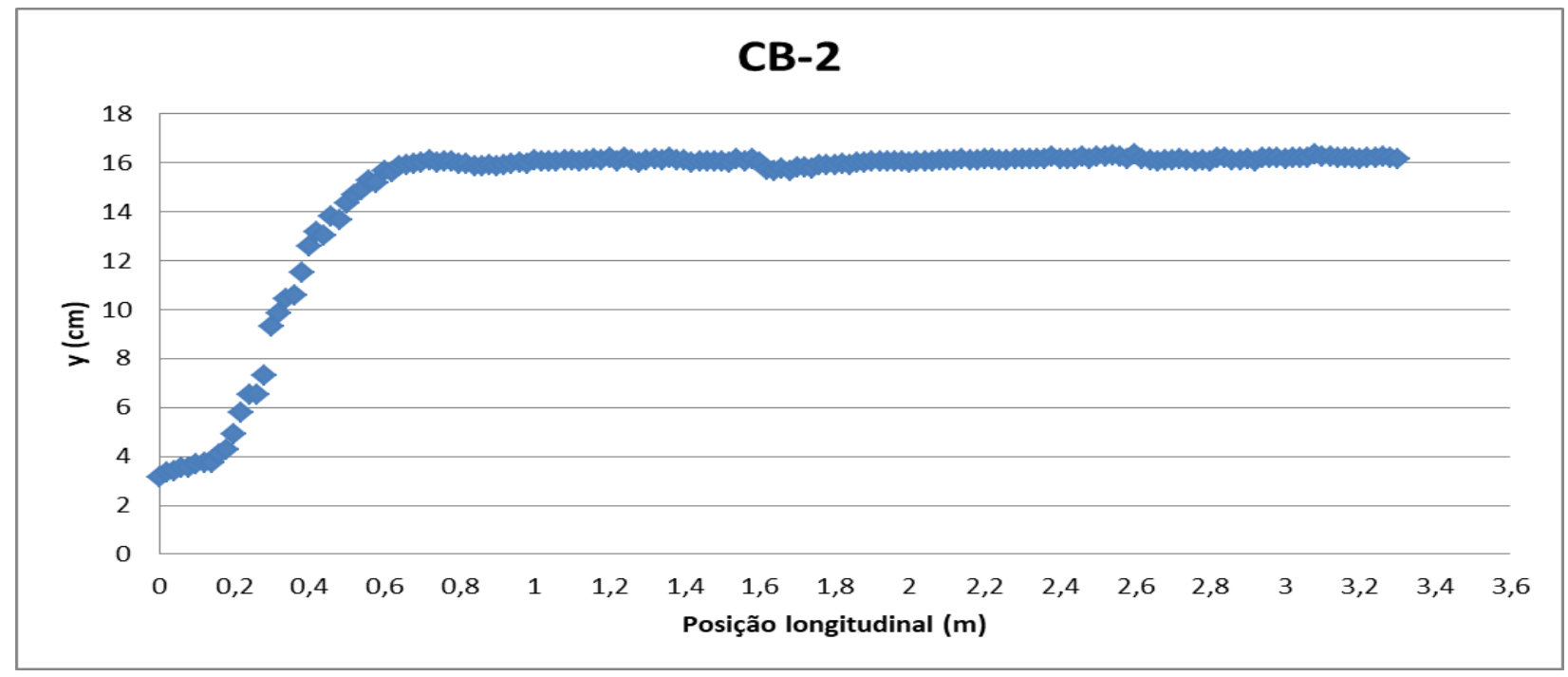

Experimento: CB-2. Vazão $=25 \mathrm{~L} / \mathrm{s} . \mathrm{y}_{1}=3,1 \mathrm{~cm} . \mathrm{y}_{2}=16,1 \mathrm{~cm} . \mathrm{F}_{1}=3,57$. Fundo liso. 


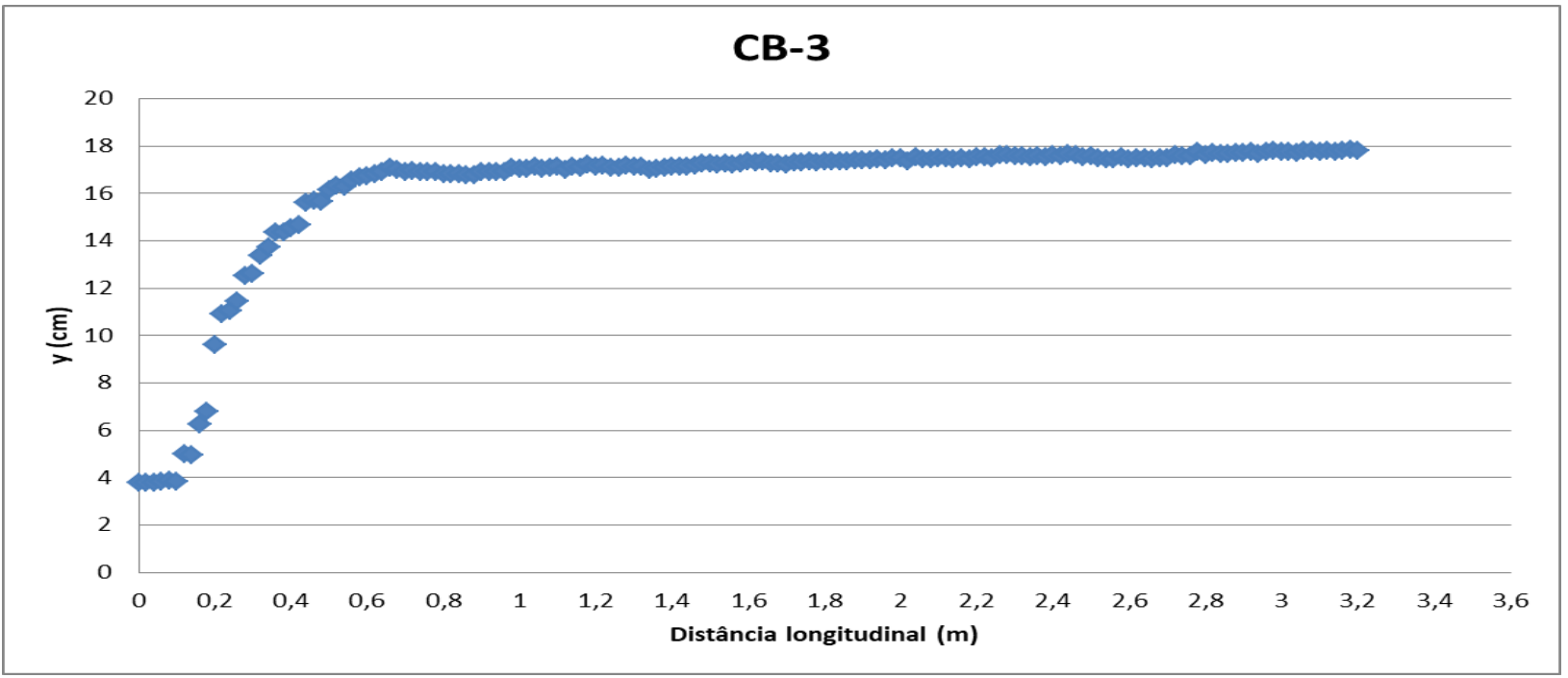

Experimento: CB-3. Vazão $=30 \mathrm{~L} / \mathrm{s} . \mathrm{y}_{1}=3,8 \mathrm{~cm} . \mathrm{y}_{2}=17,4 \mathrm{~cm} . \mathrm{F}_{1}=3,15$. Fundo liso.

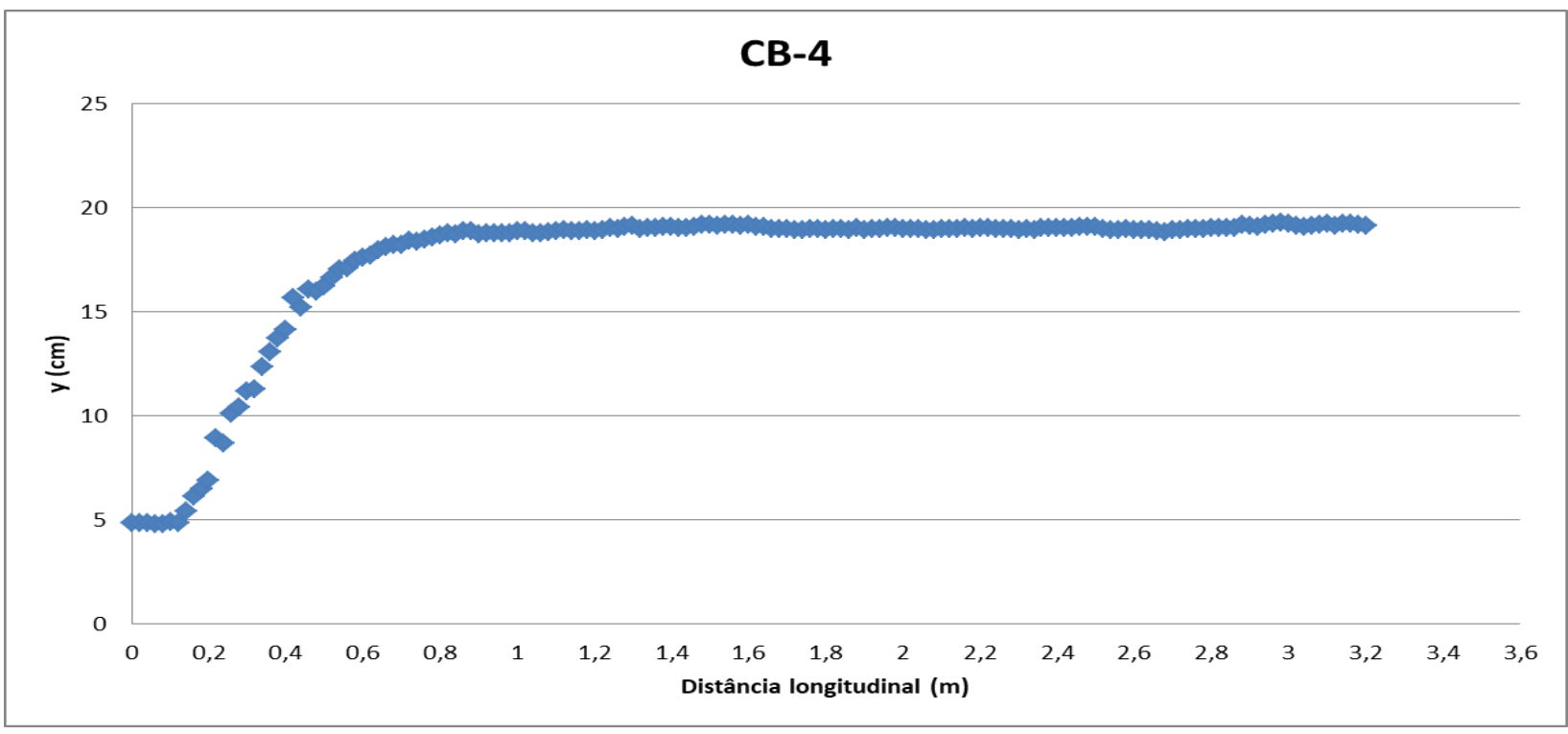

Experimento: CB-4. Vazão $=35 \mathrm{~L} / \mathrm{s} \cdot \mathrm{y}_{1}=4,3 \mathrm{~cm} \cdot \mathrm{y}_{2}=19,0 \mathrm{~cm} . \mathrm{F}_{1}=3,07$. Fundo liso. 


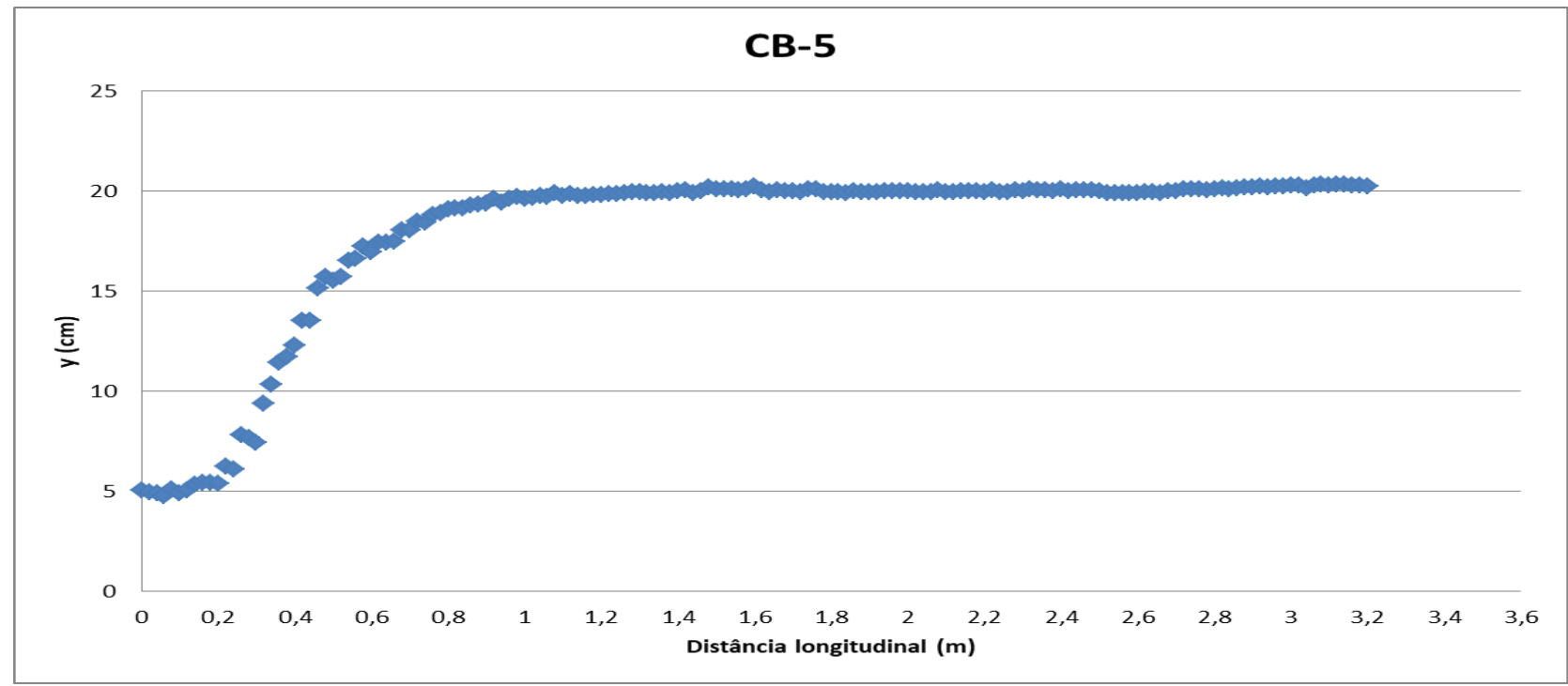

Experimento: CB-5. Vazão $=40 \mathrm{~L} / \mathrm{s} . \mathrm{y}_{1}=5,0 \mathrm{~cm} . \mathrm{y}_{2}=20,0 \mathrm{~cm} . \mathrm{F}_{1}=2,78$. Fundo liso.

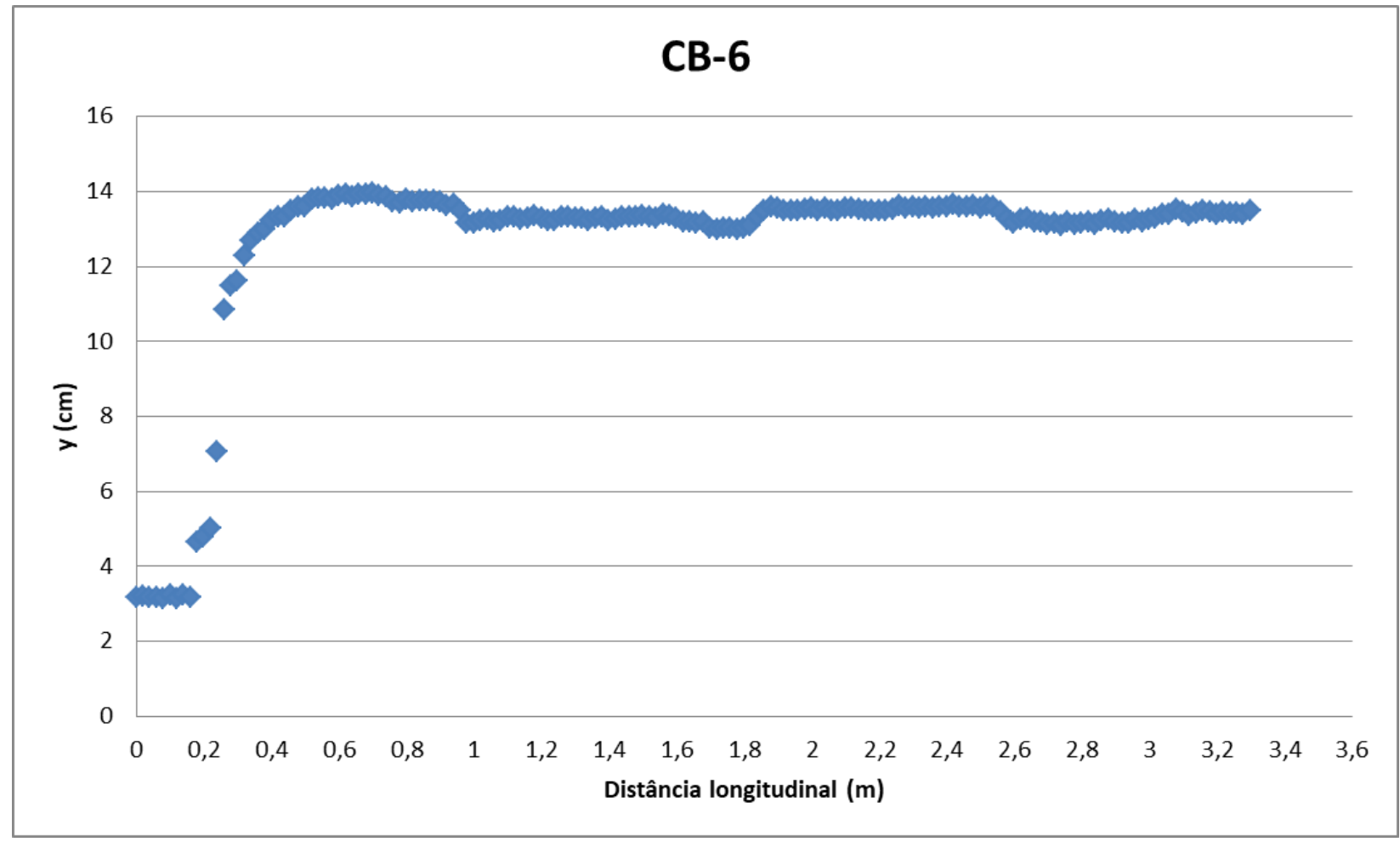

Experimento: CB-6. Vazão $=20$ L/s. $\mathrm{y}_{1}=3,2 \mathrm{~cm} . \mathrm{y}_{2}=13,3 \mathrm{~cm} . \mathrm{F}_{1}=2,73$. Fundo com material emborrachado. 


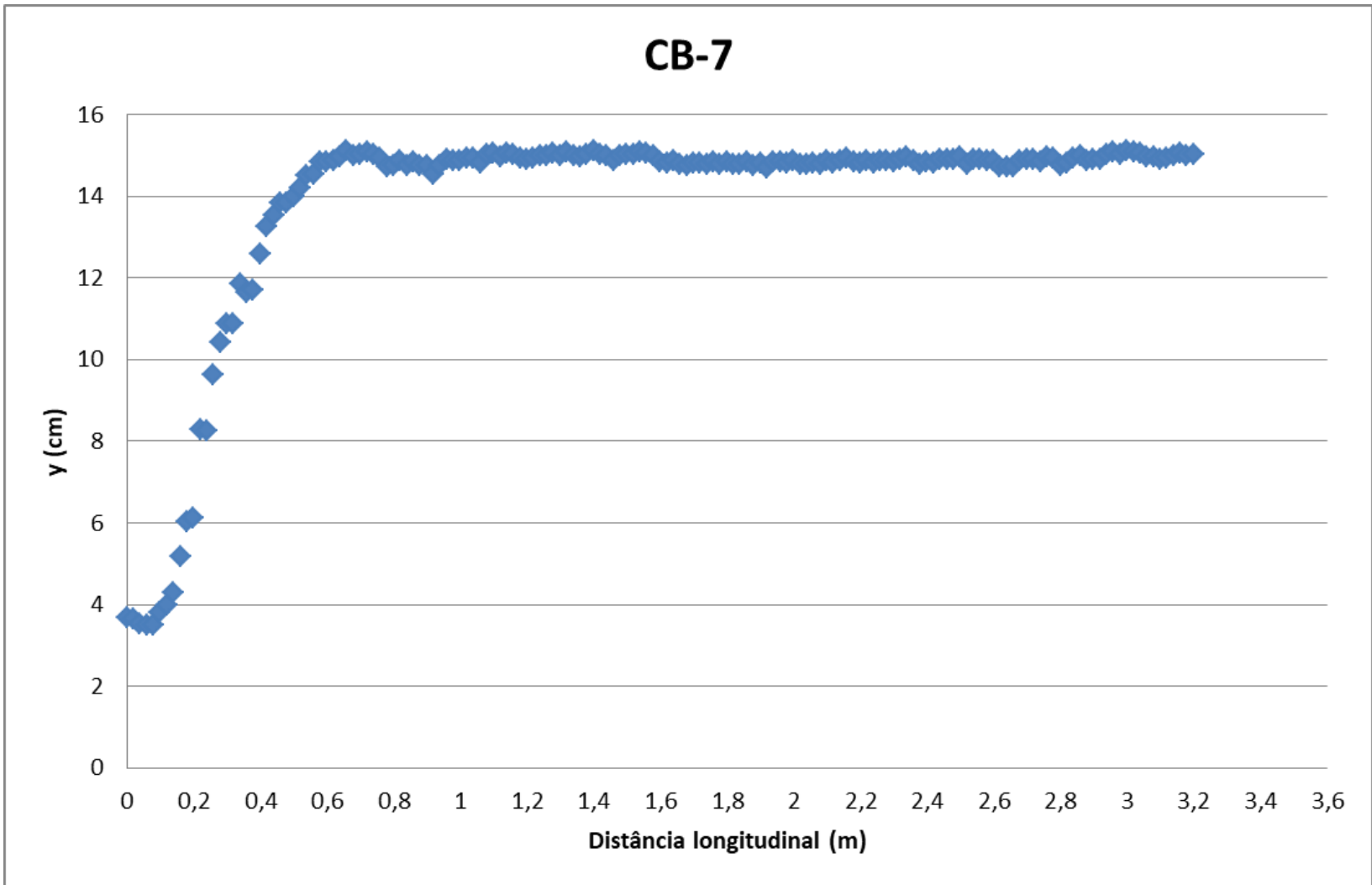

Experimento: CB-7. Vazão $=25 \mathrm{~L} / \mathrm{s} . \mathrm{y}_{1}=3,6 \mathrm{~cm} . \mathrm{y}_{2}=14,9 \mathrm{~cm} . \mathrm{F}_{1}=2,85$. Fundo com material emborrachado.

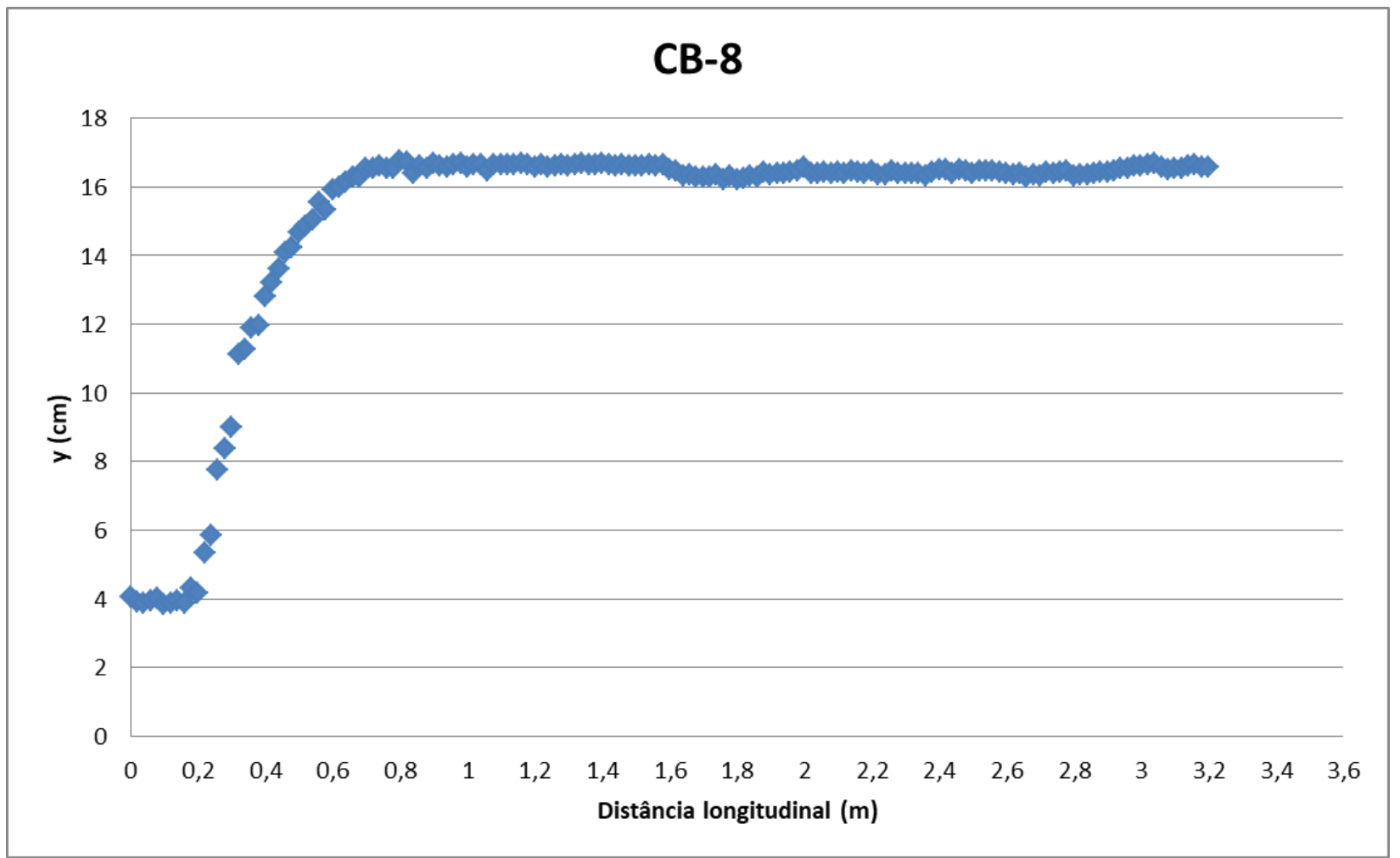

Experimento: CB-8. Vazão $=30 \mathrm{~L} / \mathrm{s} . \mathrm{y}_{1}=3,9 \mathrm{~cm} . \mathrm{y}_{2}=16,4 \mathrm{~cm} . \mathrm{F}_{1}=3,03$. Fundo com material emborrachado. 


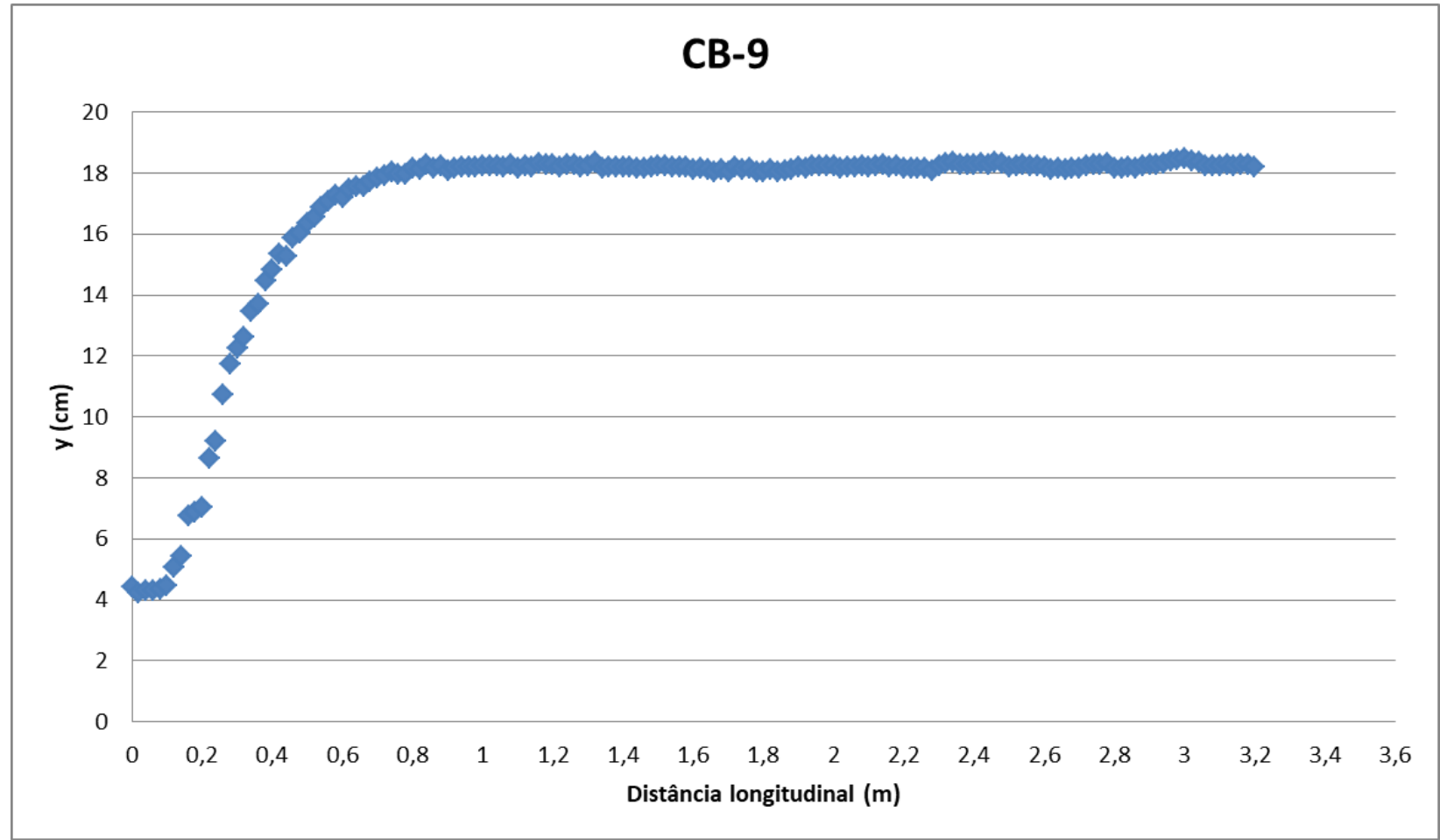

Experimento: CB-9. Vazão $=35 \mathrm{~L} / \mathrm{s} . \mathrm{y}_{1}=4,3 \mathrm{~cm} . \mathrm{y}_{2}=18,2 \mathrm{~cm} . \mathrm{F}_{1}=3,07$. Fundo com material emborrachado.

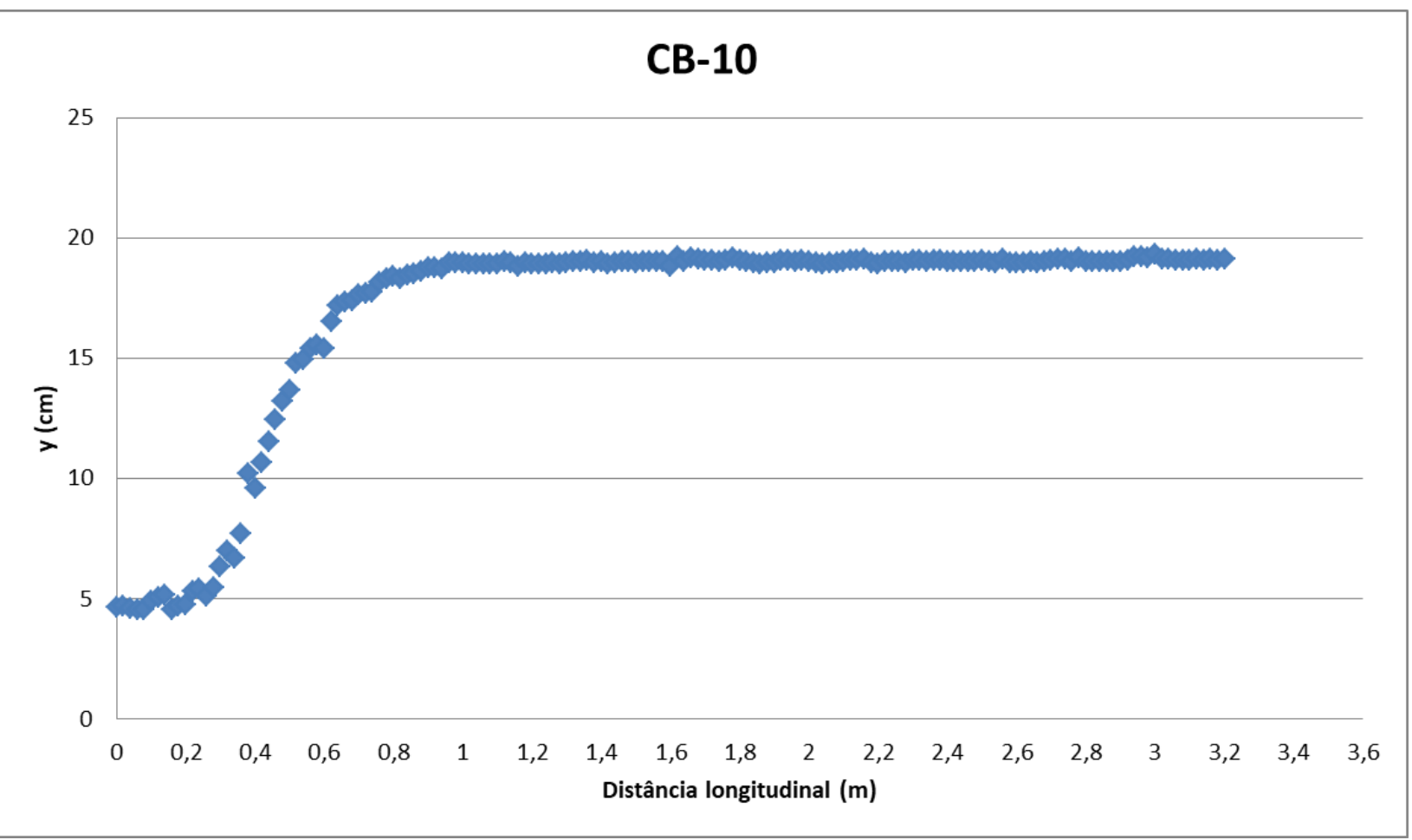

Experimento: CB-10. Vazão $=40 \mathrm{~L} / \mathrm{s} . \mathrm{y}_{1}=4,7 \mathrm{~cm} . \mathrm{y}_{2}=19,0 \mathrm{~cm} . \mathrm{F}_{1}=3,05$. Fundo com material emborrachado. 


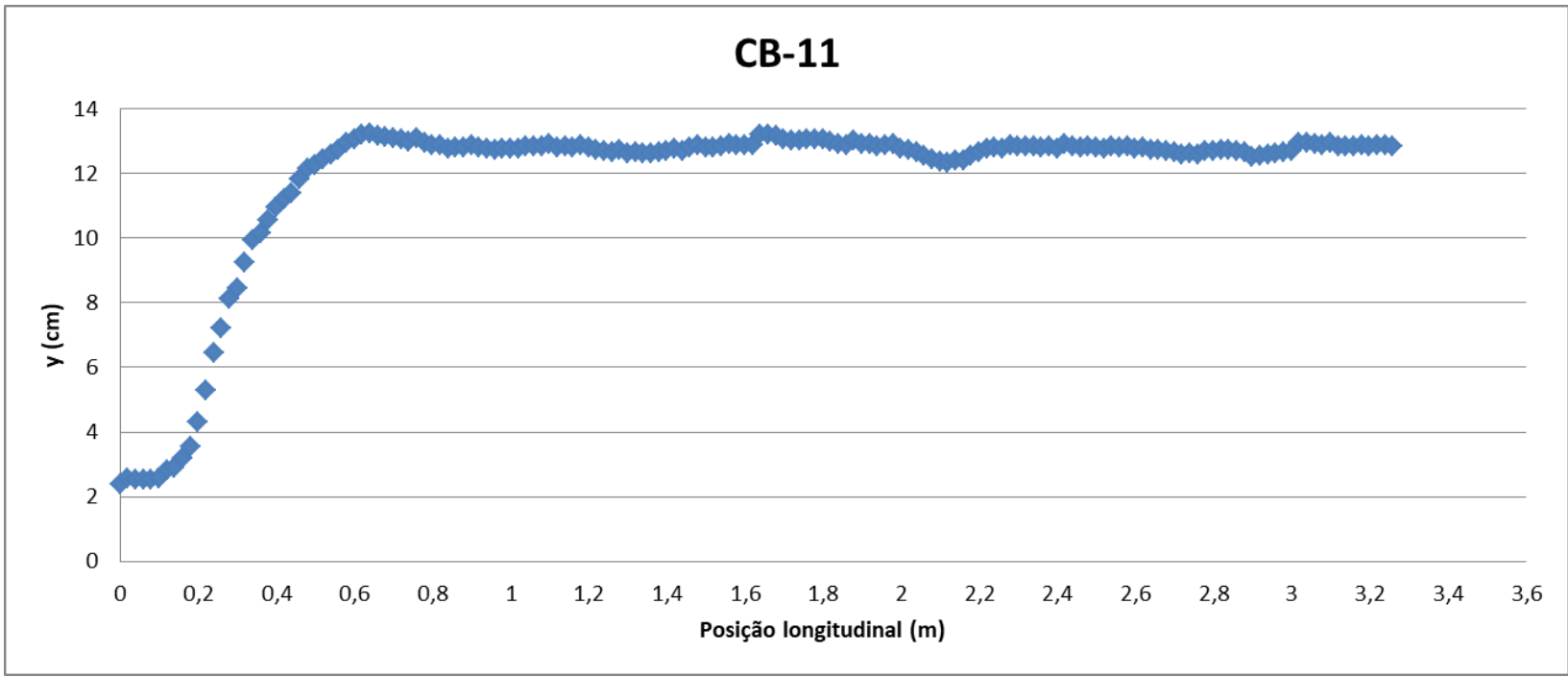

Experimento: CB-11. Vazão = 20 L/s. $\mathrm{y}_{1}=2,5 \mathrm{~cm} . \mathrm{y}_{2}=12,8 \mathrm{~cm} . \mathrm{F}_{1}=3,96$ Fundo com configuração LEGO1.

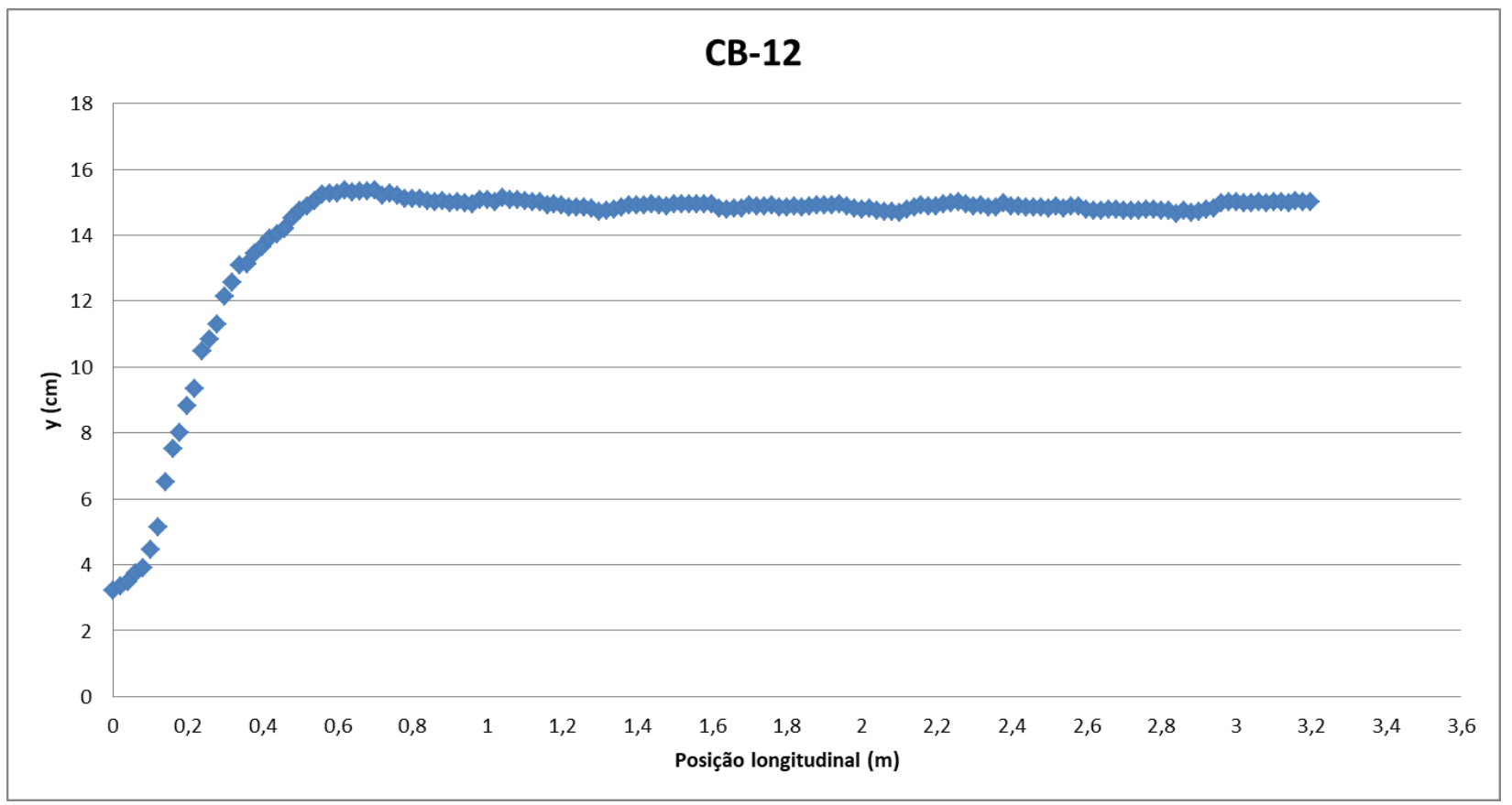

Experimento: CB-11. Vazão = 25 L/s. $\mathrm{y}_{1}=3,1 \mathrm{~cm} . \mathrm{y}_{2}=14,8 \mathrm{~cm} . \mathrm{F}_{1}=3,57$. Fundo com configuração LEGO1. 


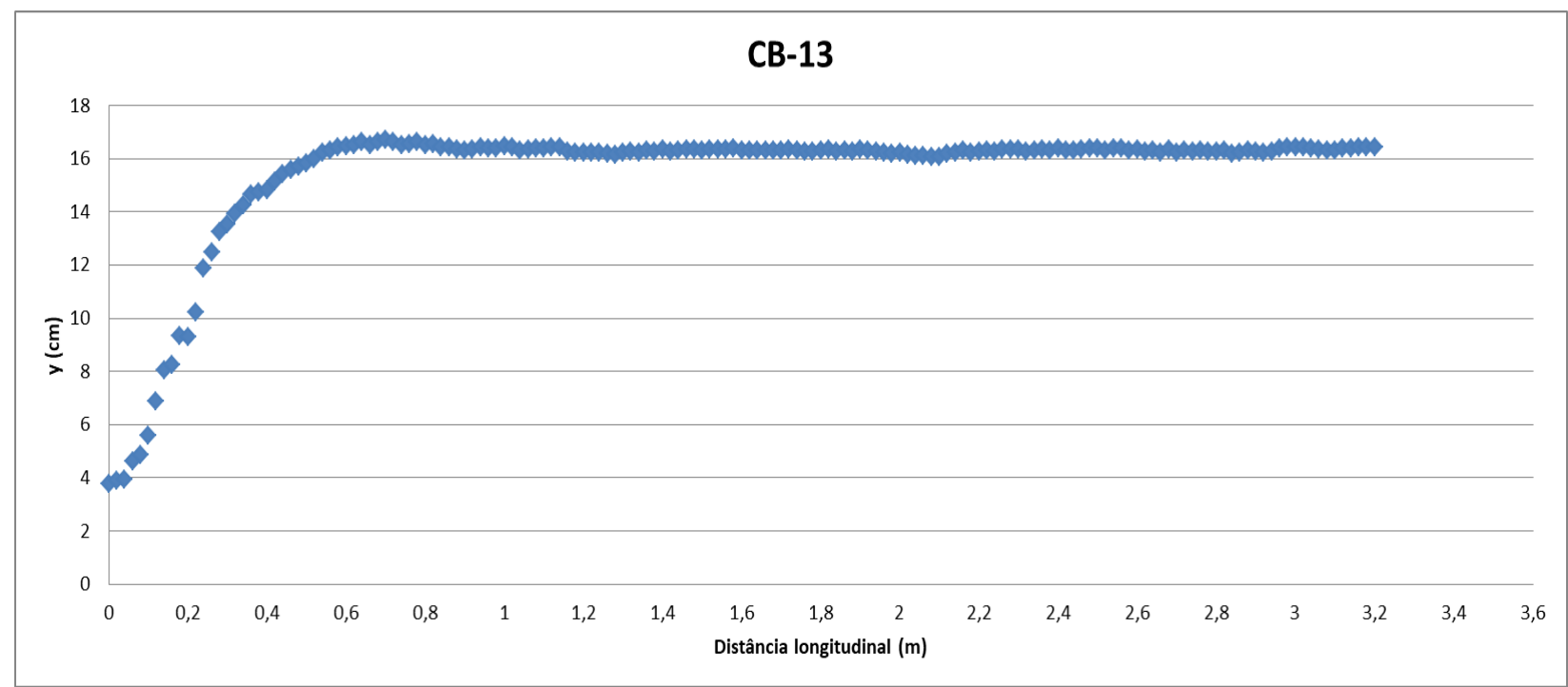

Experimento: CB-13. Vazão $=30 \mathrm{~L} / \mathrm{s} . \mathrm{y}_{1}=3,6 \mathrm{~cm} . \mathrm{y}_{2}=16,3 \mathrm{~cm} . \mathrm{F}_{1}=3,42$. Fundo com configuração LEGO1.

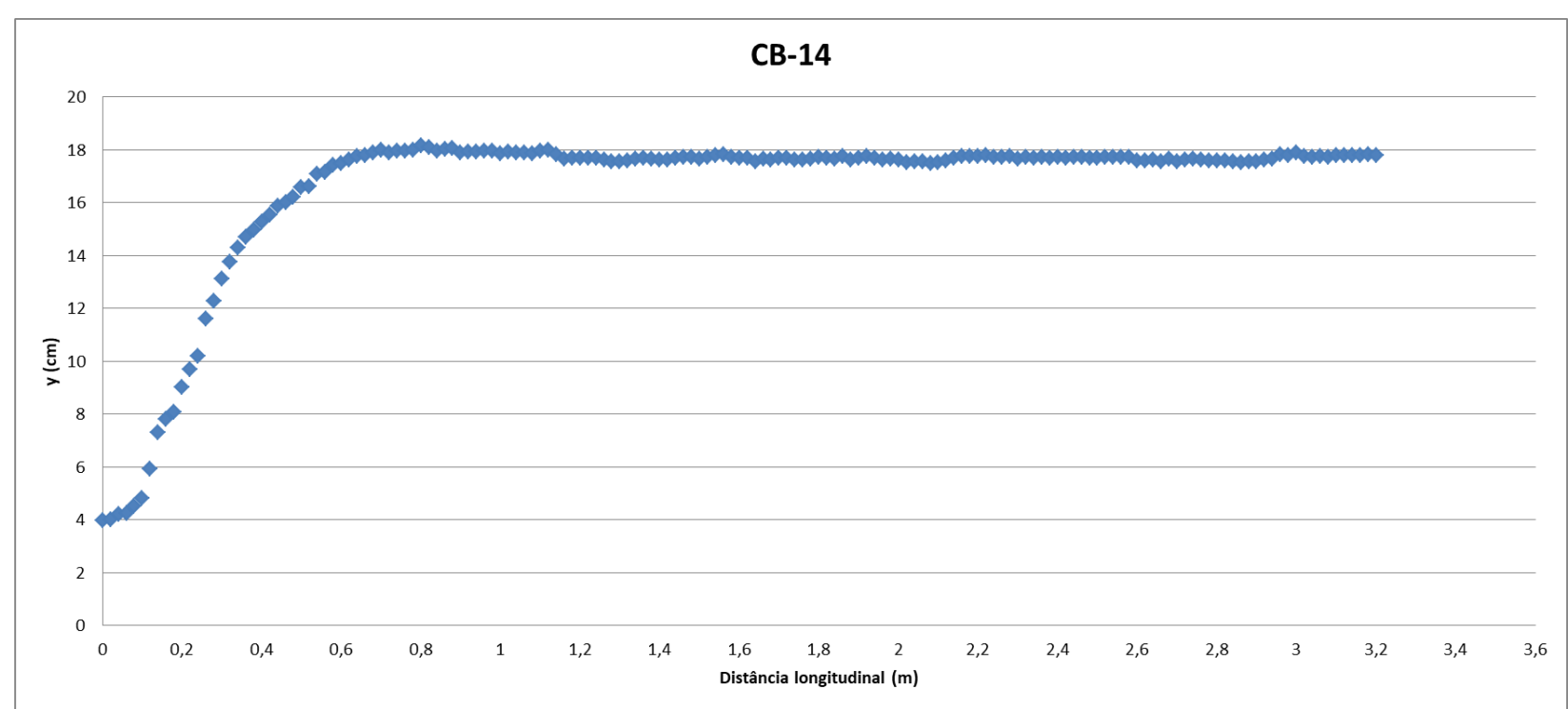

Experimento: CB-14. Vazão $=35 \mathrm{~L} / \mathrm{s} . \mathrm{y}_{1}=4,0 \mathrm{~cm} . \mathrm{y}_{2}=17,6 \mathrm{~cm} . \mathrm{F}_{1}=3,42$. Fundo com configuração LEGO1. 


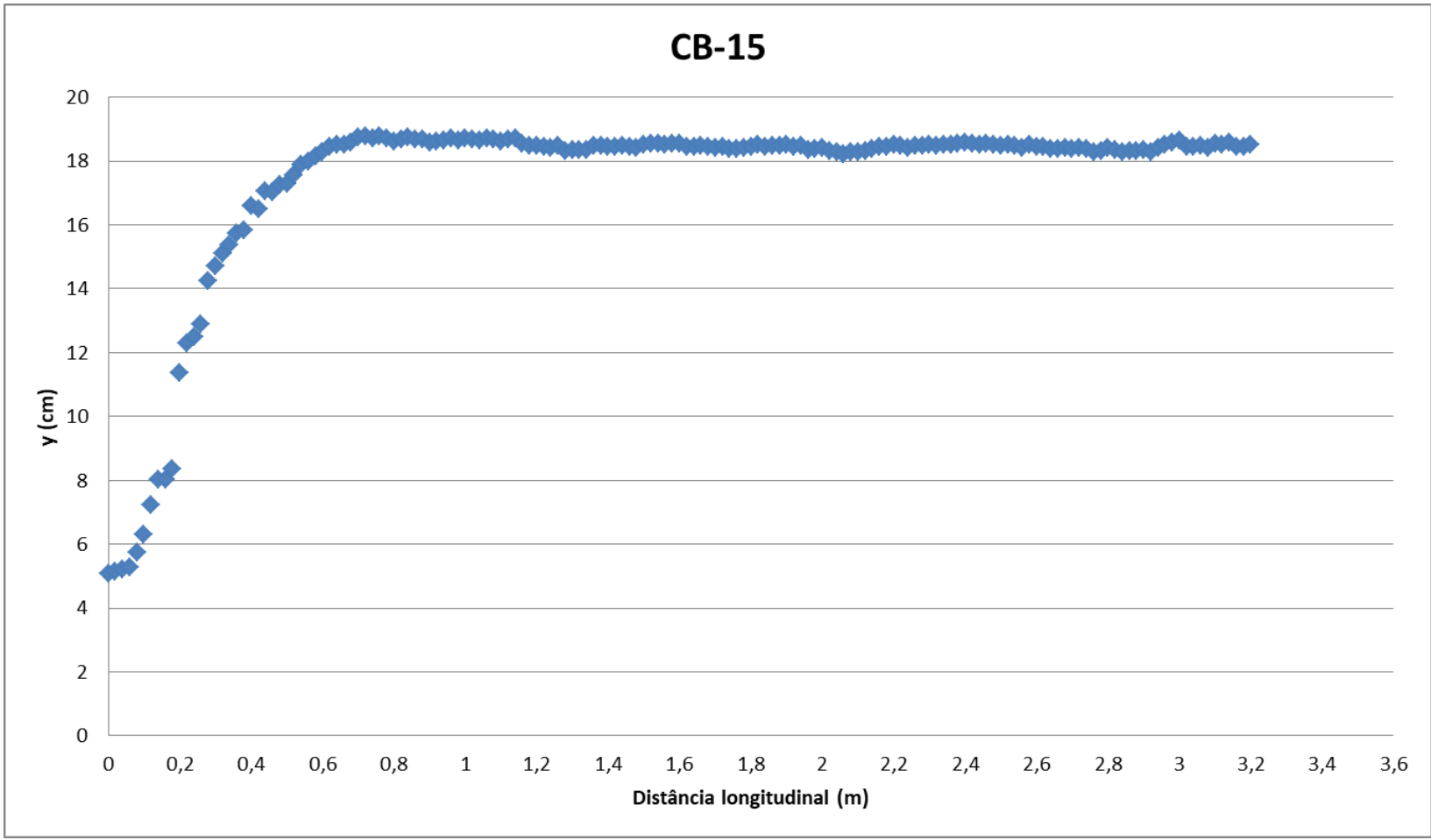

Experimento: CB-15. Vazão $=40 \mathrm{~L} / \mathrm{s} . \mathrm{y}_{1}=4,8 \mathrm{~cm} . \mathrm{y}_{2}=18,4 \mathrm{~cm} . \mathrm{F}_{1}=2,95$. Fundo com configuração LEGO1.

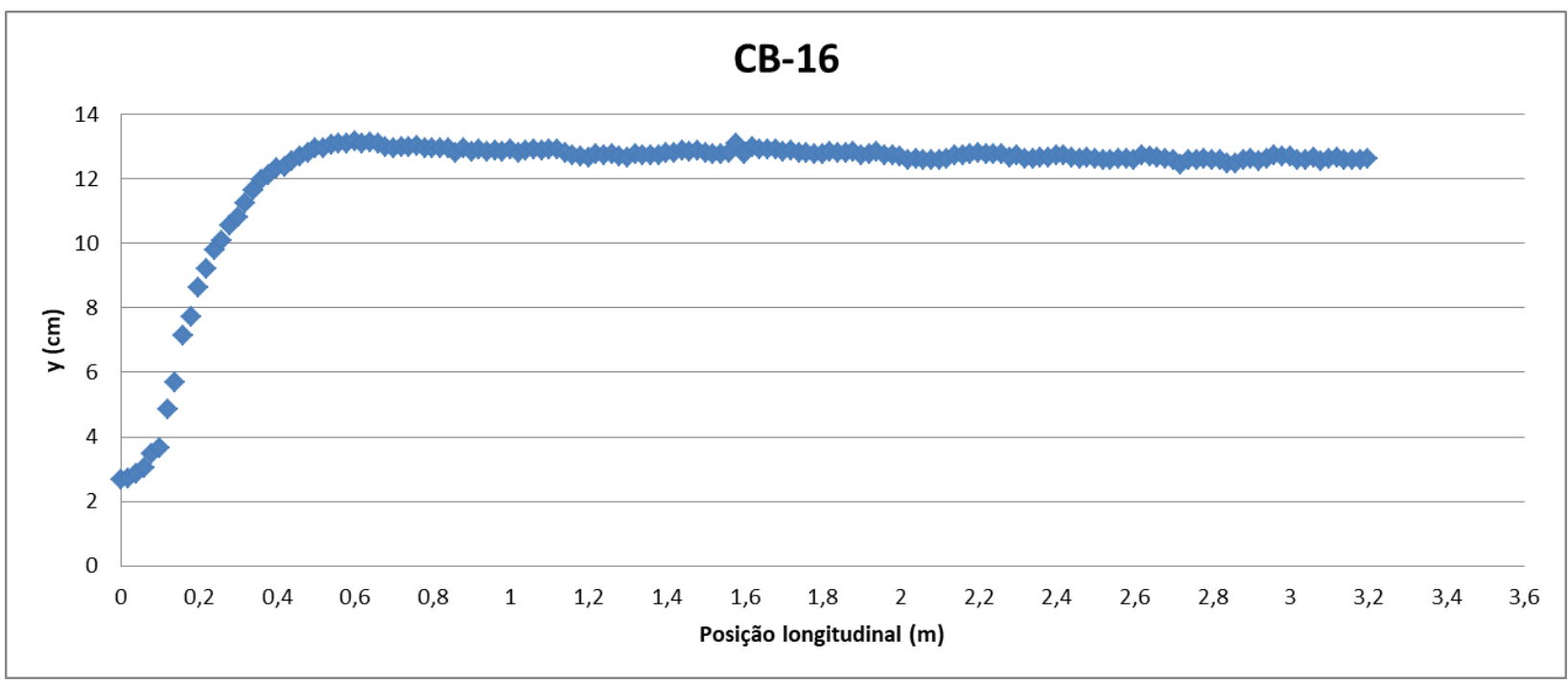

Experimento: CB-16. Vazão $=20$ L/s. $y_{1}=2,7 \mathrm{~cm} . \mathrm{y}_{2}=12,7 \mathrm{~cm} . \mathrm{F}_{1}=3,53$. Fundo com configuração LEGO2. 


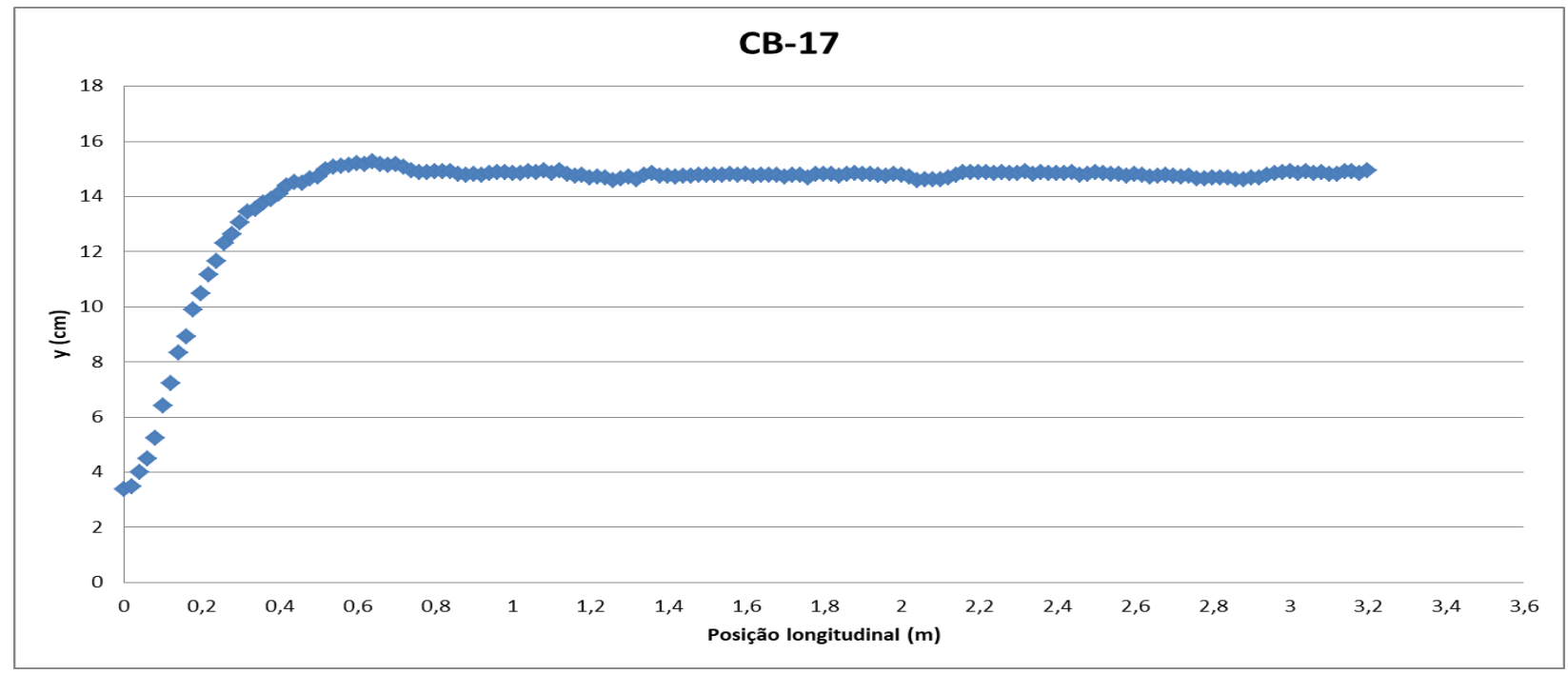

Experimento: CB-17. Vazão $=25 \mathrm{~L} / \mathrm{s} . \mathrm{y}_{1}=3,1 \mathrm{~cm} \cdot \mathrm{y}_{2}=14,8 \mathrm{~cm} . \mathrm{F}_{1}=3,57$. Fundo com configuração LEGO2.

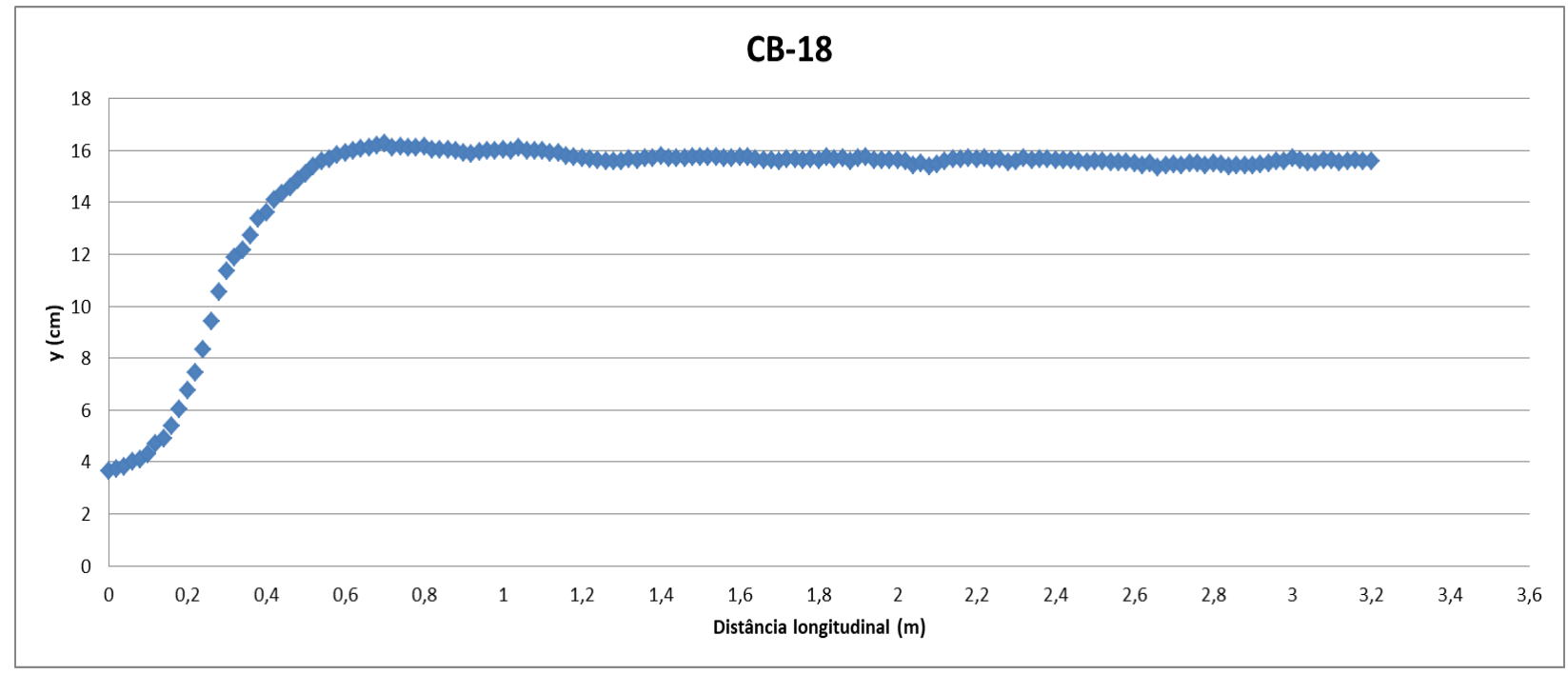

Experimento: CB-18. Vazão $=30 \mathrm{~L} / \mathrm{s} . \mathrm{y}_{1}=3,6 \mathrm{~cm} \cdot \mathrm{y}_{2}=15,6 \mathrm{~cm} . \mathrm{F}_{1}=3,42$. Fundo com configuração LEGO2. 


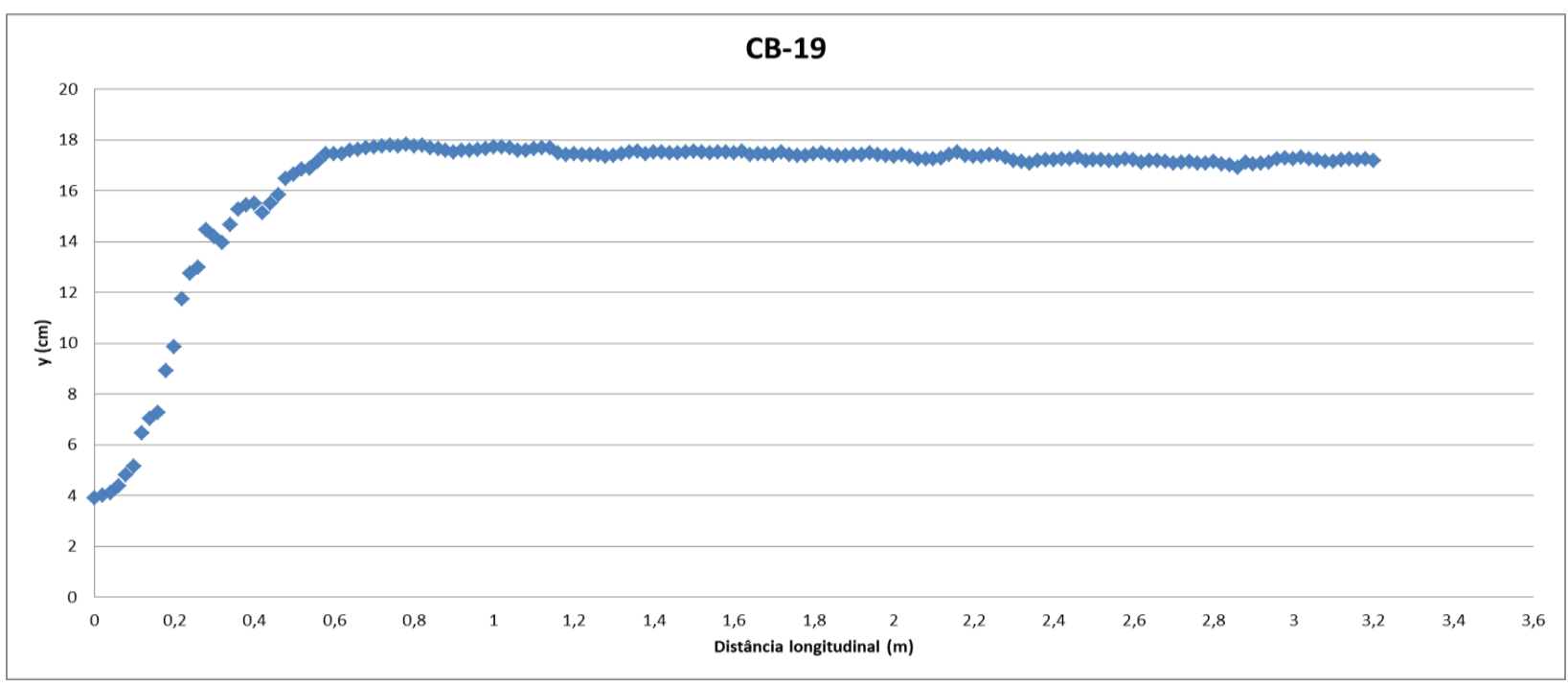

Experimento: CB-19. Vazão $=35 \mathrm{~L} / \mathrm{s} . \mathrm{y}_{1}=3,8 \mathrm{~cm} . \mathrm{y}_{2}=17,3 \mathrm{~cm} . \mathrm{F}_{1}=3,69$. Fundo com configuração LEGO2.

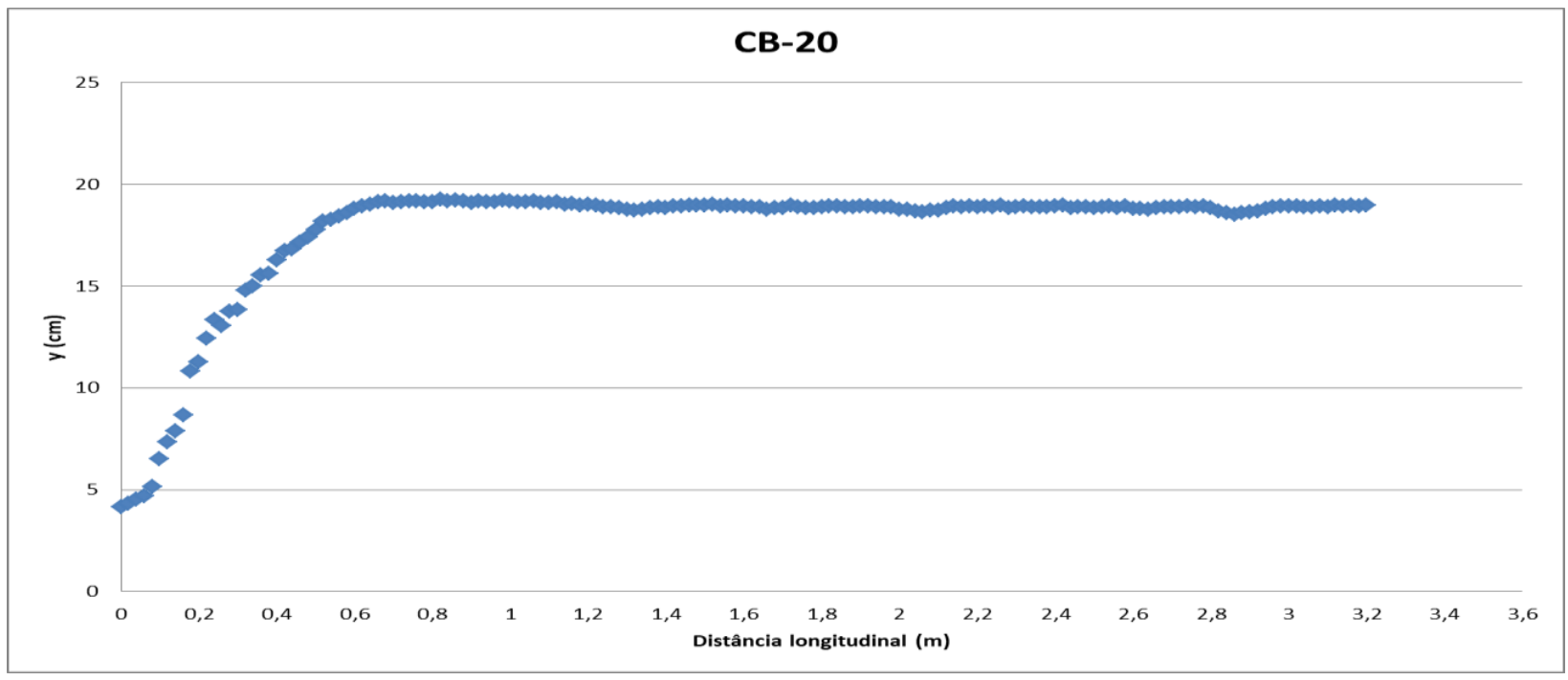

Experimento: CB-20. Vazão $=40 \mathrm{~L} / \mathrm{s} . \mathrm{y}_{1}=4,2 \mathrm{~cm} . \mathrm{y}_{2}=18,9 \mathrm{~cm} . \mathrm{F}_{1}=3,61$. Fundo com configuração LEGO2. 


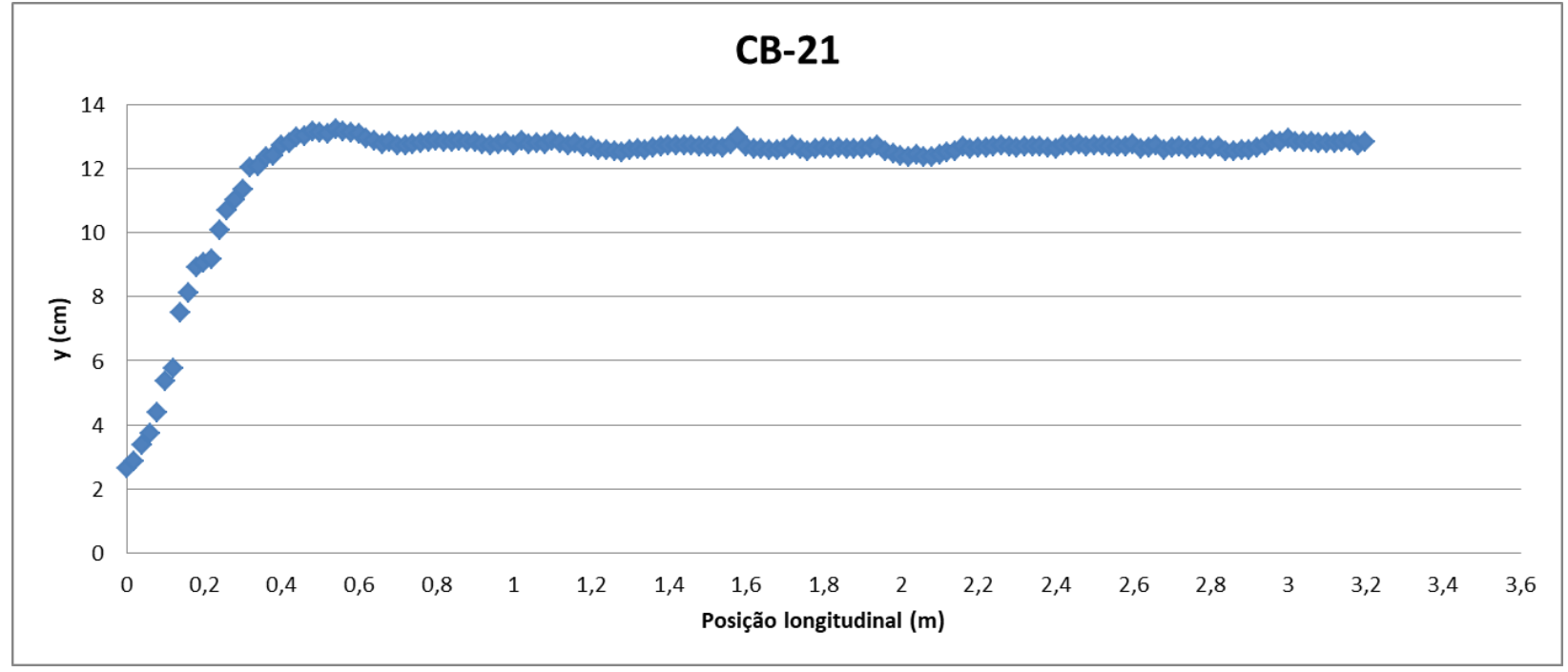

Experimento: CB-21. Vazão $=20$ L/s. $y_{1}=2,7 \mathrm{~cm} . \mathrm{y}_{2}=12,6 \mathrm{~cm} . \mathrm{F}_{1}=3,53$. Fundo com configuração LEGO3.

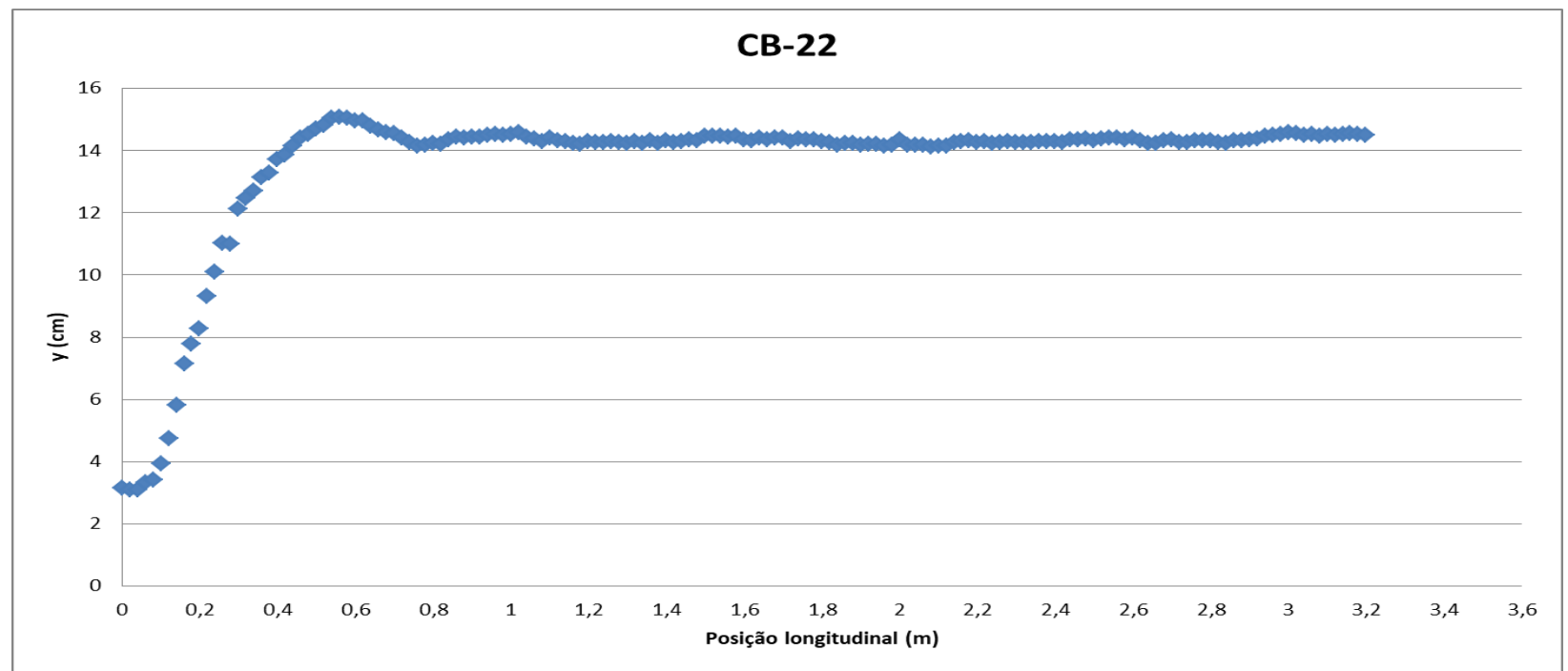

Experimento: CB-22. Vazão $=25 \mathrm{~L} / \mathrm{s} . \mathrm{y}_{1}=2,9 \mathrm{~cm} . \mathrm{y}_{2}=14,3 \mathrm{~cm} . \mathrm{F}_{1}=3,94$. Fundo com configuração LEGO3. 


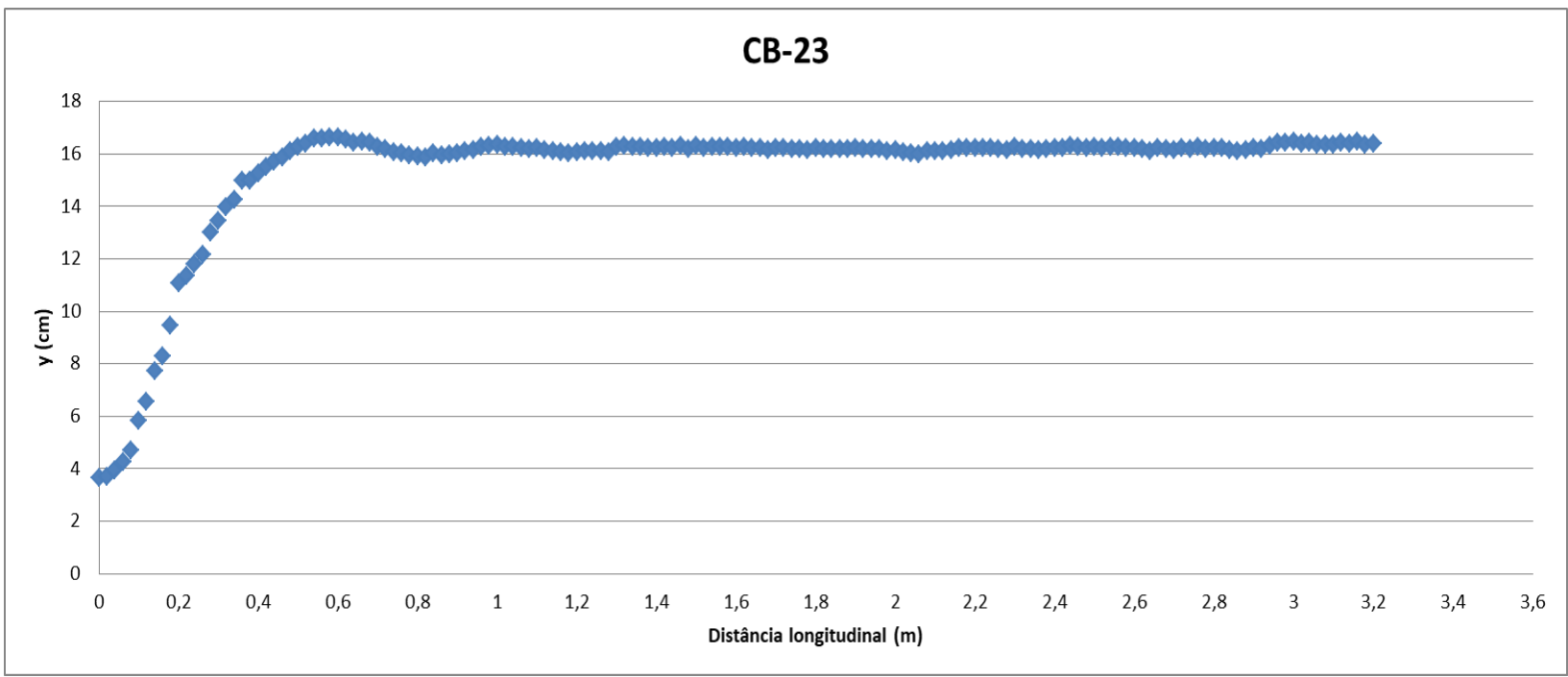

Experimento: CB-23. Vazão $=30 \mathrm{~L} / \mathrm{s} . \mathrm{y}_{1}=3,6 \mathrm{~cm} . \mathrm{y}_{2}=16,2 \mathrm{~cm} . \mathrm{F}_{1}=3,42$. Fundo com configuração LEGO3.

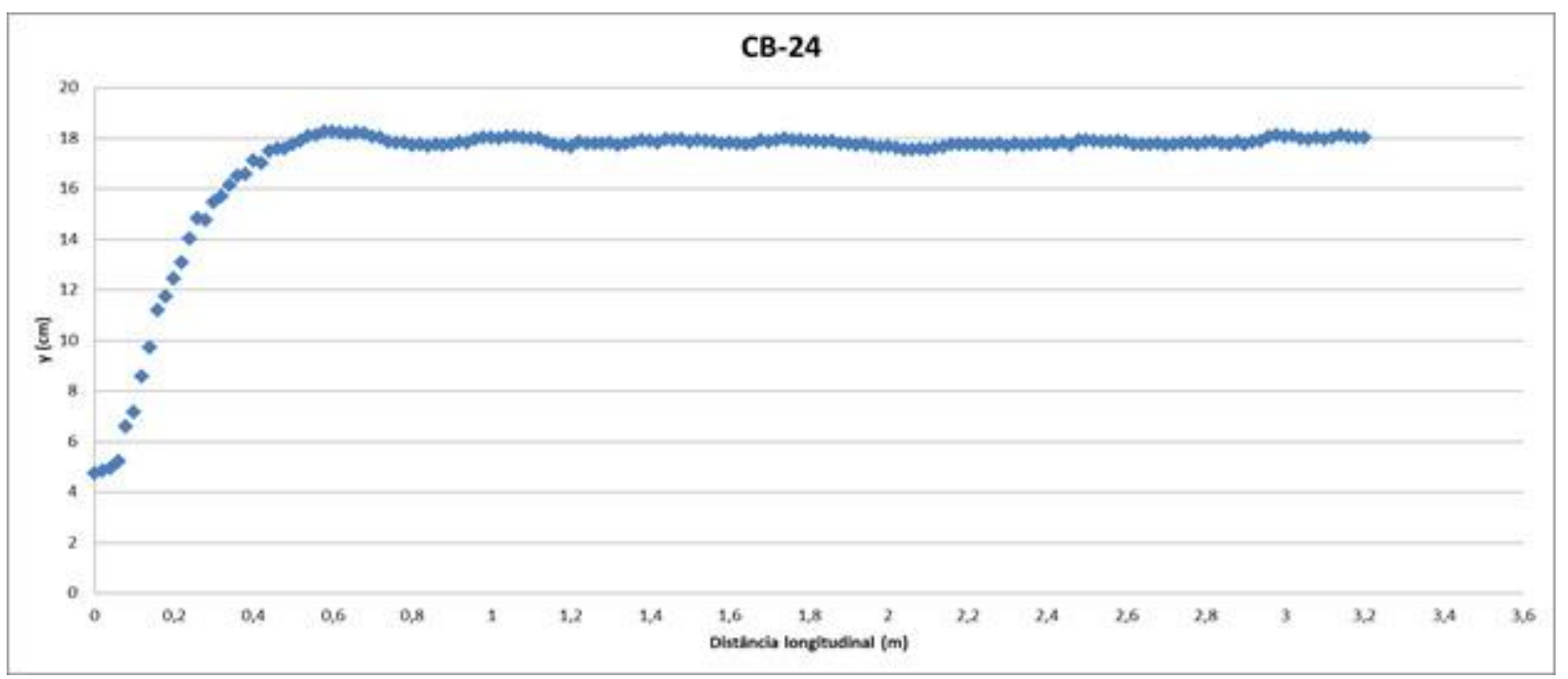

Experimento: CB-24. Vazão $=35 \mathrm{~L} / \mathrm{s} \cdot \mathrm{y}_{1}=4,6 \mathrm{~cm} \cdot \mathrm{y}_{2}=17,8 \mathrm{~cm} . \mathrm{F}_{1}=2,77$. Fundo com configuração LEGO3. 


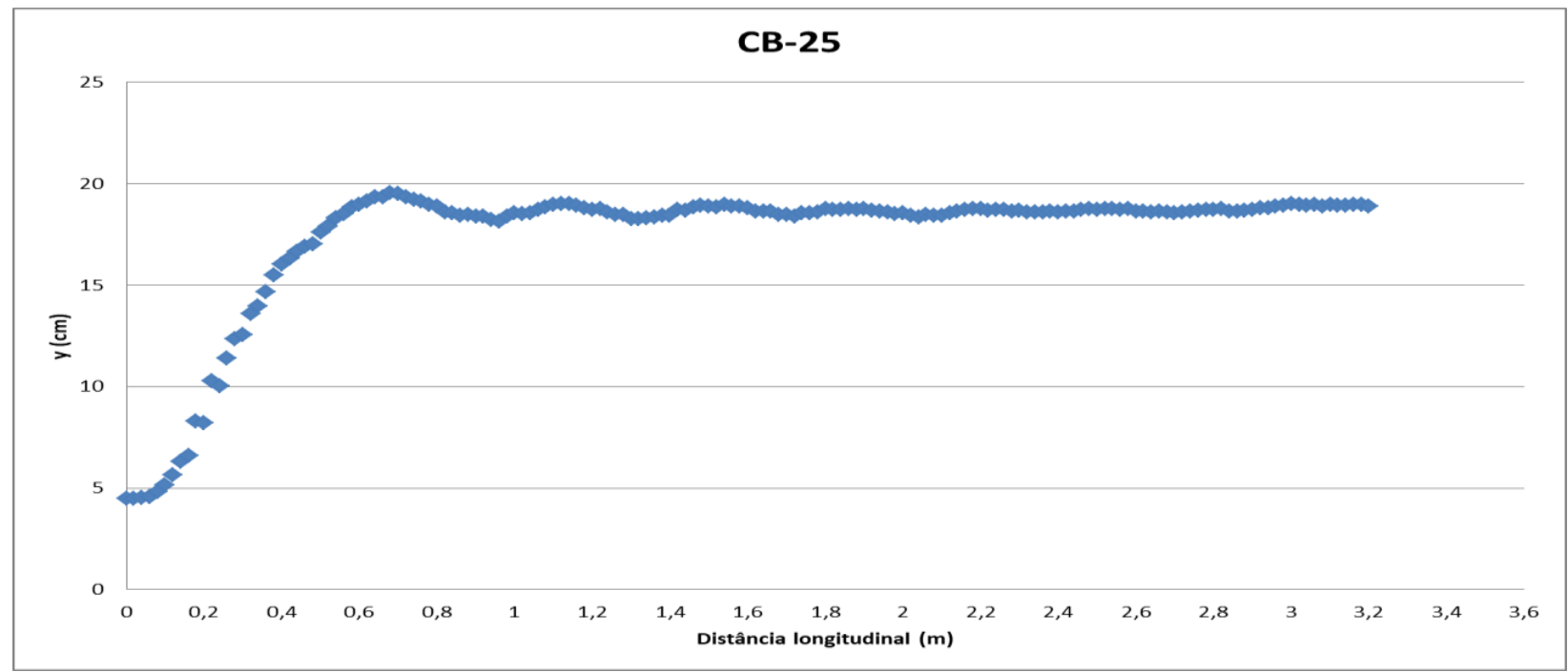

Experimento: CB-25. Vazão $=40 \mathrm{~L} / \mathrm{s} . \mathrm{y}_{1}=4,5 \mathrm{~cm} . \mathrm{y}_{2}=18,6 \mathrm{~cm} . \mathrm{F}_{1}=3,25$. Fundo com configuração LEGO3.

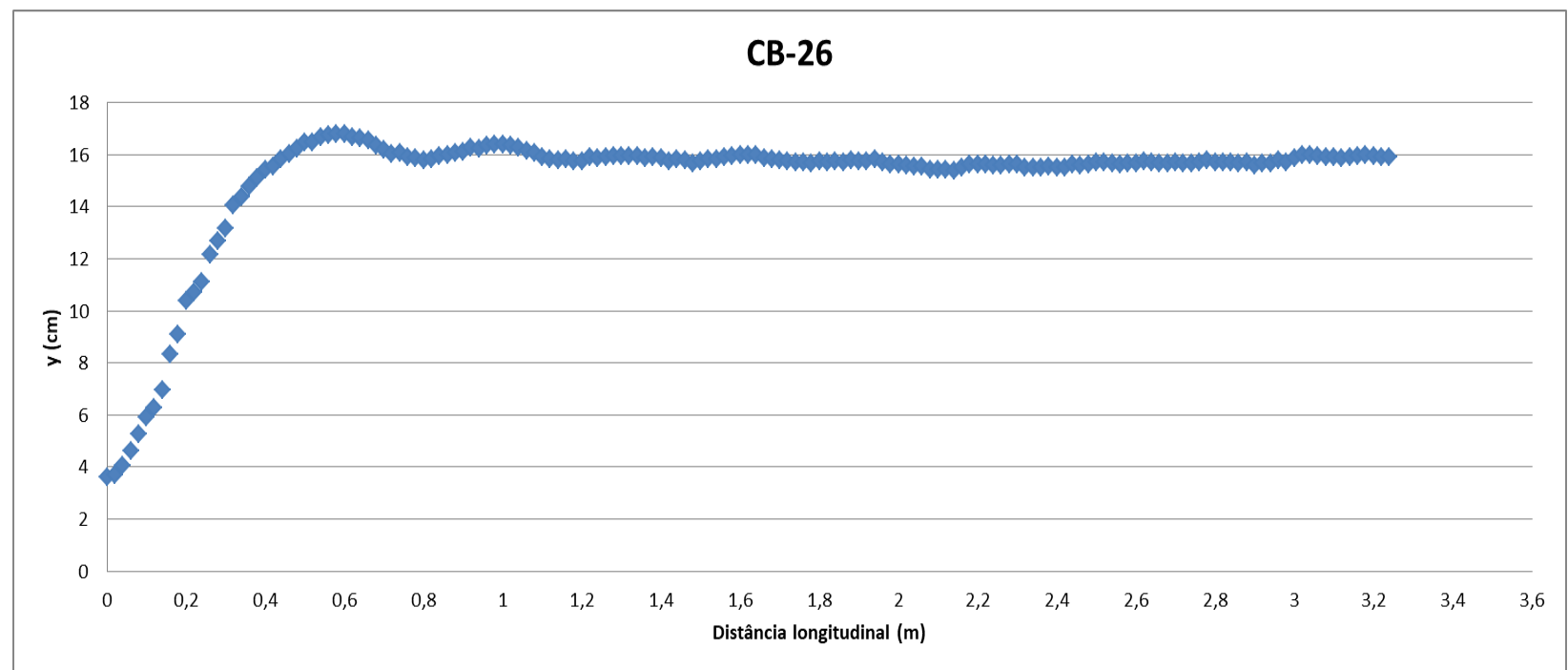

Experimento: CB-26. Vazão $=30 \mathrm{~L} / \mathrm{s} . \mathrm{y}_{1}=3,6 \mathrm{~cm} . \mathrm{y}_{2}=15,6 \mathrm{~cm} . \mathrm{F}_{1}=3,42$. Fundo com configuração LEGO4. 


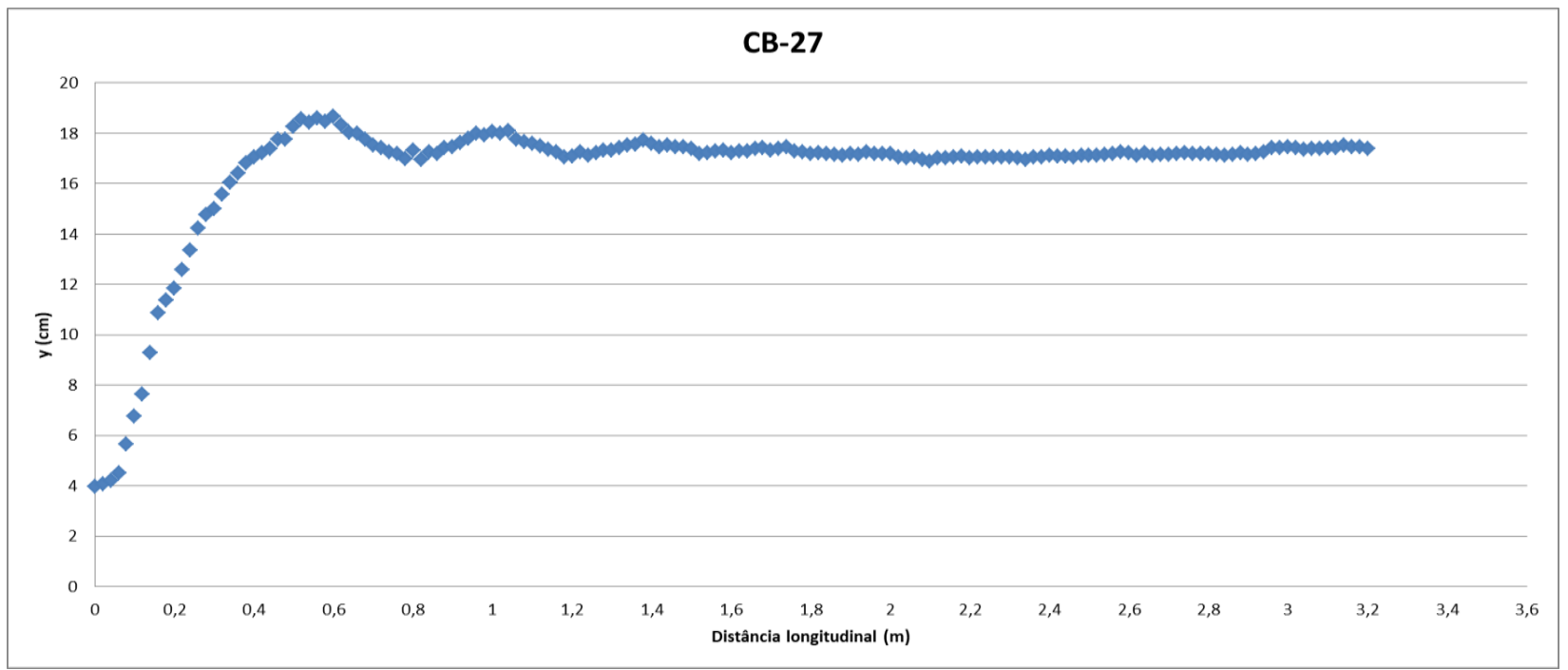

Experimento: CB-27. Vazão $=35 \mathrm{~L} / \mathrm{s} . \mathrm{y}_{1}=4,0 \mathrm{~cm} . \mathrm{y}_{2}=17,1 \mathrm{~cm} . \mathrm{F}_{1}=3,42$. Fundo com configuração LEGO4.

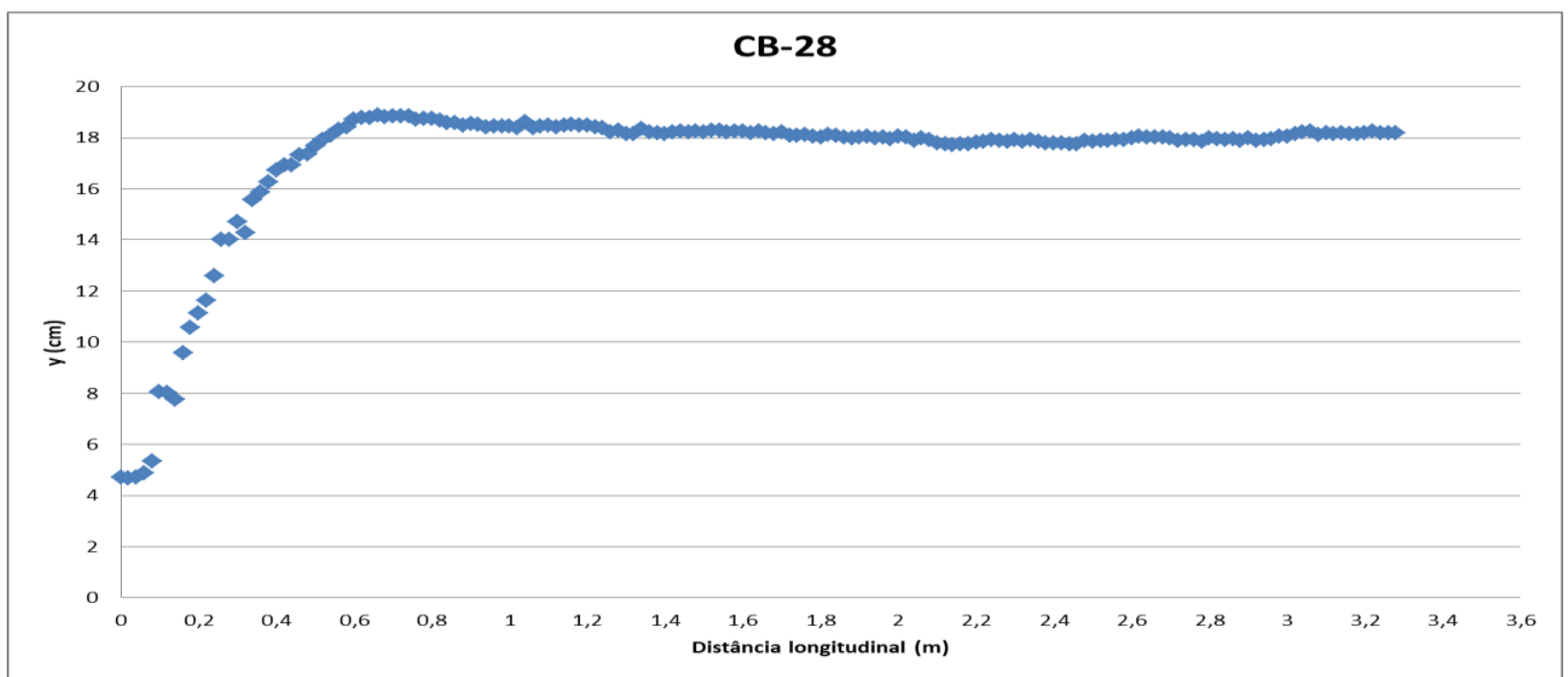

Experimento: CB-28. Vazão $=40 \mathrm{~L} / \mathrm{s} . \mathrm{y}_{1}=4,7 \mathrm{~cm} . \mathrm{y}_{2}=18,0 \mathrm{~cm} . \mathrm{F}_{1}=3,42$. Fundo com configuração LEGO4. 